\title{
The genus Clitocybe (Agaricales) in Fennoscandia
}

\author{
Harri Harmaja
}

Department of Botany, University of Helsinki, Helsinki 17, Finland

\begin{abstract}
A taxonomic revision is made of the agaric genus Clitocybe (Fr.) Staude in Fennoscandia (i.e., Norway, Sweden, Finland, and parts of the northwest of the U.S.S.R.), the material comprising 3220 specimens. The delimitation of the genus mainly follows that of modern authors (e.g. Singer 1962), and in the discussion of some intergeneric differences attention is also drawn to some previously ignored ecological features. Agaricus nebularis [Batsch] Fries is acknowledged as the type species. Fairly comprehensive descriptions are given of the infrageneric diagnostic characters. Among the characters whose genetically controlled variation and diagnostic importance has often been ignored or undervalued by previous authors are: certain features of the pileus surface, the organization of the basal mycelium of the stipe, hygrophany, odour, the responses of some parts of the dried fruit body under ultra-violet light, the colour of the spore deposit, several other spore characters, some of which are taken as the basis for a new system of spore shape classification, and pigmentation. Some characters are supposed to be original, and others derived. Several macrochemical reagents were tested, of which $\mathrm{KOH}$ proved to be the most useful. Information on the cytology (e.g. the chromosome number) of one species is given. Some macroscopical, sporal, anatomical, ecological and other characters as well as certain responses to ultra-violet light are shown to be \pm uniform throughout Clitocybe, and may thus be diagnostic of the genus. Considerable attention is paid to the habitat (substrate, forest site type, relation to lime content of ground, relation to human influence), fruiting time, and geographical distribution of the species, which may be grouped in various, often clear-cut, categories with regard to each of these aspects. The largest numbers of species are found in the coniferous and mixed deciduous and coniferous, hemiboreal and southern boreal forests, the number of eastern taxa being considerable. Some species occur in alpine Dryas heaths. Three species are recorded for the first time outside N. America, and two outside Asia. 3 subgenera, 16 sections, 2 subsections, 43 species, and 2 varieties are recognized, of which 1, 6 (in addition, 2 provisionally), 2, 14, and 1, respectively, are described as new. 4 new combinations are introduced. Lectotypes or neotypes are proposed for several species. The author citations of some sectional and specific names are corrected.
\end{abstract}

Preface

I. Introduction $\ldots \ldots \ldots \ldots \ldots \ldots \ldots$

II. Delimitation of the genus $\ldots \ldots \ldots \ldots$ A. Working hypothesis .........

B. Remarks on some related genera .. C. Type species ...............

III. Area of investigation; material and methods .................. 12

IV. Infrageneric diagnostic characters of Clitocybe .................... 14

A. Macroscopic characters ......... 14

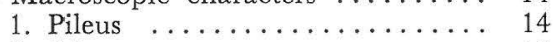

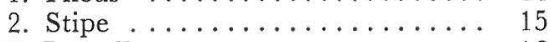

3. Lamellae $\ldots \ldots \ldots \ldots \ldots \ldots \ldots \ldots . . \ldots$

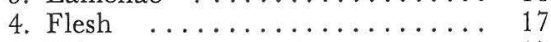

5. Odour ................... 17

6. Taste $\ldots \ldots \ldots \ldots \ldots \ldots \ldots 18$

7. Colour of the spore deposit ... 18

8. Response of the fruit body to ultra-violet light .......... 19

9. Habit of the fruit bodies ...... 20

B. Microscopic characters ......... 20

1. Spores .............. 20

2. Basidia ............... 25

3. Cystidia $\ldots \ldots \ldots \ldots \ldots \ldots \ldots \ldots . \ldots \ldots 25$

4. Anatomy of the pileus; pigmentation ..................... 25

5. Anatomy of the stipe ....... 28

6. Anatomy of the lamellae ..... 28

7. Cytology .............. 29 page

C. Macrochemical characters ....... 30

V. Ecology of Clitocybe species ........ 31

A. Habitat ...................... 31

B. Human influence ........... 34

C. Fruiting time $\ldots \ldots \ldots \ldots \ldots \ldots 35$

VI. Phytogeographical conclusions ...... 39

VII. Descriptions of the taxa ......... 42

A. Explanations and abbreviations ... 42

B. Natural key to the supraspecific taxa 43

C. Practical key to the species ...... 45

D. Genus Clitocybe (Fr.) Staude .... 50

Subgenus 1. Clitocybe ......... 52

Section I. Alexandriformes Harmaja, n. sect. ......... 52

1. Clitocybe alexandri (Gill.) Konr. ............. 53

2. Clitocybe harperi Murr. .. 54

3. Clitocybe inornata ([Sow.] Fr.) Gill. .............. 55

Section II. Clitocybe ........ 56

4. Clitocybe nebularis ([Batsch] Fr.) Kumm. .. 57

Section III. Clavipedes Harmaja,

n. sect. .......... 58

5. Clitocybe clavipes ([Pers.] Fr.) Kumm. ......... 59

Section IV. Infundibuliformes

(Fr.) Sing. \& Dig. ....... 60

6. Clitocybe geotropa ([Bull.] St.-Am.) Quél. ........ 61 
7. Clitocybe altaica singe

8. Clitocybe catinus (Fr.) Quél. ......... 63

9. Clitocybe gibba ([Pers.] Fr.) Kumm. ......... 64

10. Clitocybe squamulosa ([Pers.] Fr.) Kumm. ....

11. Clitocybe bresadoliana Sing.

12. Clitocybe lapponica Harmaja, n. sp. ......... 68

Section V. Sinopicae Harmaja, n. sect. ............... 69

13. Clitocybe sinopica

(Fr.) Kumm. . . . . . . 69

Section VI. Gilvaoideae Harma-

ja, n. sect. .......... 70

14. Clitocybe gilvaoides

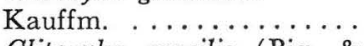

15. Clitocybe gracilis (Big. \& Smith) Harmaja, n. comb.

Section VII. Candicantes (Quél.)

Sing. \& Dig. ........... 73

16. Clitocybe candicans ([Pers.] Fr.) Kumm. .... 74

17. Clitocybe dealbata ([Sow.] Fr.) Kumm. .......... 75

18. Clitocybe ruderalis Harmaja, n. sp. .......... 76

19. Clitocybe laricicola Sing... 76

20. Clitocybe pruinosa (Lasch ex Fr.) Kumm. .........

Section VIII. Vernae (Sing.)

Harmaja, n. comb. .........

21. Clitocybe rhizophora (Vel.) Joss. .............

Section IX. Bulluliferae (Sing.)

Harmaja, n. comb. ......... 81

22. Clitocybe hydrogramma

([Bull.] Fr.) Kumm. ....

Subgenus 2. Roseospora Harmaja,

n. subg. . . . . . . . . . .

Section X. Odorae Harmaja, ad int. .............. 84

23. Clitocybe odora ([Bull.]

Fr.) Kumm. ......... 84

Section XI. Roseospora ...... 86

Subsection 1. Pruinatae Harma-

ja, n. subsect. .......... 86

24. Clitocybe phyllophila (Fr.) Kumm. v. phyllophila... 86

24.a Clitocybe phyllophila (Fr.) Kumm. v. tenuis Harmaja,

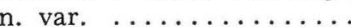

25. Clitocybe anisata Vel. .... 62 63 64

Preface

It was in the summer and autumn of 1960 that I first became acquainted with the larger fungi. The late Prof. Mauno J. Kotilainen, then in his last summer, encouraged me, still a school-boy, to take an interest in this neglected group of plants. Subsequently, the
Subsection 2. Epruinatae Harmaja, n. subsect. ......... 90

26. Clitocybe diatreta (Fr.) Kumm. ........ 90

27. Clitocybe agrestis Harmaja, n. sp. ............ 91

28. Clitocybe marginella Harmaja, n. sp. .......... 92

Section XII. Fragrantes Harma-

ja, ad int............. 93

29. Clitocybe fragrans ([Sow.] Fr.) Kumm. ......... 93

Subgenus 3. Pseudolyophyllum Sing. 95

Section XIII. Pseudolyophyllum 96

30. Clitocybe metachroa (Fr.) Kumm. ............ 96

31. Clitocybe amarescens Harmaja, n. sp. ........ 98

32. Clitocybe metachroides Harmaja, n. sp. ......... 99

Section XIV. Latisporae Harma-

ja, n. sect. ........... 100

33. Clitocybe subcordispora Harmaja, n. sp. ....... 100

34. Clitocybe globispora Harmaja, n. sp. ......... 101

Section XV. Ditopae (Sing.) Sing. 102

35. Clitocybe orientalis Harmaja, n. sp. .......... 103

36. Clitocybe vibecina (Fr.) Quél. .......... 103

37. Clitocybe langei Sing. ex Hora ............. 104

38. Clitocybe ditopa (Fr.) Gill. v. ditopa ........... 105

38.a Clitocybe ditopa (Fr.) Gill. v. odorula (Karst.) Harmaja, n. comb. ..... 106

39. Clitocybe menthiodora Harmaja, n. sp. ...... 107 Section XVI. Strigipedes Harma-

ja, n. sect. .......... 108

40. Clitocybe strigosa Harmaja, n. sp. .......... 109

41. Clitocybe fennica Harmaja, n. sp. ............ 111

42. Clitocybe schulmannii Harmaja, n. sp. .......... 112

43. Clitocybe lohjaënsis Harmaja, n. sp. ......... 112

VIII. Excluded taxa ................ 114

IX. Summary $\ldots \ldots \ldots \ldots \ldots \ldots \ldots \ldots 116$

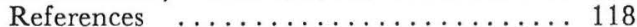

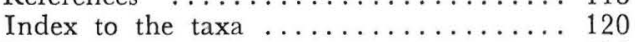

Figures ................... 121 excellent handbook and some papers on Finnish fungi of Prof. Risto Tuомiкoski confirmed me in my decision to study the taxonomy of the fleshy fungi.

The present study was begun in summer 1965. My reason for choosing the genus Cli- 
tocybe as the object of a monographic study was the fact that it appeared to be one of the most neglected genera of the Agaricales being represented in the handbooks by many dubious species with very few distinguishing characters. There were no modern monographs, either, on the European taxa. In addition, according to the literature, a considerable part of the species, if not most of them, occur especially in coniferous forests. Finland might thus be expected to possess a rich Clitocybe flora and to provide ample material for a study of the genus. Moreover, the flora of the excursion districts of E. FrIES in Sweden, especially Femsjö, could be expected to resemble that of southern Finland, the main area of study, these areas being rather similar as to vegetation.

Singer (1962: 230) has emphasized the great need for a monograph on Clitocybe because of «the scarcity of outstanding characters in this genus, usable for the distinction of species, and also because of the large number of species«. As he has also pointed out (op. cit.: 230), this need is increased by the fact that some rather confusing species are very poisonous (probably even mortal), while various antibiotics have been isolated from others.

Acknowledgements. - The laboratory work of the present study was carried out in the Department of Botany of the University of Helsinki. To the Director of that institute, Dr. Aarno Kalela, Prof. of Botany, I wish to express my deep gratitude for providing working facilities and modern research instruments, and arranging financial assistance.

Dr. Risto Tuomikoski, Prof. of Biotaxonomy, Dr. Teuvo Ahri, Docent, Curator of the Cryptogamic Herbarium, and Dr. Veiкko Hintikкa, Docent, made valuable suggestions and provided me with important literature, for which I am much indebted to them all.

Dr. PEKKa Isovirta discussed many nomenclatural problems and gave me valuable advice, for which I wish to express my grateful thanks.

Of the numerous friends who offered me hospitality during the field work, I am especially indebted to Dr. John Eriksson, Prof. of Botany, Göteborg, who helped me in so many ways during my stay in Sweden.

Mrs. Anna A. Damström, M. A., revised the English language, and Mrs. Marja Kaila, Phil. Mag., revised the Latin diagnoses, for which I wish to thank them both.

Mr. MaUri Korhonen took the excellent photographs and drew the final copies of the spore figures, for which I am much indebted to him.

I wish to thank the staff of numerous herbaria in Fennoscandia and elsewhere for placing material at my disposal.

I am indebted to the Universities of Helsinki, Turku, Oulu, Uppsala, and Göteborg, for the facilities for field work provided at their biological stations.

The University of Helsinki provided me with a long term grant which enabled me to devote my whole time to research. I also received grants from the E.J.Sariolan Säatiö Foundation, and the Finnish Biological Society Vanamo. I am much obliged for this assistance.

\section{Introduction}

The epithet «Clitocybe w was coined by E. FrIES in his «Systema Mycologicum《, vol. 1 (1821). He used it to designate a «tribus« (the «tribus« were treated as subgenera by later mycologists) of the genus Agaricus and it was divided into nine «subtribus«. Two of these subtribes (Camarophylli and Hygrocybi) contained specific names afterwards used for species of Hygrophorus sensu lato; the subtribe Oesypii contained a mixture of mainly Tricholomataceous species; Calodontes included some dubious names as well as some species now referred to Mycena; Thrausti accommodated species of Melanoleuca and Oudemansiella platyphylla; Rhizopodes contained the species known according to modern nomenclature as Oudemansiella radicata and Flammulina velutipes; Chondropodes and Scortei mainly comprised species of Collybia. Only the first and largest subtribe, Dasyphylli, comprised names subsequently used for species of the genus Clitocybe. In addition, it contained some species of Lyophyllum and some dubious names. In «Systema Mycologicum《 names and descriptions of species of Clitocybe are also found in another tribe, $\mathrm{Om}$ phalia. Some species were included in the subtribe Mycenaria of Omphalia, but most of the species of the subtribe Collybaria were subsequently transferred to Clitocybe.

In «Epicrisis systematis mycologici...《 
(1836-1838) Fries amended the tribe Clitocybe to comprise the previous subtribes Dasyphylli and Collybarii only. Many descriptions were, of course, revised and new species described by him and others were added. On the basis of macroscopical characters (e.g., hygrophany), this revised tribe was divided into six taxa, the rank of which was not indicated. These taxa, usually regarded as sections by subsequent authors (e.g. Singer), had the following names: Disciformes, Difformes, Infundibuliformes, Cyathiformes, Orbiformes, and Versiformes. It was principally in this meaning that the genus Clitocybe was usually understood by subsequent generations of agaricologists, till the era of R. Singer. This concept and subdivision as well as the status as a tribe of the genus Agaricus were maintained by FrIES in his later works, including the last of them, «Hymenomycetes Europaei...« (1874). In this opus, some species were added but the descriptions of the taxa were mostly taken word by word from the previous works. Practically no macroscopical features were more thoroughly described than earlier, nor were any microscopical characters added, although various contemporary biologists were already using the microscope. In addition, Fries almost totally neglected to preserve herbarium specimens, despite the fact that some of his countrymen (e.g. H. voN Post) collected extensive herbaria of fleshy fungi.

The epithet Clitocybe was raised to generic rank for the first time by StAude (1857) (see also p. 12). The handbook by Kummer (1871) and the floras of Qú́LET (1872, 1886, 1888 ) and Gillet (1874), in particular, have much value because of their many new combinations, resulting from transfers from Agaricus to Clitocybe, and the treatment of the Friesian groups (Disciformes etc.) as subdivisions of the genus Clitocybe. At the turn of the century many new species were described by various authors, especially in North America by Peck and Murrill, in Europe Britzelmayr and Velenovskí, but the delimitation and subdivision of the genus were principally those of Fries.

In 1926 the Swiss worker NüEsch published his local monograph on the genus in Switzerland. The best features of this work are the original and accurate measurements and observations, besides which it contains abundant references. The author always distinguishes between his own data and those obtained from the literature. The subdivision of the genus was to some degree original, and NüEsch excluded some elements which he did not consider «true Clitocybes, such as species of the present Laccaria and Lyophyllum.

The treatment of the genus by KonRAD \& Maublanc (1924-1937) is worth mentioning on account of the careful delimitation of the genus, descriptions, figures, and nomenclature.

Radical and urgently needed changes in the delimitation and subdivision of Clitocybe were made by Singer (1943), using data obtained from modern microchemical, anatomical, and cytological studies made by himself and others. His system laid the first solid foundation for additional studies and further amendments.

Singer's narrow but still somewhat heterogeneous concept of the genus was subsequently modified by the French worker MÉTrod (1949), among others, in his short monographic treatment. He excluded some foreign elements from Singer's Clitocybe, and his delimitation coincides very closely with that of the present study. MÉtrod, like SingER, emphasized the rather uniform sporal and anatomical characters of the redefined genus. His subdivision was, however, very schematic and unnatural, and its nomenclature was not well defined.

The present knowledge of Clitocybe has been summarized in Singer's monumental work «The Agaricales in Modern Taxonomy« (1962), and the concept of the genus presented in this monograph has been acknowledged by almost all modern mycologists. The delimitation is largely similar to that of MÉTrod, and, on the whole, the subdivision is rather natural. It comprises subgenera, sections, and subsections, the nomenclature being mostly valid.

In North America a comprehensive monographic work is now under preparation by H. E. Bigelow. His main studies (1962, 1965, 1968), unfortunately neglected in Europe, have so far been the only ones which can be considered consistently monographic in the modern sense. They are based on the whole material from the respective districts, and on type studies, and the specimens studied are listed (though mostly without exact locali- 
ties). He has paid attention to many neglected but important characters such as the colour of the spore deposit. The outline in Bigelow's studies is logical and the nomenclature is in accordance with the International Ciode of Botanical Nomenclature. The authors's delimitation of the genus is, however, very conservative and unnatural, including Omphalina, and such very distinct genera as Cantharellula, Hygrophoropsis, and Pseudoclitocybe, and others.

The literature on Clitocybe in Fennoscandia consists mainly of the classical publications of Fries and Karsten. Though he soon gave generic status to Clitocybe, Karsten's taxonomical treatment largely follows that of FrIEs, and his descriptions often seem to have been copied from those of the Swedish author. KaRSTEN made some use of microscopical data in his publications, and he described several new taxa but they are mainly difficult to identify or synonymous with old species (see chapter VIII., p. 114). Apart from the writings of these two authors, literature on the genus is scarce and mostly consists of short unreliable notes in floristic papers or in handbooks.
The larger part of the preserved Clitocybe material available has been collected by amateurs, many of whom never published anything. I am very grateful to all these people whose activities made it possible for me to base my study on a remarkably large amount of specimens (3220), when compared with those available in most investigations with a similar scope. The number of these collectors is so great that I will not attempt to list even the most active of them. Mention must, however, be made of Dr. S. LunDELL, since he was not only a collector, though he unfortunately published extremely few articles. He seems to have been the mycologist with the most realistic concept of the species of Clitocybe. I came to this conclusion when studying the extremely well-preserved specimens at Uppsala (UPS) collected by him and others and revised by him. His determinations are consistent to an unusually high degree, and accordingly the specific names used by him were far fewer than those of most other agaricologists. My conclusions regarding these names mostly coincide with his interpretations.

\section{Delimitation of the genus}

\section{A. Working hypothesis}

Though I carefully tried to avoid any preconceived opinions, it was necessary to take some hypothesis as the starting-point of my studies. I decided to work on the basis of Singer's (1962) concept of the genus Clitocybe. This author, who has actively investigated the agarics in so many parts of the world, has obviously the widest knowledge and the best qualifications for the delimitation of the genera of Agaricales.

During the work it became clear that at least the so-called section «Eulepistas (Konr. \& Maubl.) Sing.« should be excluded. The spores in that section are distinctly echinate, and in addition have rather thick walls which are brownish in $\mathrm{KOH}$, while in the other Clitocybe species I found the wall to be smooth, very thin, and hyaline in $\mathrm{KOH}$. When I found a pinkish buff spore deposit several times in the well-known bright brown or paler species of this section (cf. e.g. TuoMIKOSKI 1959: 57), it became obvious that this seemingly sole species of the «section
Eulepistae should be transferred to Lepista (Fr.) W. G. Sm. In that genus its name should obviously be Lepista gilva ([Pers.] Fr.) Roze. A separate study of this species in Fennoscandia and its systematic position will be published in the near future (Harmaja 1970). It can be added that Singer (op. cit.: 238) considers it possible that the species of Clitocybe with «rough « spores will later be transferred to Lepista. Bigelow \& Rowley (1968) have found that the spore ornamentations of Lepista spp. and «Clitocybe inversa (surely identical or very close to my Lepista gilva) are almost identical in electron micrographs.

A second group included in Clitocybe by Singer (op. cit.) is the «C. lignatitis complex«. Fruit bodies apparently belonging to this group have been collected from the area of the present investigation but I myself have never found them. A dried specimen from northern Finland, studied by me, proved to have more or less thick-walled hyphae throughout, which, perhaps, caused the hardness of the dry fruit bodies. This character, toge- 
ther with the lignicolous habit, is reminiscent of the family Polyporaceae sensu Singer (op. cit.). According to Singer (op. cit.: 234), the complex is in need of revision and he states that at least some of the taxa referred to it may more properly belong to other genera, e.g. Pleurocybella. For the reasons given above, I have excluded these lignicolous, whitish species, which have small subglobose spores and hard basidiocarps when dry.

The other groups of Clitocybe presented in Singer's system but not discussed in this paper do not seem to have been collected from Fennoscandia.

\section{B. Remarks on some related genera}

As regards the delimitation of Clitocybe from other genera of Tricholomataceae, I must principally refer to Singer (op. cit.: 227-230), my present knowledge of these genera being very poor. I have, however, made some occasional observations in the field and with the microscope of real or apparent quantitative and qualitative differences between Clitocybe and some closely related genera. Attention has also been paid to information on some points in the literature. In many cases my observations can serve only as working hypotheses for further detailed studies and are not to be regarded as representing definite conclusions.

As a first step in this study, it seems sound to exclude species with amyloid or dextrinoid and/or thick-walled and/or uneven spores, constant cystidia, siderophilous (carminophilous) basidia, or any pileus cortex other than one composed of filamentous and often radial hyphae. These characters are very often positively correlated with each other or with anatomical, chemical, ecological, and macromorphological features which are lacking or rare in Clitocybe s.str.

Armillariella Karst. - Especially the type species, A. mellea, possesses many characters foreign to Clitocybe. Attention can be directed to the well-developed veil, and the brown true rhizomorphae with specialized tissues, which occur in this genus, as well as to the specialized ecology (e.g. lignicolous, paludicolous).

Cantharellula Sing. - In the type species of this genus, $C$. umbonata, I found that the spores, besides being amyloid, have thickish walls, and that the gills immediately turn deep red with aniline (also when bruised). In the field, it appears that the species is always associated with a green plant, namely the mosses Polytrichum spp. or Pleurozium schreberi. None of these characters are present in Clitocybe.

Gerronema Sing. - According to the literature, the species of this genus mainly occur on the same three types of substrate as those of Omphalina (see later), so this genus, too, is generally distinct from Clitocybe as to physiology. Morphologically, it differs from Clitocybe in a manner rather similar to that of Omphalina. The general distribution of Gerronema also shows distinguishing characters.

Lepista (Fr.) W. G. Sm. - Singer (op. cit.) and Bigelow (in various papers) admit that the species of the group «Eulepistae» are unique in Clitocybe and that their spores closely resemble those of Lepista (see p. 9). Surprisingly, however, they subordinate the fundamental morphological characters of the spore to the colour of the spore deposit, which they claim to be more or less white, thus showing affinities to Clitocybe. This character alone would be no indication of affinities to Clitocybe s. str., where, besides species with pure white spore deposits, both non-hygrophanous and hygrophanous species occur with yellowish, or distinctly pinkish buff spore prints, and, even if there were species with echinate and thick-walled but white spores, I should exclude them from Clitocybe. It is probable, however, that at least some of the spore deposits studied by these authors only appeared to be white because they were too thin. Besides possessing rough to echinate, often more or less thickwalled spores and a pinkish spore print, the genus Lepista generally seems to show more ruderal tendencies than Clitocybe, since it contains a high percentage of species occurring mainly or often in man-made habitats, or environments strongly affected by human activities. Recently, Bigelow \& Smith (1969) transferred the whole genus Lepista as a section to Clitocybe, the species of «Eulepistae» also being included in this section.

Pseudoclitocybe (Sing.) Sing. - The species studied by me have amyloid and thickish-walled spores, and their flesh and lamellae have the same striking red aniline reaction as the lamellae of Cantharellula 
umbonata (two species studied for this character). There may be statistically significant differences between the ecological characters of Pseudoclitocybe and those of Clitocybe. A detailed study of the genus in Fennoscandia will be published in the future.

Tricholoma ([Fr.] Fr.) Staude and Omphalina Quél. - These two genera would appear to have the greatest morphological proximity to Clitocybe. Most of their species differ from Clitocybe in having no clamps, yet there are species where they are present, and clamps are lacking in at least one species of Clitocybe. The construction of the hymenophoral trama in Omphalina mostly differs from that of Clitocybe. Evidently so far no morphological or chemical character has been identified which is present throughout the species of any one of these three genera and differentiates it clearly from the others. However, already FrIes (1821) made distinction between these genera including their species in three separate tribes, respectively, on the basis of some macrosopical indistinctly defined differences which are no doubt the result of significant differences in their gene pool. These features will probably eventually be found to be correlated with chemical, anatomical or cytological ones. According to the literature and my own observations, these macromorphological differences are as follows: In Tricholoma the fruit body is large to medium, the pileus usually not hygrophanous, convex to plane when adult, the gills more or less sinuate, the flesh thick in the pileus and perhaps not distinctly continuous in the pileus and stipe. In Clitocybe the fruit body is mostly medium-sized (varying from large to small), the pileus hygrophanous or not, plane to deeply infundibuliform when adult, the lamellae more or less decurrent and usually (but not always) not at all sinuate, the flesh usually rather elastic, distinctly continuous in the pileus and stipe. In Omphalina the fruit bodies are more or less small, often waxy or brittle, the pileus perhaps always hygrophanous, almost plane to infundibuliform when adult, the lamellae more or less decurrent. In extreme cases these differences are very marked, and clearly separate Tricholoma and Omphalina from each other, while Clitocybe seems to be in a somewhat intermediate position «between « them.

A description will now be given of some differences in the microscopical, chemical and ecological features of the three genera, observed during the present study or reported from the literature. These may prove to be statistically significant when larger material is studied from various parts of the world. Methods may also be discovered by which every single species can easily be referred to one or other of these genera, though it is possible that some aspects of the delimitations will always be matters of opinion.

Firstly, the spores in the Omphalina species seem to be mostly rather large, more than $6 \mu \mathrm{m}$ long and sometimes even over $10 \mu \mathrm{m}$, while in Clitocybe, especially in the most Omphalina-like rather small, grey to brown hygrophanous species, i.e. those of the subgenus Pseudolyophyllum, they are less than $10 \mu \mathrm{m}$ long and often clearly shorter than $6 \mu \mathrm{m}$. The basidia are accordingly somewhat larger in Omphalina. Encrusted pigment on the hyphae of the flesh and gill trama seems to be much commoner and more abundant in Omphalina than Clitocybe and has been emphasized by Singer (op. cit.) as characteristic of the former genus.

A vast field of study remains to be explored with the macrochemical reagents, and many specific and generic differences, both quantitative and qualitative, will very probably be discovered. Singer (op. cit.: 247) reports that such substances as $\mathrm{KOH}$ and formaline produce striking colour reactions in the flesh of species of Tricholoma. In a preliminary study of some species of Clitocybe I almost always obtained negative or faint reactions with these substances (see p. 30).

A very important but usually neglected and not yet easily defined group of characters are the physiological/ecological ones. It is clear from the literature and my own field observations that there may be fundamental differences in the nutritional physiology of these three genera. In Tricholoma, according to Singer (op. cit.), a great number of species form ectotrophic mycorrhizas with trees. A few species, however, are probably saprophytic. The great majority of the Fennoscandian species of Clitocybe occur in more or less dry habitats with a distinct layer of litter and appear to be predominantly saprophytic, as physiologists have confirmed in respect of some species. Some species 
occur regularly near and above the forest limit, but then almost always on more or less calcareous ground. The distinction between the subgenus Pseudolyophyllum and the genus Omphalina is often difficult to make on a purely morphological basis, and I should like to draw attention to some features which require further study in the field and laboratory. As is seen later in the present study, the species of this subgenus are restricted to litter (principally needle or leaf), and do not seem to have obligate connections with living green plants. The species of Omphatina, on the other hand, occur rather exclusively on one of three kinds of substrate, all foreign to species of Pseudolyophyllum, at least the Fennoscandian ones, and to all the other species of Clitocybe (except those which grow on bare soil). The first two substrates are decaying wood and more or less bare soil (especially sandy soil), while by the third «substrate I mean a close association with living green plants. Such associations are very interesting and the green plants are either mosses (Musci ?, Sphagnum spp., Hepaticae such as Blasia pusilla and Marchantia polymorpha) or algae. These different kinds of substrate indicate that the physiology, enzyme systems, etc. in Omphalina differ from those of Clitocybe (and Tricholoma). The co-existence with green plants makes it possible for some Omphalina species to grow in very wet places or extremely cold climates (e.g., in arctic areas, often on very meagre ground). The photosynthesizing participant possibly supplies carbohydrates to the fungus as in the symbiosis of ectotrophic mycorrhizas (this type of symbiosis has not been reported in Omphalina). In some cases such symbiosislike co-existence has resulted in the development of «Basidiolichenes « which are at present the object of intensive study, e.g. in Finland (see Heikknü̈ \& Kallio 1967).

There are surely some differences, too, between the distributions of Tricholoma, Clitocybe, and Omphalina. On the whole, that of the last-named appears to be the most northern.

\section{Type species}

Fries (1821) did not designate a type species for his tribe Clitocybe. The correct lectotype proposed for the genus Clitocybe (Fr.) Staude (and the basionym) is Agaricus nebularis [Batsch] Fr. (DoNk 1949). Horak (1968), too, has preferred Agaricus nebularis.

Donk (1962: 56 - 59) has discussed the intricate history of the typification of the genus Clitocybe, which involves conflicting interpretations and opinions on such questions as the first author validly to raise Clitocybe to generic rank. Since I agree with DoNk's arguments, it is not worth while discussing the problem of the type species further here. It can be added, however, that later Bigelow (1965) proposed Agaricus clavipes as the type of the genus «Clitocybe w without citing any authors in connection with the generic name. In his Ph.D. thesis (Bigelow 1962), which is not an effective publication, this author has, however, used the citation «Clitocybe (Fr.) Kumm.«.

\section{Area of investigation; material and methods}

The area of the present study, Fennoscandia, is well-defined geologically and geographically and comprises Norway, Sweden, Finland, and the northwesternmost parts of the U.S.S.R., namely the Karelian A.S.S.R., the northern Leningrad Region, the Murmansk Region and parts of the western Archangel Region. The three last-named Regions belong to the Russian Sovietic Federal Socialistic Republic.

Botany, and the other sciences have long been intensively pursued in most of the area, and thus there are a number of comprehensive studies and maps concerning the geology, climate, and vegetation of Norway, Sweden, Finland, and large parts of the Soviet territory. For data of the bedrock, soils, climate, and relief of Fennoscandia, the reader is referred to publications such as that of Hultén (1950). The vegetation zones and their oceanity sections used in the present paper, and various vegetation maps, as well as references to a large number of vegetation monographs will be found in $\mathrm{AH}-$ ti, Ḧ̈мет-Анті \& Jalas (1968).

The field work, which served as the basis of this study was mainly carried out in the years 1965-1968. Excursions were made in 
many different habitats, but mostly in forests, throughout the period when the ground was free of snow, especially in the autumn. Southern Finland, particularly the rural district of Lohja, was searched rather intensively. In the unfortunately poor collecting season of 1968 I made some trips to northern Finland, and gathered material for over a month in Sweden, in FrIEs' sampling districts in Småland and Uppland, and Scania. The collections comprised almost every basidiocarp that I found, whether growing singly or in groups, the whole fruiting being taken whenever possible. Ecological observations were always made at the site, concerning the growth pattern and number of fruit bodies in the fruiting, the habitat (usually the forest site type), the substrate, any moss species occurring in the habitat, signs of human influence, and sometimes the slope of the site. In 1965 I made some dozens of measurements of the $\mathrm{pH}$ value of the substrate of Clitocybe species in S. Finland (Lohja). This project was abandoned, however, when it became obvious that the task of obtaining sufficient $\mathrm{pH}$ values for statistical purposes would require the whole of the collecting season.

Indoors, the fruit bodies were then studied macroscopically and to some degree chemically and microscopically. Special attention was paid to the hygrophany. The colours of different parts of the fruit body were described in the terms of Maerz \& Paul (1950). A spore deposit was taken (or an attempt was made to obtain one) from most of the collections on Finnish block paper with a blue grid, which is suitable for this purpose, being especially pure white.

In the winter and summer the dried collections were re-examined. The colours of the fruit bodies were observed again. The reactions of the pileus, stipe, lamellae and flesh when illuminated with ultra-violet light were studied, the light source being an apparatus with a wave length of $254 \mathrm{~nm}$. The spores of each collection were studied microscopically in Melzer's reagent (see e.g. Singer 1962: 82). The anatomy of the pileus and the nature and location of the pigments were studied (usually in a number of collections of each species) in $5 \% \mathrm{KOH}$ with very thin radial freehand sections. For sectioning a sector of the pileus was removed and placed between two pieces of Sambucus pith. The ethyl alcohol reviving method (see Bigelow
1962: 12) was tried but it was not usually superior to immediate mounting in $\mathrm{KOH}$, and was more time-consuming than the latter. The anatomy of the stipe was studied in some species only, in $\mathrm{KOH}$ mounts. The basal tomentum, and the mycelial hairs and the rhizoids when present were, however, studied in all the species, in both $\mathrm{KOH}$ and Melzer's reagent. The lamellary anatomy was studied in longitudinal sections made as described, for example, in Singer (op.cit.: 48-49) and mounted in Melzer's reagent. The microscope used was a Wild M 20 research microscope with Fluotar objectives and both bright field and phase contrast systems. All microscopical drawings were made with the aid of a camera lucida.

The present study is based on 3220 specimens deposited in the Fennoscandian herbaria $\mathrm{BG}, \mathrm{GB}, \mathrm{H}, \mathrm{HFR}, \mathrm{KUO}, \mathrm{LD}, \mathrm{O}$, OULU, S, TRH, TROM, TUR, Umeå University Herbarium, and UPS. A few specimens are in $\mathrm{M}$ (the abbreviations of the herbaria are according to LANJouw \& Stafleu 1964). About 500 of the specimens were collected by myself, and they are all deposited in $\mathrm{H}$ and some in other herbaria as well. Each collection was studied microscopically and my determination was recorded on the label or an annotation slip.

The collections of Clitocybe in the Fennoscandian herbaria represent the southern parts of the area fairly well. The northern, interior and higher districts are, however, for the most part poorly investigated in respect of $\mathrm{Aga}$ ricales. Collecting has not been uniform in Norway, Sweden, and Finland. The number of collections from Sweden is the largest, and that of Norway the smallest. The collecting localities in Finland are more diffuse than in the other countries. The Russian parts of Fennoscandia are obviously very poorly known as regards the agaric flora, and I unfortunately received no specimens of Clitocybe from these districts, from the Ciryptogamic Herbarium in Leningrad (LE). Requests were made to a great number of herbaria for the type specimen of type material of, e.g., every taxon earlier described and acknowledged in this study. In many cases, however, no original material is left, or no material was collected by the describer. The types of C. H. Peak at Albany (U.S.A.) were unfortunately not available for me though still extant. 


\section{Infrageneric diagnostic characters of Clitocybe}

\section{A. Macroscopic characters}

\section{Pileus}

The breadth of the pileus varies from ca. $1.5 \mathrm{~cm}$ to ca. $30 \mathrm{~cm}$ in adult fruit bodies of Clitocybe. Each species has its characteristic range, and the pileus size is a valid specific character when used in connection with others. The broadest pilei (and largest fruit bodies) are those of some species of the type subgenus (e.g. C. nebularis). A large pileus (= large fruit body) seems to be a primitive character in Clitocybe.

For the hygrophanous character of the pileus, see under the title «Flesh«, p. 17.

The colours of the pileus are never bright red, yellow, or blue, but white or various shades of brown, grey, or buff, rarely fleshcoloured, in one species more or less aerugineous. The colour is often a diagnostic feature, especially at the specific and sectional levels. Apparent mutations towards loss of distinct pigment, seem to occur in some species, at least in the two first subgenera. As a result, more or less albinic fruit bodies have been found in $C$. nebularis, $C$. gibba, and C. odora.

The shape of the pileus is constant in most species, but inconstant in some, e.g. $C$. gibba. A common feature of all species is that the adult pilei are never convex but always plane to infundibuliform. Accordingly, a plane, \pm depressed, umbilicate, or infundibuliform pileus is a diagnostic character of the genus.

The pileus surface is completely dry in most species, though in some it is evidently constantly more or less weakly viscid. It is usually smooth, but in some sections of the subgenus Clitocybe it may be areolate, especially over the disc. In C. squamulosa, and sometimes in $C$. sinopica, the surface is distinctly minutely scaly. In $C$. nebularis and C. clavipes it is weakly fibrillose-reticulate under the lens. In species with thin flesh the pileus surface in exsiccates is often concentrically wrinkled (parallel with the tangent of the pileus). This phenomenon is most striking in the subgenus Pseudolyophyllum. No remnants of any kind of veil ever occur on the cap surface.
A very important, mostly neglected character, useful at the sectional and subsectional levels in the first two subgenera, is the presence of a "pruina « on the pileus surface giving it a canescent, hoary appearence. Its colour varies, being a pale shade of the ground colour of the pileus, or white. This phenomenon is known to be due to a layer of minute air bubbles caught between hyphae in the otherwise water-soaked pileus (or the cortex of the pileus) the bubbles being situated somewhere below the very outermost layer of hyphae, whose interhyphal spaces are all water-filled. It is not clear whether the bubbles occur immediately below the epicutis or even deeper. A subcutis is usually present in species with a pruinose pileus. The bubbles can easily be removed by pressing with a finger upon the pileus surface: the interhyphal spaces lose the air they contain and become filled with water from nearby watery tissues. As pointed out earlier (Harmaja 1969b), watery tissues (here, those both above and below the layer with air bubbles) are darker to the human eye than tissues filled with air. It is accordingly readily understood that the pruina is most easily observed in very fresh fruit bodies before any loss of moisture. In species with a dark ground colour, such as $C$. pruinosa and $C$. ditopa v. ditopa, the «pruina « for some reason can usually be seen in dried fruit bodies, too, at least over the disc. The pileus margin of dried fruit bodies of pruinose species is often conspicuously white. Under certain circumstances, the airbearing layer may be partly water-soaked even in fruit bodies in situ, and the pileus surface must always be carefully studied to decide whether it is pruinose or not. The fact that the pileus surface may be pruinose in species with non-hygrophanous pilei (e.g. $C$. nebularis, $C$. odora), too, is explained by my observation (Harmaja op.cit.) that the cortical layers of the fruit bodies appeared to be water-soaked in all the Fennoscandian species of Clitocybe found by me. The occurrence of the "pruina is positively correlated with a more or less pronounced thickness of the pileus flesh, including that of the margin.

Only a hygrophanous pileus can be translucent-striate, i.e., the lamellae and lamellulae can be distinguished through the moist, 
water-soaked pileus. Hygrophanous and non-pruinose pilei are usually more or less clearly striate. Of the hygrophanous nonpruinose species, probably only $C$. rhizophora has a completely non-striate pileus as a constant character. Pruinose pilei are never striate (except for rare cases of weakly striate cap margins in very old fruit bodies of, for example, $C$. candicans).

\section{Stipe}

The diameter of the stipe is rather constant within the species, but within the genus it ranges from a couple of millimetres to nearly six centimetres. The stipe is concolorous with the pileus or paler, or buff to white. It is mostly more or less equal but in some species it is constantly clavate, tapering upwards, e.g. in C.clavipes and C. strigosa. The extreme base inside the tomentum may be acute or obtuse to truncate, being long and often curved in some species, sometimes even slightly radicating. In young basidiocarps the stipe is solid, but with age it often becomes hollow (especially in subg. Pseudolyophyllum). In all species it is central to slightly eccentric, straight to somewhat curved. In $C$. menthiodora the stipe becomes strikingly twisted as it dries.

The stipe surface has no very distinct diagnostic characters. It often possesses longitudinal downy fibrils, which loosen and turn dark when handled. Distinct remnants of a veil are lacking on the stipe, but the apex in various species has some mealy covering, especially in young basidiocarps. The stipe is often indistinctly pruinose in species with a pruinose pileus. The dried specimens of $C$. candicans are often recognized by the stipe, which has a peculiar, shining, «waxy« appearance when dry.

The most important diagnostic characters of the stipe, at the specific and sectional levels, are the different kinds of mycelial elements at its base. Three types can be distinguished:

1. The tomentum is usually white or whitish with a faint greyish or brownish tint (distinctly brownish in the section Gilvaoideae; in hygrophanous species watery-dark when water-soaked, but whitish when faded, and when dry). It resembles a silky coating, and is amorphous to the naked eye (Fig. 1a). It occurs at the base of the stipe usually below the surface of the litter or soil, and is evidently present in all the species in varying amounts, often being abundant and the only one of the mycelial elements. This type is surely the most primitive one.

2. The mycelial hairs are strigose, projecting, more or less hyaline hairs distinguishable with the naked eye. They occur, like the tomentum, within the substrate. They comprise two subtypes. In one of these the hairs are not conspicuously ramose, and are very thin, slender, filamentous, and completely colourless (Fig. 1b). Such hairs always occur in the section Strigipedes, either together with scanty tomentum or, on rare occasions perhaps even alone. They are also present in some species outside this section (in the subgenera Clitocybe and Roseospora), but then they are inconspicuous and, with the possible exception of $C$. inornata, are rare and inconstant. The hairs of the other subtype are \pm ramose, rather firm, compressed and rather broad and \pm hyaline (apparently

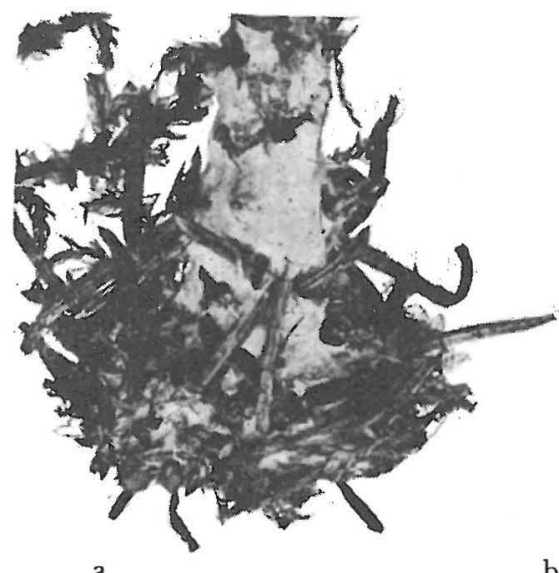

a

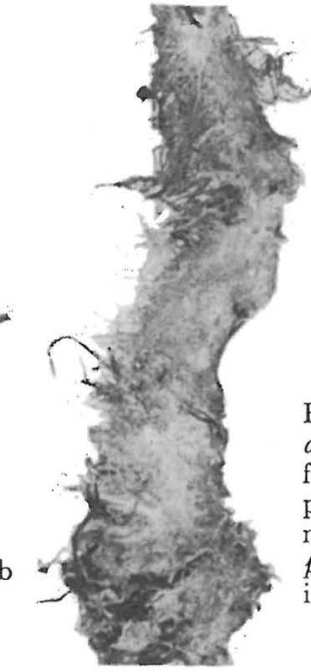

Fig. 1. a) Tomentum (C. ditopa v. ditopa, part of Fig. 78); b) slender filamentous mycelial hairs (C.strigosa, part of Fig. 81); c) firm, compressed mycelial hairs and rhizoids (C. rhizophora, part of Fig. 60). All approximately $\times 2$. 
weakly hygrophanous) (Fig. 1c). They occur in C. sinopica, C. pruinosa, and C. rhizopho$r a$, always together with the two other types of mycelial elements. It is striking that all these three species occur in the spring (at least).

3. The rhizoids are striking, pure white, terete elements of varying length and diameter (Fig. 1c). They run in all directions, and only occur deep in the litter or soil, being the lowest of the three mycelial elements. They are possibly not dependent on the formation of fruit bodies and should perhaps not be considered parts of the fruit body but, rather, differentiated tissues of the vegetative mycelium. They may be found in the substrate some dozens of centimetres from the nearest fruit bodies. It has not yet been ascertained whether the rhizoids are annual or perennial, and whether they have anything to do with the formation of the fruit bodies. In various species of all three subgenera, most rarely in Pseudolyophyllum, they are found together with the tomentum at the base of the stipe, their occurrences usually being inconstant, scattered and inconspicuous. However, in four species of the subgenus $C$ litocybe, namely $C$. inornata, $C$. sinopica, $C$. pruinosa, and $C$. rhizophora, the rhizoids are constant, conspicuous, more or less abundant, and often rather thick. These are the only four species of that subgenus in which mycelial hairs also constantly occur.

These three forms of the mycelium are microscopically rather similar (see p. 28). I consider them, however, most distinct, for they are macroscopically usually easily distinguished, intermediate elements being very infrequent.

The taxonomic value of these mycelial characters, which are especially constant in subg. Pseudolyophyllum and the vernal species, has mostly been neglected by mycologists, though mycelial elements, e.g. the hairs, can be seen in various published figures of species of Clitocybe. These characters have only received attention in the vernal species, whose abundant rhizoids have generally been noted. Singer (1962: 18) refers to the rhizoids briefly as «white mycelial strands《.

The characters described above will surely be found to be important, especially at the specific level, in other agaric genera, too, in particular in the family Tricholomataceae.
For the hygrophanous character of the stipe, see under $\ll$ Flesh $\ll$, p. 17.

\section{Lamellae}

The mode of gill-attachment is one of the macroscopical features which has fairly good diagnostic value in the delimitation of the genus Clitocybe. The lamellae are \pm decurrent in all species, and in most species have more or less straight edges. In some species they are often somewhat sinuate ( $C$. alexandri, $C$. inornata), while in others they are only rarely so.

The attachment angle varies, usually being acute, but often in some species about $90^{\circ}$. The angle may be small in both short and long decurrent lamellae. The differences in the attachment of the lamellae are sometimes useful for the identification of the species.

The colours of the lamellae show the same degree of variation as those of the pileus, though they are never very dark. C. candicans has practically pure white gills when moist. In adult fruit bodies of the species of the section Gilvaoideae, they are strikingly pale cinnamon coloured, usually resembling those of Lepista gilva. In Pseudolyophyllum the moist lamellae are grey to brownish, in contrast to the very pallid ones of the hygrophanous species of the other subgenera. The lamellae are either concolorous with the pileus, or paler but tinted with the cap colour, or distinctly paler and another colour, e.g. yellowish or buff.

In some species the gills almost always change colour somewhat when drying. The temperature at which the fruit bodies are dried at least sometimes influences the gill colour. In the exsiccates of $C$. candicans, and $C$. laricicola, and often also in those of $C$. phyllophila and others, the lamellae differ from the moist gills in being yellow. In $C$. dealbata they become dirty pink. There are no true colour changes in the lamellae when bruised.

Differences in the width of the lamellae, and the point where they are broadest are often useful at the specific level.

There is some variation in the thickness of the gills. For instance, in some species of the section Infundibuliformes, and in C. clavipes they are rather thick while in others, e.g. $C$. nebularis, they are thin. 
The spacing of the lamellae in C. anisata and some species of Infundibuliformes is strikingly wide.

In C. subcordispora the lamellae are conspicuously waxy and elastic in consistency like those of Russula cyanoxantha.

The lamellae can usually be more or less easily separated from the pileus.

The gill edges are always concolorous with the face, and entire (one exeption was found in C. phyllophila. v. phyllophila).

For the hygrophanous character of the lamellae, see the following section.

\section{Flesh}

As regards the hygrophanous nature of different parts and tissues of the fruit body, I refer to an earlier paper of mine (Harmaja $1969 \mathrm{~b}$ ). It can be repeated here (but will not be mentioned in the species descriptions) that in all the species found by me it appeared possible that the lamellae and cortical layers of the fruit body were hygrophanous, even in cases where the cap was not. The stipe appears to be weakly hygrophanous, too, at least in species with a hygrophanous pileus.

The character hygrophanous contra nonhygrophanous pileus is especially important, and varies at the subgeneric and sectional levels.

(After the manuscript of my earlier paper had been sent to press, it began to seem very probable that the inner flesh of C.clavipes fades from the periphery towards the junction of the cap and stipe which is contrary to the behaviour of all the other species studied by me.)

The other characters of the flesh are very uniform throughout the genus and show so little variation that they will not be repeated in the descriptions of the taxa.

The context is white to very faintly tinged with buff, brown or grey. Hygrophanous flesh assumes these colours when faded; in the moist condition the pileus flesh appears to be concolorous with the pileus surface, while that of the stipe is concolorous with the stipe surface. No conspicuous autoxydation reactions have been observed, but very often the flesh is faintly rusty yellow or brown at the base of the stipe or assumes this colour when pressed.

The flesh is rather uniform as to consisten- cy, too, the flesh of the pileus and that of the stipe being strikingly continuous. The flesh is perhaps more elastic in $C$. diatreta than in other species, while it is sometimes unusually fragile in C. marginella, C. vibecina, and $C$. langei.

The flesh is very thin in some taxa, especially in the section Strigipedes, and this may be a derived character.

The various taxa of Clitocybe differ slightly in the ability of their flesh to resist larvae. For example, $C$. geotropa is very often very heavily attacked by larvae, while the flesh is rather resistant in the species of the subgenera Roseospora and Pseudolyophyllum.

\section{Odour}

There is a wide variation of odour in $\mathrm{Cli}$ tocybe, and different odours can be used as diagnostic characters at all levels. Most odours are recognizable in fresh fruit bodies only, but some of them may persist in exsiccates for several decades.

Many species have only a «fungoid « smell which cannot be defined more accurately. The exsiccates of these species are always odourless. Old fruit bodies of these more or less odourless species of the section Pseudolyophyllum, and of C. strigosa, sometimes, however, have a smell very similar to that of Cystoderma carcharias, which may persist in exsiccates.

The sections Sinopicae and Ditopae have a distinct farinaceous smell, though it is sometimes difficult to observe without bruising the fruit body, which always strengthens the smell. C. gracilis and $C$. lohjaënsis have this smell, too, but the latter differs from all the other species in that the farinaceous smell is noted in very fresh and young fruit bodies only. When the fruit body of this species is bruised, only a more or less fungoid smell can be observed. The farinaceous smell never persists in exsiccates.

Another group consists of species which have a rather faint fragrant odour of strawberries (sometimes more reminiscent of anise). This odour always becomes more distinct as they dry, but totally dry fruit bodies are odourless. This odour characterizes the section Roseospora (only sometimes observable in C. diatreta), and is present in some species of the Candicantes, too. 
C. odora and C.fragrans possess a strong sweet odour which differs clearly from the preceding one in both strength and quality. It has been described as «anise-like« in the literature, but I consider it to be coumarinelike (i.e., resembling the odour of the grasses Anthoxanthum odoratum, and Hierochlö spp.). The flowers of Linnaea borealis have exactly the same odour. The exsiccates of these two Clitocybe species are usually odourless, except for some occasional, fairly recent specimens.

C. nebularis and C.clavipes have sweet, rather similar odours with their own distinctive quality. They are often persistent in exsiccates in a somewhat modified form (honey-like), especially that of the firstnamed species.

C. geotropa has a strong odour of oil of bitter almonds (benzoic aldehyde), or the flowers of the chokecherry tree (Prunus padus). It is present in fresh basidiocarps only.

In the section Infundibuliformes some species (C. catinus, $C$. gibba, $C$. squamulosa, at least) often have a faint agreeable odour when drying, which can persist in the dried fruit bodies for some time. This odour is camphor-like, or like that of Lactarius helvus.

Of the few, mostly vague kinds of odour not yet mentioned, the peculiar characters of $C$. menthiodora may be described. It has the normal farinaceous smell typical of its section Ditopae, but when drying produces a faint, very agreeable odour of menthol or Mentha (not anise), the farinaceous smell now being observable only when it is bruised. The final odour of the dried fruit bodies of this species, which persists for several years at least, is a fish-like smell, or that of diand trimethylamine.

\section{Taste}

Almost all the species have a mild taste. Most species have a mild, «fungoid « taste, though the flavour may differ slightly in some species, being agreeable, sweetish, acidulous, or disagreeable.

Those which possess a farinaceous odour have a similar, farinaceous taste, except for the adult and old fruit bodies of C.lohja- ënsis, whose taste is merely fungoid. In order to study whether a specimen belongs to, say, the section Ditopae, it is easier and more reliable to taste it than to try to judge the kind of odour. Dried fruit bodies only have a more or less fungoid taste.

In $C$. amarescens the adult and old pilei have a bitterish taste. The dry fruit bodies are mild. According to the collector v. SaHuLmann (1961: 14, «C. futigineipes Métr. E 11. 10. $57 \ll)$, the specimen which in the present study is described as C. schulmannii tasted quinine-bitter when fresh.

\section{Colour of the spore deposit}

The colour of the spore deposit is known to be of the utmost importance in the classification of Agaricales, and I have found it to be extremely constant within the species of Clitocybe, and diagnostic at supraspecific levels as well.

In accordance with the Friesian tradition, the spore deposit of Clitocybe has usually been stated to be «white«. In the species found in Fennoscandia, it is in effect always pale, and in most cases it must be described as more or less pure white, but in addition many different pallid colours may be observed if a sufficiently thick layer of spores has been obtained on a pure white surface (paper). Bigelow (1962) tried to employ this character systematically. However, he mainly confined its use to the specific level. In addition, it is probable that in some of the species found by him the spore colour is actually pinkish buff, or yellowish, although recorded by him as «white too thir a deposit.

I have got use of this character at all levels, the pinkish buff spore colour being restricted to the new subgenus, Roseospora, in the delimitation of which spore colour is perhaps the most fundamental criterion.

In the Fennoscandian species of Clito$c y b e$, five different colours or shades of spore deposit were observed in the present study, and the species and varieties from whose pilei I have obtained a sufficient deposit, group themselves in the following five categories (the colour symbols according to the codes of MAERZ \& PAUL 1950): 


\begin{tabular}{|c|c|c|c|c|}
\hline \pm pure white & $\begin{array}{l}\text { very pale yellow, } \\
9 \mathrm{~B} 1\end{array}$ & $\begin{array}{l}\text { very pale yellow } \\
\text { with a greyish tint, } \\
19 \mathrm{~A} 1-19 \mathrm{~B} \mathrm{1}\end{array}$ & $\begin{array}{l}\text { deep yellow, } \\
9 G 1-9 G 2\end{array}$ & $\begin{array}{l}\text { pinkish buff, } \\
9 \mathrm{~B} 2\end{array}$ \\
\hline $\begin{array}{l}\text { C. alexandri } \\
\text { C. inornata } \\
\text { C. clavipes } \\
\text { C. sinopica } \\
\text { C. candicans } \\
\text { C. pruinosa } \\
\text { C. rhizophora } \\
\text { C. metachroa } \\
\text { C. subcordispora } \\
\text { C. langei } \\
\text { C. ditopa } \\
\text { v. ditopa } \\
\text { C. ditopa } \\
\text { v. odorula } \\
\text { C. menthiodora } \\
\text { C. lohjaënsis }\end{array}$ & $\begin{array}{l}\text { C. catinus } \\
\text { C. gibba } \\
\text { ? C. squamulosa } \\
\text { C. amarescens }\end{array}$ & C. strigosa & C. nebularis & $\begin{array}{l}\text { C. odora } \\
\text { C. phyllophila } \\
\text { v. phyllophila } \\
\text { C. phyllophila } \\
\text { v. tenuis } \\
\text { C. anisata } \\
\text { C. diatreta } \\
\text { C. agrestis } \\
\text { C. marginella } \\
\text { C. fragrans }\end{array}$ \\
\hline
\end{tabular}

8. Response of the fruit body to ultra-violet light

Moser (1960) is probably the only author to have used the fluorescence characters of the fruit body in connection with taxonomic studies on agarics (Phlegmacium). I have studied a number of dried fruit bodies of each Fennoscandian species of Clitocybe under ultra-violet light, and even these somewhat superficial investigations have revealed some interesting correlations with other characters, differences being mainly intersectional, and often not very striking.

Firstly, it was noticed that all parts of the fruit bodies of some species which were dried only some weeks earlier were deep violet when illuminated with ultra-violet light. Every species should be studied for this character in order to find out whether it is always present, and accordingly a diagnostic character of the genus.

Several months old and older exsiccates were found to have three kinds of responses to ultra-violet light, not always very distinct from each other: 1. More or less negative reaction (no fluorescence), i.e. the colour was dirty whitish, yellowish, or brownish, according to the ground colour of the illuminated part of the basidiocarp. 2. Pale to deep violet fluorescence. 3. Chloric-yellowish to chloric-greenish fluorescence, which may either be predominant, or occur as faint reflections.
No fluorescence is observed in the lamellae of the species of the two first subgenera, and of those of the section Pseudolyophyllum, the gills remaining dirty whitish, yellowish to brownish depending upon their original colour. There are sometimes chloric-coloured reflections on the lamellae (see later). The lack of fluorescence in the lamellae may be a primitive character.

A pale to deep violet colour was always observed in: the pileus, the section surface of the context obtained just before observation (often very indistinctly in $C$. nebularis, however), the stipe, and the basal tomentum (except for C.nebularis) with the rhizoids and the compressed firm mycelial hairs. The lamellae of the section Ditopae and those of C. strigosa are violet, too.

The basal tomentum (and the occasional filamentous mycelial hairs) of C.nebularis, and the mycelial hairs of the section Strigipedes show a chloric-greenish to chloricyellow fluorescence. The lamellae of Strigipedes (C.strigosa excluded) and those of the section Latisporae also show this kind of fluorescence more or less distinctly. The chloric-yellow fluorescence was also observed as faint reflections on the stipes of the species of these two sections, and on the lamellae (rarely also on pilei) of various species of the subgenus Clitocybe. The context of C. nebularis may also have a somewhat chloric tint. A distinct chloric-coloured 
fluorescence may be considered a derived character.

The spore deposits of all five colour types (p. 19) have a fourth kind of response, for they always assumed a more or less uniform deep brown colour when illuminated with ultra-violet light.

Although they accord with my section concepts, the fluorescence characters of the different parts of the fruit bodies have not been included in the species descriptions, because the constancy of these characters should first be examined with the aid of more extensive material. This is particularly important in view of the differences between fruit bodies dried recently and those dried some time ago. Also, the characters of the fresh fruit bodies of Clitocybe under ultraviolet light are still completely unknown.

\section{Habit of the fruit bodies}

The occurrences of the fruit bodies are either solitary or gregarious. No species was observed to occur as solitary basidiocarps only, but this type of occurrence is rather usual in C.rhizophora. The fruit bodies may occur in irregular groups, as is generally the case with C.fragrans and C.lohjaënsis. However, most of the species of Fennoscandia occur in rows, arcs and even complete «fairy rings carps. Subcespitose fruit bodies may occur, but, unlike those of some species of $\mathrm{Lyo}$ phyllum, the stipes in Clitocybe are never truly cespitose, or connate, but are separate down to the base, also inside the tomentum.

As will be seen from the above, no striking diagnostic differences exist in the habit of the fruit bodies, though some might well be found to be statistically significant.

\section{B. Microscopic characters}

\section{Spores}

The spore characters, of which the colour of the spore deposit is treated in connection with the macroscopic characters (p. 18), have proved to be the most constant and most important diagnostic features in Clito$c y b e$, as in many other agaric genera.

Some spore characters which are common to all the species will not be included in the descriptions of the taxa. The spore wall is always very thin, i.e., its thickness is obviously less than $0.1 \mu \mathrm{m}$, since it cannot be measured with a light microscope. The wall is also completely smooth in every species, even under the oil immersion objective and with a magnification of $1500 \mathrm{x}$. The spores appear faintly yellowish in Melzer's reagent and are thus neither amyloid nor dextrinoid.

The supra-apicular region has always been observed to be more or less differentiated (even in the \pm globose spores of $\mathrm{C}$. globispora) from the three analogous points of the spore. The differentiation consists in this being applanated up to about the middle (along the longitudinal axis) of the spore. In small spores, however, the applanation reaches beyond the middle point. In some species, at least in some spores, this area is still more clearly differentiated, being more or less depressed (regularly in C. inornata). All the three analogous points of the spore are \pm convex. I have used the term «plage for this supra-apicular area though this term has earlier been employed to designate a smooth supra-apicular area in otherwise uneven spores. It appears consistent to use it for this purpose, since in both cases it denotes a differentiated area. The applanated plage makes the lower half of the spores very slightly broader when measured in face view than when measured in side view. This difference is so slight that it may be ignored. It is perhaps most obvious in C. laricicola and C.lohjaënsis, the spores of which may thus appear slightly compressed.

The fact that the area above the apiculus is applanated in the spores of various agarics is well known, but usually neglected in monographs. It remains to be studied whether this character is diagnostic at higher levels of the taxonomy of the Basidiomycetes.

The apex (distal end) of the Clitocybe spore is always obtuse, and usually rather broadly so. The apiculus, too, has some characters common to all the species of the present study, but they will be discussed later.

The classical (and unfortunately even nowadays often the only observed) characters of the spores are the length and breadth. They are very important and diagnostic at the specific and sectional levels. The greatest dimension of a normal spore varies from 3.0 
um (C. ditopa) to ca. $11.5 \mu \mathrm{m}$ (C. sinopica). In every species, however, most of the spores are shorter than $10.0 \mu \mathrm{m}$. The breadth varies from $1.9 \mu \mathrm{m}$ (C. rhizophora) to $6.5(-8.0)$ $\mu \mathrm{m}$ ( $C$. geotropa). The length and breadth vary with spores of the same preparation and with different populations of one species, the amplitude in respect of the length and breadth being ca. $2-3 \mu \mathrm{m}$ and ca. $1-2$ $\mu \mathrm{m}$, respectively. The variation is partly due to the existence of different genotypes within the same species (spontaneous heterozygosity), partly to such factors as the occasional occurrence of 1- and 2-spored basidia with larger spores. There is, however, usually no remarkable difference in size between spores taken from a deposit and those from the lamellae. In all the subgenera, some preparations of some of the species contained hypertrophied spores up to 13 (and even more) $\mu \mathrm{m}$ long, whose distal half had been elongated, but these have been excluded from the spore measurements. Smith \& SingER (1964) noticed a similar phenomenon in Galerina. Small spores should evidently be considered a derived character in Clitocybe.

The great variation in spore shape within the genus has forced me to create a new system of classification for mastering and describing the different types of spore shape. The starting point in this classification is the shape of the spore base (proximal end), and its relation to the apiculus. The clearest and most accurate concept of these characters is obtained when the spore is observed in side view.

Three types of spore base can be distinguished: 1 . The obtuse base. The base is broadly rounded, and the apiculus is completely distinct from the rest of the spore (sporoid), its longitudinal axis being approximately at right angles to the base surface. The spore may narrow somewhat towards the base, but not towards the oblique apiculus. (Fig. 2 a). 2. The acute base (or decurrent base). The base narrows distinctly towards the apiculus, which forms a prolongation of the base, though distinct from the latter (the length of the apiculus being measurable), the angles between the longitudinal axis of the apiculus and the base surface vary somewhat but are probably always greater than $90^{\circ}$. Since the apiculus is oblique, the spore base naturally becomes slightly curved. It remains to be studied whether the difference in the angles (right angles contra obtuse ones) can be used in every case as an absolute differentiating character between some extreme types of obtuse-based spores (e.g. obovate, see later) and the acute-based ones. (Fig. 2 b). 3. The confluent base. The spore base narrows gradually and changes into the apiculus which is thus completely continuous with the rest of the spore. Since there are no angles, the length of the apiculus cannot be measured, and must be referred to as the apicular region rather than the apiculus. The spore base, the apicular region, is distinctly to slightly curved for obvious reasons. (Fig. 2 c).

In some species there are, of course, spores intermediate between the first and the second, or the second and the third type. Experience has, however, shown that in most species every spore belongs to one of these three types, and in cases where spores of two (in a very few cases even of all three) types occur in the same preparation most of the spores can be classified as to type.

An interesting correlation exists between the size (especially the diameter) of the apiculus/apicular region and the type of spore base: the apicular region is broadest in spores with a confluent base, and the apiculus is thinnest, on the average, in spores with an obtuse base, the acute-based spores being intermediate in this respect.

The type of spore base is an extremely important diagnostic character at all levels within the genus Clitocybe. The obtuse base is the commonest type, and obviously the most primitive, too, being the only one present in the subgenus Roseospora. It is also the most frequent in the other subgenera, in which most species have only obtuse-based spores. The acute base is rarely the predominating type (sometimes in C. squamulosa and C. bresadoliana), but the occurrence of a small proportion (up to ca.

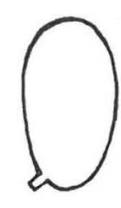

a

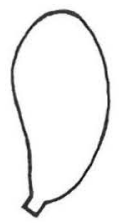

b

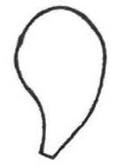

Fig. 2. The types of spore base. a) obtuse base (part of Fig. 108); b) acute base (part of Fig. $95)$; c) confluent base (part of Fig. 94). 
$50 \%$ ) of such spores, especially together with a majority of obtuse-based spores, is a constant character of some species. It (together with the more or less different shape of the acute-based spores) is important in the identification of C.clavipes, C. gracilis, $C$. subcordispora, $C$. orientalis, $C$. langei, and C. strigosa. The confluent base is present only in the spores of the sections Infundibuliformes and Bulluliferae, its proportion varying with the species from a minor amount to $100 \%$.

The various types of spore base and their significance in taxonomy have been almost completely ignored by mycologists. KITs van Waveren (1968) is one of the very few if not the sole student of Basidiomycetes who has paid some attention to these characters and utilized them in the delimitation of agaric species.

After the base type has been used to distinguish three primary spore categories, further classification can be made on the basis of the shape of the entire spore. As stated above, the acute and confluent bases affect the shape of the whole spore because of the oblique position of the apiculus. Cionsequently, the different types of spore shape are generally associated with a certain type of base. All the types of spore shape described here have been recognized earlier, and their names have been derived from Latin. During the present study it was noted that 12 different types of spore can be distinquished in Clitocybe, according to the type of base and the whole outline of the spore. Though the shape is mainly genetically controlled, gradations exist between the different types. Experience has shown, however, that the spores of each species can be roughly classified according to these twelve types. In some species all the spores belong to one type, in others there may be two or more types, the proportion of each often being constant and diagnostic to certain taxa. Spores observed in face view may, of course, appear to differ from those seen in side view even though the 3-dimensional spore shape is the same.

When the spore base is obtuse, seven types of spore shape may be distinguished (Fig. 3). The commonest (and perhaps the most primitive) type is the elliptical, in which the spore is elongated, and broadest in the middle. The fusiform (to subfusiform) type is like the elliptical, but the apices are narrower than in that type, and the spore tapers more abruptly from the middle towards the apices. This type occurs especially in $C$. inornata, in which it is the predominant type, and is present in minor amounts in some other species. The ovate spore is broadest near the base. This type is useful in the identification of C.candicans, C.fennica and C.lohjaënsis, the preparations of which usually consist predominantly or almost exclusively of spores of this type. This type occurs sparsely in very many of the species of Clitocybe. The obovate spore is broadest near the apex. It occurs sparsely in various species, and is predominant in a few, often being so in C. gracilis, C. pruinosa, C. langei, and $C$. strigosa. The oblong type has more or less parallel walls and accordingly has no broadest point. It is a matter of opinion where to draw the limit between the oblong and cylindrical types. However, the length: breadth ratio is usually so small in Clitocybe that I have preferred the term oblong. Gradations can often be observed between the elliptical and oblong types and are probably more continuous and commoner than between the other spore types. In such cases I have often not made a distinction between the two types but used the term elliptic-oblong. Oblong spores are obviously never the prevailing type in the species of the present study, but are, however, often abundant, e.g. in C. fragrans, C. metachroa and $C$. schulmannii. The subglobose type needs no further description. It is, of course, a matter of opinion whether a single spore is to be considered broadly elliptical or subglobose. In $C$. subcordispora, and usually in $C$. ditopa, too, most or all of the spores can be described as subglobose. In the former species some spores are not regularly subglobose, but «subcordiform《 (Fig. 119), but they cannot, however, be considered to form a distinct, independent type. The globose type is represented by the spores of $C$. globispora, which are, however, somewhat irregular in contour because of the distinct, applanated plage.

Four types can be distinguished among the acute-based spores (Fig. 4): elliptical (some spores in $C$. clavipes, $C$. bresadoliana and $C$. lapponica), fusiform (to subfusiform; some spores in C.clavipes and C.orientalis), more or less lacrymoid (most or some spores in 


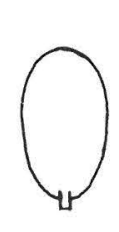

a

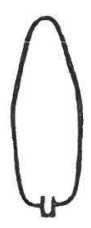

$\mathrm{b}$

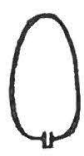

c

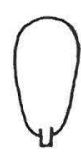

d
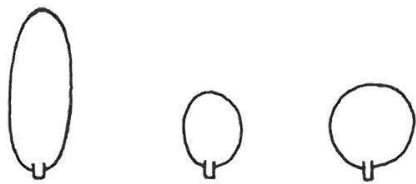

g

Fig. 3. The types of obtuse-based spores. a) elliptical (part of Fig. 89) ; b) fusiform (part of Fig. 88); c) ovate (part of Fig. 122); d) obovate (part of Fig. 105); e) oblong (part of Fig. 115); f) subglobose (part of Fig. 124); g) globose (part of Fig. 120).

species of Infundibuliformes, few to a great many in $C$. clavipes, C. gracilis, C. hydrogramma, $C$. subcordispora, $C$. langei and $C$. strigosa), and oblong (scattered spores in $C$. bresadoliana and $C$. orientalis). The outlines of the spores of these types have already been described in the preceding paragraph, or will be described in the following one (lacrymoid). Of course, the different base makes the present spore types somewhat different from the corresponding obtuse-based or confluentbased (lacrymoid) ones, but there does not seem to be any justification for creating new terms for them.

When the spore base is confluent with the apiculus the spores always belong to the lacrymoid type (Fig. 2 c). The spores are more or less curved in side view, at least the base (apicular region), and in face view they may be rather irregular, pyriform, obovate, clavate or elliptical and pointed. Lacrymoid confluent-based spores occur only in the sections Infundibuliformes and Bulluliferae, and such spores are the primary diagnostic character of at least the former section. The spore base may be abruptly or more or less gradually tapering. It tapers abruptly in C. geotropa and C. catinus and most of their

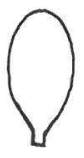

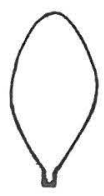

b

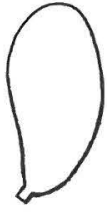

C

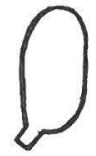

d
Fig. 4. The types of acute-based spores. a) elliptical (part of Fig. 96); b) fusiform (part of Fig. $90)$; c) lacrymoid (part of Fig. 95); d) oblong (from specimen depicted in Fig. 48). spores may be characterized as «subgloboselacrymoid «, while in C. squamulosa the spore base is usually very elongated and narrows gradually.

A morphological feature which is independent of the spore type is present in the spores of some species of the sections Ditopae and Strigipedes. It is a broad asymmetrical constriction in the middle of the spore. This constriction is most distinct on the ventral side, which is accordingly concave. The term «phaseoliform« would not be suitable for spores of this type, since they are not truly curved, and in many such spores the lateral sides are also slightly depressed and concave. We can thus speak of an asymmetrical, imperfect constriction. Some or perhaps most spores of $C$. menthiodora, a few spores of C. fennica, and often a few of C. lohjaënsis possess this configuration, which has some taxonomic importance. In addition, this phenomenon occurs indistinctly in $C$. vibecina, for in this species a few spores often exist in which the ventral side only is somewhat concave.

The spores of $C$. nebularis are peculiar, because a proportion of them (on rare occasions practically all) are always aborted, having shrunken walls and no contents. Although appearing pathological, this condition is a good diagnostic character of $C$. nebularis.

Some variation can be observed in the spore contents when they are examined in Melzer's reagent. The differences are often rather vague and exist mainly at the sectional level. In particular in very thin mounts and with the aid of good optics, one large drop and/or some smaller ones can be distinguished 
in the spores of many species. In the first three sections of the subgenus Clitocybe, in the section Fragrantes of the subgenus Roseospora, and in the subgenus Pseudolyophyllum, except for some species of the sections Ditopae and Strigipedes, the spores have heterogeneous contents being more or less guttulate. In the section Gilvaoideae the contents are very often plasmolyzed.

Some characters of the apiculus have been discussed already. It is always obliquely situated, and its end is truncate. It is always equal when it is distinct from the rest of the spore. In most species the apiculus in distinctly elongated, in a few, however, it is almost cubic. The length of the apiculus (when distinct) varies in the genus from ca. $0.4 \mu \mathrm{m}$ to ca. $1.1 \mu \mathrm{m}$, and the breadth from ca. 0.3 to ca. $1.3 \mu \mathrm{m}$, the latter being greatest in the section Infundibuliformes. The measurements of the apiculus should be included in every modern species description, for the characters connected with it are in all respects comparable to those of the sporoid, being very constant within the species, and because modern optics allows observation of these features.

Lastly, I observed a very important variation in the occurrence of the spores in the usual spore preparations, obtained by squashing a piece of lamella in Melzer's reagent between the object and cover glasses. If a preparation is made from a small amount of a spore deposit, the individual spores can always be observed to occur either singly, or stuck together in irregular heaps, in varying numbers and in all possible positions to each other. However, if the preparation, is made from a piece of lamella, two different types of occurrence can be distinguished in the mounting liquid. In the species of the subgenera Clitocybe (except for the type section) and Pseudolyophyllum (except for the type section) all, or by far the greater part, of the spores occur singly (or group themselves in irregular heaps). Contrastingly, in all the species of the subgenus Roseospora and the type sections of the two other subgenera, practically all, or the greater part, of the spores occur in regular tetrads (and dyads, evidently when the tetrads have split in two). In the cases studied, the tetrads were discernible in $5 \%$ $\mathrm{KOH}$, too. In the tetrads the four spores are parallel and adhere together as if they were glued both ventrally and laterally along a short portion above the middle of the spore. No perisporial sac (which sometimes surrounds sets of two or four spores in Coprinus) or other «extra« constructions can be observed. Except for two species, practically every single spore preparation was found to present one or other of these two types of spore occurrence. The only exceptions are C. candicans and C.vibecina; although I consider them to possess principally single spores, like the rest of the species in their respective sections, sometimes up to almost $50 \%$ of their spores may be joined together in tetrads.

The spores which occur in tetrads appear to be immature. I made several preparations from the spore deposits of various species, and others from the same basidiocarps and the same lamellae from which the deposits were obtained. In the latter preparations the spores occurred predominantly in tetrads, which had evidently mostly been attached to the sterigmata before squashing, while in the preparations from the corresponding deposits the spores occurred singly and in irregular groups. Accordingly, it seems probable that the mature spores had already been ejected from the sterigmata, while the immature ones (often somewhat smaller, but usually not conspicuously so) had not left the sterigmata until the moment when the preparation was made, and then in tetrads. Apparently the squashing has some tendency to divide the tetrads into dyads and monads. Another reason for the occurrence of the dyads may be the existence of two-spored basidia.

In those taxa in which the immature spores are stuck together before discharge, a special system may have developed which in this way ensures that all four spores are discharged at about the same moment, irrespective of whether some of them have ripened before the others. If the four spores are discharged simultaneously after the last of them has ripened, the whole set of four, i.e. spores of different polarity, land together, or, at least near each other, depending on whether the tetrad has divided during the flight or at the moment of discharge. This of course would make the formation of a dicaryotic mycelium more certain. A potential disadvantage of such a system is that it will lead to a decrease in heterozygosity.

It is remarkable that most species whose 
spores occur in tetrads have a fragrant odour which is strongest in old fruit bodies, e.g. in C. odora, and, in the section Roseospora, when drying. It is the biochemist's task to study whether there are fragrant etheric, sticky substances which glue the spores together (and to the sterigmata?) until the last of them has matured, possibly evaporating when maturation is accomplished, while the tetrad is air-borne or immediately after it has landed. It is uncertain whether the mature spores are released singly or in a tetrad, and, in the latter case, at what point the tetrad divides. In any case, if all four spores are released more or less simultaneously, they are likely to be carried on the same gust of wind and to land fairly near each other. If the above assumption of the simultaneous discharge of the four spores is correct, this is possibly a very rare system among the Agaricales. According to Ingold (1969), BuLLER and others have observed a successive spore discharge in a good many «Hymenomycetes«. He reports that a liquid drop or bubble perhaps assisting in the discharge. This observation suggests that the of the sterigma and the spore apiculus, this drop or bubble perhaps assisting in the discharge. This observation suggests that the sterigmata are able to secrete substances during spore formation, and lends some support to my hypothesis that some sticky substance causes the spores of some Clitocybe species to adhere together.

Only the primitive spore type, obtusebased and \pm elliptical, occurs in tetrads.

The literature, even including studies on Clitocybe, does not seem to contain any distinct records of the spores of larger fungi occurring in tetrads. Further studies are required to elucidate the spore discharge of Clitocybe and other genera, and my hypothesis is merely intended to serve as the basis for further experimental investigations.

\section{Basidia}

Since the basidia are very alike in all the species, they will not be included in the descriptions of the taxa. They are always more or less clavate, very thin-walled, smooth and neither amyloid nor dextrinoid. Siderophilous (carminophilous) granulation is lacking in all species (studied from dried fruit bodies). A clamp connection always seems to occur at the last septum at the base of the basidium, too, except in $C$. harperi where clamps are usually absent. There is some genetic variation in the size of the basidia; roughly speaking, the larger the spores, the larger are the basidia. However, in C. altaica they are about the same size as those of $C$. geotropa, i.e. probably the largest in the genus, though the latter has bigger spores.

In every species the number of sterigmata per basidium is generally four, though basidia with one, two, or three sterigmata may occasionally occur among the four-spored basidia. There is some genetic variation in the length and breadth of the sterigmata. They are especially tall in the section Infundibuliformes (the apiculus/apicular region is also tall in that section!), and in the section Gilvaoideae as well as, for example, in $C$. candicans they seem to be rather long and slender.

The relatively small size of the Clitocybe basidia, about $15-30(-40) \times 4.0-6.0$ $(-8.0) \mu \mathrm{m}$, is obviously a character peculiar to this genus.

\section{Cystidia}

Constant cystidia, whether at the edges or on the faces of the lamellae are always lacking, as are the other elements of the hymenium apart from the basidia, such as pseudocystidia. In some specimens of some species (C. anisata, C. fragrans, $C$. strigosa) narrow elongated cells have been observed at the gill edge. They may be occasional cheilocystidia. In many other species filamentous hyphae projecting from the gill edge have occasionally been noted, but these have turned out to be hyphae of some parasitical fungus, or sometimes, perhaps, germinated sterigmata.

\section{Anatomy of the pileus; pigmentation}

As regards anatomy, the genus is very uniform, and only the descriptions of the epicutis (and subcutis, if present) will be given in the descriptions of the taxa. The different layers of the cap will be described in the following, beginning from the surface. All the colours described are those observed under the microscope with magnifications of $600 \times$, and $1500 \times$, in $5 \% \mathrm{KOH}$. 
The epicutis can be considered to be differentiated in every species, though sometimes very weakly, e.g. in some species of the Infundibuliformes. The thickness of the epicutis varies widely, even within the species, generally being ca. $25-100 \mu \mathrm{m}$. It is distinguished by its narrow hyphae (average breadth $2.0-6.0 \mu \mathrm{m}$ ), which are narrower than those of the other layers of the pileus, and which are mostly more or less parallel, sometimes \pm interwoven. A third character typical of the epicutis is that its hyphae always contain intracellular pigment, which is always more or less brown (usually pale), irrespective of the pileus colour (in C. odora and the "white s species, too). The contents of the hyphae of pale-coloured species are, however, paler than those of species with dark pilei. In some species epimembranal brown pigment occurs on the hyphae of the epicutis in the form of very fine encrusted granules, but this kind of pigment is probably only constant in $C$. strigosa. Bigelow (e.g. 1968) seems to have overestimated the diagnostic value of the presence contra absence of encrusted pigment in Clitocybe. The hyphae of the epicutis are at times somewhat wrinkled, especially in the section Strigipedes. Some intercellular, rusty yellow to brown pigment crystals may occur between the hyphae of the epicutis, but the occurrence of this kind of pigment here and elsewhere in the pileus is more or less inconstant and irregular. The abundance of intracellular pigment often made it impossible to ascertain whether membranal pigment exists in the walls of the hyphae. The hyphae of the epicutis may only infrequently be somewhat gelatinized, e.g. as sometimes in $C$. candicans, and more often in C. lohjaënsis. The peculiar inflations of the hyphae of the epicutis in $C$. hydrogramma are unique in the genus. Horak (1968) interprets these vesicles as chlamydospores, which I do not consider very probable. The basidiospore production is normal in this species, and the pileus with the rather scanty vesicles does not disintegrate at maturity to distribute the vesicles, unlike, for example, that of Asterophora lycoperdoides. Pilocystidia and other specialized projecting cells are always lacking in the Fennoscandian species of Clitocybe.

In most species a subcutis is situated below the epicutis, though it is absent from some species of every subgenus. Like the epicutis, the subcutis is often not very distinct, and evidently there is intraspecific gradation in the degree to which two separate layers can be differentiated in the cortex. The subcutis is of about the same thickness as the epicutis. It is distinguished by the almost always \pm parallel hyphae, which in breadth are roughly intermediate between those of the epicutis and the trama. The third characteristic of the subcutis is the pigmentation, which differs from that of the epicutis and often from that of the trama, too. Intracellular pigment is less abundant than in the epicutis, and is sometimes totally lacking. Occasionally there may be some encrusted pigment on the hyphae, similar to that found in the epicutis. Intercellular pigment is usually absent. Membranal pigment is often evident, and is more or less brown under the microscope. When the hyphal walls were merely pale yellow, I considered them to lack pigment. It is a character of the section Strigipedes and some species of other sections, that the subcutis is very distinct under the microscope being the darkest, most pigmented layer of the pileus section. This dark colour is evidently due especially to the rich membranal pigment.

(It should perhaps be explained here that in my paper on hygrophany [HARMaJA 1969 b], I used the term «cutis « for the entity composed of the epicutis and the subcutis, and treated it as one of the cortical layers of the fruit body.)

The bulk of the pileus consists of the pileus trama. Here, as elsewhere in the fruit body, the hyphae are thin-walled to very thinwalled. They are always tightly packed and parallel in the lowest part, which is about equally thick throughout the pileus, and which continues downwards as the cortex of the stipe. Between this lowest layer and the subcutis (or epicutis), the hyphae vary in their arrangement from being completely interwoven to lying parallel with each other and the cap surface. This variation in the construction (interwoven to parallel) of the main part of the pileus trama is at least in some cases genetic, not resulting from differences in the age of the basidiocarp. In the section Strigipedes and some other species the arrangement of the hyphae always seems to be parallel throughout the pileus trama. The hyphae of the trama are somewhat broader than those of the upper layers, being about $5-15 \mu \mathrm{m}$ in diameter. In the section Gilvaoideae the tramal hyphae may be some- 
what narrower than in the rest of the genus. Intracellular pigment cannot usually be observed inside the tramal hyphae, and intercellular pigment is also unusual. Encrusted pigment has only occasionally been observed in some species of the subgenus Pseudolyophyllum, and its absence is evidently a good generic character. Membranal pigment is always present in the tramal hyphae of the species of the subgenus Pseudolyophyllum, but only in some species of the other subgenera. This pigment is apparently an important component of the dull colours prevailing in Pseudolyophyllum. Too little attention has been paid to the colouration of the walls of the tramal hyphae in the larger fungi, and this character will surely be found to be of taxonomic importance. The wall colour should be studied in water mounts, too, including that of the present genus.

As mentioned above, the lowest tramal layer proper has tightly packed, parallel hyphae, and should be considered one of the cortical layers of the fruit body (cf. Harmaja $1969 \mathrm{~b}$ ). Immediately below the pileus trama is the hymenophore, which always forms a continuous cover on the lower surface of the cap. The anatomy of the whole hymenophore is described in the section «Anatomy of the lamellae«, p. 28.

A very curious encrusted pigment occurs on some hyphae of some species, especially those of the section Candicantes, where it is a diagnostic character of some value, being most constant and striking in $C$. pruinosa and C. candicans. The pigment occurs in the form of large (up to $10 \mu \mathrm{m}$ in diameter, and ca. $0.5-1.0 \mu \mathrm{m}$ thick) irregularly shaped or rhomboid, weakly translucent crystals, often with a violet reflection, but brown to blackish brown when seen in side view. The crystals are attached to the hyphae, mostly on their upper wall, i.e., that facing the cap surface, and they occur especially in one or two layers of the pileus, in or below the epicutis, depending on the species, and/or in the lowest parallel layer of the trama. In the preparations, especially in thick sections, these pigmented layers can be seen as white zones with the naked eye, because there is usually an air bubble attached to each crystal. Under the microscope at low magnifications, the zones appear black. The crystals are insoluble in water, $5 \% \mathrm{KOH}, 96 \%$ ethyl alcohol, and Melzer's reagent. Such crystals are found in many other species, too, especially between the basidia, but their occurrences are scattered, and they are never abundant or localized in distinct zones in the pileus trama. A different pigment though of similar nature seems to be distributed between the basidia of $C$. globispora (see p. 100). I have not found any note in the literature about this peculiar kind of encrusted pigment.

«Lactiferous«, \pm thin-walled hyphae, which are usually about $5-6 \mu \mathrm{m}$ broad and rich in refractive contents, have been observed in the pileus trama in all the subgenera. They are most frequent in the type subgenus, being very rare in Pseudolyophyllum. Their occurrence is inconstant and shows intraspecific variation, as already stated by $\mathrm{BI}-$ GELOW (1962: 40).

Clamp connections are present throughout the pileus in all the species except $C$. harperi, and evidently occur at each septum. In $C$. harperi clamps are usually totally lacking, and their absence helps in identifying this species. However, in some otherwise typical specimens of the species scattered, well-formed, true clamps were observed on the hyphae of the pileus trama, gill trama, and basal tomentum. In some cases it appeared that either all the septa of a hypha were clamped, or none of them. Bigelow (1965) reported the species to be clampless. In spite of the exception formed by $C$. harperi, the presence of abundant clamp connections is a very important generic character of Clitocybe, as emphasized by Singer in various papers.

It has often been claimed in articles on the larger fungi that the clamp connections are most abundant in thin filamentous hyphae. This assertion was not supported by my observations of the present genus. A superficial examination of a section under the microscope may easily give the impression that there are more clamps on the thin hyphae of the epicutis than on the broader ones in the trama. This is explained by the fact that the clamps, whose size is fairly constant, are more easily observed on the thin hyphae than on the broad hyphae, where they may even be hidden behind the hypha. The clamp connection evidently has the advantage that it allows the two nuclei of the dicaryon to divide simultaneously, and makes it easier for the appropriate daughter nuclei to pass to the new cell, which would be very difficult 
if the two voluminous spindles were one behind the other in the hypha.

\section{Anatomy of the stipe}

The present study did not include a systematic examination of the anatomy of the stipe. In all the cases studied the elastic cortex was found to be composed of tightly packed parallel hyphae which become narrower towards the surface, while the inner tissue of the stipe is somewhat looser, the hyphae being less parallel. The outermost hyphae contain intracellular pigment. In principle the construction of the stipe surface is evidently rather similar to that of the pileus surface.

Ciaulocystidia and other specialized projecting elements were lacking in the species studied, and judging from the macroscopical appearance of the stipe are possibly always absent in Clitocybe.

However, the anatomy of the basal tomentum was investigated in all the species. Its construction shows very little interspecific variation. The hyphae are \pm interwoven, \pm thin-walled, ca. $2.0-7.5 \mu \mathrm{m}$ in diameter, neither amyloid nor dextrinoid, and clamped at each septum (except in $C$. harperi, see p. 27). Usually the hyphae appear almost colourless or yellowish in $\mathrm{KOH}$ but sometimes, perhaps always in the subgenus Pseudolyophyllum, \pm brown membranal pigment is present. Lactiferous hyphae are sometimes found. There are probably significant differences between some of the species in respect of the diameters of the hyphae.

The hyphae of the rhizoids and the mycelial hairs of $C$. sinopica, $C$. pruinosa, $C$. rhizophora, and of the species of the section Strigipedes are more or less similar to each other, and they are also more or less similar to those of the tomentum, apart from being tightly packed and parallel to the longitudinal axis of the mycelial element.

\section{Anatomy of the lamellae}

In every species the gill is composed of four different layers. The outermost is the hymenium, which consists of basidia only. Below the basidia is the subhymenium, which is of the common ramose type. There may be some interspecific differences in the thickness of the subhymenium, e.g. in some species of the Infundibuliformes as well as C. phyllophila v. phyllophila it seems to be rather thick. In $C$. bresadoliana the cells of the subhymenium often have striking ochre brown to pale reddish brown contents in Melzer's reagent. The following layer is the hymenopodium. It consists of narrow, \pm parallel filamentous hyphae, about $2.5-6.0 \mu \mathrm{m}$ in diameter, and it is often very indistinct, sometimes perhaps even lacking. The innermost part of the lamella, the hymenophoral trama proper, differs from the preceding layer mainly in having broader hyphae. It forms the bulk of the lamella, becoming thinner towards the edge. The gill trama is regular or subregular (often, however, interwoven at the gill base) in all the species except one. More or less interwoven hyphae may be a constant feature of $C$. clavipes and the species thus has an irregular trama, as described by Bigelow (1965). I did not distinguish the «Clitocybe subtype of the regular type« which is described by Singer (1962: 52). In all the species the hyphae are filamentous, rarely somewhat inflated, and on the average ca. $4.0-11.0 \mu \mathrm{m}$ in diameter. Scattered lactiferous hyphae sometimes occur in the gill trama, mainly in species of the type subgenus. In $C$. geotropa they are so abundant, however, that their presence represents a diagnostic character.

No element of the lamella is amyloid or dextrinoid (the subhymenium of $C$. bresadoliana may be an exception; see above) or gelatinized in any species. The type of pigmentation and clamping seem to be the same as those of the pileus trama. The encrusted pigment with small brown granules is accordingly only occasionally present, having been observed a few times in $C$. vibecina and $C$. ditopa v. ditopa.

The anatomy of the Clitocybe gill trama is rather well depicted in Douwes \& v. Arx (1965: 201) in the figure showing the gill trama of $C$. nebularis.

The title of the present section should perhaps more properly have been «Anatomy of the hymenophore , because the sporeproducing part of the fruit body is not restricted to the lamellae, though they of course contribute by far the greatest part of the spores. In all the species of Clitocybe of the present study the hymenium forms a 
continuous cover on the underside of the pileus including the interlamellary spaces. The subhymenium is more or less distinctly developed everywhere below the hymenium, but it is not certain whether the hymenopodium exists outside the lamellae. The most interesting feature is the presence of another hymenophoral trama, besides that of the lamellae. Since it is always distinct, and composed of filamentous to inflated, completely interwoven hyphae it can be distinguished from both the trama of the lamellae and the lowest part of the pileus trama, which are more or less regular (except for the gill trama of $C$. clavipes), i.e., composed of parallel hyphae. This interwoven layer might easily be treated as the lowest part of the pileus trama, but there are at least three reasons for considering it a special part of the hymenophoral trama sensu lato. Firstly, this «epihymenophoral trama« is continuous with that of the lamellae, the latter being often (always?) interwoven near the base of the gill, where, of course, the direction of the hyphae must change. Secondly, such a hymenophoral trama for the interlamellary hymenium would be analogous to the presence of a subhymenium there. Thirdly, it is the layer of tightly packed parallel hyphae below in the pileus trama that must be considered the outermost, cortical layer of the sterile part of the fruit body, because it is anatomically in some respects more or less similar to the epicutis and subcutis of the upper surface of the cap, and to the cortex of the stipe, which are of course cortical layers. Moreover, the layer of dense parallel hyphae has evidently the same function in the water economy of the fruit body (Harmaja 1969 b). Singer (1962: 54) was evidently referring to the same «epihymenophoral trama « when he described the presence in some agarics of «a special epiphyllous zone of a structure different from that of the trama of the pileus as well as the trama of the hymenophore $\ll$. He thus also distinguished it from the pileus trama. The loosely interwoven «epihymenophoral trama may be at least partly responsible for the ease with which the lamellae (the entire hymenophore?) can usually be separated from the pileus. Further studies are necessary on the exact extent of the hymenophoral trama in other agaric genera, too, before any taxonomic or other conclusions can be drawn.

\section{Cytology}

KüHNER (1945b: 165) reported that in the species $C$. «cerussata«, C. clavipes and C. «viridis« (= obviously C.odora) the somatic cells of the stipe have two nuclei each. He (1945a: 619-680) also established that the mature discharged spores of most white-spored agarics are uninucleate. According to Pinto-Lopes (1948: 201: Fig. 5), the mature spores of $C$. «suaveolens« have one nucleus each. Herm (1954: 234) found that in C. «brumalis«, C. «cerussata«, and C. nebularis the longitudinal axis of the spindle of the reductional division is in a \pm horizontal position, i.e., at right angles to the longitudinal axis of the basidium, as is usual in Agaricales. She (op. cit.: 236) records the chromosome number in the three last-named species as $n=8$.

My cytological studies were restricted to one species of Clitocybe, namely C. phyllophila v. phyllophila, the specimens of which were collected by me in the south of Finland, province of Varsinais-Suomi, rural district of Lohja, Jalassaari, on 18. IX. 1966. The corresponding herbarium specimen is preserved in $\mathrm{H}$. The somatic cells (of the gill trama and the subhymenium) were found to be binucleate. The mature spores were almost always uninucleate, but occasionally had two nuclei. The spindle of the first metaphase of meiosis was found to have a \pm horizontal position. My observations on these three important points are in accordance with the results of the previous studies mentioned in the preceding paragraph, and these characters have diagnostic value at the generic and suprageneric levels. It can be mentioned here that KüHNER (1945 a: 620) and Singer (1962: 101) have also sometimes observed occasional binucleate spores in agaric species in which they are usually uninucleate.

The chromosome number of $C$. phyllophila v. phyllophila was found to be $\mathrm{n}=3$. All the chromosomes are distinguished from each other, especially during pachytene, by differences in their length, the number and size of their heterochromatic regions, and the position and length of their constrictions. The chromosome number of this species differs considerably from those obtained by Heim (op. cit.) in the three species studied by her. It is not impossible that her $C$. «cerussata« is conspecific with the species studied 
by me. No critical comparison can, however, be made, for her studies of a great number of agarics do not seem to be very thorough, and almost all the chromosome numbers recorded by her are for some reason higher than those observed by previous workers in the same species and genera. Owing to our still very incomplete knowledge of the taxa of the larger fungi, not to speak of the unfortunate nomenclatural confusion, a critical discussion of the published cytological records is very often impossible. There are usually no descriptions, either, of the taxa studied and cytologists generally do not mention whether a herbarium specimen has been conserved. It is most important that the preservation of a herbarium specimen of the material studied should be made a qualification for the validity of a cytological record, as is already recommended, for the phanerograms.

\section{Macrochemical characters}

Singer (1962: 230) states that preliminary tests have shown some chemical reagents to be valuable in studies of the taxonomy of Clitocybe. MÉtrod (1949: 10) has made experiments with a concentrated solution of pyramidon, and reports having obtained good results in the delimitation of infrageneric taxa.

In 1965 and to a lesser degree later, too, I made some preliminary tests on fresh fruit bodies, the material being mainly taken from the ca. two dozen species of Clitocybe occurring in southernmost Finland, in the rural district of Lohja. The concentrations etc. of the ten reagents used were when possible identical with those recommended by Singer (op. cit.: 89). The reagents tested by me were the following: methol (monomethylparamidophenol), $\mathrm{KOH}, \mathrm{NH}_{3}$, $\mathrm{HNO}_{3}$, phenol, formalin, aniline (oil), $\mathrm{FeSO}_{4}, \mathrm{Fe}_{2}\left(\mathrm{SO}_{4}\right)_{3}$, and guaiac. Three parts of the fruit body were tested: the pileus surface about halfway between the centre and the margin, the stipe surface from around the middle of the stipe, and the context at the junction of the pileus and stipe. Small bits of these parts were removed and tested separately to avoid reactions between the chemicals. The aniline test was often made with the lamellae, too.
A thorough study of the macrochemical colour reactions was found to be very timeconsuming, and with most of the species the reagents could only be tested once. Most reagents evidently have no practical value in the identification of the species, because the colour effects obtained are often unstable, and depend on the age of the fruit body and evidently on other factors as well. The frequent inconstancy of the colour reactions may be due to the reacting substances being enzymes. This situation, which is evidently common in many other agaric genera seems to be different from that prevailing in the lichens, in which the macrochemical colour reactions are mostly very stable often being primary diagnostic characters at the specific level. It is, of course, very probable that statistically significant differences exist between various taxa of Clitocybe in respect of their colour reactions, but the work of acquiring sufficient material to reveal these differences would be enough to constitute a separate study of its own.

However, even though scanty, my observations revealed some positive and negative reactions which may be constant. In C. squamulosa and C. bresadoliana, the pileus surface (and that of the stipe, though less distinctly) immediately turns deep chestnut brown with $\mathrm{KOH}$, in both the fresh and dried condition. This is the only reaction so far discovered which has distinct practical importance, for in the other species of the difficult section Infundibuliformes, such as C. gibba (often very similar to the two species named), the $\mathrm{KOH}$ reaction of the cap surface is negative (the cap colour may, of course, darken somewhat owing to the tissue absorbing the liquid, $\mathrm{KOH}$ ). The response to $\mathrm{KOH}$ of the pileus surface has been studied and tested with extensive material of dried specimens belonging to the section Infundibuliformes. The fruit body, of $C$. odora for example, especially the cap, practically immediately assumed a blackish violet colour when treated with methol, while the corresponding reaction of C. strigosa was totally negative. Formalin and aniline did not provoke any eactions in the fresh fruit bodies of Clitocybe (though they sometimes became faintly pinkish after a rather long time). In the case of the latter reagent this more or less negative reaction may be a diagnostic character of the genus 
(see p. 10). A positive reaction with guaiac was observed in many species, which turned dirty green to dark or bluish green. It may be rather constant as regards the flesh. Few positive reactions were observed with ferrous and ferric sulphates, and these were vague, the material assuming a faintly pinkish or greenish colour.

\section{Ecology of Clitocybe species}

\section{A. Habitat}

The species of Clitocybe are frequently considered to be mainly forest fungi, and effective decomposers of forest litter, this ability having been proved in many cases in laboratory experiments. This genus is absent from the list of Singer \& Morello (1960), comprising genera which are known to be able to form ectotrophic mycorrhizas.

My field observations and the evidence of label notes, and the debris attached to herbarium specimens suggest that the great majority of the Fennoscandian species do indeed favour forest habitats and litter substrates (the ecology of the remainder will be described later in the present section). The fruit bodies of these species have almost always been found in dry to mesic places on a layer of litter, the constituents of which, needles, leaves and occasional remains of herbaceous plants, are mostly identifiable macroscopically. None of the Fennoscandian species grow on decaying wood, and very few of them have been collected even occasionally from such a substrate. Similarly, these litter-inhabiting species very rarely occur on bare soil. During my studies in the field, none of these mainly forest species has given the impression of being dependent on the neighbourhood of the roots of a tree of any species of genus. Judging from the above, it seems very probable that the mycelia of these species do indeed grow in and decompose forest litter.

Almost all the litter-inhabiting species were found in conifer litter (needles), and most of them in the litter of both coniferous and deciduous trees. No species have been observed to occur in the litter of one particular tree species alone, but $C$. pruinosa, C. rhizophora, C. phyllophila v. tenuis, $C$. subcordispora, C. langei and C. ditopa v. odorula occur almost exclusively among needles. On the other hand, there do not appear to be any species which are equally strictly confined to leaf litter, though the species $C$. gibba, $C$. candicans, and $C$. odora have so often been collected from such a substrate that they may somewhat prefer it. Various workers investigating Clitocybe (e.g. Bigelow, 1968, with C. gibba) have made similar observations regarding the preferences of the latter species. These interspecific differences in substrate preferences, which are often only weakly pronounced in Clitocybe, may to some extent be due to differences between the chemical compositions of leaf and needle litter. Many workers (e.g., AaLTONEN 1950: 21) have established that the ashes of deciduous litter contain more calcium than those of coniferous litter. The commensalism of some species of fungi and of some trees, too, may furnish some explanation of their occurrence in the same habitats. Altogether, fruit bodies of Fennoscandian species of Clitocybe have been collected from the needle or leaf litter of the following trees and bushes ${ }^{1}$ ): Abies sibirica, Juniperus communis, Larix decidua $\times$ leptolepis, L. sibirica, Picea abies, Pinus cembra cf. ssp. cembra, $P$. contorta, $P$. mugho, $P$. peuce, P. strobus, P. sylvestris, Acer platanoides, Alnus glutinosa, $A$. incana, Betula alba coll., Corylus avellana, Fagus sylvatica, Fraxinus excelsior, Populus tremula, Quercus robur, Rhododendron sp., Ribes alpinum, Salix caprea, Sorbus aucuparia, and Tilia cordata. The commonest substrates are, of course, the litter of the most important native forest trees, namely Picea abies, Pinus sylvestris, Betula alba, Fagus sylvatica, and Quercus robur. Only occasionally were the fruit bodies of some species found in litter completely or mostly composed of the decaying remains of herbaceous plants (ferns, grasses, or herbs).

1) Mrs. Leena Hämet-Ahti, Ph. D., has kindly determined some planted exotic conifer species. 
Fruit bodies of various litter-inhabiting species very often occur among moss, especially Hylocomium splendens and Pleurozium schreberi. These occurrences are commonest in coniferous woods and have been observed by FAVRE (1948: 61-63), too. No species, however, occurs exclusively among moss, or in association with any particular species of moss, though $C$. strigosa has mostly been found among Hylocomium splendens (on rare occasions even with no other litter present than the decaying basal parts of that moss). There may be several reasons for the fact that many species commonly occur together with mosses. Their mycelium may decompose the dead basal parts of the moss. The capacity of the moss carpet to retain moisture may favour the formation of agaric fruit bodies, and there may be many similarities between the habitat requirements of the fungus and the moss. There does not, however, seem to be any obligate relationship between the Clitocybe fruit bodies and the mosses (or other green plants), as is the case with the basidiocarps of many species of Omphatina (see p. 12) and Gaterina, and those of Cantharellula umbonata (see p. 10).

The litter-inhabiting species of Ctitocybe are thus principally forest species being almost completely lacking in other kinds of habitat (see, however, the section «Human influence«, p. 34). This follows naturally from the fact that thick layers of litter, which apparently represent an optimal substrate for these species, are generally only present in woods. There may be some other less obvious, and so far unknown reasons. Wet and moist habitats, such as swamps, bogs, and slightly paludified forests have usually not much litter, and the scantiness of oxygen in such habitats may seriously inhibit the process of decomposition. It also appears from the studies of Bigelow (1962: 21), Favre (1948: 163-190), M. Lange (1948: 26), and Malmström (1938: 103-104) that the genus Clitocybe (as delimited here) is almost totally lacking in wet plant communities, whether peatland vegetation or not. Only a few species (C.clavipes, C. squamulosa, C. candicans, C.marginella) have occasionally been found in moist habitats. The litterinhabiting species do not thrive in the most luxuriant grass-herb forests, either, in which the ground is not covered by a distinct layer of litter but the soil (mull) is more or less bare. The mineral soil and mull of such forests are often fairly rich in calcium, which allows a rapid decomposition of the litter by bacteria and the lower fungi, the litterinhabiting species of Clitocybe (and many other larger fungi) being unable to compete with these organisms. The litter-inhabiting Clitocybes may also be intolerant of some other feature of these soils, e.g. their calcium content and/or a medium to high $\mathrm{pH}$ value.

It would be interesting to study the hypothesis that the wood-inhabiting taxa are generally the most primitive in Agaricales (and Aphyllophorales), the capacity to grow in needle and leaf litter being probably a derived character, while the occurrence in wet habitats, or on bare soil (esp. rich mull), and/or in more or less obligate association with photosynthesizing plants may indicate the most advanced nutritional physiology. In the literature, growth on wood has often been considered a rather primitive character, and the genus Clitocybe has been regarded as a primitive genus among the Agaricales.

On the basis of the present data (field observations etc.) some distinction can be made between different litter-inhabiting taxa of Clitocybe as to their preference for different forest site types.

The following taxa mostly avoid meagre habitats, preferring grass-herb forest, e.g. some kinds of deciduous woods, or, often in southeastern Norway, central Sweden and south Finland, spruce forest, and woodland with varying proportions of spruce and broad-leaved trees, which often has an abundance of Oxalis acetosella and belongs to the Oxalis-Maianthemum (OMaT) site type (according to the Finnish forest site type classification):
C. harperi
C. inornata
C. nebularis
C. phyllophila
(C. geotropa)
v. phyllophila
C. gracilis
C. fragrans
C. odora
C. metachroa
C. ditopa v. ditopa
C. lohjaënsis

C. geotropa very often grows on bare soil, too, and it is treated more thoroughly later.

Contrastingly, the following species clearly prefer dry to mesic, more or less meagre and barren heath forests, mostly dominated by Pinus and/or Picea (in the north often 
Betula), and where Vaccinium vitis-idaea and the mosses Pleurozium schreberi, Dicranum polysetum and Hylocomium splendens are often abundant. For instance, in south Finland such forest can usually be referred to the Vaccinium vitis-idaea (VT) and the Vaccinium myrtillus (MT) site types.
C. clavipes
C. metachroides
C. squamulosa
C. subcordispora
C. pruinosa
C. vibecina
C. phyllophila v. tenuis
C. diatreta
C. marginella
C. langei
C. ditopa v. odorula

It will be seen that there are no distinct correlations between the taxonomic grouping and the preference for forests of different degrees of productivity.

The rest of the litter-inhabiting species favour mesic heath woods (e.g. of the OxalisMaianthemum [OMT] site type), or have a very wide amplitude as far as the forest site type is concerned, or they are so rare that it has not been possible so far to come to any conclusions on this point. Some species of Clitocybe are very occasionally found in the most meagre and driest Pinus (or Betula) heath forests with abundant lichen (especially Cladonia) vegetation.

Some Fennoscandian species do not seem to be dependent on a layer of leaf or needle litter, and many of them grow exclusively on more or less bare soil. The ecology of C. anisata is very curious as to habitat, for it has so far only been collected from boulders, on which it occurs in moss (see p. 89). There is, of course, some litter, e.g. decaying basal parts of mosses, present in the habitats of this species, but I consider that it should be excluded from the species described as «litter-inhabiting «. I do not know of any record in the literature of an agaric with a similar ecology. All occurrences of this very rare small species should be carefully studied in order to determine whether this peculiar character is constant. C. sinopica almost always occurs on bare soil, mostly in sand in heath forests (especially on roadsides), sometimes on charcoal, or on lawns, or on bare soil other than sand. It is remarkably often found near pines (P. sylvestris), and laboratory experiments should be made to find out whether it is able to form a mycorrhiza with this tree. C. geotropa occurs very often on bare calcareous soil, especially mull, in grassherb forests (often in litter, too) and at the verges of forests, and in pastures, etc. C. bresadotiana is unique in that it seems to be confined to more or less open, natural (not man-made), often steppe-like habitats, which are sunny and dry, such as the «alvar «, and alpine Dryas heaths. The fruit bodies emerge from bare calcareous soil, or occur on calcareous rocks among calciphilous mosses, sometimes in scanty litter. C. laricicola is also not dependent on the presence of litter, and its fruit bodies have been found on various kinds of bare, fairly fertile soil. $C$. dealbata, $C$. ruderalis, and $C$. agrestis thrive in manmade habitats only, on roadsides, lawns, in pastures, rubbish dumps and stubble-fields, etc., on more or less exposed, relatively fertile soil, sometimes among low mosses typical of such habitats.

So far this discussion of the habitats of species of Clitocybe has only treated occurrences below the forest limit. There are, however, some species which very often, or perhaps only, occur above it, in the oroarctic (alpine) vegetation zone. Unfortunately little information is available on the ecology of these species; I myself have not collected any specimens from this zone, and there are only a few collections in the herbaria. The fruit bodies which have been collected above the forest limit do not usually seem to have grown on bare soil, but in a dense cover of mosses, or by Dryas, Ericales, etc., in more or less dry places. The chief observation regarding the Clitocybe species most frequently found in alpine conditions was that they occurred almost exclusively in dry Dryas octopetala heaths on calcareous ground. Such species are C. geotropa, C.altaica, C. bresadoliana, C. laricicola and C. strigosa. According to the literature, Dryas heaths are favourable habitats for many agarics, including species of Clitocybe.

Glear interspecific differences have been noted in Clitocybe in respect of the response to different lime contents of the soil. The literature contains only a few vague observations on this point. With the aid of plants, especially mosses, known to be indicators of calcareous soils or bedrocks (often left at the bases of the stipes of exsiccates!), as well as label notes, and the knowledge of the geology of Fennoscandia, I have made a rough classification of most of the Fennoscandian 
species, dividing them into four groups according to the lime contents of the soil in their habitats. No exact measurements of the concentration of $\mathrm{Ca}$ have been made in the present work.

Strongly calciphilous species, which occur only in sites where the soil is highly calcareous:
C. geotropa
C. bresadoliana
C. altaica

Weakly calciphilous species, which on the whole seem to favour habitats and districts where the lime content of the soil is high, but which have also been found elsewhere:
C. alexandri
C. dealbata
C. harperi
C. laricicola
C. inornata
C. nebularis
? C. anisata
? C. catinus
C. lapponica
C. fragrans
C. strigosa
C. lohjaënsis

More or less indifferent species, whose habitats differ as to the lime content of the soil:
C. gibba
C. sinopica
C. pruinosa
C. rhizophora
C. odora
C. phyllophila
v. phyllophila
C. agrestis
C. metachroa
C. globispora
C. menthiodora

Acidophilous species, which on the whole appear to avoid calcareous soils and favour very meagre habitats where the lime content of the soil can be expected to be very low:
C. clavipes
C. subcordispora
C. squamulosa
C. orientalis
C. candicans
C. vibecina
C. phyllophila v. tenuis
C. langei
C. diatreta
C. ditopa v. ditopa
C. marginella
C. metachroides
C. ditopa v. odorula

As might be expected, especially the strongly calciphilous species grow on bare soil, because differences in the $\mathrm{Ca}$ content are most marked in mineral soil, and welldecomposed organic soil. According to the literature, the $\mathrm{Ca}$ content of litter, i.e., dead leaves and needles, is fairly constant and generally rather low, not being greatly affected by the nature of the bedrock, or the soil. In addition, the superficial layers of the ground, i.e. the litter, may be to some degree beyond the reach of the often fertile ground water. There are, however, litter-inhabiting species which seem to be weakly calciphilous (the second group).

There also seem to be some differences between the supraspecific taxa. All the strongly calciphilous species belong to the section Infundibuliformes, all species of the section Alexandriformes are weakly calciphilous, and the species of the section Ditopae are mostly acidophilous. The type subgenus is, on the whole, more calciphilous than the two others.

\section{B. Human influence}

The distribution of the Clitocybe species in Fennoscandia seems to be the result of natural spreading, like that of the great majority of the cryptogams and unlike that of many phanerogams, which were introduced by man. Only a few exceptions do not appear to be indigenous (C. dealbata, C.ruderalis and $C$. agrestis), having evidently immigrated fairly recently and occurring solely in man-made habitats.

There are, however, great differences in the relation of the species to human influence as a habitat factor. One group seems to occur in natural, more or less undisturbed habitats, usually various kinds of forests and/or alpine heaths, where there are no clear signs of human influence. It must be mentioned, however, that probably most of the Fennoscandian forests are not untouched, since earlier human activities, especially slashing and burning, and the forestry and felling practised nowadays have inevitably had some influence on the vegetation and the composition of soil. The species favouring natural conditions can be expected to lose suitable habitats as a result of human activities. On the other hand, the reforestation of fields and reclamation of swamps and bogs have provided more habitats for some of these species, sometimes even outside their native range since conifers are often planted beyond their natural distribution areas. In principle, however, such created habitats may be regarded here as representing natural vegetation. The taxa 
which do not occur where human influence is distinct can be called ahemerobic (the nomenclature in the present section concerning the response of plants to human activities is according to JaLAS, 1955), and they are the following:
C. alexandri
C. inornata
C. phyllophila v. tenuis
C. altaica
C. subcordispora
C. lapponica
C. orientalis
C. laricicola
C. vibecina
C. odora
C. langei
C. phyllophila v. phytlophila
C. ditopa v. odorula
C. strigosa
C. lohjaënsis

Besides occurring in natural environments, a second group of species is found remarkably often in habitats which are more or less distinctly affected by human activity, such as thinned grassy woods, half-open grassy places by paths and roads, and pastures, sometimes even in completely man-made habitats, such as gardens, lawns and rubbish dumps. Despite the practice of forestry and the destruction of forests, these species may well have gained more habitats and become more frequent as a result of human settlement. These species, which may be called oligo- and mesohemerobic, are:
C. nebularis
C. squamulosa
C. clavipes
C. sinopica
C. geotropa
C. fragrans
C. gibba
C. metachroa

Thirdly, there are three species (one of them, however, only found once) which occur only in man-made habitats, such as open roadsides, parks, lawns, stubble-fields, rubbish dumps, open grassy places in pastures etc. They may be native (occur in natural plant communities) somewhere outside Fennoscandia, e.g. in the steppes of eastern Europe and central Asia. In Fennoscandia they probably only occur in habitats which best correspond to the natural ones (see p. 76). These ruderal species, which can be called euhemerobic, are as follows:
C. dealbata
C. agrestis
C. ruderalis

The species which have not been included in any of the preceding groups, are either indifferent to human influence, or so rare that it has not been possible to determine their relation to it.

Statistically significant differences very probably exist between various agaric genera in respect of their relation to human influence in a certain area, but no exact studies on this subject seem to have been made. However, the morphologically very uniform genus Melanoleuca is clearly also ecologically uniform, almost none of its species being able to thrive in natural Fennoscandian vegetation.

\section{Fruiting time}

The fruiting time of each species and variety is presented in the phenological diagram (Fig. 5), which is based on the dates on the labels of the specimens studied. Each month has been divided into six periods of five days. A period consists of 100 units in the diagram. One-hundredth of the space for a period has been blackened when a specimen from the area described below, a part of Fennoscandia, has been collected on any of the five days of the corresponding period. I have noticed that in every species the lifespan of a single fruit body is well in excess of five days (in species with large basidiocarps it is very long, e.g. in C.alexandri ca. 40 days at least; for C. pruinosa, see later), so it is appropriate and practical to distinguish six units only per month. The specimens which have been included in the diagram have been collected from districts which are climatically rather uniform, i.e., the southern and central parts of Fennoscandia, an area roughly comprising the temperate, hemiboreal, and southern boreal vegetation zones (for the vegetation zones, consult the following chapter). Almost all the species occur in this area, and the great majority of the specimens of Ctitocybe have been collected from there. However, those specimens have been excluded which were collected in provinces with a very oceanic climate (on the Norwegian coast), as well as those from provinces where there are great differences in altitude, and consequently different climatic conditions and vegetation zones. Accordingly, the provinces whose specimens were used in the diagram are the following (their sequence is the 


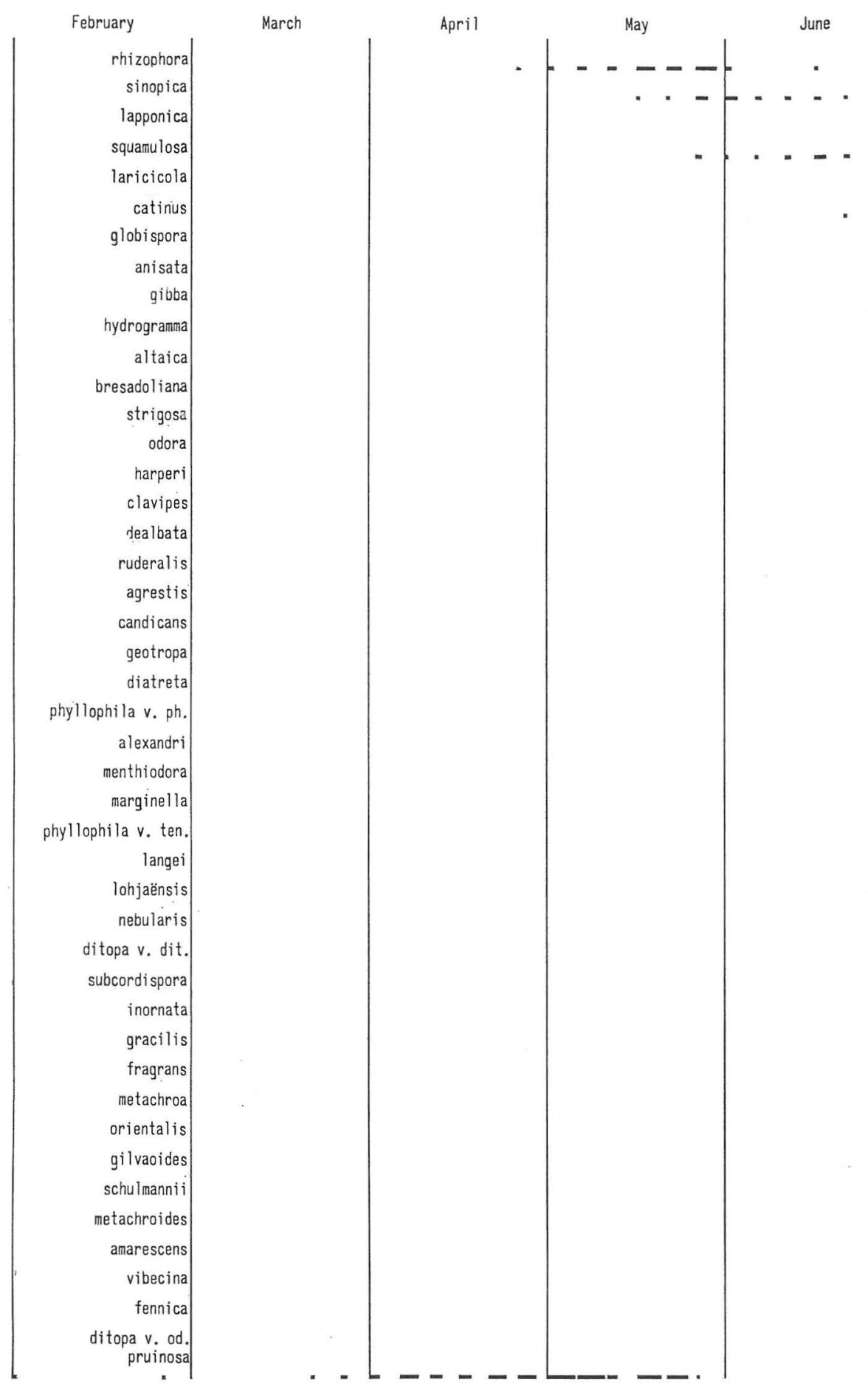




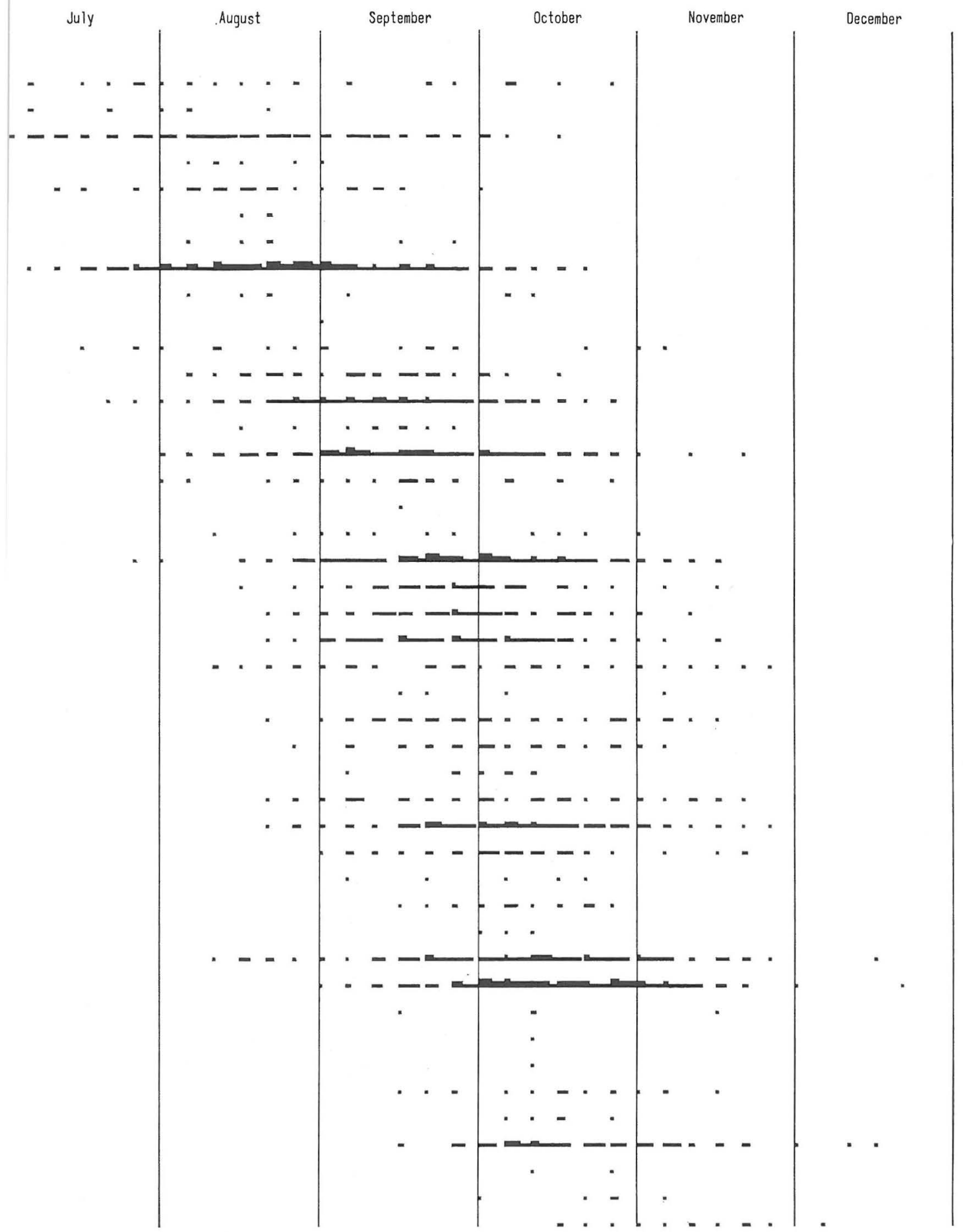

Fig. 5. The fruiting times of species of Clitocybe in southern and central Fennoscandia (the sequence of the taxa is according to their «mean period《 of fruiting, i.e., the period before and after which there are an equal number of collections; for further explanations, see the text on the pages 35 and 38 ). 
standardized one): Østfold, Akershus and Vestfold in Norway, the provinces from Skåne up to and including Gästrikland (Värmland and Dalarna excluded) in Sweden, and the provinces from Ahvenanmaa up to and including Laatokan Karjala in Finland. The specimens of the northern species, C. altaica, C. lapponica, and C. laricicola, which occur well outside the area described above, have, nevertheless, been included in Fig. 5, but they have been excluded from Fig. 6, which shows the number of fruiting taxa per month, and will not be further considered in the present section. Four specimens of $C$. nebularis, $C$. clavipes, and $C$. geotropa have been excluded from the present study because of the exceptionally early dates on the labels. There may have been some confusion with the labels, though they may also be correct (see under the respective species descriptions).

The fruiting time of the genus as a whole can be said to cover the whole year (see later) which is very unusual in genera in which the basidiocarp is annual. The culmination of the fruiting of Clitocybe is in September with 33 fruiting species and varieties, and October with 37 (Fig. 6). The numbers of fruiting taxa in the different months is as follows: February 1, March 1, April 2, May 4, June 4, July 7, August 24, September 33, October 37, November 21,
December 4. The coming of the winter abruptly diminishes the number of fruiting taxa.

As can be seen in the diagram (Fig. 5) great differences exist in the fruiting times of the Fennoscandian taxa. Although they vary from year to year, characteristic patterns can be discerned and the taxa often differ clearly, especially in their mean dates of fruiting. This partly disagrees with Bigelow's (1962: 16-17) observations in Michigan. The diagram reveals that on the whole the subgenus Clitocybe is the earliest, while Pseudolyophyllum is the latest. Some sections are rather uniform as to the time of fruiting, while others are heterogeneous in this respect. The section Infundibuliformes is early on the average, while the Ditopae (and evidently also the Gilvaoideae, which are represented by very scanty material) are late.

There are also interspecific differences in the extent of the fruiting period, for instance C. sinopica has a very long fruiting period, more than 5 months, while those of $C$. rhizophora and $C$. inornata last about 1.5 months only.

The most curious fruiting pattern is that of $C$. pruinosa, which (under various names) has usually been considered a species of the early spring. My field observations (p. 79) and the collecting dates of the specimens examined have, however, shown that living,

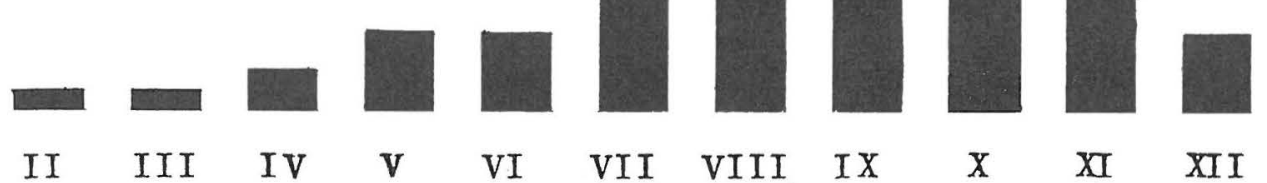

Fig. 6. Fruiting species and varieties of Clitocybe per month (2 $\mathrm{mm}$ corresponds to one taxon; see 
potentially sporulating fruit bodies (for the most part even the same ones !) of this species apparently always occur throughout the winter, from the middle of October to the end of May. This species must accordingly be described as a winter species rather than a vernal. There are very few of these winter species in the Agaricales.

There appears to be some justification for distinguishing five annual seasons in respect of the prevailing Clitocybe flora, though these are not very clearly delimited. The winter season, whose only Clitocybe is C. pruinosa, lasts from the beginning of January to the end of April. The spring season, which is characterized by $C$. pruinosa, $C$. rhizophora, C. sinopica, and C.squamulosa, extends from the beginning of May to about the middle of June. The summer season, which is marked in particular by the occurrence of species of the section Infundibuliformes, and C.sinopica, with some others, lasts from around the middle of June to about the middle of August. The early autumn season, between about the middle of August and late October, is the time when most species of the genus are fruiting. The late autumn season is distinguished by the species which occur between the end of October and the end of December.

Frost, or cold weather in general, may be of importance in stimulating the formation of the fruit bodies of the late species, or their fruit bodies may be more resistant to cold than those of the other species, as supposed by M. LANGe (1948: 52) in respect of the larger fungi in general. I have found frozen fruit bodies of most of the late species of southern Finland and observed that when brought indoors and thawed they appeared fully normal in all respects: the hygrophanous or non-hygrophanous characters were usual, the flesh was normal in appearance, the odour and taste were unchanged and typical of the taxon concerned, the spore deposit was as readily obtained as from fruit bodies which had not frozen, and lastly, no changes could be observed in the spores and anatomical properties. Malmström (1933: 90) discovered that the basidiocarps of some species, e.g. C. ditopa (v. ditopa according to a probably corresponding specimen) and $C$.fragrans, tolerate freezing well.

\section{Phytogeographical conclusions}

The distribution of each species and variety is presented in distribution maps (at the end of this paper), where a dot (in some maps a circle in addition) represents material examined by me. The total number of specimens per Clitocybe species so far collected, is usually not great, e.g. when compared with that of moss species, though many species of Clitocybe are very common in the area. The distribution maps generally give a more or less false picture of the distribution of the taxon in question, when studied in detail, because there is usually an «artificial« concentration of records in the neighbourhoods of the Fennoscandian capital towns, and in some other areas, while large areas (where the taxon surely occurs) remain without dots. This is, of course, due to the fact that the latter areas are poorly collected, and this lack of uniformity must be kept in mind when studying the distribution of the species. On the basis of the present material, the species and varieties can be divided among 10 more or less distinct groups, according to their distribution pattern, though some of the less collected taxa may be assigned to different groups after more data have been accumulated.

The areas of the distribution groups (like the distributions of individual taxa in the species descriptions) have been described as projected on the vegetation zone system of Анті, Нӓмет-Анті \& Jalas (1968). This is an extremely important and practical synthesis based on extensive knowledge of the mineral soil vegetation of northwestern Europe collected in the field and from the literature. (However, in the present study the three oroarctic, or alpine, vegetation zones have been treated as one, the oroarctic zone.) The system is principally based on the thermal conditions, but sections with different degrees of oceanity have been distinguished, too. When dealing with regions such as Fennoscandia it would be inaccurate to define the distribution areas with such in- 
flexible terms as «southern « or «northern « because of the great variations in the relief (especially in Norway) and resultant variations in the climate.

1. To the first distribution group belong taxa which occur in all the forested vegetation zones of Fennoscandia, i.e. from the temperate zone up to and including the northern boreal zone, and which seem to be indifferent to the oceanity of the climate. The species which have also been collected (very few specimens in each case) above the forest limit, or, in other words, in the oroarctic (alpine) zone, obviously in the lowest parts, have here and later been marked with «a«. - The distribution maps are given in Figs. 136, 139, 142, 151, 161.

\section{a C. geotropa \\ C. squamulosa \\ (very rare in sub- \\ alpine conditions) \\ C. sinopica \\ (very rare in sub- alpine conditions) \\ C. phyllophila \\ v. phyllophila \\ C. vibecina}

2. The species of the second group have distribution areas similar to those of the first, but are lacking (or very rare) in districts where the climate is very oceanic, i.e. approximately section $\ll \mathrm{O}_{3}$ « on the Norwegian west coast. - Figs. 135, 138, 140, 144, 150, $154,166$.
a $C$. clavipes
C. gibba
a C. bresadoliana
C. candicans
C. odora
a $C$. diatreta (not yet collected in the temperate zone)
a C. strigosa ${ }^{1}$ )

3. Species which are lacking in the oroarctic (alpine) and northern boreal zones, occurring from the temperate up to and including the middle boreal zone, and which are indifferent to oceanity. - Figs. 134, 156, 157.

\section{C. nebularis \\ C. fragrans \\ C. metachroa}

4. Taxa which have distributions very similar to those of the third group, but are lacking in districts with a very oceanic climate, i.e. approximately section $« \mathrm{O}_{3} \ll$ on the Norwegian west coast. - Figs. 131, 133, $148,163$.

1) See also p. 111.

\author{
C. alexandri \\ C. rhizophora \\ C. inornata (not yet \\ collected in the \\ temperate zone) \\ C. ditopa v. ditopa
}

5. Distribution which resembles those of the species of the fourth group, but is more northern, extending from the temperate (very rare) up to and including the northern boreal zone. - Fig. 147.

\section{C. pruinosa}

6. Eastern taxa, occurring from the temperate or hemiboreal up to and including the middle boreal zone, sometimes even in the northernmost/upper (subalpine) parts of the northern boreal zone; mostly in Finland, lacking in Norway. - Figs. 132, 143, 152, 153, 155, 162, 165, 168.
C. harperi
? C. gilvaoides
C. marginella
C. phyllophila v. tenuis C. menthiodora
C. agrestis
C. lohjaënsis

7. Southeastern taxa, occurring in the hemiboreal and southern boreal zones, sometimes in the temperate zone, too; mostly in southeastern Sweden and southern Finland, lacking in Norway. The very rare species, whose material may be particularly misleading, have been marked with a questionmark. - Figs. 137, 143, 145, 145, 149, 153, 158, 159, 159, 164, 167, 167.
C. catinus
? C. amarescens
? C. gracitis
C. subcordispora
C. dealbata
C. globispora
? C. ruderalis
C. ditopa v. odorula
C. hydrogramma
? C. fennica
C. anisata
? C. schulmannii

8. Northeastern species, occurring from the hemiboreal zone up to and including the northernmost/upper (subalpine) parts of the northern boreal zone; mostly in Finland, lacking in Norway except for the very northeasternmost parts. - Figs. 158, 160.
C. metachroides
C. orientalis

9. Species occurring predominantly in subalpine conditions, i.e., in the northernmost/ 
upper parts of the northern boreal zone, but also found above the forest limit in the oroarctic (alpine) zone (obviously in the lower parts). Relation to oceanity unknown. Figs. 141, 146.

\section{C. lapponica C. laricicola}

10. Oroarctic (alpine) species, collected above the forest limit only, obviously in the lower parts of this vegetation zone. Relation to oceanity unknown. - Fig. 136.

\section{? C. altaica}

Although the material on which they are based requires to be complemented, many interesting observations can be made in respect of the distribution maps and the above grouping. Firstly, the limits of the distribution areas of at least the frequent species, for which fairly ample material is already available, usually coincide surprisingly well with the limits of the vegetation zones and oceanity sections of AHTI, HӒмет-Анті \& Jalas (op. cit.). The best fit can be noted in respect of the northern/ upper limits of the middle boreal and the northern boreal ( $=$ the forest limit) zones, and the boundaries of oceanity section $\ll \mathrm{O}_{3} \ll$. From this it would appear that the distribution areas of most Clitocybe species in Fennoscandia are primarily determined by the regional (macro-) climate, including both the thermal and hygric conditions. Similar distribution patterns seem to be present in, for example, Gyromitra (Pezizales) (Harmaja 1969 a).

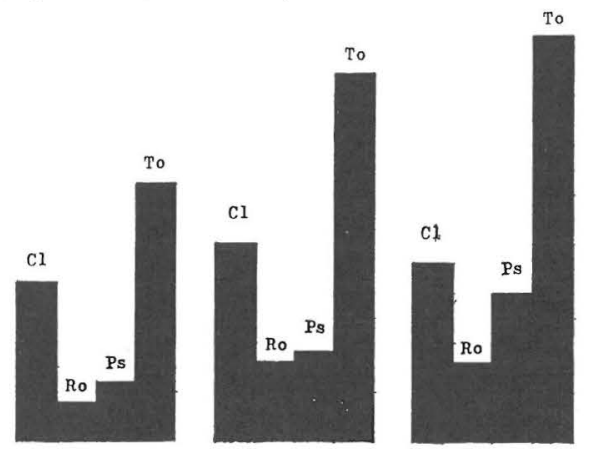

Fig. 7. The numbers of species and varieties of Clitocybe in Norway (left), Sweden (middle) and Finland (right) $(\mathrm{Cl}=$ subgenus Clitocybe, $\mathrm{Ro}=$ subgenus Roseospora, $\mathrm{Ps}=$ subgenus Pseudolyophyllum and To $=$ total; $1 \mathrm{~mm}$ corresponds to one species or variety; see also the text on p. 41).
Another interesting feature is the very great proportion of eastern species, especially in the subgenus Pseudolyophyllum, thanks to which Finland has the richest Clitocybe flora, with 41 species and varieties, Sweden having 37, and Norway 26 taxa (Fig. 7). As far as the other groups of plants (and evidently many other genera of fungi) are concerned, Sweden is usually the country richest in species. These eastern distribution areas can only partially be explained by the increase in oceanity towards the west, since large areas exist in both Sweden and Norway where the climate is as continental as in Finland (see the map in Arrt, Hämet-Ahtr \& JaLAS, op. cit.: 188). These species may have an eastern distribution in Eurasia, and some historical factors are obviously also involved, as in the case of the eastern distributions of many vascular plants, e.g. the effects of the latest glaciation. ERIKSSON (e.g. ERIKSSON \& Strid 1969) has drawn attention to the eastern elements among species of Aphyllophorales in Fennoscandia. NANNFELDT (1966: 315) supposes Otidea caligata (Nyl.) Sacc. (Pezizales) to be a northeastern species, and judging from the localities listed by him, its Fennoscandian distribution is indeed very like those of the taxa of the sixth distribution group in the present study.

The great majority of the species can be seen to occur in the area formed by the hemiboreal and southern boreal vegetation zones, the number of species decreasing both towards the south and towards higher latitudes and altitudes. Also, it is noteworthy that so many not truly eastern species of Clitocybe avoid the extremely oceanic Norwegian west coast. While there are some pronouncedly northern (subalpine to alpine) species of Clitocybe, and many eastern ones, I know so far of none with distinctly southern, western or southwestern distributions, e.g. species restricted to the temperate beech forests, like many plants of other groups and some larger fungi.

It is remarkable that all the subalpine to alpine species show a more or less distinct tendency to favour calcareous ground. In related genera, e.g. Omphalina, there are more or less northern species which occur in very meagre habitats on the low barren Finnish fjelds. The species of Clitocybe and those of Omphalina seem to have different physiological qualifications for standing 
extremely hard climatic conditions (see p. $11-12)$.

C. bresadoliana may be a principally alpine species (see p. 67) in spite of the southern records, since in Fennoscandia there are several distinctly northern, even alpine, species of vascular plants, mosses and lichens (e.g. Thamnolia vermicularis), which possess some relic occurrences in the south, also on extremely calcareous soils, often in the steppe-like «alvar « vegetation of the Baltic islands, Öland and Gotland (and in some other, mainly coastal districts). The southern occurrences of $C$. bresadoliana may also be relics from the more or less arctic late-glacial conditions.

For some reason, in Fennoscandia no «moderately« northern species of Clitocybe are known, i.e. species occurring mainly in the middle and/or northern boreal zones (see, however, p. 84). Such species are frequent among the phanerogams and in other plant groups, and are also found among the larger fungi; e.g. Mitrula gracilis Karst. (Helotiales) represents this type of distribution though occurring above the forest limit, too (see KanKaINEN 1969).

The influence of microclimatic and edaphic factors on the distribution of the taxa of Clitocybe generally seems to be rather small, at least on the basis of the material so far accumulated. C. geotropa is, however, distinct exception: it is able to grow in widely differing climates, its distribution most probably being limited by a low concentration of calcium in the soil. The occurrences of a good many species of the fleshy fungi outside Clitocybe may also depend more on macroclimatic than on microclimatic and edaphic factors. In this they differ from a large part of the lichens, mosses, pteridophytes and phanerogams, which generally also have smaller distribution areas.

\section{Descriptions of the taxa}

\section{A. Explanations and abbreviations}

The synonyms are included only when the species was described on the basis of Fennoscandian material, and when, in addition, its type or type material exists.

For the meanings of terms and expressions used in the taxon descriptions and keys of the present study, especially those used for describing the spores, which are not selfevident, the reader is advised to consult the relevant text in the general part.

The colours of parts of the fruit body and spore deposits are given according to the code of Maerz \& Paul (1950). When hygrophanous species are considered, the term «faded « means the condition when the fruit body (pileus) has lost most of the interhyphal water and has become more or less distinctly paler than when water-soaked («when moist «), though not yet dried in the usual meaning, i.e. exsiccate (for more detailed information, see Harmaja $1969 \mathrm{~b}$ ). In the descriptions of non-hygrophanous species, the terms «fresh « and «dry (or «in exsiccates«) have been used. The characters (colours, the possible lustre of the pileus, odour, etc.) described in the keys refer to those of fresh/ moist fruit bodies, if not otherwise stated. Of the measurements of the stipe, the first two figures express in centimetres the amplitude of the variation observed in the length of the stipe, while the two following figures present in millimetres the amplitude of the diameter of the stipe. The lengths of the spores include the apiculus/apicular region, the contrary usage being unnatural (see p. 21). The measurements of the spores and apiculi are exact to $0.1 \mu \mathrm{m}$; those of the diameters of the hyphae to $0.5 \mu \mathrm{m} . \mu \mathrm{m}=$ micrometre, i.e., one-millionth of a metre and one-thousandth of a millimetre, is used instead of the classical $\ll \mu \ll$, since the latter symbol is not in line with the recommendation of the International Organization for Standardization, according to which measurements should be expressed in terms of their respective MKSA unit (here, metre $=\mathrm{m}$ ) with a certain prefix (e.g., $\mu, \mathrm{m}, \mathrm{c}$ ), as has long been the usage in some cases $(\mathrm{mm}, \mathrm{cm})$.

In the paragraphs on ecology, the specific epithet of most of the tree species, often the sole native species of their respective genera in Fennoscandia, has not been given but only 
the generic name. Such species are Juniperus communis, Picea abies, Pinus sylvestris, Acer platanoides, Betula alba coll., Corylus avellana, Fagus sylvatica, Fraxinus excelsior, Populus tremula, Quercus robur, and Tilia cordata. The same applies to the names of the commonest mosses of the habitats of species of Clitocybe, i.e., Dicranum polysetum («undulatum «), Hylocomium splendens, and Pleurozium schreberi. The fruiting times refer to the fruiting in the area described on p. 35, 38 , roughly speaking southeastern Norway, southern and central Sweden, and southern Finland.

The distributions are described in the terms of Ahti, Hämet-Ahti \& Jalas (1968).

In the lists of specimens examined, the names in italics are those of the counties (Norway), or historical provinces (Sweden), or biogeographical provinces (Finland), which are commonly used, their sequence being standardized. For their boundaries, see Dissing's paper in Dansk Botanisk Arkiv 25: 1 (1966), p. 144 as to Norway and Sweden, and that of MäKINEN in Annales Botanici Fennici 1: 214 (1964) as to Finland (and the parts of Fennoscandia which belong to the U.S.S.R). The names which follow those of the provinces refer to parishes (or towns, or market towns; «mlk. in connection with Finnish names means rural district). The figure in brackets following the parish name indicates the number of specimens collected in that parish. In the case of very rare species, more data of the specimens are given. The abbreviations of the herbaria are according to Lanjouw \& Stafleu (1964).

In the parts headed «Discussion « I have always indicated the cases where I myself have not collected the species. In such cases the descriptions of the macroscopical features as well as the odour and taste have been cited from those of BrgeLow, or the most important macroscopic differences noted in comparisons with related species have been given in the parts «Discussion«. These facts must be borne in mind when considering some of the indications in the key and the supraspecific treatment of those species not found by me in the field, because some notes in the literature and on labels may be based on erroneous observations.

The description of the genus (p. 50) is based on the material of the present study only.

\section{B. Natural key to the supraspecific taxa}

1 Colour of fruit body variable, \pm conspicuous rhizoids and/or mycelial hairs may be present at the base of the stipe, odour very variable, spores occur singly or in tetrads in preparations from lamellae, spore base obtuse, acute, or confluent, spore shape very variable, apiculus of varying breadth, spore deposit pure white, very pale yellow, or deep yellow 2

2 Pileus very large to small, hygrophanous or not, colour variable, even white, lamellae white to greyish and brownish, being white to pallid in species with hygrophanous pileus, odour very variable, often agreeable, membranal pigment absent or present, being absent in species with hygrophanous pileus, lactiferous hyphae very often present, sometimes \pm exclusively on bare soil 3 subgenus 1. Clitocybe

3 Pileus very large to small, not hygrophanous, spores of ten large and about $8 \mu \mathrm{m}$ long, also longer, membranal pigment present or absent

4

4 Pileus of varying colour, basal tomentum of stipe white to whitish, rhizoids and mycelial hairs may be present, lamellae white or yellowish to somewhat brownish or greyish, spores usually more than 6.0 $\mu \mathrm{m}$ long (when distinctly shorter, clamps completely or almost completely lacking), apiculus of varying size 5

5 Colours only rarely reddish brown, pileus pruinose or not, conspicuous rhizoids and \pm filamentous mycelial hairs present only if pileus brown-grey and pruinose, odour and taste never farinaceous, when spores obtusebased most of them shorter than ca. $8.0 \mu \mathrm{m}$ or less than 5.0 $\mu \mathrm{m}$ broad

6

6 Pileus pruinose (always ?), never infundibuliform, flesh always thick, all spores obtusebased, elliptical etc. but never lacrymoid, apiculus $0.3-0.7$ $\mu \mathrm{m}$ in diameter 7

7 Pileus pale brown to greyish brown, often areolate, odour never sweet, spores single, \pm white in deposit

section I. Alexandriformes 
$7^{\prime}$ Pileus darker, grey to greybrown (rarely \pm white), not areolate, odour \pm sweet, especially in exsiccates, most spores in tetrads, deep yellow in der posit section II. Clitocybe

6' Pileus not pruinose (at most very indistinctly), sometimes \pm infundibuliform with thin flesh, some to all spores confluent- and/or acute-based, obtuse-based ones lacking or present in varying amounts, sometimes dominant, in shape mostly lacrymoid, or subfusiform and/or elliptical, apiculus/apicular region very broad, $0.7-1.3 \mu \mathrm{m}$ in diameter

8

8 Pileus dark brown, only depressed when adult, stipe concolorous, flesh hygrophanous, most spores usually obtuse-based, the rest acute-based (no confluent-based ones), elliptical to \pm fusiform and broadest in the middle (a very few broadest near the apex and \pm lacrymoid) section III. Clavipedes

8' Pileus paler brown to white, often with reddish tint, plane to infundibuliform when adult, stipe concolorous or paler, flesh not hygrophanous, most spores confluent- or acutembased (confluentbased spores always present) and \pm lacrymoid, being broadest near the apex section IV. Infundibuliformes

5' Colours \pm bright, reddish to orange brown, pileus not pruinose, conspicuous rhizoids and firm, compressed mycelial hairs present, odour and taste strongly farinaceous, spores very large, $7.5-11.5 \times 4.8-6.1 \mu \mathrm{m}, \quad$ all obtuse-based sectionV. Sinopicae

4' Pileus deep brown, only tomentum present, its colour pale, brownish, lamellae rich-coloured, pale cinnamon brown in adult fruit bodies, spores small, up to $6.5 \mu \mathrm{m}$ long and $4.0 \mu \mathrm{m}$ broad, apiculus small, up to ca. $0.6 \mu \mathrm{m}$ in diameter, clamps present at each septum

section VI. Gilvaoideae

3' Pileus small to medium, hygrophanous, at least when adult, spores \pm small, $8.0 \mu \mathrm{m}$ long at most, no membranal pigment

9 Epicutis composed throughout of filamentous hyphae, all spores with obtuse bases, never lacrymoid 10

10 Pileus rather small, hygrophanous, at least when adult, probably always pruinose, whitish, rarely \pm brown, mycelial hairs and rhizoids absent or present, large encrusted crystals present on hyphae in some parts of pileus, occurring throughout the year

section VII. Candicantes

10' Pileus hygrophanous even when young, not pruinose, flesh-coloured, mycelial hairs and rhizoids present, encrusted pigments lacking, only in spring, in May and June section VIII. Vernae

9' Hyphae of epicutis with striking vesicles up to ca. $20 \mu \mathrm{m}$ in diameter, most spores with confluent bases and lacrymoid section IX. Bulluliferae

2' Pileus medium to small, always hygrophanous and \pm dull-coloured (grey, fuscous, brown), lamellae dark to pale grey or brownish, odour mostly fungoid or farinaceous (very rarely fragrant), distinct membranal pigment always present, lactiferous hyphae usually absent, only occasionally on bare soil

subgenus 3. Pseudolyophyllum

11 Pileus conspicuously concentrically wrinkled in exsiccates or not, mycelial hairs lacking, lamellae often rather dark, grey, odour and taste farinaceous or not, subcutis present or absent 12 12 Pileus concentrically wrinkled or not in exsiccates, lamellae dirty brownish or \pm chloric-greenish under ultra-violet light, flesh 
not thin in pileus, odour and taste never farinaceous but usually fungoid

13 Distinct grey tinges mostly present in colours of fruit body, pileus only indistinctly wrinkled in exsiccates or not at all, lamellae usually more or less grey-tinged, being dirty brownish under ultraviolet light, spores rather lam ge varying in length from 5.5 $\mu \mathrm{m}$ to ca. $9.5 \mu \mathrm{m}$, most of them in tetrads, all obtusebased, most elliptical to oblong, the remaining few ovate or obovate or subfusiform section XIII. Pseudolyophyllum

$13^{\prime}$ Grey tinges \pm absent in colours of fruit body, pileus \pm conspicuously concentrically wrinkled in exsiccates, lamellae with brown tinges, being dirty brownish with \pm chloricgreenish tinges under ultraviolet light, spores small ranging from 3.2 to $6.2 \mu \mathrm{m}$ in length/diameter, single, obtuse- or acute-based, mostly subglobose to lacrymoid, or globose

section XIV. Latisporae

$12^{\prime}$ Pileus \pm distinctly concentrically wrinkled in exsiccates, lamellae always rather dark, being violet under ultra-violet light, flesh \pm thin in pileus, odour (at least when bruised) and taste distinctly farinaceous section XV. Ditopae

$11^{\prime}$ Pileus very conspicuously concentrically wrinkled in exsiccates, mycelial hairs, chloric-greenish under ultra-violet light, always present, lamellae usually \pm pale brownish, odour and taste not farinaceous in adult and old fruit bodies, subcutis always present and very distinct section XVI. Strigipedes

1' Colours of fruit body more or less pallid, never dark or dull, mycelial hairs lacking, rhizoids occasional and very few, never conspicuous, odour almost always agreeable, fragrant (rarely fungoid), most spores in tetrads, spores mostly small, base always obtuse, always elliptical or nearly so (ovate, obovate, or oblong), apiculus ca. $0.7 \mu \mathrm{m}$ in diameter at most, spore deposit always pinkish buff

subgenus 2. Roseospora

14 Pileus not hygrophanous, pruinose, \pm aeruginous, rarely \pm white to pale buff, odour strongly coumarine-like, spores large, ca. $6.0-8.0 \times 3.6-5.0 \mu \mathrm{m}$ section X. Odorae

14 ' Pileus hygrophanous, pruinose or not, white to \pm brown, odour faintly strawberry-like, or fungoid, or strongly coumarine-like, spores either small, ca. 4.0 $6.0 \times 2.4-3.8 \mu \mathrm{m}$, or large, ca. $6.2-8.6$ $\times 3.4-4.6 \mu \mathrm{m}$, pileus not pruinose if spores large

15 Pileus pruinose or not, translucent striate or not, odour faintly strawberry-like, or fungoid, spores small, ca. $4.0-6.0 \times 2.4-3.8 \mu \mathrm{m} \quad 16$ section XI. Roseospora

16 Pileus pruinose, not translucentstriate, fleshy in the disc subsection 1. Pruinatae

$16^{\prime}$ Pileus not pruinose (or weakly so at the very margin), translucent-striate in old fruit bodies at least, flesh rather thin subsection 2. Epruinatae

15' Pileus not pruinose, distinctly translucent-striate, strong odour of coumarine, spores large, ca. $6.2-8.6 \times 3.4$ $-4.6 \mu \mathrm{m} \quad$ section XII. Fragrantes

\section{Practical key to the species}

1 Pileus not hygrophanous, either in young or old fruit bodies (when, however, only adult and old pilei hygrophanous, young buttons being non-hygrophanous, then \pm small species with pileus pruinose, at least over disc, cf. C. candicans, p. 74, and C.pruinosa, p. 77)

2

1' Pileus already distinctly hygrophanous when young, fading regular and beginning from the centre

2 Pileus often \pm greenish, otherwise brown to grey, or white, or buff, (always pruinose), odour strong, sweet, coumarine-like when fresh, or like that of Swedish turnips, and then persistent and honey-like in exsiccates, most spores in tetrads, all of them obtusebased, most elliptical, pinkish buff ( 9 B 2) or deep yellow (9 G 1-9 G 2) in deposit 3

$2^{\prime}$ Pileus of varying colour but never greenishtinged, odour very variable, sometimes even 
sweet but usually dissimilar to that described above, all or practically all spores single, with obtuse, acute, or confluent bases, of different shapes, white or very pale yellow (as deep as 9. B 1, at most) in deposit

4

3 Pileus medium to very large, brown to grey, rarely \pm white, odour turnip-like, exsiccates fragrant, too, spores 3.2-4.3 $\mu \mathrm{m}$ broad, deep yellow in deposit 4 4. nebularis (p. 57)

3' Pileus medium-sized, mostly aerugineous, sometimes buff, or \pm white, odour strongly coumarine-like when fresh but exsiccates \pm odourless, spores ca. 3.6-5.0 $\mu \mathrm{m}$ broad, pinkish buff in deposit 23. C. odora

4 Lamellae rich-coloured, pale cinnamon brown in adult fruit bodies, basal tomentum clearly brownish, spores small, up to $6.5 \mu \mathrm{m}$ long and $4.0 \mu \mathrm{m}$ broad, apiculus up to ca. 0.6 $\mu \mathrm{m}$ broad (clamp connections present at each septum)

4' Lamellae white to pale brownish or greyish, basal tomentum white to whitish, spores on the average distinctly longer and/or broader than above (when as small, clamps none to few)

5 Odour and taste \pm fungoid, spores $4.2-6.0$ $\times 2.9-3.3 \mu \mathrm{m}$, all obtuse-based, elliptical to oblong, or ovate

14. C. gilvaoides (p. 71)

$5^{\prime}$ Odour and taste farinaceous, more slender species than above and with thinner flesh, spores $5.0-6.5 \times 3.0-3.7 \mu \mathrm{m}$, rather variable in shape, obtuse- or acute-based, many obovate or lacrymoid

15. C. gracilis

6 Pileus and stipe bright-coloured being redbrown to almost orange, lamellae \pm white, odour and taste strongly farinaceous, \pm conspicuous rhizoids and mycelial hairs present, spores very large, $7.5-11.5 \times 4.8-6.1$ $\mu \mathrm{m}$, all of them obtuse-based, most elliptical, none lacrymoid

13. C. sinopica

(p. 69)

6' Colours usually less bright, odour and taste never farinaceous, conspicuous rhizoids and mycelial hairs mostly lacking (when present, spores less than $4.2 \mu \mathrm{m}$ broad), spore morphological characters very variable, shape often lacrymoid

7 Pileus not (at least distinctly) pruinose, lamellae usually \pm paler than pileus, odour very often agreeable, a few to all spores with acute or confluent bases, often lacrymoid (sometimes elliptical or subfusiform), apiculus/ apicular region very broad, $0.7-1.3 \mu \mathrm{m}$ in diameter, occurring in summer especially, sometimes in alpine and subalpine vegetation

7' Pileus pruinose (always ?), lamellae in fresh fruit body \pm concolorous with pileus, odour not agreeable, all spores obtuse-based, most always broadest in the middle, never lacrymoid, apiculus small to medium-sized (ca. 0.3 $-0.7 \mu \mathrm{m}$ broad), in autumn from the middle of August on, never in alpine or subalpine conditions

8 Pileus dark brown, flesh hygrophanous, only a minor part of spores acute-based, confluentbased ones lacking, elliptical, subfusiform etc. and broadest in the middle (sometimes a very few \pm lacrymoid) 5. C. clavipes (p. 59)

8' Colours never dark brown, flesh not hygrophanous, most spores confluent- and/or acutebased (confluent-based spores always present) and lacrymoid being broadest near apex 9

9 Pileus surface chestnut brown with $\mathrm{KOH}$, flesh rather thin

$9^{\prime} \mathrm{KOH}$ reaction of pileus surface negative (see p. 30 , too), flesh thick to thin

10 Pileus surface smooth (rarely slightly areolate over disc) and usually \pm shining in exsiccates, stipe rather short, lamellae becoming pale brownish, their colour not contrasting markedly with that of stipe, spores rather small, $5.5-8.0 \times 3.1-4.0 \mu \mathrm{m} \quad$ 11. C. bresadoliana (p. 67)

10' Pileus surface scaly, at least over disc, and mat, stipe usually rather long $(4-9 \mathrm{~cm})$, lamellae whitish, contrasting in colour with the distinctly darker stipe, spores larger, 6.0$9.0(-11.0) \times 3.2-5.0(-6.5) \mu \mathrm{m}$

10. C. squamulosa (p. 65)

11 Stipe very tall, $10-16 \times 15-30$, distinctly (ca. 1.5 to 4 times) longer than diameter of pileus, odour strong, reminiscent of oil of bitter almonds, most spores subglobose in contour, lactifers abundant in gill trama

6. C. geotropa

(p. 61)

$11^{\prime}$ Stipe distinctly shorter and thinner, also shorter in relation to pileus diameter, odour fungoid or otherwise unlike that described above (at least fainter), spores usually more elongated, lactiferous hyphae few or absent in gill trama

12 Pileus usually not infundibuliform, surface 
distinctly to indistinctly squamulose, usually except over disc, sometimes only areolate or radiately fibrillose, flesh thick, spores 6.0$11.0 \times 4.2-6.2 \mu \mathrm{m}$, part of them acutebased and almost obovate or even elliptical (subalpine to alpine) 12. C. lapponica (p. 68)

12' Pileus mostly infundibuliform, sometimes almost plane, surface completely smooth, flesh rather thin to very thin, spores often smaller than above, practically all of them with confluent bases, \pm lacrymoid, none elliptical

13 Pileus whitish, spores large, broad, 6.8-9.6 $(-10.8) \times(4.2-) 4.6-6.8 \mu \mathrm{m}, \quad$ tapering very abruptly towards the apicular region

8. C. catinus

(p. 63)

$13^{\prime}$ Pileus colour different shades of brown (only very rarely whitish), spores shorter and narrower, (4.2-) $5.5-8.0(-10.0) \times(2.4-)$ $3.4-5.4(-6.4) \quad \mu \mathrm{m}$, usually tapering \pm gradually towards the apicular region 14

14 Pileus \pm infundibuliform (rarely plane), surface not wrinkled nor shining nor yellow in exsiccates but mat and usually tan to somewhat darker brown (very rarely whitish), lamellae thin and \pm crowded, flesh not very thin, basidia medium-sized, not occurring above forest limit

9. C. gibba (p. 64)

$14^{\prime}$ Pileus \pm plane, in exsiccates with rather striking yellow tones and \pm shining wrinkled surface, lamellae thick and rather distant, flesh very thin, basidia very large $(25-40 \times$ $5.0-7.5 \mu \mathrm{m})$, in alpine Dryas vegetation

7. C. altaica

(p. 62)

15 Lamellae very narrow and crowded being ca. $3-5 \mathrm{~mm}$ at broadest point, spores only 4.5 $6.5 \times 2.9-3.6 \mu \mathrm{m}$, clamp connections totally absent or very scattered

2. C. harperi (p. 54)

15' Lamellae broad, being ca. 4-12 $\mathrm{mm}$ at broadest point, not crowded, spores clearly longer and/or broader than above, clamp connections at each septum

16 Pileus not areolate, stipe diameter ca. 7-13 $\mathrm{mm}$, rather conspicuous rhizoids and mycelial hairs usually present, spores $7.5-10.5 \times 3.0$ $-4.2 \mu \mathrm{m}, \pm$ fusiform (part of them rarely narrowly elliptical to oblong) 3. C. inornata

(p. 55)

16' Pileus areolate, stipe diameter ca. $12-50 \mathrm{~mm}$, rhizoids and mycelial hairs absent or not con- spicuous, spores $5.5-7.5(-8.7) \times 3.5-5.0$ $\mu \mathrm{m}$, most of them broadly elliptical

1. G. alexandri

(p. 53)

17 Conspicuous strigose \pm hyaline mycelial hairs present at stipe base, often white rhizoids, too

$17^{\prime}$ Strigose mycelial hairs absent, only tomentum present (rarely a few inconspicuous, thin rhizoids, too)

18 Pileus pruinose or not, not translucent-striate at margin, often not conspicuously wrinkled when dry, conspicuous white rhizoids present, lamellae \pm buff, spores never constricted, in late autumn, winter, and especially throughout the spring, even in June

19

$18^{\prime}$ Pileus never pruinose, translucent-striate at margin, surface very conspicuously concentrically wrinkled in exsiccates, white rhizoids lacking (or very few and thin), lamellae pale brownish to greyish, spores often with asymmetrical and imperfect median constriction, in autumn only

19 Pileus pruinose (indistinctly when old; check over disc), its colour somewhat dependent on age but never flesh-coloured, stipe slender, ca. $2-5 \mathrm{~mm}$ in diameter, spores $4.5-6.5(-7.5)$ $\times 2.5-3.8 \mu \mathrm{m}$, most of them obovate to elliptical, apiculus long and often deformed, from late autumn to end of May

20. C. pruinosa (p. 77)

$19^{\prime}$ Pileus not pruinose, flesh-coloured when moist ( \pm alutaceous when faded and when dry), stipe stouter, ca. $5-15 \mathrm{~mm}$ in diameter, spores shorter and narrower, 3.8-5.5 (-7.0) $\times 1.9-3.0(-3.5) \mu \mathrm{m}$, most of them narrowly elliptical to oblong, apiculus inconspicuous, occurring in May and June

21. C. rhizophora (p. 80)

20 Pileus $2.5-6.5 \mathrm{~cm}$ broad, chestnut brown, umbilicate, stipe tapering upwards, spores ca. $5.8-8.4 \times 3.4-4.8 \mu \mathrm{m}$, most of them \pm obovate to lacrymoid (rarely elliptical)

40. C. strigosa

(p. 109)

$20^{\prime}$ Pileus somewhat smaller and mostly paler than above, usually not umblicate but only depressed, stipe equal, spores shorter and/or thinner, most ovate or elliptical to oblong, a very few obovate, none lacrymoid 21

21 Taste bitter, spores $6.2-8.0 \times 3.0-4.0 \mu \mathrm{m}$, most narrowly elliptic-oblong, the rest narrowly ovate 42. C. schulmannii (p. 112) 
$21^{\prime}$ Taste mild, spores smaller, ranging from 4.2 to $7.0(-8.0) \mu \mathrm{m}$ in length and from 2.8 to $3.6 \mu \mathrm{m}$ in breadth, most of them ovate (especially in face view)

22 Pileus \pm dark brown, indistinctly striate, odour always fungoid or somewhat musty, never farinaceous, spores 5.5-7.0 $(-8.0) \times$ 2.8-3.3 $\mu \mathrm{m} \quad$ 41. C. fennica (p. 111)

22' Pileus pale brown, distinctly striate, odour always faintly farinaceous in young basidiocarps, spores shorter, $4.2-6.0 \times 3.0-3.6 \mu \mathrm{m}$ 43. C. lohjaënsis (p. 112)

23 Odour (at least when bruised) and taste farinaceous (colours dull, also in lamellae) 24

23' Odour (and taste) fungoid, fragrant etc., but never farinaceous

24 Spores only $3.0-4.2(-5.5) \times 2.3-3.1 \mu \mathrm{m}$, pileus very often pruinose and non-striate, rarely non-pruinose and striate

24' Spores distinctly larger, pileus mostly nonpruinose and translucent-striate, only young buttons sometimes pruinose and non-striate 26

25 Colours usually rich tones of grey, pileus pruinose, with thick, inrolled, \pm pruinose and non-striate margin 38. C. ditopa v. ditopa

$25^{\prime}$ Colours with less grey and more brown tinges, pileus not pruinose (or very indistinctly so over disc), with thin non-pruinose and distinctly translucent-striate margin

$$
\text { 38.a C.ditopa v. odorula }
$$

26 Lamellae not truly decurrent, but narrowly adnate (see Fig. 34), odour when drying faint, very agreeable resembling that of menthol, exsiccates having faint smell of fish

39. C. menthiodora (p. 107)

26' Lamellae decurrent to broadly adnate, fresh fruit bodies have farinaceous odour only, exsiccates odourless

27 Colours with brown tinges, spores 5.0-6.5 $(-7.0) \times 2.9-3.6 \mu \mathrm{m}$, a considerable part of them obovate to lacrymoid (the rest mainly elliptical)

37. C. langei

(p. 104)

$27^{\prime}$ Colours with predominantly grey tinges, length of spores exceeding that in 27 to greater or lesser degree and breadth sometimes also greater, most of them ovate or elliptic-oblong (a very few obovate, none lacrymoid)
28 Spores $5.0-7.0(-7.5) \times 2.9-3.6 \mu \mathrm{m}$, all obtuse-based, most (usually) narrowly elliptical to oblong, the rest (sometimes most) being mainly ovate, apiculus small, ca. 0.6$0.8 \times 0.4-0.6 \mu \mathrm{m}$

36. C. vibecina (p. 103)

$28^{\prime}$ Spores $6.0-8.0(-9.0) \times 3.0-4.2(-5.0)$ $\mu \mathrm{m}$, rather variable in size and shape, a minor part of them acute-based, most of them ovate, a few fusiform, apiculus large, ca. $0.8-1.0 \times$ $0.6-0.8 \mu \mathrm{m}$

35. C. orientalis

(p. 103)

29 Spores $5.0-7.0(-8.0) \times 3.0-4.2 \mu \mathrm{m}$, perhaps most of them confluent-based, without separate apiculus, and lacrymoid (the rest \pm elliptical), apicular region ca. $0.5-0.9 \mu \mathrm{m}$ in diameter, epicutis with conspicuous vesicles up to ca. $20 \mu \mathrm{m}$ in diameter (colours of basidiocarp pale) 22. C. hydrogramma (p. 82)

29' Spores not confluent-based, shape variable, but only very rarely lacrymoid, apiculus always distinct, thinner than above, epicutis composed of filamentous hyphae only $\quad 30$

30 Spores small, either 4.2-6.2 × 3.0-4.0 $\mu \mathrm{m}$, and most \pm subglobose to \pm lacrymoid, mixed with a few spores of other shapes, or globose and 3.2-5.0 $\mu \mathrm{m}$ in diameter, pileus brown, not pruinose, very conspicuously concentrically wrinkled in exsiccates, lamellae (always ?) strikingly waxy and elastic in consistency, having more or less brownish tinge, odour fungoid

$30^{\prime}$ Spores elliptical, ovate, or oblong, when small usually thinner than above, pileus often pruinose, its surface in exsiccates usually not as above, odour of ten fragrant

31 Spores irregularly globose, 3.2-5.0 $\mu \mathrm{m}$ in diameter, their bases obtuse, lamellae ferrugineous in exsiccates, in August

34. C. globispora

(p. 101)

$31^{\prime}$ Spores 4.2-6.2 × 3.0-4.0 $\mu \mathrm{m}$, \pm subglobose to \pm lacrymoid etc., their bases being obtuse or acute, lamellae only pale brown in exsiccates, occurring from September to November in very meagre dry coniferous heath forests 33. C. subcordispora (p. 100)

32 Colours \pm dull, grey to fuscous, sometimes pale brown, pileus not pruinose, lamellae not conspicuously changing colour when drying, odour either fungoid or like that of Cystoderma carcharias, or strongly fragrant, spores 
\pm large, their range within ca. 5.5-9.5 $\times$

$3.2-4.8 \mu \mathrm{m}$

$32^{\prime}$ Colours pale, being white, buff, pale brown, or flesh-colour, pileus often pruinose, lamellae often changing colour when drying (often yellow in exsiccates), odour fungoid, or faintly fragrant, or \pm acidulous, spores small, ca. $4.0-6.6 \times 2.4-3.8 \mu \mathrm{m}$

33 Grey tints lacking or indistinct, odour strong and sweet, coumarine-like, spore deposit pinkish buff

29. C. fragrans

(p. 93)

33' Grey tints present, mostly even predominant, in colours of fruit body, odour fungoid or like that of Cystoderma carcharias, spore deposit white or very pale yellow

34

34 Colours (even of lamellae) strikingly dark, pileus \pm small, $1.5-4.5 \mathrm{~cm}$ broad, stipe rather slender, 2-6 $\mathrm{mm}$ in diameter, spores rather small, 5.5-7.5 $\times 3.2-4.2 \mu \mathrm{m}$ (taste mild)

32. C. metachroides

(p. 99)

$34^{\prime}$ Colours usually not so dark, especially lamellae being paler than above, pileus medium-sized, 3-7 cm broad, stipe not so slender, 3-9 $\mathrm{mm}$ in diameter, spores larger than above, ca. $6.4-9.5 \times 3.5-4.8 \mu \mathrm{m}$

35 Stipe equal, \pm one-coloured, lamellae rather narrowly decurrent, taste of adult and old pilei bitterish, spores $6.4-8.4(-9.4) \times$ $(3.1-) 3.6-4.8 \mu \mathrm{m}$, very pale yellow in deposit

31. C. amarescens

(p. 98)

$35^{\prime}$ Stipe usually enlarged downwards, its apex conspicuously paler than the rest of it, becoming darker and greyer downwards, lamellae obliquely adnate to short decurrent, taste of all parts always very mild, spores $6.4-9.5(-11.0) \times 3.5-4.2(-4.6) \mu \mathrm{m}$, in deposit \pm pure white 30. C. metachroa

(p. 96)

36 Almost all to distinct majority of spores occurring in tetrads (and dyads) in preparations made from lamellae, spore deposit pinkish buff

$36^{\prime}$ Spores single (rarely a minority in tetrads) in all preparations, colour of spore deposit, when known, pure white

37 Pileus pruinose, not translucent-striate, flesh rather thick in disc

$37^{\prime}$ Pileus not pruinose (though extreme margin, often \pm weakly so), translucent-striate, at least in old fruit bodies at margin, flesh less thick
38 Pileus very small to small, up to $4 \mathrm{~cm}$ broad, lamellae strikingly distant, in half-open habitats on boulders in moss 25. C. anisata

(p. 89)

$38^{\prime}$ Pileus rather large to rather small, $3-10 \mathrm{~cm}$ broad, lamellae «normally« close, in forest litter

39 Pileus $4-10 \mathrm{~cm}$ broad, rather weakly hygrophanous, ground colour when moist watery pale brownish, disc hardly darker, stipe not very elastic, 士 stout, $4-15 \mathrm{~mm}$ in diameter, whitish to buff, flesh thick

24. C. phyllophila v. phyllophila

(p. 86)

39' Pileus $3-7 \mathrm{~cm}$ broad, strongly and very regularly hygrophanous, ground colour somewhat darker than above, disc often darker than the rest of pileus, stipe very elastic, long and slender, 3-6 $\mathrm{mm}$ in diameter, darker than above, flesh thinner than above

24. a $C$. phyllophila v. tenuis

(p. 88)

40 Pileus very pale, more or less beige throughout, margin not pruinose, all parts turning faintly brownish when drying, in man-made habitats (road-sides, stubble-fields, pastures, etc.) on \pm bare soil, sometimes together with low mosses

27. C. agrestis (p. 91)

40 ' Pileus darker than above and flesh-coloured, or, when equally pale, possessing distinctly darker disc, extreme margin very often pruinose, fruit body not turning brownish when drying, in \pm meagre heath forests, mostly in conifer litter

41

41 Pileus flesh-coloured throughout, margin \pm thick, translucent-striate in old fruit bodies only, only very narrow pruinose border on extreme margin (usually evident in exsiccates, too), stipe usually equal, compressed in age, lamellae broadest around the middle, flesh very elastic, odour mostly fungoid (rarely faintly fragrant)

26. C. diatreta (p. 90)

41' Pileus paler, less reddish-tinted, \pm clearly darker in disc, more distinctly striate than above (even when \pm young), margin thinner, usually with $1-2 \mathrm{~mm}$ broad whitish pruinose zone, stipe usually tapering upwards and terete, lamellae usually broadest proximally (near stipe), flesh rather fragile, odour almost always faintly fragrant 28. C. marginella (p. 92) 
42 In man-made habitats (road-sides, pastures, rubbish dumps, stubble-fields, lawns etc.) only, on \pm bare soil, often together with low mosses, lamellae sordid pinkish or dirty whitish in exsiccates

$42^{\prime}$ In \pm natural plant communities, either in woods or, rarely, above forest limit in alpine conditions, mostly in litter of deciduous and coniferous trees, rarely on bare soil (then near forest limit), lamellae yellow in exsiccates (occasionally whitish)

44

43 Lamellae short decurrent, conspicuously sordid pinkish in exsiccates, spores 4.0-6.0 6 2.5-3.3. $\mu \mathrm{m}$

17. C. dealbata

(p. 75)
43' Lamellae narrower, and longer decurrent than above, dirty whitish in exsiccates, spores broader, $4.0-6.0 \times 2.9-3.7 \mu \mathrm{m}$

18. C. ruderalis

(p. 76)

44 Pileus whitish to pearl grey in exsiccates, spores $4.6-6.6(-7.8) \times 2.6-3.6 \mu \mathrm{m}$, below forest limit, in litter 16. C. candicans (p. 74)

44' Pileus with \pm distinct red tinges, e.g. sordid pinkish, in exsiccates, spores shorter and relatively broader, $4.0-5.6 \times 2.9-3.5 \mu \mathrm{m}$, in vicinity of forest limit, in both subalpine and alpine conditions, often on calcareous \pm bare soil

19. C. laricicola

(p. 76)

D. Genus Clitocybe (Fr.) Staude, Die Schwämme Mitteldeutschlands, insbesondere des Herzogthums Coburg, 122. 1857.

Basionym: Agaricus tribus Clitocybe Fries, Syst. Mycol. 1: 9, 78. 1821. - Typus: No original designation. Lectotype Agaricus nebularis [Batsch] Fr. (see p. 12).

Fruit bodies solitary, or in irregular groups, or in rows, arcs, or whole «fairy rings «, sometimes subcespitose but never truly cespitose with connate stipes; very large to very small; development may usually be gymnocarpic.

Pileus in adult fruit bodies varying in breadth from ca. $1.5 \mathrm{~cm}$ to $\mathrm{ca} .30 \mathrm{~cm}$, hygrophanous or not (in rare cases only adult and old pilei hygrophanous), pruinose or not, when hygrophanous may or may not be translucent-striate (but always non-striate when pruinose), colours when fresh/moist white, buff, various shades of brown from pale alutaceous to dark sepia (rarely fleshcoloured), or grey, in one species \pm aerugineous, colour sometimes changing somewhat when drying (in one species even sordid pinkish in exsiccates), plane to slightly depressed, or deeply depressed, or umbilicate, or infundibuliform when adult; margin thick to thin, often inrolled, especially when young, often pruinose; surface usually dry, sometimes \pm slightly viscid, sometimes shining, mostly smooth and \pm glabrous, sometimes finely fibrillose-reticulate under lens, or areolate, rarely scaly, in exsiccates often concentrically (tangentially) wrinkled if flesh is thin in pileus, traces of veil always lacking; under ultra-violet light in exsiccates pale to deep violet.

Stipe length ranging from a copule of centimetres to about $15 \mathrm{~cm}$, only rarely distinctly longer than diameter of pileus, diameter of stipe varying from a few to almost 60 millimetres, hygrophanous or not, concolorous with pileus or paler, even white, equal or upward (rarely downward) tapering, extreme base obtuse to truncate, or acute, or slightly radicate, solid, often becoming hollow in age, straight to somewhat curved, terete, sometimes compressed; surface dry, sometimes shining, often longitudinally fibrillose, distinct traces of veil always lacking, but some mealy covering may occur at apex; \pm whitish (rarely brownish) tomentum present at base of stipe, often \pm hyaline mycelial hairs (often chloric-greenish under ultra-violet light in exsiccates) and white rhizoids, too; stipe pale to deep violet under ultra-violet light in exsiccates, sometimes with chloric-coloured reflection.

Lamellae short to long decurrent, sometimes narrowly to broadly adnate, rarely somewhat sinuate, perhaps always weakly hygrophanous, colour variable, usually concolorous with pileus or a paler shade of the same colour, being white, buff, yellowish, brownish, various shades of brown, grey, rarely \pm aeruginous, sometimes changing colour when drying to yellow or sordid pinkish, lamellae and lamellulae more or less distinctly arranged in ca. 3-5 verticils, mostly about $3-6 \mathrm{~mm}$ broad at the broadest point, which is usually in the middle, or at proximal end (near stipe), not forked, some- 
times anastomosed at bases, not changing colour when bruised; ultra-violet reaction in exsiccates either negative, or more or less chloric-coloured, or violet.

Flesh continuous in pileus and stipe, hygrophanous or not, white or faintly tinged with buff, brown, or grey, conspicuous autoxydation reactions lacking, but often rusty tints occurring at the base of stipe, or when under ultra-violet light in exsiccates pale to deep violet, very rarely with some chloric tint.

Odour very variable, fungoid, or fragrant in many different ways, or farinaceous etc., usually present in fresh fruit bodies only.

Taste usually mild, fungoid with different faint flavours, or farinaceous, in two species at least more or less bitter, exsiccates more or less tasteless.

Spores ranging in length from $3.0 \mu \mathrm{m}$ to ca. $11.5 \mu \mathrm{m}$, though most of them always shorter than $10.0 \mu \mathrm{m}$, amplitude of breadth 1.9 to $6.5(-8.0) \mu \mathrm{m}$, single in mounts when taken from deposit, but either single or in tetrads (and dyads) if preparation is made from piece of lamella, spore base of three types, broadly rounded, obtuse and distinct from apiculus, or acute, \pm pointed towards distinct and separate apiculus, or confluent with apiculus, which is then not distinct, distal end (apex) always obtuse, almost always even broadly so, spore shape very variable but more or less constant within species, mostly \pm elliptical, often lacrymoid, or oblong or ovate, or obovate, very rarely globose, spores always very thin-walled and completely smooth, neither amyloid nor dextrinoid, supra-apicular region always at least applanated, sometimes even depressed, spore contents homogeneous, or heterogeneous and \pm guttulate, apiculus always oblique and with truncate end, always equal when distinct from sporoid, its length (when distinct) ranging from ca. 0.4 to $1.1 \mu \mathrm{m}$, and the breadth of apiculus/apicular region from ca. 0.3 to $1.3 \mu \mathrm{m}$; spore deposit mostly pure white, otherwise very pale yellow, very pale yellow with greyish tint, deep yellow, or pinkish buff, deposits always dark brown under ultra-violet light.

Basidia relatively small, ca. $15-30(-40)$ $\times 4.0-6.0(-8.0) \mu \mathrm{m}$, always \pm clavate, very thin-walled, smooth, neither amyloid nor dextrinoid, lacking siderophilous granulation, having a clamp connection at their bases (except for $C$. harperi), most of them always with four sterigmata.

Cystidia always lacking in all parts of the lamella (very rarely occasional inconspicuous cheilocystidia may be present), all other elements other than basidia, e.g. pseudocystidia, also absent.

Epicutis always present, always composed of filamentous hyphae, these being thinner (ca. 2.0-6.0 $\mu \mathrm{m}$ in diameter) than those of the pileus trama, mostly \pm parallel with each other and pileus surface, sometimes interwoven, contain almost always intracellular pigment, only very rarely with fine encrusted pigment, rarely somewhat gelatinized, in $C$. hydrogramma with vesiculose elements, pilocystidia always lacking; subcutis often differentiated, its construction being very like that of epicutis; pileus trama composed of thin-walled to very thin-walled, filamentous to slightly inflated hyphae, these having an average diameter of 5-15 $\mu \mathrm{m}$, and always being tightly packed and parallel in the lowest part, elsewhere interwoven to parallel, lactiferous hyphae often present, brown membranal pigment present or absent, fine encrusted pigment only occasionally present, large encrusted crystals, \pm localized in zones, sometimes present, intercellular pigment occasionally present, a clamp connection evidently at each septum in pileus (except in C.harperi, in which clamps are totally lacking to few).

Basal tomentum, mycelial hairs, and rhizoids composed of thin (ca. 2.0-7.5 $\mu \mathrm{m}$ in diameter) filamentous, \pm thin-walled hyphae, neither amyloid nor dextrinoid, clamped at each septum (except in C.harperi), being \pm interwoven in tomentum, but parallel in mycelial hairs and rhizoids.

Lamellae composed of hymenium, ramose subhymenium, \pm indistinct hymenopodium and \pm parallel (in C.clavipes \pm interwoven) gill trama, the hyphae of the lastnamed being filamentous, ca. $4.0-11.0 \mu \mathrm{m}$ in diameter, and only rarely somewhat inflated, fine encrusted pigment only occasionally present, lactiferous hyphae sometimes present; no element of lamella amyloid or dextrinoid (see, however, p. 28) or gelatinized; a layer, evidently homologous with the gill trama, always present between gill bases and lowest layer of pileus (see p. 28-29).

In the sole species cytologically studied by the present author, somatic cells binucleate, 
mature spores uninucleate, and the spindle of the first metaphase of meiosis \pm horizontally situated.

Occurring in various kinds of forest, from dry, meagre heath forest to grass-herb woodland, not infrequently in habitats where some human influence is evident, sometimes in more or less open, dry plant communities, e.g. above the forest limit in alpine vegetation or in man-made habitats (roadsides, fields, rubbish dumps, lawns etc.), never in wet or moist habitats (swamps, bogs, wet meadows etc.), usually in litter, mostly that of trees, a few species on various kinds of bare soil (never on peat, however), very rarely on charcoal, never (or only a few species occasionally) on decaying wood, evidently never in obligate association with living green plant, relation of occurrence to lime contents of soil very variable; on the whole, the fruiting of the genus extends throughout the year, culminating in September and October; occurring in all the vegetation zones from the temperate to the lower parts of the oroarctic (alpine), often avoiding districts with a very oceanic climate, the greatest number of taxa being found in the hemiboreal and southern boreal zones.

\section{Subgenus 1. Clitocybe}

Typus: Agaricus nebularis [Batsch] Fr., the lectotype of the genus.

Pileus very large to small, non-hygrophanous or hygrophanous, pruinose or not, usually not translucent-striate even if hygrophanous, dark to pale brown, grey, \pm cinnamon to almost orange, or flesh-coloured to white, plane to infundibuliform when adult; surface dry to slightly viscid, being dry in most species, smooth, rarely areolate or scaly. Stipe, besides basal tomentum, sometimes with rhizoids, too, sometimes also with often inconspicuous and inconstant, hyaline, slender mycelial hairs, in three species firm, \pm hyaline, compressed mycelial hairs present, in exsiccates all mycelial elements violet under ultraviolet light expect in section Clitocybe (= C. nebularis), in which chloric-greenish. Lamellae of different colours, greyish or brownish to white (white to buff in species with a hygrophanous pileus), sometimes changing colour when drying (then even being yellow when dry), in exsiccates pale under ultraviolet light, i.e. yellowish to dirty brownish, sometimes with additional chloric-tinged reflection. Odour variable, fungoid, fragrant in many different ways, farinaceous, etc., often persisting in exsiccates. Taste mild, \pm fungoid, sometimes farinaceous. Spores small to very large, all to most of them single in preparations, but the great majority in tetrads in preparations made of lamellae in section Clitocybe, of very different shapes, spore base obtuse, acute, or confluent, apiculus/ apicular region small to large (up to $1.3 \mu \mathrm{m}$ in diameter); spore deposit pure white, or very pale yellow, $9 \mathrm{~B} 1$ (or paler), or deep yellow, between $9 \mathrm{G} 1$ and 9 G 2. Membranal pigment absent or present in hyphae of pileus trama, e.g. totally lacking in all species with a hygrophanous pileus (i.e., in sections Candicantes, Vernae, and Bulluliferae); lactiferous hyphae often present in pileus and gill trama; clamps always present except in C. harperi, in which there are none or few. In various kinds of forest, or outside them, in different types of litter, infrequently on bare soil, often on calcareous ground, sometimes in habitats influenced or created by man; throughout the year, especially in summer and autumn.

Section I. Alexandriformes Harmaja, n. sect.

Fructificationes carnosae; pileus non hygrophanus, saepe (semper?) pruinosus; odor non gratus; sporae solitarii, basi obtusa, haud lacrymoideae, apiculo \pm parvo, sporarum massa alba vel indistincte flavida; fibu- lae occurrunt vel nullae. - Holotypus: Clitocybe alexandri (Gill.) Konr.

Pileus large, about $5-20 \mathrm{~cm}$ broad, not hygrophanous, often (always ?) pruinose, colours as a rule not very dark, with predom- 
inantly brown and grey tinges, plane to shallowly depressed when adult, only occasionally broadly infundibuliform; margin strongly inrolled for a long time, becoming horizontal at most in old fruit bodies; surface often weakly viscid, often partly areolate. Stipe clavate to cylindrical, in addition to tomentum, slender, hyaline mycelial hairs and white rhizoids sometimes present at its base. Lamellae decurrent to somewhat sinuate, rather concolorous with pileus and stipe. Flesh thick, not truly hygrophanous but often partially (rarely almost totally) watery in adult and old fruit bodies. Odour resembling that of caraway, or raddish (being raw and disagreeable), or fungoid, never sweet, often persisting in exsiccates. Taste mild, fungoid. Spores of different sizes, always practically all single in preparations, all obtuse-based, of different shapes but most of them always broadest in the middle, never lacrymoid, plage applanated to distinctly depressed, most \pm guttulate, with small to medium-sized apiculus (ca. 0.9 $\mu \mathrm{m}$ long, and ca. $0.7 \mu \mathrm{m}$ broad, at most); spore deposit \pm pure white to very faintly pale yellow, but never reaching the degree of 9 B 1. Subcutis distinct to indiscernible; membranal pigment present in tramal hy-

1. Clitocybe alexandri (Gill.) Konrad, Bull. Soc. Mycol. France 43: 186. $192 \%$.

Basionym: Lepista alexandri Gillet, Les hyménomycètes ..., 196. 1874. - Typus: No original designation. No material of Gillet in PC. I have not examined material from France. A neotype has not been designated.

Figs. 8, 38, 86.

Pileus 6-21 cm broad, not hygrophanous, pale brown (11 B 6, $11 \mathrm{D} \mathrm{6}$ ) because of pruina, ground colour darker brown with red tint (13 G 8), in exsiccates colour somewhat darker, 11 D 5, 12 D 6, 12 E 5, 12 E 6, at first convex, becoming plane to somewhat depressed, finally sometimes very broadly infundibuliform; margin strongly inrolled at first becoming horizontal only in old fruit bodies, in age undulate, extreme margin white pruinose; surface usually slightly viscid, the margin excluded, areolate, the darker areolae becoming smaller towards the disc, sometimes low radiate ridges at the phae, encrusted pigment sometimes present on hyphae of epicutis; clamps present at each septum, or absent from many to all. In litter, in grass-herb to mesic heath forests, especially in districts with calcareous soils; from middle of August to end of November. Temperate to middle boreal, but lacking in districts with very oceanic climate.

Discussion. The old section Disciformes (Fr.) is far too heterogeneous to be acceptable as such even in its modern sense, and I have been forced to divide it into smaller, rather natural sections. The present section includes the subsection Inornatinae (Sing.) (Singer 1948). Since the type species of this taxon ( $C$. inornata) deviates from the two other species of my section Alexandriformes in having rather peculiar spores and more or less conspicuous mycelial hairs and rhizoids, I have not been willing to raise the rank of this subsection and accept $C$. inornata as the type species of the present section. This species may, however, deserve a subsection of its own because of the characters mentioned above, but until I have examined more extensive material, e.g. some $\mathrm{N}$. American species, I prefer not to accept SiNGER's subsection.

very margin, sometimes with darker roundish watery spots near the margin.

Stipe 6-12 × 12-50, concolorous with pileus or slightly paler, enlarging downwards, often abruptly at the base, solid, terete or slightly compressed; surface mat, at times fibrillose especially at the apex; basal tomentum copious (even $1 \mathrm{~cm}$ thick) and whitish, short very slender mycelial hairs occurring very occasionally at the upper part of the tomentum, a few rhizoids usually present, too internal cavities sometimes present.

Lamellae often shallowly sinuate in both young and old fruit bodies with acute decurrent teeth, sometimes decurrent with straight edges, angle of attachment $45^{\circ}$ at most, slightly paler than pileus when moist $(10 \mathrm{~F} 4)$, in exsiccates somewhat paler $(10 \mathrm{~F} 2,10 \mathrm{~F} 3,10 \mathrm{~F} \mathrm{4}$ ), in young pilei in 3 , in adult and old ones in 4 to 6 verticils, 70 -90 reach the stipe, being broadest around their distal end, 4-12 $\mathrm{mm}$, in the middle about as broad as overlying context is thick, at times slightly forked near stipe, 
intervenose right from the beginning, sometimes very distinctly so, forming "phylloporus pattern on the stipe apex.

Odour like that of caraway-seeds (C.arum carvi), sometimes persisting in exsiccates for several months.

Taste mild, fungoid.

Spores $5.5-7.5(-8.7) \times 3.5-5.0 \mu \mathrm{m}$, single in all preparations, often rather variable in size and shape, all obtuse-based, most broadly elliptical, the rest being oblong, obovate, or ovate, plage applanated to slightly depressed, most with one large guttule the rest being irregularly guttulate or with homogeneous contents, apiculus ca. $0.7-0.9 \times$ $0.5-0.7 \mu \mathrm{m}$; spore deposit almost pure white (in thick deposits with a faint yellowish tinge, but distinctly paler than 9 B 1).

Anatomy of cortex of pileus. Epicutis 50$300 \mu \mathrm{m}$ thick, hyphae more or less interwoven, sometimes in fascicles (= areolae?), 2.5-9.5 $\mu \mathrm{m}$ in diameter, membranal and rich intracellular pigments present; subcutis distinct, $100-200 \mu \mathrm{m}$ thick, hyphae \pm parallel, 3.5-7.0 $\mu \mathrm{m}$ in diameter, pigments as in epicutis but intracellular pigment less abundant.

Ecology. In arcs and rows, usually in coniferous mesic heath forest (e.g., OMT, MT), almost always in litter of Picea, rarely Pinus, or Quercus, or mixed litter of Picea and deciduous trees, often together with Hylocomium, Pleurozium, or Rhytidiadelphus triquetrus, often in districts with calcareous soils. From middle of August to end of November (Fig. 5).

Distribution. Temperate to middle boreal, but lacking in districts with very oceanic climate, up to ca. $150 \mathrm{~m}$ (S. Norway; central Sweden). Rare. (Fig. 131).

Specimens examined.

Norway: Hedmark. Furnes (1). - Buskerud. Røyken (1). - Telemark. Porsgrunn (1).

SWEDEn: Öland. Böda (1). - Gotland. Othem

(1); Västerhejde (1). - Halland. Ö. Karup (1). - Värmland. Dalby (8). - Södermanland. Södertälje (1); Västerljung (1); Ytterenhörna (1). - Uppland. Adelsö (1); Bälinge (1); Börje (2); Djurö (8); Riala (1); Stockholm (1); Sånga (1); Uppsala (9); Älvkarleby (2); Ärentuna (2).

FrnLAND: Varsinais-Suomi. Lohja mlk. (5); Turku (1). - Etelä-Häme. Lammi (2); Tammela (2). - Pohjois-Pohjanmaa. Kiiminki (2).

Discussion. For differences between the present species and the obviously nearly related $C$. harperi, see under the latter.
The breadth of the pileus is usually larger in Fennoscandian specimens than the measurements given in the literature. E. g., BIGELow (1965: 149) gives the breadth as 5-10 $\mathrm{cm}$ in North America, and Lange (19351940, Vol. I: 74) cites the values 7-12 cm from Denmark.

According to Konrad \& Maublanc (1924 -1937, Vol. 3: 291), C. alexandri occurs especially on calcareous soil, but FAVRe (1960: 419) does not mention such a preference.

2. Clitocybe harperi Murrill, Mycologia 5: 209. 1913.

Typus: Holotype (U.S.A., California, leg. Harper 57; NY) examined.

Figs. 39, 87.

Pileus 5-15 cm broad, convex or plane with a strongly inrolled margin, becoming shallowly depressed, in age the margin elevated and frequently lacerated or irregular, remaining inrolled for some time, surface smooth and glabrous at first but appressed felty-fibrillose if viewed under a lens, disc becoming more or less fibrillose-furfuraceous, typically dry, when water-soaked appearing subhygrophanous, occasionally mottled with large watery spots, color sordid and near «vinaceous buff« at first, more alutaceous when moist or water-soaked, fading to «tilleul buff«, gradually becoming grayish in age, old caps sometimes sordid drab; flesh thick, $\pm 15 \mathrm{~mm}$ near the stipe, tapered evenly to the margin, pallid but gradually becoming grayer in age, odor and taste not distinctive or sometimes rancid-farinaceous.

Lamellae adnate but soon becoming decurrent, crowded to close, narrow (4-5 $\mathrm{mm}$ ), somewhat intervenose, pallid when young («tilleul buff«) but gradually cinerescent, in age pale dirty gray to dark sordid brownish, edges even.

Stipe 5-10 $\mathrm{cm}$ long, $1-3 \mathrm{~cm}$ thick at apex, clavate or equal, solid (pallid within), surface uneven, unpolished to appressed fibrillose, concolorous with pileus and discoloring in the same manner, becoming quite sordid with age.

Spores $4.5-6.5 \times 2.9-3.6 \mu \mathrm{m}$, almost all single in preparations, all obtuse-based, most elliptical to oblong, the rest ovate, or (very 
few) obovate, most indistinctly guttulate with minute internal drops, the remaining few with one guttule or homogeneous contents, apiculus ca. 0.5-0.7 × 0.3-0.4 $\mu \mathrm{m}$; spore deposit white according to Bigelow (1965).

Anatomy of cortex of pileus. Epicutis rather indistinct, ca. $15-50 \mu \mathrm{m}$ thick, hyphae parallel to somewhat interwoven, $2.5-5.0$ $\mu \mathrm{m}$ in diameter, intracellular pigment present and probably membranal pigment, too; subcutis not differentiated.

Ecology. Mostly in grass-herb forest, especially on calcareous ground, on various kinds of litter (Picea, Alnus incana, Betula, etc.) From middle of August to end of September (Fig. 5).

Distribution. Hemiboreal to middle boreal, in eastern parts of the area, up to ca. $100 \mathrm{~m}$ (S. Finland). Very rare. (Fig. 132).

\section{Specimens examined.}

Sweden: Gotland. Visby (1). - Uppland. Bondkyrka (3); Munsö (1).

Finland: Etelä-Häme. Tammela (9). - Pohjois-Karjala. Säyneinen (1). — Pohjois-Pohjanmaa. Kiiminki (4); Muhos (1).

Discussion. I have not collected this species myself, so the descriptions of the macroscopic characters and odour and taste have been cited from Bigelow (1965).

Though the present species usually lacks clamps, (sometimes scattered ones present in various parts of the fruit body, see p. 25, 27 , and 28) being the sole clampless species of Clitocybe in the present study, I prefer not to describe a new section or subgenus for it but to place $C$. harperi in the same section with $C$. alexandri and $C$. inornata, with which it has a good many features in common. It is easy to distinguish from these two species by the different clamping, smaller and more or less differently shaped spores, and the crowded and very narrow gills.

The pileus colour seems to darken with age, and the margin is also strikingly inrolled even in rather old fruit bodies. These may both be constant characteristics.

The type specimen of $C$. harperi lacks clamps in the pileus trama, gill trama, basal tomentum, and at the bases of the basidia. Besides the type specimen, I have also seen a specimen in much better condition, collected from Washington in the west of the U.S.A. and determined by H. E. Bigelow. It did not reveal any clamps, eiher. Except for occasional, scanty occurrences of clamps, the Fennoscandian specimens were both macroscopically and microscopically in perfect agreement with these North American ones.

This is perhaps the first time that C. harperi is reported from Europe, or outside N. America.

3. Clitocybe inornata ([Sow.] Fr.) Gillet, Les hyménomycètes..., 155. 1874.

Basionym: Agaricus inornatus [Sow.] Fries,
Syst. Mycol. 1: 93. 1821. - Typus:
No original designation. No material of
Frres existing, and none of SowERBY
in K. I have examined material from
England belonging to the present spe-
cies. A neotype has not been designated.

Figs. 9, 40, 88.

Pileus 6-10 $\mathrm{cm}$ broad, not hygrophanous, pale brown or greyish because of pale pruina (9 C 2, 9 D 4, $10 \mathrm{E} \mathrm{4,11} \mathrm{D} \mathrm{6,} 11$ B 2), ground colour reddish brown (12 G 7), at first convex, becoming broadly but shallowly depressed, rarely indistinctly gibbous; margin inrolled for a long time, finally horizontal or somewhat elevated, extending slightly further than the distal ends of lamellae; surface dry or slightly viscid, smooth but sometimes with low radiate ridges at the margin.

Stipe 5-8 $\times 7$-13, more or less concolorous with pileus, equal or indistinctly clavate, extreme base attenuated, solid, cylindrical or somewhat compressed; surface dry, mat, with fibrillose coating; at the base copious tomentum, at the upper part of tomentum often hyaline \pm slender mycelial hairs, rhizoids almost always present.

Lamellae at first adnate, then short decurrent, the angle of attachment being ca. $40^{\circ}-60^{\circ}$, usually some of them (sometimes even all) shallowly sinuate, pale brown, $10 \mathrm{~B} 2$ when moist, 9 D 4, 9 E 5, 10 B 2, $10 \mathrm{D} 3$ when dry, in 4 verticils, $50-60$ reach the stipe, being broadest in the middle or towards the stipe, $7-8 \mathrm{~mm}$, in the middle $2.5-3$ times broader than overlying context is thick, some of them forked near stipe, slightly intervenose even when young.

Odour either like that of caraway-seeds (Carum carvi), or disagreeable, raw and raddish-like (persisting for years), rarely more or less fungoid only.

Taste mild, fungoid. 
Spores $7.5-10.5 \times 3.0-4.2 \mu \mathrm{m}$, single in all preparations, all obtuse-based, narrowly fusiform to subfusiform (rarely a good number of them oblong to almost cylindrical), in face view broadest in the middle or near the base, in side view very inequilateral, apical end obtuse but narrower than the basal, plage indistincly to very distinctly depressed, indistinctly guttulate with small drops, apiculus ca. $0.7-0.8 \times 0.5-0.7 \mu \mathrm{m}$; spore deposit \pm pure white.

Anatomy of cortex of pileus. Epicutis 50$150 \mu \mathrm{m}$ thick, hyphae more or less interwoven, 2.5-6.0 $\mu \mathrm{m}$ in diameter, intracellular and membranal pigments present, most hyphae often encrusted, too, sometimes large intercellular pigment crystals present; subcutis $45-65 \mu \mathrm{m}$ thick, hyphae interwoven to practically parallel, $3.5-7.0 \mu \mathrm{m}$ in diameter, pigment as in epicutis but encrusted pigment lacking and intracellular pigment less abundant.

Ecology. Solitary, in groups, or arcs, in grass-herb forest, sometimes in the most productive mesic heath forest, rarely in drier woods, occurring especially on calcareous ground, mostly in litter of Picea, rarely Alnus incana, or Pinus, sometimes in moss (e.g.
Hylocomium) in shady depressions in rocks. From middle of September to end of October (Fig. 5).

Distribution. Hemiboreal to middle boreal, but lacking in districts with very oceanic climate, up to ca. $100 \mathrm{~m}$. Uncommon. (Fig. 133).

\section{Specimens examined.}

Norway: Akershus. Asker (3); Oslo (1). Buskerud. Røyken (2).

Sweden: Gotland. Hejdeby (1). - Södermanland. Julita (1). - Uppland. Djurö (2); Uppsala (2); Älvkarleby (1). - Angermanland. Sollefteå (2).

Finland: Varsinais-Suomi. Lohja mlk. (6); Parainen (1); Pusula (1). - Uusimaa. Helsinki mlk. (1). - Etelä-Häme. Kuhmoinen (1); Tammela (3). - Keski-Pohjanmaa. Kälviä (1). Pohjois-Pohjanmaa. Kiiminki (2).

Discussion. A pale brown or grey species with a slender stipe, easily identified by the \pm fusiform spores with a depressed plage.

There is evidently some genetic variation in the manner in which the lamellae join the stipe, in the odour, and in the size and shape of the spores.

The rhizoids appear to constitute a rather constant character, and have also been observed by Bigelow (1965) and KonRAD \& Maublanc (1924-1937, Vol. 3: pl. 294).

\section{Section II. Clitocybe}

Typus: Agaricus nebularis [Batsch] Fr., the lectotype of the type subgenus.

Pileus large, about $10-25 \mathrm{~cm}$ broad when adult, not hygrophanous, pruinose, colours dark, brown to dark grey, occasionally pale to \pm white, plane to somewhat depressed when adult; margin usually remaining moderately inrolled for a rather long time; surface dry, fibrillose-reticulate under lens, not areolate. Stipe clavate or cylindrical, base without rhizoids, but besides tomentum in rare cases with a few hyaline, slender mycelial hairs, both mycelial elements in exsiccates chloric-greenish under ultra-violet light. Lamellae decurrent, not sinuate, usually clearly differentiated in colour from pileus and stipe. Flesh thick, not hygrophanous. Odour with strong sweet component persisting in exsiccates for a long time. Taste mild with somewhat sweetish flavour. Spores large, the great majority in tetrads in preparations made of lamellae, always obtusebased, mostly elliptical, never lacrymoid, plage applanated to distinctly depressed, mostly guttulate, with a rather small (ca. $0.6-0.7 \times 0.4-0.5 \mu \mathrm{m}$ ) apiculus; spore deposit deep yellow, between $9 \mathrm{G} 1$ and $9 \mathrm{G} 2$ in thick deposits. Subcutis distinct; membranal pigment at least sometimes present in hyphae of pileus trama, encrusted pigment entirely absent from pileus. In litter, especially that of deciduous trees, sometimes on bare soil, especially in grass-herb forests and on calcareous ground, often in habitats influenced by man; from end of August to end of November. Temperate to middle boreal.

Discussion. The spore and colour characters, and probably the chloric-coloured ultraviolet fluorescence of some parts of the dried basidiocarp of C. nebularis (see also p. 19), justify considering this species to constitute a section of its own.

Since $C$. nebularis is considered to be the type species of the genus in the present study 
(see p. 12), the sectional name Disciformes (Fr.) unfortunately becomes a synonym of the sectional name Clitocybe, for C.nebularis

4. Clitocybe nebularis ([Batsch] Fr.) Kummer, Der Führer in die Pilzkunde, 124. 1871.

Basionym: Agaricus nebularis [Batsch] Fries, Syst. Mycol. 1: 86. 1821. - Typus: No original designation. No material of FrIES existing, and none of BATSCH in $\mathrm{JE}$. I have not examined material from Germany. A neotype has not been designated.

Synonyms: Clitocybe stenophylla Karsten, Hedwigia 20: 177. 1881. - Typus: Holotype (Herb. P.A. Karsten no. 221, Finland, prov. Etelä-Häme, par. Tammela, Mustiala X. 1881, leg. P. A. Karsten; $\mathrm{H}$ ) examined.

Clitocybe nebularis* $\left.{ }^{*}=\mathrm{ssp}.\right]$ stenophylla (Karst.) Karsten, Acta Soc. Fauna Flora Fennica 2: 6. 1881.

Clitocybe nebularis v. stenophylla (Karst.) Karsten, Medd. Soc. Fauna Flora Fennica 9: 41 (Symb. mycol. fennicam 9). 1882.

Figs. 10, 41, 89.

Pileus $10-25(-30) \mathrm{cm}$ broad, not hygrophanous, totally covered by pale pruina which is most distinct over disc, grey-brown, $13 \mathrm{~B} \mathrm{5,} 13 \mathrm{E} 6,14 \mathrm{E} 6$, when fresh, rarely whitish, disc darker, 8 A 10 , in exsiccates mostly 11 B 2, 12 B 6, 12 C 7, 13 B 3, 14 B 5, disc 12 B 5, 12 B 6, 14 B 3, or even as dark as $8 \mathrm{~A} 8$ or $16 \mathrm{C} 8$, convex at first, becoming plane and somewhat depressed, finally sometimes even vase-shaped; margin inrolled for a long time becoming more or less horizontal in old fruit bodies; surface dry, mat, faintly fibrillose-reticulate under lens.

Stipe 5-9 $\times 12-55$, concolorous with pileus or somewhat paler and greyer, \pm clavate or equal, extreme base truncate or obtuse, mostly solid even in old fruit bodies, cylindrical; surface dry, with indistinct fibrillose coating; basal tomentum scanty to rather abundant, very rarely strigose, slender, hyaline mycelial hairs at the upper part of the tomentum.

Lamellae moderately decurrent even when young, angle of attachment becoming wider with age, being ca. $45^{\circ}-60^{\circ}$ in old basidiocarps (ca. $20^{\circ}-30^{\circ}$ in young ones), yellowish, becoming slightly darker in age, $9 \mathrm{~B} \mathrm{3}$, $9 \mathrm{D} 2,10 \mathrm{D} 2$ when moist, $12 \mathrm{H} 7,12 \mathrm{H} 8$ is the lectotype of Disciformes (e.g. according to Singer 1962: 231).

in exsiccates (or even paler), in 4 or 5 verticils, very close, thin, $110-150$ reach the stipe, being broadest in the middle or distally, 8-11 $\mathrm{mm}$, in the middle about as broad as overlying context is thick (in young pilei, however, the breadth may be only a half or a third of the thickness of the context), sometimes with small red spots near edges.

Odour in fresh fruit bodies strong, sweet, resembling that of Swedish turnip, sometimes with disagreeable rancid flavour when bruised, in old and dried basidiocarps sweet, honey-like, persisting for decades in exsiccates.

Taste mild, fungoid, with sweetish flavour. Spores 6.0-8.3 $(-9.5) \times 3.2-4.3 \mu \mathrm{m}$, the great majority in tetrads in preparations made of lamellae, always some proportion (sometimes all) with shrunken walls and without contents, all obtuse-based, most elliptical, the rest obovate and oblong, plage applanated to distinctly depressed, with one large drop or many small ones, apiculus ca. $0.6-0.7 \times 0.4-0.5 \mu \mathrm{m}$; spore deposit deep yellow, thin deposits $9 \mathrm{~B} 1$, thick ones between $9 \mathrm{G} 1$ and $9 \mathrm{G} 2$.

Anatomy of cortex of pileus. Epicutis distinct, 55-120 $\mu \mathrm{m}$ thick, hyphae interwoven to almost parallel, $2.0-5.0 \mu \mathrm{m}$ in diameter, intracellular pigment present, sometimes membranal pigment, too; subcutis 90-230 $\mu \mathrm{m}$ thick, distinct under the microscope, being seen as the darkest layer of the pileus section, hyphae more or less parallel, 3.0$8.0 \mu \mathrm{m}$ in diameter, pigmentation as in epicutis, but intracellular pigment scanty, and intercellular crystals sometimes present.

Ecology. Mostly in arcs and rows with abundant fruit bodies, rarely solitary, in grass-herb forest, sometimes in mesic, rarely in dry heath forest, often on calcareous ground, in litter of various deciduous and coniferous trees (Acer, Alnus incana, Betula, Corylus, Fagus, Fraxinus, Quercus, Larix sibirica, Picea, Pinus), sometimes among mosses (especially Rhytidiadelphus triquetrus), of ten more or less removed from woodland in pastures, gardens and on compost heaps, and then often in herbaceous litter, sometimes among Urtica dioeca, some- 
times on more or less bare, fertile soil, very often within the sphere of human influence, or even in man-made habitats. From latter half of August to end of November (Fig. 5).

Distribution. Temperate to middle boreal, up to $450 \mathrm{~m}$ (S. Norway). Rather common. (Fig. 134).

Specimens examined.

Norway: Østfold. Rygge (1). - Akershus. Asker (1); Baerum (1); Oslo (3); Skedsmo (1). - Buskerud. Drammen (1); Hole (1); Hurum (2); Nes (2); Norderhov (2). - Vestfold. Borre (1); Horten (1). - Telemark. Eidanger (2); Gjerpen (1); Porsgrunn (1). - Hordaland. Fana (3); Granvin (2); Voss (5). - More og Romsdal. Molde (1). - Sør-Trøndelag. Malvik (1); Melhus (1); Statsbygd (1); Trondheim (1). Nord-Trøndelag. Frosta (1); Stjørdal (1); Verdal (1).

SwEDEN: Skåne. Ivetofta (1); Silvåkra (1). Blekinge. Nättraby (1). - Småland. Femsjö (3); Nässjö (3). — Gotland. Buttle (1); Lummelunda (2); Martebo (1); Stenkyrka (1); Västerhejde (1). - Ostergötland. Skedevi (1). - Västergötland. Göteborg (13); S. Kedum (1). Bohuslän. Orust (1); Uddevalla (1). - Värmland. Dalby (2). - Södermanland. Trosa (1). Uppland. Bondkyrka (1); Börje (1); Djurö (2); Ljusterö (1); Stockholm (1); Uppsala (5, including Lundeli \& NANNFELDT: «Fungi Exsiccati Suecici...«, no. 6, in UPS); Ärentuna (1). Gästrikland. Gävle (1). - Angermanland. Sollefteå (2). - Västerbotten. Umeå (1). - Norrbotten. Nedertorneå (2); Övertorneå (1).

Finland: Varsinais-Suomi. Aura (1); Bromarv (1); Karjalohja (2); Laitila (1); Lieto (3); Lohja (1); Lohja mlk. (12); Lokalahti (1); Nauro
(1) ; Parainen (2); Piikkiö (1); Pohja (1); Pöytyä (1); Turku (11); Uusikaupunki mlk. (1). Uusimaa. Elimäki (1); Espoo (4); Helsinki (9); Helsinki mlk. (2); Kauniainen (5); Kirkkonummi (1); Porvoo (9); Tuusula (2). - Etelä-Karjala. Virolahti (1). - Satakunta. Lappi (2). Etelä-Häme. Asikkala (1) ; Jämsänkoski (1); Lammi (2); Somero (3); Tammela (2); Tampere (1). - Etelä-Savo. Sääminki (1). - Pohjois-Häme. Petäjävesi (1); Virrat (2). - Pohjois-Savo. Iisalmi (2); Joroinen (1); Kuopio (5); Vieremä (1). - Pohjois-Karjala. Juuka (1). - Pohjois-Pohjanmaa. Kiiminki (3); Oulu (2).

U.S.S.R.: Leningrad Region. Vyborg (Viipuri mlk.) (2).

Discussion. As with C. alexandri, the measurements given in the literature for this species are smaller than those of the present material.

It is evidently the more or less albino mutant that has been called C. alba (Bat.) (or C.nebularis v. alba), and C.robusta Peck, especially in N. America, but according to the Fennoscandian material the whitish form shares all the diagnostic characters of the typically coloured form, such as the odour, the colour of the spore deposit, and the other peculiar spore characters.

According to the label, a specimen from Sweden, Gamla Uppsala parish, was collected as early as on July 9, but I have excluded this specimen because it would be difficult to check whether there is an error in the date or not.

\section{Section III. Clavipedes Harmaja, n. sect.}

Pileus non hygrophanus nec pruinosus, colore obscuro, non infundibuliformis; caro hygrophana; odor gratus vel haud notabilis; sporae magnae, solitarii, basi obtusa vel acuta, ellipsoideae, nonnullae \pm fusiformes vel \pm lacrymoideae, maximum crassitudinis maximae partis earum ad partem medianam, apiculo magno, sporarum massa \pm alba. Holotypus: Clitocybe clavipes ([Pers.] Fr.) Kumm.

Pileus medium-sized, neither hygrophanous nor pruinose, colours dark, brown to brown-grey, plane to somewhat depressed when adult; margin somewhat inrolled in young pilei; surface dry, fibrillose-reticulate under lens, not areolate. Stipe \pm clavate, \pm concolorous with pileus, base with tomentum only. Lamellae decurrent, not sinuate, almost whitish when fresh, pale yellow when dry, always clearly differentiated in colour from pileus and stipe, somewhat thickish. Flesh thick, hygrophanous, fading evidently spreading from periphery towards the joint of pileus and stipe. Odour sweetish to \pm fungoid when fresh, sweetish in drying and persisting for some time in exsiccates. Taste mild, fungoid. Spores large, single in all preparations, obtuse- or acute-based, of varying shape but most broadest in the middle, a few \pm fusiform or \pm lacrymoid, plage applanated to distinctly depressed, uniguttulate, with a large apiculus (ca. 0.9-1.1 $\times$ $0.7-0.9 \mu \mathrm{m})$; spore deposit \pm pure white. Subcutis present; membranal pigment lacking in hyphae of pileus, encrusted pigment also absent. In litter in various kinds of forest; from beginning of August to middle of November. Temperate to northern boreal, occasionally even in the oroarctic zone.

Discussion. The spore and other charac- 
ters, not least the hygrophanous flesh, indicate that $C$. clavipes deserves a section of its own. The colours and spore characters suggest that Clavipedes is more or less nearly related to Infundibuliformes.

5. Clitocybe clavipes ([Pers.] Fr.) Kummer, Der Führer in die Pilzkunde, 124. 1871.

\section{Basionym: Agaricus clavipes [Pers.] Fries, Syst. Mycol. 1: 86. 1821. - Typus: No original designation. No material of Fries existing, and none of Persoon in L. I have not examined material from Germany. A neotype has not been designated.}

Figs. 11, 42, 90.

Pileus 5-10 $\mathrm{cm}$ broad, not hygrophanous, not pruinose, greyish brown to dark brown.

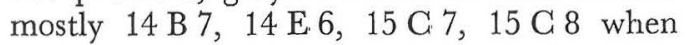
fresh, usually somewhat paler and greyer towards the margin, e.g. $13 \mathrm{~A} 4$, or browner, 12 D 3, in exsiccates mostly 13 B 4, 14 B 3, $15 \mathrm{C} 8$, slightly convex at first, becoming plane and usually slightly depressed, rarely even bowl-shaped in old basidiocarps; margin somewhat inrolled at first becoming horizontal to slightly elevated; surface dry, mat, faintly fibrillose-reticulate under lens, rarely mottled with darker spots near margin.

Stipe 2-10 $\times 8-30$, concolorous with pileus, sometimes slightly paler, clavate, the lower part often enlarging very abruptly, extreme base attenuated, solid; surface dry, \pm mat, fibrillose; only white tomentum at the base.

Lamellae moderately decurrent, angle of attachment $30^{\circ}-60^{\circ}$, whitish to faintly yellowish, rarely with buff tinges, in exsiccates very pale yellow to yellow (e.g. $9 \mathrm{G} 2$ ), $30-50$ reach the stipe, being broadest in the middle or nearer stipe, $5-7 \mathrm{~mm}$, in the middle somewhat broader than overlying context is thick, or equally broad, some of them often forked near stipe, thickish, not close, somewhat intervenose in age.

Odour faintly like that of Swedish turnip when fresh, in old fruit bodies sometimes like that of oil of bitter almonds, or Hygrophorus agathosmus (however, especially young basidiocarps may be odourless), in drying and dried fruit bodies sweet, honeylike, persisting for some time.

Taste mild, fungoid.

Spores $6.0-8.5(-11.0) \times 3.6-5.3 \mu \mathrm{m}$,
I have seen a specimen from N. America, labelled C. avellaneialba Murr., which seems to represent a valid, nearly related species, and accordingly belong to the present section.

single in all preparations, often very variable in size and shape, most obtuse-based and elliptical, subfusiform, or ovate, the rest with an acute base being \pm fusiform or (very few) \pm lacrymoid, plage applanated to distinctly depressed, with one large, distinct drop, apiculus ca. $0.9-1.1 \times 0.7-0.9$ $\mu \mathrm{m}$; spore deposit \pm pure white (in very thick deposits a very faint yellowish tint can be seen).

Anatomy of cortex of pileus. Epicutis 35$65 \mu \mathrm{m}$ thick, hyphae interwoven to almost parallel, 2.5-7.5 $\mu \mathrm{m}$ in diameter, only intracellular pigment observable (sometimes a few intercellular crystals, too); subcutis often indistinct, 35-70 $\mu \mathrm{m}$ thick, hyphae \pm parallel, 2.5-5.0 $\mu \mathrm{m}$ in diameter, pigment as in epicutis, but intracellular pigment scanty and intercellular lacking.

Ecology. Solitary, in groups or arcs especially in various kinds of dry and mesic heath forests, sometimes in grass-herb forests, at times in habitats affected by human activities, such as pastures and pathsides, usually in litter of Picea (rarely even among pieces of spruce bark), or Pinus, but not infrequently in that of Alnus incana, Betula, Fagus or Quercus, sometimes in herbaceous litter, once observed in needles of Pinus peuce, likewise in those of Abies sibirica and Larix decidua $\times$ leptolepis, often among Pleurozium, Hylocomium, and other mosses. From beginning of August to late November (Fig. 5).

Distribution. Temperate to northern boreal, sometimes even in the oroarctic (alpine) zone, but very rare or lacking in districts with very oceanic climate, up to ca. $1100 \mathrm{~m}$ (S. Norway). Very common. (Fig. 135).

\section{Specimens examined.}

Norway: Østfold. Moss (1). - Akershus. Oslo (4). - Oppland. Lom (1). - Buskerud. Nes (1); Norderhov (2). - Vestfold. Larvik (2). Telemark. Siljan (1). - Sør-Trøndelag. Trondheim (4). - Nordland. Bodø (1). - Troms. Lyngen (1); Nordreisa (2).

SwEDEN: Skåne. Sövde (1). - Blekinge. Karlskrona (1); Sölvesborg (1). - Småland. Almesåkra (4); Femsjö (6); Hallingeberg (1); Kärda 
(2) ; N. Solberga (1); Växjö (1). - Ostergötland. Skedevi (1). - Västergötland. Fässberg (2) ; Göteborg (5). - Halland. Fjärås (1); Onsala (2). - Bohuslän. Björlanda (3); Jörlanda (1); Romelanda (1); Uddevalla (1); Öckerö (1); Ödsmål (1). - Värmland. Dalby (3); N. Finnskoga (1); S. Finnskoga (3); N. Ny (1); Nedre Ullerud (1). - Södermanland. Österhaninge (1). - Uppland. Alsike (2, Lundell \& NANNFELDT: «Fungi Exsiccati suecici... no. 324, in S, UPS) ; Bondkyrka (6); Bälinge (1); Danderyd (1); Danmark (1); Djurö (1); Kårsta (1); Läby (1); Ǒ. Ryd (1); Solna (2); Stockholm (10); Sånga (1); Täby (1); Uppsala (5); Vallentuna (1); Össeby-Garn (1). - Västmanland. Köping (1). - Dalarna. Rättvik (1). - Gästrikland. Gävle (2). - Angermanland. Sollefteå (1). - Västerbotten. Umeå (12). - Norrbotten. Haparanda (1); Nedertorneå (1); Övertorneå (5). - Torne Lappmark. Jukkasjärvi (2).

FInLAND: Varsinais-Suomi. Karjalohja (3); Korppoo (3); Lieto (2); Lohja mlk. (6); Lokalahti (1); Masku (2); Merimasku (1); Piikkiö (1); Pohja (5); Raisio (1); Turku (7). - Uusimaa. Elimäki (2); Espoo (1); Helsinki (12); Helsinki mlk. (2); Kauniainen (2); Kirkkonummi (1) ; Porvoo (2); Porvoo mlk. (5); Siuntio (1); Tammisaari mlk. (1); Tuusula (4). - EteläKarjala. Hamina (1); Vehkalahti (3). - Satakunta. Lappi (1); Oripää (1); Yläne (2). Etelä-Häme. Hattula (1); Hollola (1); Jämsä (1); Jämsänkoski (2); Kuhmoinen (2); Lempäälä (1); Orivesi (1); Padasjoki (1); Pohjaslahti (1); Ruovesi (1); Somero (2); Tammela (6, including Karsten: «Fungi Fenniae Exsiccati«, no. 208, in H) ; Tampere (2). - Etelä-Savo. Imatra (2); Juva (1); Mäntyharju (1); Rantasalmi (1); Taipalsaari (1). - Laatokan Karjala. Parikkala (1); Simpele (1). - Etelä-Pohjanmaa. Alavus (1); Vaasa (1). - Pohjois-Häme. Toi- vakka (1); Virrat (9); Ähtäri (1). - PohjoisSavo. Iisalmi (1); Kuopio (3); Suonenjoki (1); Vieremä (2). - Pohjois-Karjala. Eno (2); Juuka (1); Tuupovaara (1). - Keski-Pohjanmaa. Kokkola (3); Kälviä (1). - Kainuu. Paltamo (1). - Pohjois-Pohjanmaa. Kiiminki (3); Muhos (2); Oulu (1). - Kuusamo. Kuusamo (1). - Inarin Lappi. Inari (2); Utsjoki (21).

U.S.S.R.: Leningrad Region. Vyborg (Viipuri mlk.) (1).

Discussion. Macroscopically and in odour rather similar to $C$. nebularis, but smaller, its stipe being more distinctly clavate, its gills paler, more sharply contrasting with the dark stipe, and being thicker and less close. The spores in $C$. clavipes occur singly in preparations, are differently shaped, never have shrunken walls, possess a larger apiculus, and are much paler in deposit. Previous mycologists have missed the peculiar spore characters of the present species (and those of $C$. nebularis) which alone allow identification.

There is some genetic variation in the proportion of the acute-based spores.

EKLUND (1943) claimed that $C$. clavipes was restricted to coniferous woods in his area of study, but this is not true for the whole of Fennoscandia.

There is a specimen from Sweden, Sånga parish in Uppland, collected unusually early in the year, June 9, but I have excluded it from the present study, for the date on the label may be erroneous.

\section{Section IV. Infundibuliformes (Fr.) Singer \& Digilio, Lilloa 25: 27.1952.}

Basionym: Agaricus tribus Clitocybe II [= taxon without designation of rank] Infundibuliformes Fries, Epicrisis systematis mycologici..., 67. 1836-1838. — Typus: No original designation. Lectotype (Int. Code Bot. Nomencl., Art. 22) Agaricus infundibuliformis [Schaeff.] Weinm. (= obviously C. $g i b b a)$.

Pileus small to large, ca. $2-15 \mathrm{~cm}$ broad, not hygrophanous, not pruinose (unless very weakly so in C. geotropa?), colours consist of various shades of brown ( $\tan$, reddish brown, yellowish brown, etc.), rarely \pm white or buff, never very dark-coloured, slightly depressed to deeply infundibuliform when adult; margin inrolled at first; surface dry, smooth, or scaly, or slightly areolate. Stipe concolorous with pileus or paler to white, mostly equal, sometimes clavate, usually only white tomentum present at the base, rarely also a few inconspicuous rhizoids (on very rare occasions together with inconspicuous, slender hyaline mycelial hairs), firm compressed mycelial hairs always lacking. Lamellae not sinuate, in colour whitish to yellowish, or buff, or faintly brownish-tinted, sometimes thickish and rather distant. Flesh thick to very thin, not hygrophanous. Odour of fresh fruit body fungoid, or camphor-like, or like that of oil of bitter almonds (or blossom of Prunus padus), exsiccates odourless. Spores never small, occurring singly in preparations, always all to a minority having confluent base, most to none acute-based, in one species some obtuse-based ones, too, always most to $100 \%$ of them \pm lacrymoid being broadest above the middle, plage applanated to distinctly depressed, contents ho- 
mogeneous to granulose, apiculus/apicular region always large, ca. $0.7-1.3 \mu \mathrm{m}$ in diameter; colour of spore deposit, when known, very pale yellow, $9 \mathrm{~B} 1$ to somewhat paler. Subcutis absent or present; membranal pigment lacking in hyphae of pileus trama except in C.bresadotiana, encrusted pigment only exceptionally present on hyphae of epicutis. In different types of forest, in litter of various kinds, some species in open habitats such as alpine Dryas heaths, some species mainly to occasionally on \pm bare soil, often in places where human influence is evident, such as roadsides, pasturelands, and yards; from end of May to middle of November, but mostly in summer and early autumn. Temperate to oroarctic.

Discussion. In the present restricted meaning, the section is most natural. The species are very nearly related to each other, and there are some specimens which suggest hybridization between C. gibba and C. squamulosa, and between C.catinus and $C$. gibba.

In the sense of Bigelow (1968), the section is heterogeneous, including C. sinopica, a peculiar hygrophanous $C$. crispa, and «C. socialis«, the last name referring to Calocybe cf. persicolor, judging from a specimen provided with that name, collected by Bigelow and studied by me.

In the alpine Dryas vegetation of Fennoscandia there seems to be one additional rather tall, evidently undescribed species of the present section, sharing some characters of C. geotropa, C.altaica, and C.lapponica, but the defective material so far available

\section{Clitocybe geotropa ([Bull.] St.-Amans) Quélet, Les champignons du Jura et des Vosges, 89. 1872. \\ Basionym: Agaricus geotropus [Bull.] Saint- Amans, Flore Agenaise, 575. 1821. - Typus: No original designation. No material of Bulliard, at least, in PG. I have examined a specimen from France, near Paris, belonging to the present species. A neotyne has not been designated.}

Figs. 12, 43, 91.

Pileus 9-15 $\mathrm{cm}$ broad, not hygrophanous, possibly very weakly pruinose, buff to alutaceous, sometimes with reddish tinge, e.g. $9 \mathrm{E} \mathrm{2}$, when fresh, in exsiccates $9 \mathrm{E} 3,9 \mathrm{~F} 3$, does not allow its inclusion. In addition, another undescribed species, which is ruderal in character and nearly related to C. bresadoliana (and C.squamulosa), seems to exist.

FrIes is almost always considered the revalidating author of SaHAEFFER's A. infundibuliformis, but WEINMANN revalidated this name slightly earlier (1836) than FrIES (1836-1838), as pointed out by DennIs, Orton \& Hora (1960). FrIEs' work was definitely published later since he discussed WeInmans's concept of the species.

It may be mentioned that slightly before Fries, WeInmann (op. cit.) published «Agaricus tribus Omphalia subtribus Infundibuliformes«, which includes $A$. infundibuliform$i s$, but this taxon is a nomen invalidum, because according to the «Code« tribes and subtribes are only legitimate at the suprageneric level (FrIes' tribes in «Systema Mycologicum《 being exceptions).

QUÉLET is almost without exception regarded as the last author (quoted after the brackets) of the present sectional name, but this usage is not valid, since QuéLET (1872) did not combine his taxon (the rank of which was not indicated) Infundibuliformes with the subgenus Clitocybe but treated it as a taxon immediately below the generic level. Singer and Digilio were the first authors to combine the sectional name with the subgenus Clitocybe. Though unintentional and without complete reference to the basionym, their combination is valid since it was published before 1. I. 1953.

at first convex, becoming plane to broadly shallowly depressed but never infundibuliform, often gibbous; margin strongly inrolled at first, becoming almost straight; surface dry, mat, near margin sometimes shallowly ridged.

Stipe 10-16 × 15-25(-30), always longer than pileus diameter (about 4 times in young basidiocarps, in old ones usually at least 1.5 times), whitish to almost concolorous with pileus, weakly downwards enlarged, solid, terete; surface dry, mat, indistinctly fibrillose, at the base some whitish tomentum, often some white inconspicuous rhizoids, too (occasionally also very slender hyaline mycelial hairs). 
Lamellae rather short decurrent, angle of attachment $25^{\circ}-60^{\circ}$, whitish or with a faint tint of pileus colour, being paler than pileus, in 4 verticils, more or less distant and thickish, 30-40 reach the stipe, being broadest in the middle, $5-7 \mathrm{~mm}$, where they are 1.5-3 times broader than overlying. context is thick, not forked, weakly intervenose in age.

Odour strong, sweet, like that of oil of bitter almonds, or flowers of Prunus padus.

Taste mild, somewhat sweetish.

Spores $\quad 7.0-9.0(-11.0) \times 4.5-6.5$ (-8.0) $\mu \mathrm{m}$, single in all preparations, almost all with abruptly confluent base, being «subglobose-lacrymoid《 (apicular region excluded, subglobose to globose), the rest with more gradually confluent base, being distinctly lacrymoid, plage applanated to depressed, almost all with granulose contents, the rest with homogeneous contents, apicular region ca. $0.9-1.1 \mu \mathrm{m}$ in diameter; exact colour of spore deposit unknown.

Anatomy of cortex of pileus. Epicutis indistinct, ca. 30-75 $\mu \mathrm{m}$ thick, hyphae \pm parallel, 3.0-10.0 $\mu \mathrm{m}$ in diameter, only intracellular pigment present, being found especially in the outermost hyphae; subcutis not differentiated.

Ecology. Mostly in «fairy rings«, arcs, and rows in grass-herb forests, or pasturelands and other half-open, often grassy habitats, on \pm calcareous ground, in litter of Picea, Corylus, Fagus, Quercus, etc., or on bare fertile soil (mull), sometimes in alpine Dryas octopetala heaths above forest limit. From latter half of August to middle of November (Fig. 5).

Distribution. Temperate to oroarctic, mostly in southern areas, in districts with calcareous soils only, up to $1050 \mathrm{~m}$ (central Sweden). Rare on the whole but may be rather common locally. (Fig. 136).

Specimens examined.

NoRWAY: Akershus. Asker (2); Baerum (4); Oslo (4). - Oppland. Gran (1). - Buskerud. Hole (1). - Vestfold. Tjølling (1). - Hordaland. Os (1); Ulvik (1); Voss (2). - SørTrondelag. Strinda (1). - Troms. Lyngen (2); Tromsø (2).

SwEDEN: Skåne. Dalby (2); Vä (1). - Öland. Böda (1); Hulterstad (3). - Gotland. Endre (2); Fide (1); Lokrume (1); Västkinde (1). Västergötland. Göteborg (1); Medelplana (1); Skallsjö (1). - Halland. Onsala (2); Släp (1). - Södermanland. Mariefred (1); Nacka (1); Salem (1). - Uppland. Almunge (3, including Lundell \& Nannfeldt: «Fungi Exsiccati Sueci- ci... no. 1727, in S, UPS); Bondkyrka (8, including Lundell \& NANNFELDT: «Fungi Exsiccati Suecici ... no. 1726, in S, UPS); Danderyd (2) ; Djurö (1); Ekerö (1); Husby-Ärlinghundra (1) ; Kulla (1); Lovö (1); Länna (1); Roslagsbro (1); Ö. Ryd (1); Stockholm (10); Uppsala (3) ; Värmdö (1); Össeby-Garn (1); Österåker (1). - Härjedalen. Storsjö (3).

Finland: Ahvenanmaa. Eckerö (2); Finström (1) ; Jomala (1); Lemland (1). - VarsinaisSuomi. Karjalohja (1); Lohja mlk. (2). - Kuusamo. Kuusamo (5).

Discussion. Hardly to be confused with any other species if the macroscopical and microscopical characters and the odour are taken into consideration. Attention should also be paid to the abundant lactiferous hyphae in the gill trama. The fruiting time of $C$. geotropa is clearly the latest one within the section Infundibuliformes. Two specimens from Stockholm, (Sweden, Uppland) have, however, unusually early dates on their labels, namely 4. VI. and 9. VI. The dates are not necessarily erroneous, but I have excluded these specimens from the present study, including the phenological diagram.

The Fennoscandian distribution of C. geotropa closely resembles that of the likewise more or less distinctly calciphilous fern, Asplenium ruta-muraria (Hultén 1950).

C. geotropa may somewhat prefer an oceanic climate, but this is not certain on the basis of the present material.

7. Clitocybe altaica Singer, Ann. Mycol. 41: 37. 1943.

Typus: Holotype (U.S.S.R., Altai Mts., leg. R. Singer; LE) examined.

Figs. 44, 92.

Spores $6.0-8.0 \times 4.0-5.0 \mu \mathrm{m}$, single in preparations, rather uniform in size and shape, all with a gradually to rather abruptly confluent base, lacrymoid, plage applanated to distinctly depressed, contents \pm homogeneous, apicular region ca. 0.9-1.3 $\mu \mathrm{m}$ in diameter; spore deposit white according to Singer (1943).

Anatomy of cortex of pileus. Epicutis very indistinct, ca. 50-75 $\mu \mathrm{m}$ thick, hyphae subparallel to rather interwoven, 3.0-6.0 $\mu \mathrm{m}$ in diameter, only very scanty intracellular pigment present; subcutis not differentiated. Ecology. Found above the forest limit in 
dryish alpine heath on very calcareous soil, among Dryas octopetala and the moss Tomentypnum nitens. Early September (Fig. 5).

Distribution. Oroarctic (alpine) zone, altitude somewhere between several hundred metres and about $1000 \mathrm{~m}$ (not - known exactly) (N. Norway). Evidently not common even in suitable habitats. (Fig. 136).

Specimens examined.

Norway: Troms. Nordreisa (1, on the fjeld Javroaive 2. IX 1954, J. Stordal 9694; O).

Discussion. Externally this species most resembles $C$. gibba, but, according to the sole specimen from Fennoscandia (I myself have not collected this species), C. altaica differs from C. gibba in its pileus, which is only slightly depressed and dirty yellowish, with very thin flesh and a shining wrinkled surface, in its rather distant and thick lamellae (obviously due to the larger basidia), and very different ecology and distribution. Evidently there is a difference in odour, too (see SingER 1943). The differences between C. altaica and C.lapponica are dealt with in the description of the latter. The distant and thick lamellae and large basidia (and odour?) suggest proximity to C.geotropa, too.

The specimen of C.altaica exactly resembles the type specimen as regards its macroscopical and microscopical characters and likewise has a negative $\mathrm{KOH}$ reaction of the cap surface.

This seems to be the first time that C. altaica is reported from Europe, or outside the Altai Mountains.

8. Clitocybe catinus (Fr.) Quélet, Les champignons du Jura et des Vosges, 235. 1872.

Basionym: Agaricus catinus Fries, Epicrisis systematis mycologici..., 72. 18361838. - Typus: No original designation. No material of Fries existing. A neotype has not been designated.

Figs. 45, 93.

Pileus 5-10 cm broad, not hygrophanous, not pruinose, watery spots, arranged in concentrical zones, sometimes present, very pale, whitish to pale buff when fresh, slightly darker (9 B 2, $9 \mathrm{~B} \mathrm{3,9}$ D 2, even $9 \mathrm{~F} \mathrm{3)}$ in exsiccates, somewhat convex when young, becoming depressed and shallowly infundibuliform; margin slightly inrolled at first becoming horizontal and often somewhat undulate in age; surface dry, mat, otherwise smooth but sometimes radiately ridged at margin.

Stipe 4-6 6 7-15, concolorous with pileus or paler, or white, usually slightly tapered upwards, solid, terete; surface dry, mat, indistinctly white-fibrillose; at the base, copious whitish tomentum.

Lamellae rather short decurrent, angle of attachment about $20^{\circ}-40^{\circ}$, whitish to buff when moist, in exsiccates often yellowish, $50-60$ reach the stipe, being broadest in the middle, 4-5 $\mathrm{mm}$, where they are about twice as broad as overlying context is thick, not conspicuously forked or intervenose; small red spots sometimes near edges.

Odour faint, becoming stronger in drying, agreeable, resembling that of camphor (sometimes persisting in exsiccates).

Taste mild, fungoid.

Spores 6.8-9.6 (-10.8) $\times(4.2-) 4.6-$ $6.8 \mu \mathrm{m}$, single in all preparations (rarely some in tetrads), all with a \pm abruptly confluent base, \pm lacrymoid, plage applanated to depressed, contents homogeneous to granulose, apicular region ca. $0.9-1.1 \mu \mathrm{m}$ in diameter; spore deposit very pale yellow, 9 B 1.

Anatomy of cortex of pileus. Epicutis rather indistinctly differentiated, up to 60 $\mu \mathrm{m}$ thick, hyphae \pm interwoven, (1.5-) 3.5-13.0 $\mu \mathrm{m}$ in diameter, only intracellular pigment present; subcutis not differentiated.

Ecology. In rows and arcs, rarely solitary, in various kinds of forest (not in very barren and dry ones nor in luxuriant grass-herb forest), mostly in litter of Picea, sometimes Quercus, rarely Populus or Betula, often together with the mosses Rhytidiadelphus triquetrus, Hylocomium, and Pleurozium. From latter half of June to beginning of October (Fig. 5).

Distribution. Hemiboreal and southern boreal, in eastern parts of the area, up to ca. $100 \mathrm{~m}$ (S. Finland). Locally common. (Fig. 137).

\section{Specimens examined.}

SwEDEN: Oland. Böda (1). - Östergötland. Gryt (1). — Södermanland. Hölö (1); Nacka (1); Ornö (1); Västerhaninge (1). - Uppland. Bondkyrka (5); Djurö (1); Ekerö (1); Fresta (1); Lena (3, including Lundell \& NANNFeldT: «Fungi 
Exsiccati Suecici...«, no. 325, s.n. C. infundibuliformis [p.p.], in S., UIPS); Läby (1); Länna (1); Munsö (1); Stockholm (2); Väddö (1); Ärentuna (1). - Västmanland. Sala (1). - Hälsingland. Harmånger (1).

Finland: Ahvenanmaa. Eckerö (1). - Varsinais-Suomi. Halikko (1); Karjalohja (1); Kemiö (1); Korppoo (1); Lohja mlk. (5); Merimasku (1); Parainen (1); Pohja (1); Turku (1). Uusimaa. Helsinki (1). - Satakunta. Lappi (1); Yläne (1). — Etelä-Häme. Asikkala (1); Hattula (1); Tammela (1). - Pohjois-Häme. Virrat $(2)$.

Discussion. Very similar to C. gibba, differing from that species in its generally somewhat larger and stouter fruit body, invariably whitish colours, larger spores which taper more abruptly towards the base, being less curved, and its peculiar south-eastern distribution. C. catinus probably also occurs more often than $C$. gibba in natural habitats.

It is not certain that FrIEs meant the present species with his Agaricus catinus, but, rather than create a new species, I prefer to use the Friesian name so far.

9. Clitocybe gibba ([Pers.] Fr.) Kummer, Der Führer in die Pilzkunde, 123. 1871.

Basionym: Agaricus gibbus [Pers.] Fries, Syst. Mycol. 1: 81. 1821. - Typus: No original designation. No material of FrIES existing, and none of PERSOON in L. I have not examined material from Germany. A neotype has not been designated.

Figs. 13, 46, 94.

Pileus $2-10 \mathrm{~cm}$ broad, not hygrophanous, not pruinose, colour when fresh various shades of pale brown, $\tan , 9 \mathrm{E} 6,9 \mathrm{~F} 6,10 \mathrm{~B} 3$, $10 \mathrm{E} 6$, sometimes more reddish, $4 \mathrm{~A} 10$, rarely yellowish brown (old pilei often slightly tinted with yellow), rarely almost white to pale pinkish buff, e.g. somewhat paler than $9 \mathrm{~B} 2$, young pilei usually slightly darker than adult and old ones, colour in exsiccates of young pilei may be $5 \mathrm{~A} 10,10 \mathrm{C} 5,12 \mathrm{~B} \mathrm{7}$, $12 \mathrm{~B} 8$, adult ones reddish brown, $5 \mathrm{~A} 10$, $13 \mathrm{~B} 8$, or pale brown, $9 \mathrm{D} \mathrm{5,} 9 \mathrm{E} \mathrm{4,} \mathrm{10} \mathrm{B.3,}$ 10 B 5, 10 C 2, 10 D 5, 10 E 5, 11 B 6, 11 B 7,

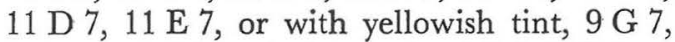
$10 \mathrm{~F} 5,10 \mathrm{G} \mathrm{7}$, pale forms e.g. $9 \mathrm{~B} \mathrm{2,} 9 \mathrm{D} 4$, at first convex but soon becoming plane and then more or less infundibuliform when the margin becomes elevated, very occasionally \pm plane even in adult fruit bodies, often gibbous; margin somewhat inrolled at first; surface dry, mat, otherwise smooth but radiate ridges often present at margin.

Stipe 2.5-5 $\times 5-13$, colour usually similar to that of pileus but paler (even whitish), rarely concolorous with pileus, mostly equal, sometimes distinctly clavate, usually solid even in old basidiocarps, terete; surface dry, mat, indistinctly palely fibrillose; at the base white tomentum.

Lamellae usually rather long and narrowly decurrent, angle of attachment $5^{\circ}-20^{\circ}$, whitish to pale buff when moist, mostly pale yellowish (9 B 1, 9 D 3) in exsiccates, in 4 verticils, usually close to crowded, $30-50$ reach the stipe, being broadest in the middle or distally, 3-5 mm, in the middle 2-4 times broader than overlying context is thick, a few sometimes forked or intervenose; small red spots sometimes present.

Odour often more or less fungoid, sometimes faint, especially in drying agreeable, resembling that of camphor, or Lactarius helvus.

Taste mild, fungoid.

Spores $(4.2-) 5.5-8.0(-10.0) \times(2.4-)$ $3.4-5.4(-6.4) \mu \mathrm{m}$, single in all preparations, often rather variable in size within the same preparation, almost all with confluent base, a few acute-based, all lacrymoid, plage applanated to distinctly depressed, contents \pm homogenous, apicular region ca. $0.8-1.0 \mu \mathrm{m}$ in diameter; spore deposit abundant, very pale yellow, $9 \mathrm{~B} 1$.

Anatomy of cortex of pileus. Epicutis often indistinct, $30-60 \mu \mathrm{m}$ thick, hyphae interwoven to \pm parallel, $1.5-10.0 \mu \mathrm{m}$ in diameter, usually only intracellular (rarely encrusted, too) pigment present; subcutis often not differentiated, when discernible differing from epicutis in slightly broader hyphae and scantier intracellular pigment.

Ecology. Solitary, in rows, arcs, or groups in various kinds of forest (often in grassherb forest), in grassy depressions in rocks, very often in half-open grassy places where human influence is evident, such as roadand pathsides, and pastures, in litter of a number of broad-leaved (Alnus incana, Betula, Corylus, Fagus, Populus, Quercus, Tilia) or coniferous (Picea, Pinus, Larix sp., Juniperus) trees, sometimes in litter of herbaceous plants, often among mosses, e.g. Hylocomium. From beginning of July to late October (Fig. 5). 
Distribution. Temperate to northern boreal, but lacking in districts with very oceanic climate, up to $1030 \mathrm{~m}$ (S. Norway). Very common. (Fig. 138).

\section{Specimens examined.}

Norway: Hedmark. Nes (1). - Buskerud. Gol (1); Krødsherad (1); Nes (2). - Troms. Harstad (1); Lenvik (1); Lyngen (2); Målselv (1); Nordreisa (5); Tromsø (3). - Finnmark. Nesseby (1); Polmak (1); Vadsø (1).

Sweden: Skåne. Dalby (1) ; Kristianstad (1). Blekinge. Augerum (1); Ronneby (1). - Småland. Eksjö (1); Femsjö (6); Hallingeberg (1); Mistelås (1); Voxtorp (1). - Óland. Böda (1); Ventlinge (1). - Gotland. Ardre (1); Boge (1); Endre (1); Lummelunda (1); Viklau (1); Visby (1). - Östergötland. Gryt (1); Skedevi (1); Tjärstad (1). - Västergötland. Göteborg (3). Halland. Fjärås (2); Onsala (1). - Bohuslän. Grinneröd (1). - Värmland. S. Finnskoga (1). - Södermanland. Husby-Rekarne (1); Nacka (1): Ytterenhörna (1). - Uppland. Bondkyrka (22); Bro (1); Bälinge (1); Börje (2); Danderyd (5); Djurö (5); Funbo (1); Lovö (1); Läby (2); Länna (1); Munsö (2); S:t Olof (1); Ramsta (1); Roslags-Kulla (1); Ö. Ryd (2); Stockholm (16); Stockholms-Näs (1); Uppsala (4); Vallentuna (1); Värmdö (4); Ärentuna (3). - Västmanland. Sala (4). - Gästrikland. Valbo (1). - Hälsingland. Bollnäs (1). - Angermanland. Sollefteå (2). - Härjedalen. Tännäs (1). - Norrbotten. Nedertorneå (1); Övertorneå (1). - Torne Lappmark. Jukkasjärvi (3).

Finland: Ahvenanmaa. Finström (1). - Varsinais-Suomi. Bromarv (1); Houtskari (2) ; Kaarina (2); Karjalohja (3); Kemiö (1); Korppoo (4); Koski Tl. (1); Laitila (1); Lemu (1); Lieto (1); Lohja (1); Lohja mlk. (31); Lokalahti (1); Masku (1); Merimasku (1); Nummi (1); Parainen (2); Piikkiö (2); Pohja (1); Rymättylä (1); Suomusjärvi (1); Turku (9); Vehmaa (1); Vihti (3); Västanfjärd (4). - Uusimaa. Elimäki (3); Espoo (2); Helsinki (12); Kauniainen (7); Kirkkonummi (2); Mäntsälä (1); Pornainen (1); Porvoo mlk. (3); Sipoo (2); Siuntio (1); Tammisaari mlk. (5); Tuusula (5). - Etelä-Karjala. Vehkalahti (5). - Satakunta. Karkku (1); Oripää (1); Pomarkku (1); Yläne (4). — EteläHäme. Asikkala (1); Hattula (2); Hollola (2); Juupajoki (1); Jämsä (2); Kuhmoinen (1) ; Lammi (3); Nokia (1); Orivesi (1); Padasjoki (1); Somerniemi (2); Somero (3); Tammela (7, including Karsten: «Fungi Fenniae Exsiccatik, no. 209, s.n. Agaricus infundibuliformis, in H). Etelä-Savo. Imatra (1); Taipalsaari (1); Varkaus (1). - Etelä-Pohjanmaa. Alavus (1); Jalasjärvi (1); Vaasa (1); Vöyri (1). — Pohjois-Häme. Petäjävesi (1); Virrat (3). - Pohjois-Savo. Kuopio (1); Leppävirta (2); Maaninka (1); Piela vesi (3); Suonenjoki (3). - Pohjois-Karjala. Juuka (2); Rääkkylä (1); Tuupovaara (3). Keski-Pohjanmaa. Kälviä (1). - Pohjois-Pohjanmaa. Kiiminki (1); Muhos (1); Rovaniemi mlk. (2). - Kuusamo. Kuusamo (2). - Inarin Lappi. Inari (1); Utsjoki (36).

U.S.S.R.: Leningrad Region. Vyborg (Viipuri mlk.) (5); Valkjärvi (1).
Discussion. The delimitation of C. gibba from the nearly related species C.catinus, C. squamulosa and others is discussed under those species.

Variation, obviously genetic, has been observed in the size, colours and shape of the pileus, and the size and shape of the spores, and the colour and shape of the stipe. Bigelow (1968) claims that the lack of brown pigment in more or less white fruit bodies results from some environmental factors, but the occurrence of whole groups of pale basidiocarps (apparently emerging from a common mycelium) beside groups of brown ones seems to indicate genetic mutations, just as in C.nebularis and $G$. odora.

The present species is the commonest Clitocybe in Finland, whereas in Norway (the northernmost parts excluded) it is very rare.

The specific epithet gibba, recommended by Singer (e.g. 1961, 1962) and Donk (1962) is to be used for the present species, and the better known name infundibuliformis must be rejected for the reasons given by these authors, e.g. because the latter name was revalidated later.

10. Clitocybe squamulosa ([Pers.] Fr.) Kummer, Der Führer in die Pilzkunde, 123. 1871.

Basionym: Agaricus squamulosus [Pers.] Fries, Syst. Mycol. 1: 82. 1821. Typus: No original designation. No material of Frres existing, and none of Persoon in L. I have not examined material from Germany. A neotype has not been designated.

Figs. 14, 47, 95.

Pileus 4-8 (-15) cm broad, not hygrophanous, not pruinose, brown with greyish or reddish tint, when fresh e.g. $7 \mathrm{C} 12,11 \mathrm{G} \mathrm{7}$, disc often slightly darker, pileus in exsiccates 7 A 10, 10 D 5, 10 D 6, 12 G 7, 15 C 9, usually soon becoming infundibuliform, rarely plane even in adult fruit bodies; margin bent or slightly inrolled when young soon becoming horizontal and elevated; surface dry, \pm mat, cracked into small scales, at least over disc, sometimes over the whole surface, the scales being largest in the centre.

Stipe 4-9 $\times 4$ 4, rather long and slen- 
der, \pm concolorous with pileus, equal or slightly enlarged downwards, solid, terete; surface dry, mat, indistinctly palely fibrillose; at the base some white tomentum, sometimes a few thin rhizoids, too.

Lamellae often long and narrowly decurrent, angle of attachment $10^{\circ}-30^{\circ}$, whitish to pale yellow, contrasting distinctly with the darker colour of the stipe, in exsiccates shades such as $9 \mathrm{D} 2$, in 3 verticils, not very close, usually thickish, 25-30 reach the stipe, being broadest in the middle or proximally, $3-4 \mathrm{~mm}$, in the middle ca. 3 times broader than overlying context is thick, some of them forked, often intervenose in age.

Odour fungoid, or faint and agreeably camphor-like, especially in drying.

Taste mild, agreeable ( \pm fungoid).

Spores $\quad 6.0-9.0(-11.0) \times 3.2-5.0$ (-6.5) $\mu \mathrm{m}$, single in all preparations, often rather variable within the same preparation, many to almost all of them with gradually (usually) confluent base, the rest (often the majority) acute-based, all \pm narrowly lacrymoid, plage weakly to very distinctly depressed, contents \pm homogeneous to granulose, apiculus/apicular region often very oblique, ca. 0.9-1.1 $\mu \mathrm{m}$ in diameter; spore deposit very pale yellow, evidently paler than $9 \mathrm{~B} 1$.

Anatomy of cortex of pileus. Epicutis distinct, 40-90 $\mu \mathrm{m}$ thick, hyphae interwoven to subparallel, often in fascicles (= scales), 2.5-8.5 $\mu \mathrm{m}$ in diameter, containing rich intracellular pigment, sometimes encrusted pigment present, intercellular pigment crystals sometimes present, too; subcutis not differentiated.

Ecology. Solitary, or in groups or arcs, especially in grassy plant communities with some human influence such as path- and roadsides in various kinds of forest (especially dry coniferous), and pastures, in litter of Picea, Pinus, Alnus incana etc., or in herbaceous litter, sometimes on various kinds of \pm bare soil, often together with mosses (especially Rhytidiadelphus squarrosus, and Pleurozium). From end of May to middle of October (Fig. 5).

Distribution. Temperate to northern boreal, but very rare in northernmost/upper (subalpine) parts of the latter zone, up to $1050 \mathrm{~m}$ (S. Norway). Common. (Fig. 139).

Specimens examined.

Norway: Østfold. Onsøy (1). Akershus. Nes- odden (1); Oppegård (1); Oslo (2); Ski (2); Ås (1). - Hedmark. Elverum (1); Hamar (1); Stor-Elvdal (1); Trysil (4). - Buskerud. Gol (1); Nes (2). - Vestfold. Våle (1). - Telemark. Skien (1). - Rogaland. Stavanger (1). Hordaland. Tysnes (1); Voss (1); Vossestrand (1). - Sør-Trøndelag. Klaebu (1); Tiller (1). - Nord-Trøndelag. Frosta (2). - Nordland. Nord-Rana (1).

Sweden: Blekinge. Fridlevstad (1). - Småland. Femsjö (5); Kärda (1); Mellby (1); Odensjö (1). - Östergötland. Skedevi (4). - Västergötland. Göteborg (4); Medelplana (1); Mösseberg (1). - Halland. Onsala (1). - Dalsland. Dals Ed (2). - Värmland. Dalby (2); S. Finnskoga (1). - Närke. Kumla (1). - Södermanland. Höö (1) ; Nacka (1); Salem (2); Sorunda (1) ; Västerhaninge (1). - Uppiand. Bondkyrka (7); Djurö (2); Husby-Sjutolft (1); Roslags-Kulla (1); Stockholm (6); Uppsala (13, including Lundeli \& NANNFELDT: «Fungi Exsiccati Suecici...«, no. 326, in S, U.PS) ; Värmdö (1); Ärentuna (2); Österåker (1). - Västmanland. Köping (2); Munktorp (1). - Dalarna. Rättvik (2). - Gästrikland. Gävle (2). - Hälsingland. Järvsö (2). - Härjedalen. Storsjö (3). - Jämtland. Áre (1). - Västerbotten. Umeå (2).

Finland: Ahvenanmaa. Eckerö (1). - Varsinais-Suomi. Karjalohja (1); Karkkila (1); Korppoo (3); Lieto (1); Lohja mlk. (4); Parainen (1); Piikkiö (1); Sauvo (1); Turku (7); Vihti (6). - Uusimaa. Elimäki (1); Espoo (3); Helsinki (4); Hyvinkää mlk. (1); Kauniainen (2); Kirkkonummi (1); Porvoo mlk. (1); Tammisaari (2); Tuusula (2). - Etelä-Karjala. Vehkalahti (2). - Satakunta. Lappi (3); Yläne (2). - Etelä-Häme. Hollola (1); Jämsä (1); Lammi (4); Nokia (1); Somero (1); Tammela (6). - EteläSavo. Imatra (2). - Etelä-Pohjanmaa. Kauhajoki (1). - Pohjois-Häme. Toivakka (1); Virrat (1). - Pohjois-Savo. Lapinlahti (1); Pielavesi (1). - Pohjois-Karjala. Nurmes mlk. (1). Keski-Pohjanmaa. Kälviä (1). - Pohjois-Pohjanmaa. Oulu (1); Rovaniemi mlk. (3). - Kuusamo. Kuusamo (4). - Inarin Lappi. Inari (1).

U.S.S.R.: Leningrad Region. Vyborg (Viipuri mlk.) (2). - Murmansk Region. Soukelo. (Sokolozero) (1).

Discussion. Very nearly related to C. gib$b a$, differing from that species in the usually somewhat deeper and less bright colours, which are equally dark in the cap and stipe, the apex of the latter thus contrasting with the whitish lamellae. The cap surface is scaly, too, in C.squamulosa, as its Latin name indicates, and the spores are somewhat longer and more gradually tapering towards the base than in C. gibba. C. squamulosa also seems to stand an oceanic climate better. The differences between C. squamulosa and the nearly related $C$.bresadoliana and $C$. lapponica are given under the latter two species.

The different collections vary somewhat 
from each other (evidently owing to genetic differences) in respect of the colour and shape of the pileus as well as the density and degree of decurrence of the lamellae.

\section{Glitocybe bresadoliana Singer, Rev.} Mycol., N. S. 2: 228. 1937.

Typus: No original designation. Lectotype (selected here): «Clitocybe flaccida Sow., in pascuis, Tajo $\mathrm{X} / 15$, leg. G. Bresadola« (S).

Figs. 48, 96.

Spores $5.5-8.0 \times 3.1-4.0 \mu \mathrm{m}$, single in preparations (except for a few sometimes), usually very variable in size and shape within the same preparation, perhaps most of them acute-based and \pm lacrymoid (a part, however, elliptical to oblong), some confluent-based and \pm lacrymoid, the rest obtuse-based and elliptical to oblong, plage applanated to distinctly depressed, contents homogeneous to irregularly granulose, apiculus/apicular region ca. $0.7-1.1 \mu \mathrm{m}$ in diameter; exact colour of spore deposit unknown.

Anatomy of cortex of pileus. Epicutis very thin (about 20-30 $\mu \mathrm{m}$ ), hyphae 3.0 - 5.0 $\mu \mathrm{m}$ in diameter, \pm interwoven to subparallel, rich intracellular and faint membranal pigments present; subcutis $30-80 \mu \mathrm{m}$ thick, hyphae parallel to slightly interwoven, $4.0-7.0 \mu \mathrm{m}$ in diameter, only membranal pigment distinctly present, hyphal walls often appear rough but are not encrusted.

Ecology. In dry, usually \pm treeless, open to half-open, often grassy habitats, always on distinctly calcareous ground, in alpine Dryas octopetala heaths, in steppe-like «alvar《 vegetation, and on calcareous rocks, habitat usually without litter, accordingly mostly on \pm bare soil, sometimes in some herbaceous litter (once in scanty litter of Larix sp.), very often together with calciphilous mosses, such as Abietinella abietina, Barbula sp., Brachythecium glareosum, Ditrichum flexicaule, Tortella tortuosa, and Tortula ruralis. From middle of July to early November (Fig. 5).

Distribution. Found in the temperate, hemiboreal and oroarctic (alpine) vegetation zones, never in districts with very oceanic climate, up to about $1000 \mathrm{~m}$ (N. Norway, central Sweden). Evidently lacking in the greater part of Fennoscandia, but may be more or less common on calcareous soils on fjelds, and in «alvar" vegetation (i.e., on Öland and some other areas in S. Sweden). (Fig. 140).

Specimens examined.

Norway: Akershus. Baerum (1). - Nordland. Fauske (2).

Sweden: Skåne. Åhus (2). - Öland. Hulterstad (2); Högsrum (1); Kastlösa (1); Resmo (2); Smedby (2). - Gotland. Hangvar (1); Visby (1). - Uppland. Djurö (9); Häverö (1). Härjedalen. Storsjö (1).

FinLAND: Inarin Lappi. Utsjoki (1).

Discussion. I myself have not collected the present species. The description and figure of «C. flaccida《 in Bresadola (1928, pl. 169) may be consulted for macroscopical characters.

In the herbaria C.bresadoliana was usually labelled «C. infundibutiformis«, but the latter $(=C$. gibba) differs clearly from C. bresadoliana in having somewhat different colours, mat cap surface, paler gills, negative $\mathrm{KOH}$ reaction of the cap surface, and distinctly different spores, and in its ecology and distribution. C. squamulosa is perhaps the most nearly related species to $C$. bresadoliana, but they are easily distinguished from each other, for the latter generally has smaller fruit bodies, somewhat different, more reddish-tinted colours, a smooth (rarely slightly areolate over disc) cap surface, which is usually glossy (in exsiccates, at least), a shorter stipe, somewhat brownish-tinted gills in adult fruit bodies, being also narrower and perhaps closer, spores which are shorter, and markedly thinner, and usually partly of somewhat different shape. There are also distinct differences in the habitat ecology, fruiting time and distribution. For the distinctions between C.bresadotiana and C. lapponica, see under the latter.

According to Singer (1937), too, the species favours calcareous soil, and he also reports that it favours high altitudes, occurring in the Alps, and in the Altai and Caucasian Mountains in the U.S.S.R. Besides BRESADOlA's material, I have seen specimens from Asia, viz. those (in PR) collected by A. Pilát above the forest limit on the mountains of Asia Minor, in Turkey. The very interesting ecology and distribution (in Fennoscandia) of this species is discusse: further in the general part, pp. 33 and 42. Singer, when proposing the epithet bre- 
sadoliana as nomen novum for C.flaccida sensu BrEsAdola 1928, did not designate a type specimen but cited the plate (erroneously as no. 149; should be 169) representing «C. flaccida《 in BresadolA's «Iconographia« (1928), as well as the poorly defined material and data of three other mycologists. Bresadola did not cite any material in his description of «C. flaccida《. There are some specimens of Bresadola in S, which are labelled $C$. flaccida (apparently a dubious species), and were collected before 1928. They all correspond well with the descriptions of Bresadola and Singer, and their fruit bodies also seem to have grown on calcareous, more or less bare soil. I considered that the best way of typifying $C$. bresadotiana is to select the lectotype among those specimens, especially as this species was named after their collector.

\section{Clitocybe lapponica Harmaja, n. sp.}

Figs. 49, 97.

Pileus mediocriter latus, carnosus, \pm brunneus, non vel mediocre infundibuliformis, superficie minutissime squamulosa vel areolata, $\mathrm{KOH}$ non reagente; basis stipitis non strigosa nec rhizoidea; lamellae pallidae; sporae 6.0-11.0 × 4.2-6.2 $\mu \mathrm{m}$, solitarii, pars maxima earum basi confluente et lacrymoideae, nonnullae subobovatae et ellipsoideae, apiculo crasso; aestate, subalpina et alpina. - Holotypus: Finland, prov. Inarin Lappi, par. Utsjoki, Nuorgam 30. VII. 1961, Paavo Kallio, s.n. C. sp. (TUR; isotype in MICH).

Spores $6.0-11.0 \times 4.2-6.2 \mu \mathrm{m}$, single in preparations, often rather variable in size and shape within the same preparation, most with abruptly to gradually confluent base being \pm lacrymoid, the rather small remainder with \pm acute base, being \pm lacrymoid or almost obovate or even elliptical, plage applanated to distinctly depressed, most with minute internal guttules, the rest with homogeneous contents, apiculus/apicular region ca. $0.9-1.3 \mu \mathrm{m}$ in diameter; exact colour of spore deposit unknown.

Anatomy of cortex of pileus. Epicutis ca. 50-75 um thick, hyphae \pm parallel to somewhat interwoven, $3.5-6.0 \mu \mathrm{m}$ in dia- meter, especially the outermost of them containing rich intracellular pigment, other pigments absent; subcutis not differentiated.

Ecology. In \pm dry subalpine forests, mostly of Betula (B. «tortuosa«), sometimes perhaps above the forest limit, in litter of Betula, or Picea, sometimes in partly herbaceous litter, or on bare soil. From beginning of July to latter half of August (Fig. 5).

Distribution. Northernmost/upper (subalpine) parts of the northern boreal zone, rarely also in the oroarctic (alpine) zone, from below $100 \mathrm{~m}$ (N. Finland) up to ca. $1000 \mathrm{~m}$ (central Sweden). Possibly not very infrequent near forest limit. (Fig. 141).

\section{Specimens examined.}

Norway: Troms. Kåfjord (1, Ankerlia 22. VIII. 1961, S. Sivertsen 163, s.n. C. sp.; TROM).

Sweden: Härjedalen. Storsjö (1, Ramundberget-Helags 1. VIII. 1947, G. Haglund, s.n. C. sp.; S); Tännäs (1, Hamrafjället 9. VII. 1947, Th. Arvidsson \& G. Haglund, s.n. G. gilva?; S). - Jämtland. Åre (1, Duved 8. VII. 1962, H. Smith, s.n. C. sp.; UPS). - Torne Lappmark. Jukkasjärvi (5: Abisko 6. VIII. 1915, L. Romell, s.n. C. gilva v. lapponica ad int., S; Abisko 22. VII. 1948, A. Melderis, s.n. C. bresadoliana, UPS; Abisko 25. VII. 1948, A. Melderis 51, s.n. C. bresadoliana, UPS; Abisko 4. VII. 1952, G. Sandberg, s.n. $G$. bresadoliana?, UPS; Abisko 10. VIII. 1957, O. Persson, s.n. C. bresadoliana, UPS).

Finland: Inarin Lappi. Utsjoki (1, holotype).

Discussion. I myself have not collected this species.

Morphologically C.lapponica most resembles $C$. altaica, $C$. squamulosa and $C$. bresadotiana. The first of these is smaller, paler and more yellowish-tinted, its cap surface is not at all squamulose or areolate but is wrinkled in exsiccates, its flesh is much thinner, its spores smaller and of somewhat different shape, and its basidia larger. C. squamulosa and C. bresadoliana are smaller and less fleshy, too, their pileus has a thinner and less inrolled margin than that of C. lapponica, and their cap surface becomes chestnut brown when treated with $\mathrm{KOH}$, while there is no reaction in C.lapponica. The gills are thicker and slightly more distant in $C$.lapponica, and there are more or less marked differences between its spores and those of the two other species. Also C. lapponica differs in its ecology and distribution from the other species, C. altaica evidently included. C. squamulosa is also distinguished from C. lapponica by the somewhat different pattern formed by the cracks 
in the pileus surface, for in the former the scales are distinct, being most conspicuous in the cap centre (often present there only), whereas in the latter the surface is minutely scaly to areolate (rarely only radiately fibrillose) the scales or darker areoles usually being lacking in the centre. The pileus surface of C.bresadoliana is usually more or less shining, being completely smooth, rarely somewhat areolate.

\section{Section V. Sinopicae Harmaja, n. sect.}

Pileus non hygrophanus nec pruinosus, lateritius-fulvus; stipes basi rhizoidea et strigosa; caro non hygrophana; odor et sapor distincte farinaceus; sporae magnae, solitarii, basi semper obtusa, maxima pars earum ellipsoideae vel ovatae, haud lacrymoideae, apicuto magno, sporarum massa \pm alba. Holotypus: Clitocybe sinopica (Fr.) Kumm.

Pileus medium-sized, neither hygrophanous nor pruinose, \pm red-brown, depressed when adult; margin hardly inrolled; surface dry, smooth or areolate, rarely minutely scaly. The base of stipe with scanty white tomentum and, in addition always more or less conspicuous, firm, compressed mycelial hairs and rhizoids. Lamellae very pale, \pm whitish. Flesh not hygrophanous. Odour and taste strongly farinaceous in fresh fruit bodies, exsiccates odourless and tasteless. Spores very large (more than $6.5 \mu \mathrm{m}$ long and $4.5 \mu \mathrm{m}$ broad), single in all preparations, all obtuse-based, most elliptical or

13. Clitocybe sinopica (Fr.) Kummer, Der Führer in die Pilzkunde, 123. 1871.

Basionym: Agaricus sinopicus Fries, Syst. Mycol. 1: 83. 1821. - Typus: No original designation. No material of FrIes existing. A neotype has not been designated.

Figs. 15, 50, 98.

Pileus 6-10: $\mathrm{cm}$ broad, not hygrophanous, not pruinose, red-brown to almost orange, in fresh condition $13 \mathrm{~B} \mathrm{12}, 6 \mathrm{~B} 12,5 \mathrm{~B} 11$, at first often slightly darker, $7 \mathrm{H} \mathrm{10}$, slightly convex at first, becoming plane and somewhat depressed but not infundibuliform; margin usually bent down, sometimes split; surface dry, \pm mat, rarely already cracked into small scales in young fruit bodies.

Stipe 3-5 ×6-13, concolorous with pileus, sometimes slightly paler, equal or slightly enlarged both upwards and downwards, extreme base obtuse, solid at all ovate, none lacrymoid, plage applanated, contents \pm homogeneous, apiculus large, ca. $0.9-1.1 \times 0.7-1.0 \mu \mathrm{m}$; spore deposit \pm pure white. Subcutis not differentiated; membranal and encrusted pigments lacking in hyphae of pileus. Mostly on \pm bare soil, especially sandy, rarely in litter, very often near pines (Pinus sylvestris), sometimes in burnt areas, and habitats subject to more or less marked human influence; from May to end of October. Temperate to northern boreal, but very rare in northernmost/upper (subalpine) parts of the latter zone.

Discussion. C. sinopica has usually been included in the preceding section, but the strong farinaceous odour and taste, the conspicuous rhizoids and firm, compressed mycelial hairs, and the always obtuse-based and non-lacrymoid shape of the spores separate this species from the Infundibuliformes and make it necessary to create a new section for it.

stages, cylindrical to slightly compressed; surface dry, mat, with inconspicuous very thin fibrillose coating; at the base scanty white tomentum and \pm conspicuous, firm, compressed mycelial hairs and rhizoids.

Lamellae short decurrent, angle of attachment $10^{\circ}-20^{\circ}$ at first, somewhat wider in adult fruit bodies (e.g. $30^{\circ}$ ), whitish with creamy or buff tinges, in young pilei in 3 verticils, later in 4 to $5,40-50$ reach the stipe, being broadest around the middle, 4-6 $\mathrm{mm}$, where 3-4 times broader than overlying context is thick, not forked, often intervenose in old pilei.

Odour farinaceous, distinct in both young and old basidiocarps.

Taste mild, farinaceous.

Spores 7.5-11.5 × 4.8-6.1 $\mu \mathrm{m}$, single in all preparations, all obtuse-based, broadly elliptical, oblong, ovate, or obovate, the percentage of each type variable, contents \pm homogeneous, apiculus ca. $0.9-1.1 \times$ 
0.7-1.0 $\mu \mathrm{m}$; spore deposit \pm pure white.

Anatomy of cortex of pileus. Epicutis 40 $100 \mu \mathrm{m}$ thick, hyphae \pm parallel, 2.5-6.5 $\mu \mathrm{m}$ in diameter, only intracellular pigment present; subcutis not differentiated.

Ecology. Solitary or in arcs, mainly on bare sandy soil (rarely in litter of Pinus) in dry heath forests near Pinus, especially on roadsides, also in other places where human influence is evident (lawns, yards etc.), sometimes in burnt-over places, even among pieces of charred wood, occasionally on bare soil other than sand. From middle of May to end of October (Fig. 5).

Distribution. Temperate to northern boreal, but very rare in northernmost/upper (subalpine) parts of the latter zone, up to ca. $300 \mathrm{~m}$ (N. Finland). Scattered. (Fig. 142).

\section{Specimens examined.}

Norway: Akershus. Oslo (1). - Hedmark. Trysil (1). - Buskerud. Hønefoss (1). - Hordaland. Voss (1).

Sweden: Smáland. Höreda (1). - Öland. Böda (2); Vickleby (1). - Gotland. Follingbo (1); Hangvar (1). - Ostergötland. Skedevi (1). Södermanland. Ornö (1). - Uppland. Djursholm (1) ; Djurö (3, including Lundell \& NANNFELDT: «Fungi Exsiccati Suecici ...«, no. 2522, in UPS); Stockholm (2); Stockholms-Näs (1); Uppsala (5, including LunDELL \& NANNFELDT: «Fungi Exsiccati Suecici ... Dalarna. Rättvik (1).

Finland: Ahvenanmaa. Eckerö (1). - Varsinais-Suomi. Lohja mlk. (3). - Uusimaa. Helsinki (4); Kauniainen (3); Kirkkonummi (2); Tammisaari (1); Tammisaari mlk. (3). - Etelä-Häme. Lammi (1); Tammela (5). - Etelä-Savo.
Imatra (2). - Pohjois-Häme. Petäjävesi (1). Pohjois-Savo. Iisalmi (2); Kuopio (1). - Kuusamo. Kuusamo (2). - Inarin Lappi. Inari (2).

U.S.S.R.: Leningrad Region. Vyborg (Viipuri mlk.) (1).

Discussion. C. sinopica is easily recognized by its red-brown colours and the contrast between them and the whitish gills, its conspicuous rhizoids and mycelial hairs, its strong farinaceous odour and taste, and its spores, which are larger than those of all the other species of Clitocybe studied here.

Some features of the ecology of $C$. sinopica are rather peculiar, especially its tendency to occur on bare soil near pines (see above, and in the general part, p. 33).

There is an undescribed variety or species, not collected by me, which has a great deal in common with the typical C. sinopica (colours, mycelial characters, odour, ecology) but has somewhat shorter spores (ca. 6.0 $-10.0 \mu \mathrm{m}$ long). It may be slightly more gracile, and have a more slender stipe and a more northern distribution on the average, but I have not included the few specimens from Fennoscandia belonging to this taxon in the present study, because spore length is the only clear differentiating character that I have so far observed between it and C. sinopica. This taxon has been mentioned in the literature by v. Schulmann (1961: 13, s.n. C. bresadoliana) judging from the corresponding specimen studied by me. Also the C. «sinopica of Bigelow (1968) may belong here.

\section{Section VI. Gilvaoideae Harmaja, n. sect.}

Pileus non hygrophanus, colore \pm cinnamomeo, \pm areolatus; tomentum basale stipitis non album sed pallide brunneum, elementa alia mycelii desunt; lamellae coloratae, pallide cinnamomeae; odor et sapor fungoideus vel farinaceus; sporae parvae, solitarii, omnes vel pars maxima earum basi obtusa, nullae vel pars minor \pm lacrymoideae, apiculo parvo vel medio. - Holotypus: Clitocybe gilvaoides Kauffm.

Pileus medium-sized to rather small, not hygrophanous, red-brown, dingy orange, or cinnamon, shallowly depressed to almost infundibuliform when adult; margin \pm inrolled; surface \pm areolate, at least over disc. Basal tomentum of stipe pale brownish, rhizoids and mycelial hairs absent. Lamellae having conspicuous colour in adult fruit bodies, about the same as that of pileus but clearly paler, narrow. Flesh thick, not white but with brown tinges. Odour and taste fungoid, or farinaceous, in fresh fruit bodies. Spores small, up to $6.5 \mu \mathrm{m}$ long and $4.0 \mu \mathrm{m}$ broad, single (or a few in tetrads) in preparations, all or most of them obtuse-based, in the latter case the rest being acute-based, most spores elliptical to oblong, or obovate, none to a minority \pm lacrymoid, plage applanated to depressed, contents \pm homogeneous but often plasmolyzed, apiculus small to medium, ca. $0.6-0.9 \times 0.3-0.6$ $\mu \mathrm{m}$; spore deposit white when known (according to Bigelow 1968). Subcutis absent; \pm faint membranal pigment pres- 
ent in tramal hyphae, encrusted pigment lacking in hyphae of pileus. In woods in fairly fertile habitats, in various kinds of litter; very late in the year. Found in hemiboreal and middle boreal zones, in eastern parts of Fennoscandia.

Discussion. The two very nearly related species on the basis of which I have established the present section have been included in the section Infundibuliformes by BrgeLow (1968). However, the following characters

14. Clitocybe gilvaoides Kauffman, Pap. Mich. Acad. Sci., Arts and Letters 8: 195. 1927.

Typus: Holotype (U.S.A., New York, Adirondack Mts. 2. IX. 1921, G. H. Kauffman; MIGH) examined.

Figs. 51, 99.

Pileus (1.5-) 3-9 $\mathrm{cm}$ broad, convex at first soon becoming plane with a slight umbo and the margin incurved, expanding to shallowly depressed, occasionally deeply depressed or umbilicate, the margin broadly undulate at times, surface glabrous and moist, lubricous at times, soon showing a pattern of areolations or concentric zones, in age the disc obscurely diffracted-scaly to squamulose, color dingy orange at first (nearest «ochraceous orange «), becoming darker in age to deep red brown «rufous «Sanford's brown«) or more cinnamon color; context rather thick on the disc and tapering abruptly to the margin, concolorous with pileus near the cuticle, odor and taste not distinctive, $\mathrm{FeSO}_{4}$-negative.

Lamellae soon long decurrent (often unevenly), close, narrow, occasionally forked, not intervenose, color dingy pinkish cinnamon at first but darkening to more vinaceous cinnamon (nearly concolorous with the pileus margin) or cinnamon buff, edges even and straight.

Stipe short, 1-4 (-6) cm long, (3-) 6-12 $\mathrm{mm}$ broad at the apex, usually enlarged downward, the base with copious tomentum intergrown with the needles, central to somewhat eccentric, becoming hollow in age, surface faintly fibrillose to unpolished, rather hoary in age, nearly concolorous with the pileus and darkening at the same time («pinkish buff« to «burnt sienna $\ll)$.

Spores $4.2-6.0 \times 2.9-3.3 \mu \mathrm{m}$, practi- suggest that they should be placed in a separate section: the colours of the lamellae, context, and basal tomentum (the basal tomentum is more strongly coloured than in all the other species of Clitocybe), the farinaceous odour and taste of one of the species, the small spores with thin apiculus, the absence of confluent-based spores and the small proportion of lacrymoid and acutebased spores (which may even be absent).

cally all single in preparations, all obtusebased, most elliptical to oblong, the rest ovate, contents \pm homogeneous but often plasmolyzed, apiculus ca. $0.6-0.7 \times 0.3-$ $0.5 \mu \mathrm{m}$; spore deposit white according to Bigelow (1968).

Anatomy of cortex of pileus. Epicutis 30$50 \mu \mathrm{m}$ thick, hyphae parallel to rather interwoven, $1.0-3.0 \mu \mathrm{m}$ in diameter, gradually becoming broader towards the trama, only rather abundant intracellular pigment present; subcutis not differentiated.

Ecology. Subcespitose habit, apparently in grass-herb forests, in litter of Picea, or Alnus incana, or partly of herbaceous plants, once among the moss Mnium spinosum. Middle of October (in the north latter half of September) (Fig. 5).

Distribution. Hemiboreal and middle boreal, in eastern parts of the area, near sea level. Very rare. (Fig. 143).

Specimens examined.

Norway: Troms. Kåfjord (1, Kåfjorddalen, Hauskielva 19. IX. 1962, S. Sivertsen 629, s.n. C. cf. bresadoliana; TROм).

SwEDEN: Uppland. Färentuna (1, Vendtholmen 12. X. 1947, S. Rundquist, s.n. C. gilva; S).

Discussion. The differences between the present species and $C$. gracilis, with which it can easily be confused, have been described under the latter.

I myself have not found the present species, so the descriptions of the macroscopical features as well as the odour and taste have been cited from Bigelow (1968, s. n. C. gilvaoides v. gilvaoides).

The collections from Fennoscandia agree perfectly with the holotype and another specimen from $\mathrm{N}$. America, in both the macroscopical and microscopical characters.

This is apparently the first time that C. gilvaoides is reported from Europe, or outside N. America. 
15. Clitocybe gracilis (Big. \& Smith) Harmaja, n. comb.

Basionym: Clitocybe gilvaoides v. gracilis Bigelow \& Smith, Mycologia 54: 506. 1962. - Typus: Holotype (U.S.A., Oregon, A. Smith 24844; MICH) examined.

Figs. 52, 100.

Pileus 2.5-5 $\mathrm{cm}$ broad, plane with an inrolled margin, with a spreading margin when expanded, shallowly depressed, surface dry and unpolished, areolate-checked over disc, margin cottony, color evenly «cinnamon rufous« or disc slightly darker; context sordid cinnamon tan (near «cinnamon buff « but more cinnamon), thick and firm, odor somewhat pungent, taste farinaceous.

Lamellae short decurrent, narrow $( \pm 3$ $\mathrm{mm}$ ), moderately close to subdistant, color «light pinkish cinnamon « or slightly darker.

Stipe short, $2.5-4 \mathrm{~cm}$ long, 2.5-5 mm thick at apex, subclavate, base somewhat contorted and fleshy, with mass of mycelium which binds debris, solid (flesh within concolorous with pileus), rather tough and pliant, surface unpolished, concolorous with lamellae at first, later darkening and becoming more or less concolorous with pileus.

Spores 5.0-6.5 $\times 3.0-3.7 \mu \mathrm{m}$, single in preparations (a few in tetrads), rather variable in shape, most obtuse-based being obovate, elliptical, oblong and ovate, the rather small remainder acute-based being \pm lacrymoid, plage applanated to depressed, contents \pm homogeneous but often plasmolyzed, apiculus ca. $0.6-0.9 \times 0.4-0.6$ $\mu \mathrm{m}$; exact colour of spore deposit unknown.

Anatomy of cortex of pileus. Epicutis 35$70 \mu \mathrm{m}$ thick, hyphae subparallel to more or less interwoven, 2.0-4.4 $\mu \mathrm{m}$ in diameter, rich intracellular and faint brownish membranal pigments present; subcutis not differentiated.

Ecology. In woodland with some character of grass-herb forest, in litter of Picea, often mixed with litter of broad-leaved trees, sometimes on areas burnt-over earlier. First half of October (Fig. 5).
Distribution. Hemiboreal zone, in eastern parts of the area, near sea level. Very rare. (Fig. 143).

\section{Specimens examined.}

Sweden: Uppland. Bälinge (1, Löten 5. X. 1937, S. Lundell, s.n. C. subinversa ad int.; UPS); Älvkarleby (2: Billudden 7. X. 1945, J. A. Nannfeldt \& G. Sandberg, s.n. C. sp., UPS; Brämsand 13. X. 1946, G. Stenlid, s.n. C. sp., UPS).

Discussion. I myself have not collected C. gracilis, so the descriptions of the macroscopical features as well as the odour and taste have been cited from BigELow (1968, s. n. C. gilvaoides v. gracilis).

In spite of the opinion of its authors, the present taxon clearly represents a species of its own rather than a variety of $C$. gilvaoides. It differs distinctly from $C$. gilvaoides in odour and taste (farinaceous and fungoid respectively) and in spore size and shape, all characters of high diagnostic value in Clitocybe. According to the description of Bigelow (op. cit.), there is also a difference in basidiocarp size, which I observed as well, C. gracilis being more slender («gracitis $« !)$. Moreover, the colours of C. gracilis are slightly less bright, slightly less red-tinged.

The present three specimens and the holotype agree perfectly in all respects. The odour has been recorded as farinaceous in the label notes of the Fennoscandian specimens, while according to BigELow (op. cit.), only the taste is farinaceous, the odour being «pungent«. According to my experience (see p. 17-18), the odour is always farinaceous when the taste is so, though in a few cases less distinct and easily defined than the taste. The spore length of $C$. gracilis cited by BIGELow (op. cit.) is too small. According to my measurements, the length in the type specimen is about the same as in the Fennoscandian material.

This is obviously the first time that C. gracilis is reported from Europe, or outside N. America. It is interesting that the species is now known from three localities in the first-named continent whereas the type specimen is the only specimen existing from N. America. 
Section VII. Candicantes (Quél.) Singer \& Digilio, Lilloa 25: 28. 1952.

Basionym: Omphalia [taxon without designation of rank] Candicantes Quélet, Flore mycologique de la France et des pays limitrophes, 000. 1888. - Typus: No original designation. Lectotype (Int. Code Bot. Nomencl., Art. 22) Omphalia candicans ([Pers.] Fr.) Quél. (= C. candicans).

Pileus small to medium-sized, hygrophanous when adult and old, but, at least in C. candicans and C. pruinosa, not hygrophanous in young fruit bodies, pruinose (not surely in the case of C.laricicola, though its pileus margin, at least, is pruinose in exsiccates), not translucent-striate (in C. laricicola?) (except occasionally at margin in very old fruit bodies of some species), usually very pale when fresh/moist, white to buff, only in C. pruinosa grey-brown to reddish brown at first, sometimes becoming pinkish-tinted in exsiccates, depressed (sometimes infundibuliform) when adult; margin usually distinctly inrolled for a rather long time; surface usually dry, rarely \pm viscid, smooth. Stipe often slender, the base with white tomentum, rarely also a few rhizoids, in C. pruinosa conspicuous rhizoids and firm compressed mycelial hairs present, too. Lamellae very pale, being white to buff when fresh, often turning yellow, or pinkish in exsiccates. Flesh hygrophanous (in C.laricicola?). Odour fungoid, or somewhat acidulous, or faintly fragrant, strawberry-like, exsiccates being odourless. Spores small, up to ca. $6.5 \mu \mathrm{m}$ long and ca. $3.8 \mu \mathrm{m}$ broad, all to the great majority single in preparations (in G.candicans, however, sometimes up to almost $50 \%$ in tetrads in preparations made of lamellae), all obtuse-based, most elliptical to oblong, or ovate, or obovate, none lacrymoid, plage applanated, contents \pm homogeneous, apiculus \pm thin, ca. $0.5-0.9 \times 0.3-0.5(-0.7) \mu \mathrm{m}$; colour of spore deposit \pm pure white when known (i.e., in C.candicans and C. pruinosa). Subcutis not differentiated; membranal and very small-grained «normal « encrusted pigments absent in hyphae of pileus, but large epicellular crystals present, being located in more or less conspicuous layers on hyphae of epicutis or uppermost and/or lowest tramal hyphae, most abundant and constant in C. candicans and C.pruinosa (for more information, see p. 27). In forests, or exclusively man-made habitats, or alpine vegetation, not infrequently on calcareous ground, in litter of different kinds, or on bare soil; from end of July to end of May but mostly in the autumn. Temperate to oroarctic, but lacking in districts with very oceanic climate.

Discussion. The present section may be less homogeneous than the others in this study. For a better understanding of the Candicantes and a better delimitation of this section, careful attention should be paid in future especially to the exact colour of the spore print, the pileus surface (whether pruinose or not), and the water-absorbing capacity (hygrophany) of different parts of the fruit body.

There are several additional, apparently mostly undescribed species of Candicantes (especially in open vegetation, such as ruderal and alpine), often very nearly related to each other and the recognized species of this section, but the material so far available is defective and does not allow their inclusion.

The basionym of the present section should be typified in a way similar to the typification of Infundibuliformes (see p. 60), and the different lectotypes proposed earlier must be rejected. Singer (1951) proposed C. suaveolens ([Schum.] Fr.) Kumm. and later (1962) C. rivulosa ([Pers.] Fr.) Kumm., but these would not be suitable in any case because in my opinion they are nomina dubia (especially since there is no type material in C or L).

Konrad and Maublanc are almost uniformly regarded as the last authors (those after the brackets) of the present sectional name, but this usage is not valid, since these authors (1924-1937) combined the sectional (this rank was indirectly indicated by them) name Candicantes with the subgenus Eu-Clitocybe Konr. \& Maubl. Singer and Digilio were the first authors to combine the sectional name with the correct citation (subgenus Clitocybe) of the type subgenus as indicated by the prevailing nomenclatural rules. They again made the combination unintentionally, as in the case of Infundibuliformes (p. 61). 
16. Clitocybe candicans ([Pers.] Fr.) Kummer, Der Führer in die Pilzkunde, 122. 1871.

Basionym: Agaricus candicans [Pers.] Fries, Syst. Mycol. 1: 91. 1821. - Typus: No original designation. No material of FrIes existing. Neotype (selected by Singer 1961 as lectotype) examined: «Agaricus candicans Syn. Fung.« (Herbarium C. H. Persoon, L, no. 910.250 $-1606)$.

Figs. 16, 53, 101.

Pileus $1.5-5 \mathrm{~cm}$ broad, at first nonhygrophanous but soon with watery spots or circles and weakly hygrophanous when adult and old, white-pruinose, not translucentstriate (or the margin weakly so in very old fruit bodies), ground colour, the pruina excluded, pale buff (near $9 \mathrm{~B} 2$ ) or with greyish-lilac tones (near 10 B 2) or very faintly brownish, disc only rarely slightly darker, in exsiccates the same colour as when moist or slightly darker, e.g. 9 B 2, 10 B 2 or pearl-greyish, $11 \mathrm{~B} 2$, rarely whitish with faint yellowish tint, at first indistinctly convex soon becoming plane and slightly depressed, rarely vase-shaped and almost infundibuliform finally; margin somewhat inrolled for a long time, finally becoming \pm horizontal; surface usually totally dry or weakly viscid (very rarely almost slimy), more or less mat, smooth.

Stipe $2.5-6.0 \times 2-5(-8)$, in moist condition \pm concolorous with pileus, in exsiccates somewhat yellowish, $9 \mathrm{E} 2,9 \mathrm{~F} 2$, in older exsiccates more brownish-tinted, 9 D 5, 9 F 5, rarely almost concolorous with pileus, equal or indistinctly enlarged either downwards or upwards, extreme base often somewhat curved, attenuated and often indistinctly radicate, at times solid, at times becoming hollow in age, terete, rarely compressed; surface dry, \pm mat or slightly shining when moist, but almost always strikingly shining in exsiccates, usually with thin fibrillose coating; the base with scanty to rather abundant white tomentum only (occasionally in addition a few rhizoids or indistinct mycelial hairs).

Lamellae short decurrent, angle of attachment rather great $\left(40^{\circ}-60^{\circ}\right)$, in most deeply depressed pilei longer and more narrowly decurrent (angle even $25^{\circ}$ ), usually almost pure white when moist thus being slightly paler than pileus, in exsiccates generally pale yellow (e.g., slightly paler than $9 \mathrm{~F} 2$ ), rarely dirty whitish or concolorous with pileus, in 4 verticils, $40-60$ reach the stipe, being broadest in the middle or slightly towards the stipe, $2-4 \mathrm{~mm}$, in the middle 1.5-4 times broader than overlying context is thick, a few rarely forked or intervenose; edges usually straight.

Odour, especially when bruised, slightly acidulous (of same quality as that of Paxillus involutus but fainter), rarely faintly «alkaline

Taste mild, but slightly disagreeable.

Spores 4.6-6.6(-7.8) × 2.6-3.6 $\mu \mathrm{m}$, most single in all preparations, a minor proportion (sometimes up to almost $50 \%$ ) in tetrads in preparations made of lamellae, all obtuse-based, most almost always \pm ovate, the rest oblong to narrowly elliptical, contents \pm homogeneous, apiculus ca. 0.5$0.8 \times 0.3-0.4 \mu \mathrm{m}$; spore deposit pure white.

Anatomy of cortex of pileus. Epicutis distinct, $50-140 \mu \mathrm{m}$ thick, hyphae \pm parallel, 2.0-6.0 $\mu \mathrm{m}$ in diameter, only intracellular pigment present, outermost hyphae rarely gelatinized; subcutis not differentiated.

Ecology. Solitary, or in groups, more rarely in rows, in various kinds of forest (dry heath to grass-herb forest, very rarely even somewhat paludified, \pm eutrophic spruce or Alnus glutinosa forest), in litter of both deciduous (Alnus glutinosa, A. incana, Betula, Corylus, Fagus, Quercus, Tilia) and coniferous (Larix decidua $\mathrm{x}$ leptolepis, L. cf. sibirica, Picea, Pinus) trees, rarely in herbaceous litter, once found in decaying wood of Corylus, sometimes among forest mosses (once Sphagnum). From end of July to latter half of November (Fig. 5).

Distribution. Temperate to northern boreal, but lacking in districts with very oceanic climate, up to $1040 \mathrm{~m}$ (S. Norway). Rather common to very common. (Fig. 144).

\section{Specimens examined.}

Norway: Akershus. Moss (2); Nannestad (2); Oppegård (1); Oslo (1); Ski (6). — Buskerud. Nes (1); Norderhov (1). - Vestfold. Sandefjord (1). - Troms. Tromsø (1). - Finnmark. Karasjok (1).

Sweden: Skåne. Dalby (1); Ravlunda (1); Tolånga (1). - Blekinge. Karlskrona (1). - Småland. Almesåkra (2); Bringetofta (2); Dörarp (1); Femsjö (15, including Lundell \& NANN- 
FELDT: «Fungi Exsiccati Suecici... nos. 1728 [S, UPS] and 1729 [S]); Kärda (1); Nässjö (1); Voxtorp (1); Värnamo (1); Växjö (1). Öland. Böda (1). - Östergötland. Skedevi (2). - Västergötland. Göteborg (3); Surteby (1); Sätila (1). - Halland. Fjärås (2). — Södermanland. Botkyrka (1). - Uppland. Adelsö (1); Bondkyrka (21); Djurö (2); Frösunda (1); Ingarö (1); Munsö (1); Ö. Ryd (2); Solna (2); Stockholm (9); Uppsala (17, including LundeLI \& Nannfeldt: «Fungi Exsiccati Suecici... «, no. 207, in S, UPS, first distributed under the name $C$. dealbata, later «corrected « to $C$. tenuissima); Värmdö (1); Älvkarleby (1); Ärentuna (1). Angermanland. Resele (1); Sollefteå (1); Tåsjö (1). - Jämtland. Åre (1). — Västerbotten. Umeå (2). - - Norrbotten. Nedertorneå (1). Torne Lappmark. Jukkasjärvi (1).

Finland: Ahvenanmaa. Vårdö (1). - Varsinais-Suomi. Aura (1); Halikko (1); Kemiö (1); Lohja mlk. (15); Masku (2); Mietoinen (1); Nauvo (1); Parainen (1); Pohja (2); Suomusjärvi (1); Taivassalo (1). - Uusimaa. Espoo (3); Helsinki (6); Helsinki mlk. (2); Kauniainen (1); Tammisaari (2); Tuusula (1). - EteläKarjala. Hamina (1); Miehikkälä (1); Vehkalahti (1); Virolahti (1). — Satakunta. Lappi (1); Metsämaa (1); Tyrvää (1); Vampula (1); Yläne (1). - Etelä-Häme. Asikkala (1); Hattula (1); Jämsä (1); Kuhmoinen (2); Lammi (2); Padasjoki (1); Pertunmaa (1); Riihimäki (2); Somero (3); Tammela (10). - Etelä-Savo. Imatra (1); Juva (1); Mäntyharju (1); Rantasalmi (1). - Laatokan Karjala. Parikkala (2) ; Simpele (1). - Pohjois-Häme. Toivakka (1). - Pohjois-Savo. Kuopio mlk. (1); Lapinlahti (2); Siilinjärvi (1). - Pohjois-Karjala. Juuka (1); Tuupovaara (2). - Keski-Pohjanmaa. Paavola (1). - Pohjois-Pohjanmaa. Kiiminki (1); Muhos (1). - Inarin Lappi. Inari (1); Utsjoki (9).

U.S.S.R.: Leningrad Region. Vyborg (Viipuri mlk.) (4); Valkjärvi (1).

Discussion. This species, which is often confused with others, can be recognized by: the small size, usually only depressed whitish pileus, which is often pearl-greyish in exsiccates, slender stipe, which is shining in exsiccates, short decurrent crowded lamellae, which are \pm pure white when moist but usually become yellow in exsiccates, faint acidulous smell, and rather small, predominantly narrowly ovate spores, which are pure white in deposit. These and some ecological characters distinguish C.candicans from those species which superficially are most similar, namely C. dealbata, C.ruderalis, C.laricicola, C.hydrogramma, and some species of the subgenus Roseospora. The spore characters of $C$. candicans, though not striking, must be very carefully observed, for they are in most cases very valuable in identifying this species.

Genetic variation seems to be evident in the following characters: size, colour and shape of pileus, length and diameter of stipe, degree of decurrence of lamellae and their colour when dry, thickness of flesh, length and breadth of spores, and nature of the outermost hyphal walls of the epicutis (whether gelatinized or not).

Since there is no proof that the specimen which Singer (1961) selected for lectotype was collected before 1801 (the year of publication of A.candicans Pers. in Persoon's «Synopsis Fungorum...«), I regard that specimen as neotype rather than lectotype.

17. Clitocybe dealbata ([Sow.] Fr.) Kummer, Der Führer in die Pilzkunde, 121. 1871.

Basionym: Agaricus dealbatus [Sow.]. Fries, Syst. Mycol. 1: 92. 1821. - Typus: No original designation. No material of FrIes existing, and none of Sowerby in $K$. I have examined a specimen from England belonging to the present species. A neotype has not been designated.

Figs. 54, 102.

Spores $4.0-6.0 \times 2.5-3.3 \mu \mathrm{m}$, almost all single in all preparations, all obtuse-based, most narrowly elliptical to oblong, the rest (rarely even ca. $50 \%$ ) being \pm ovate, contents homogeneous, apiculus ca. 0.6$0.9 \times 0.3-0.5 \mu \mathrm{m}$; exact colour of spore deposit unknown.

Anatomy of cortex of pileus. Epicutis 80$120 \mu \mathrm{m}$ thick, changing gradually into the pileus trama, hyphae subparallel to \pm interwoven, $2.0-5.0 \mu \mathrm{m}$ in diameter, faint intracellular pigment and some large encrusted crystals (see p. 27) present; subcutis not differentiated.

Ecology. In man-made \pm open habitats only, i.e., on lawns, in gardens, parks, pastures, stubble-fields, rubbish dumps, etc., on various kinds of more or less bare, nutrient-rich soil (once on calcareous, almost pure sand), often among grasses and herbs, and mosses (Ceratodon purpureus, Rhytidiadelphus squarrosus, Brachythecium sp., etc.) typical of such habitats. From beginning of August to end of October (Fig. 5).

Distribution. Temperate and hemiboreal, but lacking in western parts of the area, up to ca. $140 \mathrm{~m}$ (S. Sweden). In inhabited districts, rare. (Fig. 145). 


\section{Specimens examined.}

Sweden: Småland. Femsjö (3). - Öland. Böda (1); Köping (1); As (2). - Gotland. Visby (2). - Östergötland. Skedevi (1). - Halland. Onsala (2). - Uppland. Bondkyrka (2); Bälinge (3, Lundell \& NannfeldT: «Fungi Exsiccati Suecici... , no. 510 , s.n. C. rivulosa, in S, UPS); Roslags-Kulla (1); Stockholm (1); Uppsala (3); Värmdö (1).

FinLAND: Varsinais-Suomi. Turku (1). - Uusimaa. Helsinki (2); Porvoo (1).

Discussion. This species is characterized by the pileus, which is whitish-pruinose when moist but has faint lilac tones (like the stipe) in exsiccates, and whose margin is usually strongly inrolled, the lamellae, which are pale when moist but dirty pinkish to dirty pinkish buff (darker than the cap and stipe !) in exsiccates, and the short, narrow spores, which are single in preparations. The unusual habitats are also a very important diagnostic character of $C$. dealbata, because it is morphologically very similar to e.g. the forest species C.phyllophila in the moist condition (especially small basidiocarps of the latter). Its delimitation from the two other species with similar habitats, $C$. ruderalis and $C$. agrestis, is discussed under those species.

This species seems to be the famous «small, white poisonous species of lawns and roadsides which has especially often been referred to as C. dealbata or C. rivulosa, in $\mathrm{N}$. America evidently as C.morbifera, too. It may be native to steppe-like vegetation in E. Europe, for, through the kindness of Dr. G. Bohus (BP), I have received some specimens labelled C.corda Schulz. ex Szem., collected in grassy vegetation in Hungary, which seem to belong to the present species.

The nomenclature of $C$. dealbata is confusing, and for the present I have preferred to use this well-known name. Neither FrIES nor SOWERBy seem to have left any material of this species. I have studied 13 specimens from England (K) labelled C. dealbata, but the present species was not represented among them, though most of them seemed to belong to species of the section Candicantes. However, one specimen from England, without information on the locality, is deposited in $\mathrm{S}$. The species occurs also in FrIEs' native parish, Femsjö, in S. W. Sweden. It is not certain whether FrIes in his «Systema Mycologicum《 is referring to
SowERBy when describing the typical $A$. dealbatus.

18. Clitocybe ruderalis Harmaja, n. sp.

Figs. 55, 103.

Clitocybes dealbatae (sensu studii praesentis) valde similis, sed sporis crassioribus (crassitudine 2.9-3.7 $\mu \mathrm{m}$ ); lamellis angustioribus et colore leniter pallidiore in exsiccatis. - Holotypus: Finland, prov. Uusimaa, town Helsinki, Pasila rubbish dump 18. IX. 1966, Harri Toppari ( = Harri Harmaja) ( $\mathrm{H}$; isotype in MICH).

Spores $4.0-6.0 \times 2.9-3.7 \mu \mathrm{m}$, all but a few single in preparations, all obtuse-based, most \pm broadly elliptical, the fairly large remainder being ovate, contents irregularly guttulate, apiculus ca. $0.5-0.7 \times 0.4-0.5$ $\mu \mathrm{m}$; exact colour of spore deposit unknown.

Anatomy of cortex of pileus. Epicutis 50$80 \mu \mathrm{m}$ thick, hyphae more or less parallel, $2.0-6.5 \mu \mathrm{m}$ in diameter, faint intracellular pigment present, and usually large encrusted crystals, too (for more information, see p. 27); subcutis not differentiated.

Ecology. On rubbish dumps, on bare, fertile soil, sometimes together with the moss Ceratodon purpureus. Middle of September (Fig. 5).

Distribution. Found in the hemiboreal zone, in eastern part of the area, near sea level. Very rare. (Fig. 145).

Specimens examined.

Finland: Uusimaa. Helsinki (1, holotype).

Discussion. Differs from $C$. dealbata, which has similar habitats, in having narrower, more decurrent, and paler (in exsiccates) lamellae, and broader spores. For its delimitation from C.agrestis, see under the latter.

19. Clitocybe laricicola Singer, Ann. Mycol. 41: 28. 1943.

Typus: No original designation. Lectotype (selected here) : $:$ C. laricicola A $396 \ll$, leg. R. Singer in the U.S.S.R., Altai Mts. (LE).

Figs. 56, 104.

Spores $4.0-5.6 \times 2.9-3.5 \mu \mathrm{m}$, almost all single in preparations, all obtuse-based, slightly compressed (appearing slightly broad- 
er in face view than in side view), most broadly to moderately elliptical and ovate in varying proportions, the remaining few (sometimes perhaps none) \pm obovate, contents \pm homogeneous, apiculus ca. $0.5-0.8$ $\times 0.3-0.4 \mu \mathrm{m}$; exact colour of spore deposit unknown.

Anatomy of cortex of pileus. Epicutis ca. $35-50 \mu \mathrm{m}$ thick, hyphae parallel to slightly interwoven, $2.0-6.0 \mu \mathrm{m}$ in diameter, containing intracellular pigment, especially the outermost, other pigments absent; subcutis not differentiated.

Ecology. In subalpine Betula (B. «tortuosa $)$ and Pinus forest, and perhaps in some more open habitats, too, sometimes above the forest limit in Dryas octopetala heaths, mostly on various kinds of bare, fairly fertile soil (also on soil with large fraction of sand), sometimes in scanty herbaceous or Pinus litter, often among small (often calciphilous) mosses, such as Mnium ortorrhynch$u \mathrm{~m}$. From first half of August to beginning of September (Fig. 5).

Distribution. Northernmost/upper (subalpine) parts of the northern boreal zone, sometimes also in the oroarctic (alpine) zone, from an altitude of some hundred metres (N. Norway, N. Sweden) up to ca. $1000 \mathrm{~m}$ (N. Norway). Probably not infrequent near the forest limit in districts with calcareous soils. (Fig. 146).

Specimens examined.

Norway: Nordland. Fauske (1, Lund-Veten 19. VIII. 1954, F.-E. Eckblad, s.n. C. diatreta; O); Saltdal (1, between Saltfjell hotel and Løndalselven 15. VIII. 1954, G. \& F.-E. Eckblad, s.n. C. cerussata; O). - Troms. Målselv (1, Fosshøgda 26. VIII. 1954, J. Stordal, s.n. C. diatreta; O); Nordreisa (1, Sappen, near the school 2. IX.1954, J. Stordal, s.n. $C$. diatreta; O).

SWEDEN: Torne Lappmark. Jukkasjärvi (2: Björkliden-Abisko 9. VIII. 1915, L. Romell, s.n. C. sp., S; Abisko, Björkliden 13. VIII. 1965, A. Bresinsky, s.n. G. dealbata, M).

Discussion. I myself have not collected the present species.

Exsiccates of $C$. laricicola are usually easily recognized by the pale pinkish to distinctly sordid pink colours of the more or less shining pileus and stipe, and the contrasting yellowish to yellowish buff of the lamellae. The size and shape of the spores, which are broad and single in preparations, are good characters, too, especially when compared with those of $C$. diatreta, which often occurs in the same districts. The distribution and ecology of $C$. laricicola also make it easier to identify it.

The specific epithet, indicating a substrate of Larix, is unfortunate, for, like the other species of Clitocybe, C.laricicola is not restricted to the litter of certain tree species, or to a wood substrate, and it is in fact not dependent on the presence of litter at all.

This is obviously the first time that C. laricicola is recorded in Europe, or outside Asia.

Singer did not designate a type specimen in his original description. From Leningrad (LE) I received two specimens, which had clearly been labelled by Singer as C. laricicola, and which both satisfactorily corresponded to the somewhat incomplete original description. Each of them bore the word «Typus«, written, however, with other ink and in other handwriting. Of them, I have selected for lectotype the smaller specimen, «A 396 «, in which the fruit bodies are clearly attached to some needles of Larix and a piece of wood (obviously Larix). The other specimen, «A $519 \ll$, comprises larger fruit bodies among the moss Rhytidium rugosum and Larix needles. The spores of the latter specimen are mostly in tetrads and are also thinner than those of the former. Specimen «A 519 « probably represents an undescribed northern species, related to C. phyllophila (see p. 84).

20. Clitocybe pruinosa (Lasch ex Fr.) Kummer, Der Führer in die Pilzkunde, 120. 1871.

Basionym: Agaricus pruinosus Lasch ex Fries, Epicrisis systematis mycologici..., 75. 1836-1838. - Typus: No original designation. The type material consists of one single specimen, preserved in the E. Fries Herbarium in UPS, and it bears the following text, obviously written by LASCH: «Agaricus pruinosus m. (forma minor.) Lasch« (Fig. 58). This specimen is herewith designated as lectotype.

Figs. 17, 57, 58, 105.

Pileus $2-5 \mathrm{~cm}$ broad, at first non-hygrophanous but hygrophanous in adult and old fruit bodies, greyish-pruinose (in late spring the pruina may be observable over the disc only), the margin usually non-striate, sometimes translucent-striate in old fruit bodies in spring, ground colour (the pruina excluded) 
in fresh young fruit bodies reddish brown,

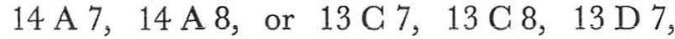
somewhat paler after loss of moisture (the flesh having faded), about between $12 \mathrm{~A} 4$ and $12 \mathrm{~B} 4$, colours in fruit bodies of more or less advanced age (i.e., in spring) bleached, when moist some pale shade of brown with reddish tints, $12 \mathrm{D} 6,12 \mathrm{D} \mathrm{7}, 12 \mathrm{E} 6$, $12 \mathrm{E} 7$, the disc being slightly darker, in the faded condition pale brownish, about $9 \mathrm{C} 2$, in exsiccates young pilei greyish brown, e.g. 13 D 6 or 14 B 6 , old ones with indistinct colours, being brownish, or with faint buff or greyish shades, the disc, at least (in young pilei the whole surface), usually characteristically \pm shining and grey-pruinose, pileus becoming plane very early, and then more or less depressed, finally slightly depressed, or bowl-shaped, or even infundibuliform; margin bent down to almost inrolled at first becoming more or less horizontal; surface dry or very weakly viscid, smooth.

Stipe 2-5 $52-5$, slender, concolorous with pileus to much paler than it, in the latter case being more or less buff, e.g. in moist condition $11 \mathrm{~B} 4$, in exsiccates often somewhat darker than when moist, equal or indistinctly enlarged both upwards and downwards, extreme base obtuse, solid for a long time finally becoming hollow, more or less terete; surface dry, more or less glabrous, pruinose in manner similar to that of pileus; at the base some whitish tomentum uppermost, lower down scanty to abundant, \pm hyaline, \pm firm, compressed, ramose mycelial hairs, and below them some white, thin to rather thick rhizoids.

Lamellae short decurrent, angle of attachment variable, even $40^{\circ}-50^{\circ}$, almost white to buff when moist, creamy yellow to dirty buff in exsiccates, in 4-5 verticils, $30-45$ reach the stipe, being broadest in the middle or proximally, $3-5 \mathrm{~mm}$, in the middle ca. 4 times broader than overlying context is thick, sometimes a few forked near the stipe, sometimes weakly intervenose in old pilei.

Odour fungoid or slightly acidulous.

Taste mild, fungoid, sometimes slightly acidulous.

Spores $4.5-6.5(-7.5) \times 2.5-3.8 \mu \mathrm{m}$, single in all preparations, rather variable in size and shape, all obtuse-based, most obovate and elliptical in varying proportions, the rest oblong and ovate, contents \pm homo- geneous, apiculus ca. $0.7-0.9 \times 0.4-0.7$ $\mu \mathrm{m}$, often being deformed; in vernal fruit bodies some to many spores often seem to have germinated with a (sometimes two or three) very thin germ tube, mostly arising from the apical end; spore deposit \pm pure white.

Anatomy of cortex of pileus. Epicutis 20 $60 \mu \mathrm{m}$ thick, hyphae subparallel to somewhat interwoven, 3.5-13.0 $\mu \mathrm{m}$ in diameter, usually only rich intracellular pigment present, sometimes scattered intercellular crystals, too; subcutis not differentiated.

Ecology. In groups, rarely solitary, \pm exclusively in coniferous woods (sometimes with admixture of deciduous trees), mostly in dry to mesic heath forests (VT, MT), sometimes also in grass-herb forests, usually in litter of Picea or Pinus, sometimes amongst the mosses Hylocomium or Pleurozium. From middle of October to end of May (in the north even in June) occurring throughout the winter (Fig. 5).

Distribution. Temperate to northern boreal except for the northernmost/upper (subalpine) parts of the latter zone, but lacking in districts with very oceanic climate, up to ca. $350 \mathrm{~m}$ (S. Norway). Rather infrequent. (Fig. 147).

\section{Specimens examined.}

Norway: Akershus. Baerum (1); Oslo (9); Ski (3). - Oppland. Lunner (1). - Buskerud. Lier (2). - Vestfold. Tjølling (1). —. Telemark. Eidanger (1).

Sweden: Skane. Åhus (1). - Gotland. Bro (1); Hörsne (1); Stenkumla (1); Visby (1). - Östergötland. Klockrike (1); Skedevi (4); St. Åby (1). - Västergötland. Österplana (1). - Södermanland. L:a Malma (1). - Uppland. Almunge (1); Björklinge (2, Lundell \& NANNFELDt: «Fungi Exsiccati Suecici...«, no. 1741, s.n. C. rhizophora, in S, PR); Bondkyrka (8); Börje (2); Danmark (1); Djurö (1); Funbo (1); Kulla (1); Lena (2); Ö. Ryd (1); Sigtuna (1); Stockholm (1); Uppsala (1); Uppsala-Näs (1); Vallentuna (1); Älvkarleby (1) ; Ärentuna (3). - Dalarna. Rättvik. (1). - Gästrikland. Gävle (3).

Finland: Ahvenanmaa. Eckerö (1). - Varsinais-Suomi. Lohja mlk. (12). - Uusimaa. Elimäki (2); Espoo (1); Helsinki (1); Kauniainen (2); Porvoo (1); Tammisaari (1); Tenhola (3); Tuusula (1). - Etelä-Karjala. Vehkalahti (1). Etelä-Häme. Hattula (1); Lammi (1); Loppi (1); Längelmäki (2); Tammela (1); Tuulos (1). - Pohjois-Savo. Kuopio (1); Suonenjoki (1). Pohjois-Pohjanmaa. Kiiminki (4).

U.S.S.R.: Karetian A.S.S.R. Oulanka (1).

Discussion. C. pruinosa is distinguished by the pruinose pileus, which is rather dark 
except in late spring, the striking mycelial elements at the base of the stipe, the spore size and shape, and the peculiar encrusted pigment (see p. 27 and 73). In spring this species may be (and has been) confused with $C$. rhizophora. It should be noted that in the latter species the fruit body is fleshier, the pileus is flesh-coloured when moist (and usually dissimilar in colour under other conditions as well), lacks a pruina, and is usually not shining when dry, the lamellae never have a distinct yellow tinge in exsiccates, the spores are smaller and of somewhat different shape, and the occurrence is strictly vernal.

There may be some genetic variation, at least in the shape (depth) of the pileus as well as the density of the lamellae.

Though the original description of $C$. pruinosa as well as that of the much-used name (obviously a synonym) C. radicellata Gill. 1874 indicate autumnal species, the present species has usually been considered a vernal one. During the present study it was observed both in the field and the herbarium (notes on the labels) that $C$. pruinosa does also occur in the autumn. The first specimens in the spring were collected in February, late March and early April, often in places where the snow had just melted, and in the vicinity of patches of snow. This suggested that the species possibly occurred throughout the winter below the snow, and to study this hypothesis I marked some young buttons of $C$. pruinosa in the rural district of Lohja, in SW Finland, in late November 1967 and late October 1968. In both cases the marked fruit bodies were found in the following spring (April), about half a year later, having overwintered on their sites! They were larger and somewhat paler in colour than in the autumn, and the pilei were weakly hygrophanous. They appeared to be alive and were quite normal in all respects. Spore deposits were obtained, and the spores were found to be completely similar to those of autumnal fruit bodies. The fruit bodies thus appear to tolerate freezing well, like many species of the late autumn (cf. p. 39). Freezing may cause the pilei to become hygrophanous since they are not so in the autumn, but this difference may also be due to the fact that in autumn young fruit bodies only are present. It seems very probable that $C$. pruinosa, though having annual basidiocarps, is actually a winter species. It remains to be discovered whether $C$. pruinosa is able to produce new fruit bodies in the spring, too, or can only do so during the autumn (and perhaps also mild weather in the winter). Sarcoscypha coccinea (Pezizales) may have a similar fruiting period, for I have seen apothecia of this species in Lohja in late autumn and among patches of melting snow, in early spring.

It is very probable that LAScH collected the type specimen in the same district as the specimens he collected for RABENHORST's exsiccate «Herbarium Mycologicum... editio nova [series I], Dresdae 1856 « where specimens of «Agaricus (Clitocybe) pruinosus Lasch" were distributed under the number 205 (specimens in $\mathrm{H}$ and $\mathrm{S}$ studied). According to the labels, these specimens were collected by LASCH near the little town Driesen, which now belongs to Poland, its name being Dresdenko. The date of collection is lacking as in the type specimen.

Clitocybe verna Egeland ex Lundell (LuNDELL 1937) is no doubt a synonym of C. pruinosa. Strangely enough, I did not find any type material in the Fennoscandian herbaria, but LuNDELL's description and figure clearly refer to $C$. pruinosa, which, in addition, occurs in several places in the probable type locality, the Oslo district in southeastern Norway.

\section{Section VIII. Vernae (Sing.) Harmaja, n. comb.}

Basionym: Clitocybe sugbenus Eu-Clitocybe section Vernae Singer, Ann. Mycol. 41: 34. 1943. - Typus: No original designation. Lectotype (selected by Singer 1951) Clitocybe rhizophora (Vel.) Joss.

Pileus small to medium-sized, hygrophanous already when young, neither pruinose nor translucent-striate, more or less fleshcoloured when moist, only depressed when adult; margin somewhat inrolled for a long time, not pruinose; surface dry, smooth or areolate over disc. Stipe rather thick, the base with scanty tomentum, conspicuous, 
firm, compressed, \pm hyaline mycelial hairs, and long and often thick rhizoids. Lamellae adnate to short decurrent, occasionally somewhat sinuate, \pm buff. Flesh rather thick. Odour fungoid to somewhat fruity. Spores small, $3.8-5.5(-7.0) \times 1.9-3.0(-3.5)$ $\mu \mathrm{m}$, single in all preparations, all obtusebased, most of them elliptical to oblong, the rest ovate or obovate but never lacrymoid, plage applanated, contents homogeneous, apiculus small, ca. $0.5-0.8 \times 0.4 \mu \mathrm{m}$; spore deposit \pm pure white. Subcutis absent; membranal and encrusted pigments absent in hyphae of pileus. In woods, usually in

21. Clitocybe rhizophora (Vel.) Josserand, in Josserand et Pouchet, Bull. Soc. Linn. Lyon 10: 51. 1931.

Basionym: Collybia rhizophora Velenovský, Česke Houby 2: 335. 1920. - Typus: No original designation. Lectotype (selected here): «Collybia rhizophora Vel. = Clitocybe vermicularis, Jíloviště, $1914-\mathrm{V}$, leg. et det. J. Velenovský, PR 619937《 (PR).

Figs. 1 c, 18, 59, 60, 106.

Pileus 2.5-4.5 $\mathrm{cm}$ broad, hygrophanous already when young, neither pruinose nor translucent-striate, totally flesh-coloured, reddish-brown when moist, $13 \mathrm{~B} 8,13 \mathrm{~B} \mathrm{9,}$ alutaceous with faint reddish tint when

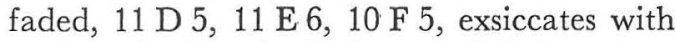
various shades of pale brown, $9 \mathrm{G} \mathrm{5}, 10 \mathrm{D} \mathrm{5}$, $10 \mathrm{E} 4,10 \mathrm{~F} 5$, sometimes as dark as $11 \mathrm{D} 6$, more or less convex at first becoming plane, even in old fruit bodies plane to somewhat depressed; margin always more or less bent down, not pruinose; surface dry, \pm mat, smooth or slightly areolate over disc.

Stipe 1.5-6.5 $\times$ 5-15, more or less thick, watery-brownish or buff when moist, becoming very pale brownish when faded and in exsiccates, equal or indistinctly enlarged downwards, extreme base obtuse, solid at first apparently becoming hollow, cylindrical or somewhat compressed; surface dry, mat, glabrous or with very thin white fibrillose coating, especially at apex; the base with scanty white tomentum, fairly abundant, firm, compressed, \pm hyaline, ramose mycelial hairs, and below them short to very long, often thick, white rhizoids.

Lamellae obliquely adnate to short decur- litter of conifers; from end of April to late June. Temperate to middle boreal, but lacking in districts with very oceanic climate.

Discussion. Because of the important differences between C.rhizophora and the species of the preceding section (see e.g. the key, p. 44), I consider it best to restrict the present section to comprise the type species only. Singer obviously included C. pruinosa as well.

The sectional name obviously was not validly combined with the subgenus Clitocybe earlier.

rent, rarely somewhat sinuate and decurrent with teeth, of about the same colour as the stipe in all stages, e.g. in exsiccates $9 \mathrm{D} 4$, $9 \mathrm{~F} \mathrm{5}$, in adult fruit bodies often rather distant, in 3-4 verticils, 35-50 reach the stipe, being broadest in the middle or distally, 3-4 $\mathrm{mm}$, in the middle (1-) 2-3 (-4) times broader than overlying context is thick, rarely a few forked near stipe, not intervenose.

Odour fungoid to faintly agreeable, fruity. Taste mild, fungoid.

Spores $3.8-5.5(-7.0) \times 1.9-3.0(-3.5)$ $\mu \mathrm{m}$, the great majority to all single in all preparations, rather variable in size, all obtuse-based, most narrowly elliptical to oblong, the remaining few ovate, or obovate, contents homogeneous, apiculus ca. $0.5-0.8$ $\times 0.4 \mu \mathrm{m}$; spore deposit \pm pure white (becoming yellowish in herbarium).

Anatomy of cortex of pileus. Epicutis ca. 30-80 $\mu \mathrm{m}$ thick, hyphae subparallel to somewhat interwoven, $1.5-7.0 \mu \mathrm{m}$ in diameter, only some intracellular pigment present, especially in outermost hyphae; subcutis not differentiated.

Ecology. Solitary or in groups in mesic heath forest (MT, OMT, etc.), sometimes in grass-herb woods, consisting of conifers, or mixed deciduous and coniferous trees, usually with Picea as the dominant tree, usually in litter of Picea, sometimes Pinus, rarely in mixed litter of coniferous and herbaceous species, or litter of Alnus incana, or Betula, sometimes among Hylocomium or Pleurozium. From end of April to middle (in the north, to the end) of June (Fig. 5).

Distribution. Temperate to middle boreal, but lacking in districts with very oceanic 
climate, up to ca. $150 \mathrm{~m}$ (N. Sweden, S. Finland). Rare. (Fig. 148).

Specimens examined.

Norway: Østfold. Onsøy (3).

SwEDEN: Gotland. Follingbo (1). - Bohuslän. Torslanda (1). - Södermanland. Botkyrka (1). - Uppland. Almunge (1); Börje (2); Djurö (1); Läby (1); Ärentuna (4). - Norrbotten. Övertorneå (1).

Finland: Ahvenanmaa. Eckerö (1). - Varsinais-Suomi. Karjalohja (1); Koski Tl. (1); Lohja mlk. (9). - Uusimaa. Tuusula (1). -- EtetäHäme. Kuhmoinen (2); Somero (1). - PohjoisSavo. Suonenjoki (1). - Pohjois-Pohjanmaa. Kiiminki (2).

U.S.S.R.: Leningrad Region. Vyborg (Viipuri mlk.) (1).

Discussion. For the delimitation of this species from C.pruinosa, which likewise occurs in spring, and with which it has often been confused (usually under the dubious name C.vermicularis), see under $C$. pruinosa. The other vernal species are not hygrophanous, have distinctly larger spores of more or less different shape, and, except for C. sinopica, only have tomentum at the stipe base. The last-named species, in addition, possesses a farinaceous smell and taste. It must be remembered, however, that C.rhizophora is often found in the faded condition in the dry springtime, and may thus appear non-hygrophanous.
There seems to be slight genetically determined variation in the shades of colour of the fruit body, the length of the stipe, and the length and breadth of the spores.

As already mentioned, this is the species usually called C.vermicularis (Fr.), though Fries did not indicate vernal occurrence (which he seems to have done whenever appropriate), or the presence of rhizoids or strigose hairs at the base of the stipe. A striking figure of the present species is found under that dubious name in BRESADOLA's work (1928, pl. 171), and I have examined a specimen of $\ll C$. vermicularis $\ll$ collected by BRESADOLA and belonging to the present species, preserved in $\mathrm{S}$.

The name $C$. rhizophora has often been used for $C$. pruinosa, and it is unfortunate that VeLENovskýs description and figure of «Collybia rhizophora were not studied more carefully by contemporary and later mycologists, since much confusion might thus have been avoided. The original description as well as Velenovskŕ's specimens in Prague (PR) agree in all respects with the present species and not with $C$. pruinosa. In addition, Velenovský himself later considered his species to be synonymous with $C$. vermicularis, and wrote this opinion on the label of the lectotype, too.

\section{Section IX. Bulluliferae (Sing.) Harmaja, n. comb.}

Basionym: Clitocybe subgenus Eu-Clitocybe section Bulluliferae Singer, Ann. Mycol. 41: 23. 1943. Typus: Holotype Clitocybe hydrogramma ([Bull.] Fr.) Kumm. (originally the nomen invalidum «Clitocybe kuehneri Singer, nom. nov.«, typified with a description and figure representing C. hydrogramma).

Pileus small to medium-sized, hygrophanous, evidently neither pruinose nor translucent-striate (perhaps sometimes striate at margin?), rather pale-coloured in adult fruit bodies when moist, more or less infundibuliform when adult; margin inrolled for a long time; surface smooth, not areolate. Stipe with copious, whitish basal tomentum only, mycelial hairs and rhizoids being absent. Lamellae very pale, being yellowish in exsiccates. Odour rather striking, unpleasant. Spores medium-sized, $5.0-7.0(-8.0) \times 3.0$ $-4.2 \mu \mathrm{m}$, single in preparations, perhaps most of them with confluent bases and lacrymoid, the remainder consisting of acutebased and \pm lacrymoid, and obtuse-based and \pm elliptical spores, plage applanated to distinctly depressed, contents homogeneous, apiculus/apicular region rather thick being ca. $0.5-0.9 \mu \mathrm{m}$ in diameter; spore deposit white according to Bigelow (1962, under $C$. adirondackensis). Vesiculose elements up to $20 \mu \mathrm{m}$ in diameter present in hyphae of epicutis; subcutis absent; membranal and encrusted pigments absent in hyphae of pileus. In fairly fertile woods, in litter of deciduous or coniferous trees; from first half of August to first half of October. Temperate to southern boreal, in eastern parts of the area.

Discussion. The macroscopical and spore characters of $C$. hydrogramma would probably be sufficient to justify placing it in a section of its own, even apart from the 
peculiar features of the epicutis. The section Bulluliferae, as represented by the Fennoscandian species C. hydrogramma, does not belong to the subgenus Pseudolyophyllum as Singer (1962) thought. The more or less pale colours (especially of the lamellae), presence of confluent-based spores, and lack of membranal pigment reveal affinity to the sections Candicantes and Vernae, and the type subgenus, under which it was originally described.

The holotype of the present section, $C$. kuehneri Sing., which was proposed by SinGER (1943) as a nomen novum for C. gatli-

22. Clitocybe hydrogramma ([Bull.)] Fr.) Kummer, Der Führer in die Pilzkunde, 122. 1871.

Basionym: Agaricus hydrogrammus [Bull.] Fries, Syst. Mycol. 1: 69. 1821. Typus: No original designation. No material of FrIEs existing, and none of BUlliard in PC. I have examined a specimen from France (Val d'Oise) belonging to the present species. A neotype has not been designated.

Figs. 61, 107

Pileus 1-6(11) $\mathrm{cm}$ broad, plane or convex at first soon becoming subinfundibuliform to infundibuliform, margin inrolled at first remaining decurved or becoming elevated, at times incised, usually not striate, disc narrowly and deeply depressed, surface appearing glabrous when moist, innately fibrillose when faded, at times subviscid, usually with a satiny luster, color near umber when young and moist, gradually paler to «avellaneous buff series through «isabella color« to «cream buff «, «light buff« «Cartridge buff «, «warm buff «, «pinkish buff or «vinaceous buff«, hygrophanous, whitish to pallid when faded, disc often remaining dark; flesh thin, concolorous with the pileus, moist when fresh, odor strong, resembling that of fish or somewhat spermatic to rancid-farinaceous, taste unpleasant.

Lamellae short decurrent at first soon becoming long decurrent (often unevenly), the posterior ends often forming a collar on the stipe apex, usually close to crowded, rarely subdistant, forked, intervenose or not, narrow, thin, separable from the pileus trama, concolorous with the pileus or somewhat nacea sensu KüHNER, is a nomen invalidum because of the lack of a Latin description or a reference to such. The real, indirectly designated type species is thus the species Kühner (1934, Atlas: Pl. 64) described. The excellent description, coloured figure of the basidiocarp, and the illustrations of the spores and the epicutis in the last-named paper clearly refer to a species which I prefer to call C. hydrogramma ([Bull.] Fr.) Kumm.

The sectional name was obviously not combined with the subgenus Clitocybe earlier.

paler, edges even, straight to somewhat undulate.

Stipe 1-5(7) cm long, 2-7(15) $\mathrm{mm}$ broad at the apex, equal or the apex somewhat enlarged, usually terete, solid-stuffed becoming hollow, usually central, surface appearing glabrous when moist, somewhat innately fibrillose with fading, bases often fused together or somewhat enlarged and not radicating, with copious basal tomentum binding the surrounding debris and appearing water-soaked when moist, concolorous with the pileus or somewhat paler.

Spores $5.0-7.0(-8.0) \times 3.0-4.2 \mu \mathrm{m}$, single in preparations, rather variable in size and shape, perhaps most of them confluentbased and lacrymoid, a good number of them acute-based and \pm lacrymoid, too, the remaining few being obtuse-based and \pm elliptical, plage applanated to distinctly depressed, contents homogeneous, apiculus/ apicular region ca. $0.5-0.9 \mu \mathrm{m}$ in diameter; spore deposit white according to Brgelow (1962, under C. adirondackensis).

Anatomy of cortex of pileus. Epicutis ca. 25-50 $\mu \mathrm{m}$ thick, hyphae more or less parallel, $1.0-5.0 \mu \mathrm{m}$ in diameter, only scanty intracellular pigment present, in places the hyphae inflating, gradually to abruptly, into inamyloid, thin-walled, subglobose to fusiform vesicles, $12-30 \mu \mathrm{m}$ long and $10-20 \mu \mathrm{m}$ broad, with crosswall and clamp connection at either end and rich granulose contents (in exsiccates); subcutis not differentiated.

Ecology. In woods on more or less fertile ground, in litter of Fagus, or Picea. First half of August to first half of October (Fig. 5). 
Distribution. Temperate to southern boreal, in eastern parts of the area, up to ca. $100 \mathrm{~m}$ (S. Finland). Very rare. (Fig. 149).

Specimens examined.

Sweden: Skåne. Bara (1, Torup 11. X. 1948, O. Andersson, s.n. C. parilis; LD); Ivö (2: Ivön 7. X. 1943, O. Andersson, s.n. C. candicans f. phyllophila, LD; Ivön 9. X. 1943, O. Andersson, s.n. C. candicans f. phyllophila, LD). - Blekinge. Karlskrona (4, Lundell \& NANNFeldt: «Fungi Exsiccati Suecici... no, no. 1730, collected in V. Mark 9. IX. 1946 by S. Lundell \& S. Wikland, s.n. C. candicans forma, in S, UPS). - Uppland. Djurö (3: Munkön 24. VIII. 1948, R. Rydberg, s.n. C. sp., S; Munkön 7. VIII. 1949, R. Rydberg, s.n. C. sp., S; Munkön 19. VIII. 1949, R. Rydberg, s.n. C. sp., S).

Finland: Etelä-Häme. Urjala (1, Nuutajärvi, Raikko, Kalkkivuori 23. VIII. 1958, T. Brander \& N. Malmström, s.n. C. fragrans; $\mathrm{H}$ ).

Discussion. Since I myself have not collected the present species, the descriptions of its macroscopical characters as well as those of its odour and taste have been cited from Bigelow (1962). He has treated this species under the no doubt synonymous name $C$. adirondackensis (Peck) Sacc.

I have observed no vesicles on the hyphae of the cortex of the stipe or those of the gill trama, though these are reported by Singer (1943, 1951, 1962).

Raithelhuber (1969) has discussed the occurrence of $C$. hydrogramma in southwestern Germany and the variation of that species. He describes, too, the new variety C. hydrogramma v. gibboides Raith., which differs from the type variety (to which the Fennoscandian specimens belong) in having a larger fruit body and a strigose stipe.

Some nomenclatural and other problems are also discussed in connection with the description of the section Bulluliferae (p. $81-82$ ).

\section{Subgenus 2. Roseospora Harmaja, n. subg.}

Pileus plerumque hygrophanus, pruinosus vel epruinosus, striatus vel non striatus, colore \pm pallido, non fusco nec griseo, \pm depressus in adultis; stipes non strigosus nec rhizoideus, vel rhizoideis paucis; odor fere semper fragrans, cumarino vel pseudofructibus Fragariae similis; sapor mitis; maxima pars sporarum in preparatis e lamellis factis semper in tetradibus occurrit, sporae semper basi obtusa, maxima pars earum semper ellipsoideae-oblongae (lacrymoideae desunt), apiculo non magno, sporarum massa semper rosea, 9 B 2 (MAERZ \& PAUL 1950); aestate seriore et autumno. - Holotypus: Clitocybe phyllophila (Fr.) Kumm.

Pileus medium-sized to small, hygrophanous except in $C$. odora, pruinose or not, being \pm translucent-striate when non-pruinose, never dull-coloured (fuscous, grey) but whitish to buff to pale brown, or flesh-coloured, or \pm aeruginous, somewhat depressed, occasionally infundibuliform when adult; surface \pm dry, smooth. The base of the stipe with tomentum, in exsiccates always violet under ultra-violet light, sometimes also a few inconspicuous rhizoids, mycelial hairs lacking as a rule. Lamellae pallid (never grey or distinctly brown), rather concolorous with pileus, sometimes discolouring in drying, in exsiccates pale under ultra-violet light, i.e. dirty whitish, yellowish, or brownish. Odour sweet, strongly coumarine-like, or fainter, strawberry-like ( $C$. diatreta, however, perhaps mostly odourless), only occasionally persisting for some time in exsiccates. Taste mild, \pm fungoid. Spores roughly of either of two size categories, i.e. large, ca. $6.0-8.5 \times$ $3.5-5.0 \mu \mathrm{m}$, or small, ca. $4.0-6.0 \times 2.4-$ $3.8 \mu \mathrm{m}$, the great majority (rarely only somewhat above $50 \%$ ) of them always in tetrads (and dyads) in preparations made of a piece of lamella, all obtuse-based, most of them always elliptical to oblong, the rest ovate and obovate (e.g. lacrymoid and fusiform ones being totally lacking), apiculus small to medium-sized, ca. $0.7 \mu \mathrm{m}$ in diameter at most; spore deposit always pinkish buff, $9 \mathrm{~B}$ 2 in adequate deposit. Membranal pigment absent, or rarely present in hyphae of pileus trama; lactiferous hyphae sometimes present in pileus trama; clamp connections always present, evidently occurring at each septum. Mostly in various kinds of forest on different kinds of litter, sometimes in habitats influenced, rarely even created, by man, in the last case on \pm bare soil; in late summer and throughout the autumn.

Discussion. This new, rather natural subgenus consists of some new species and some earlier included in the sections Candicantes 
and Disciformes of the type subgenus. The main diagnostic characters are described in the key (p. 45) and in the Latin diagnosis, the features of the spores, the odour, and the colours being the most important. Compared with the two other subgenera, Roseospora is remarkably uniform in respect of the odour, spores, and basal mycelium of its species, which thus display fewer distinguishing characters than are present in the other subgenera.

There are no doubt several evidently undescribed species which should be included in the present subgenus, mainly in the type section, but, as their material is defective in one way or another, I have postponed their description. For instance, there may be a northern species related to $C$. phyllophila with a less fleshy basidiocarp, more sordid colours (the lamellae included), and a long, slender, radicating stipe. It is probably this species that is the other element in the type material of C.laricicola (see p. 77).

Section X. Odorae Harmaja, ad int.

Pileus medium-sized, occasionally rather large, $5-15 \mathrm{~cm}$ broad, not hygrophanous, pruinose, greyish-green to glaucous or aeruginous, old fruit bodies often with bleached buff colours, sometimes \pm white already when young; margin more or less inrolled for a long time. Odour strongly reminiscent of coumarine, exsiccates usually odourless. Spores large, ca. $6.0-8.0 \times 3.6-5.0 \mu \mathrm{m}$, plage applanated, contents homogeneous, apiculus ca. $0.7-0.9 \times 0.6-0.7 \mu \mathrm{m}$. Subcutis present; membranal and encrusted pigments mostly absent, at times present, the

23. Clitocybe odora ([Bull.] Fr.) Kummer, Der Führer in die Pilzkunde, 121. 1871.

Basionym: Agaricus odorus [Bull.] Fries, Syst. Mycol. 1: 90. 1821. - Typus: No original designation. No material of FrIEs existing, and none of Bulliard in PC. I have not examined material from France. A neotype has not been designated.

Figs. 19, 62, 108.

Pileus 5-15 $\mathrm{cm}$ broad, not hygrophanous but sometimes with hygrophanous watery spots, pruinose, ground colour mostly aeruginous, greyish green, or more glaucoustinted, e.g. 26 B 1, 26 C 2, $35 \mathrm{~B} 1$, in age the colours often become more or less bleached and the dominant colour in old fruit bodies may be more or less buff, near $9 \mathrm{C} 2$, dirty yellow spots present, especially near the disc and in age, sometimes the whole disc \pm yellow, $11 \mathrm{~J} \mathrm{7}$, in exsiccates often devoid of green tints being more or less buff, latter pigment in hyphae of epicutis only when present. In woods, on various kinds of litter; from late July to end of October. Temperate to northern boreal, but lacking or very rare in districts with very oceanic climate.

Discussion. Although C. odora surely deserves a new section, I do not wish to give a formal description until I have made a thorough study of, for example, $C$. aeruginosa Big., and C. glaucoalba (Sing.) Sing., which are considered to be nearly related to $C$. odora (see Brgelow 1965).

9 C 2, 10 C 3, 11 B 2, sometimes with aerugineous shades even in exsiccates (especially young fruit bodies), 13 B 1, 20 A 1, 20 A 2, or more greyish, $19 \mathrm{~B} \mathrm{1}$, rarely whitish in fresh fruit bodies, turning dirty brownish, e.g. $10 \mathrm{E} 3$, in drying, convex at first becoming plane, finally usually more or less depressed, bowl-shaped, rarely even infundibuliform, often gibbous for a long time; margin at first distinctly inrolled remaining bent down for a long time; surface dry, very often faintly marked with darker radiate streaks, smooth or sometimes with radiate ridges at margin.

Stipe 3.5-6 $6 \times 4-18$, usually paler than the pileus having rose tinges, sometimes concolorous with pileus, often indistinctly enlarged both upwards and downwards, sometimes equal, extreme base attenuated, at times hollow already when young, at times solid even in old fruit bodies, often somewhat curved at the thinnest point, terete to compressed; surface dry, with thin, whitish, 
fibrillose coating; at the base whitish tomentum (one specimen also with some very slender, hyaline mycelial hairs).

Lamellae obliquely adnate to narrowly short decurrent, more or less concolorous with pileus in all stages, in exsiccates, however, sometimes yellowish, $9 \mathrm{E} 2,9 \mathrm{~F} 2$, contrasting with pileus colour, in 4 or 5 verticils, $50-60$ reach the stipe, being broadest in the middle, (3-) $5-6 \mathrm{~mm}$, about 3 times broader than overlying context is thick, rarely some of them forked, often intervenose in age; small red spots often near edges.

Odour strong, sweet, like that of coumarine or flowers of Linnaea borealis, strongest in old basidiocarps (exsiccates usually odourless but rarely faintly fragrant, even about a year after drying).

Taste mild, fungoid.

Spores $6.0-8.0(-10.0) \times(3.0-) 3.5-$ $5.0 \mu \mathrm{m}$, most of them in tetrads (and dyads) in preparations made of lamellae, all obtusebased, most elliptical to oblong, the rest being ovate and obovate, contents homogeneous, apiculus ca. $0.7-0.9 \times 0.6-0.7$ $\mu \mathrm{m}$; spore deposit pinkish buff, $9 \mathrm{~B} 2$ (the reddish tint has even persisted 38 years in the spore prints of herbarium specimens).

Anatomy of cortex of pileus. Epicutis 25$50 \mu \mathrm{m}$ thick, hyphae \pm parallel to almost interwoven, $2.5-8.0 \mu \mathrm{m}$ in diameter, usually only rich intracellular pigment present, rarely some encrusted pigment, too; subcutis (sometimes indistinct) 60-100 $\mu \mathrm{m}$ thick, hyphae more or less parallel, 3.5-9.5 um in diameter, only scanty intracellular pigment present.

Ecology. Solitary, in groups, rows, or arcs in grass-herb to mesic heath forests (occasionally even in dry pine heaths), often in shady and even somewhat moist places, and on northern slopes, in litter of both coniferous (esp. Picea, rarely Pinus, or Larix sibirica) and especially deciduous trees ( $A l$ nus glutinosa, A. incana, Betula, Corylus, Fagus, Populus, Quercus, Tilia), rarely in herbaceous litter, in coniferous woods and on shady forest rocks often in deep moss, e.g. amongst Hylocomium, Rhytidiadelphus triquetrus, or Pleurozium. From late July to end of October (Fig. 5).

Distribution. Temperate to northern boreal, but lacking or very rare in districts with very oceanic climate, up to $900 \mathrm{~m}$
(S. Norway), 530 m (N. Sweden). Very common. (Fig. 150).

Specimens examined.

Norway: Østfold. Degernes (1). - Akershus. Oslo (2); Ski (1). - Hedmark. Vinger (1). Buskerud. Hol (1); Krødsherad (2); Nes (1); Norderhov (1). - Sør-Trøndelag. Klaebu (1); Trondheim (1). - Nord-Trøndelag. Stjørdal (1). -Troms. Nordreisa (1). - Finnmark. Alta (1); Nesseby (2).

Sweden: Blekinge. Fridlevstad (2); Karlskrona (2). - Småland. Eksjö (1); Femsjö (5); Hallingeberg (1); Kärda (1); Säby (1). - Gotland. Fårö (1). - Västergötland. Grönahög (1); Göteborg (4); Kilanda (1); Medelplana (1); Skallsjö (1); Sätila (1); N. Ving (1). - Halland. Fjärås (2). - Bohuslän. Romelanda (1); Valla (1). Värmland. Dalby (2). - Södermanland. HusbyRekarne (1); Mariefred (1); Svärta (1). - Uppland. Bondkyrka (3); Börje (1); Danmark (3, including Lundelt \& Nannfeldt: «Fungi Exsiccati Suecici... n, no. 327, in S, UPS); Djurö (1) ; Estuna (1) ; Ljusterö (1); Läby (1); Täby (1); Uppsala (4); Vallentuna (1). - Västmanland. Sala (1). - Dalarna. Rättvik (1). - Norrbotten. Haparanda (1); Luleå (1); Övertorneå (1). - Torne Lappmark. Jukkasjärvi (3).

Fintand: Ahvenanmaa. Jomala or Hammarland (1); Lemland (1). - Varsinais-Suomi. Bromarv (1); Karjalohja (3); Kemiö (1); Korppoo (2); Koski Tl. (1); Laitila (1); Lohja mlk. (13); Lokalahti (1); Merimasku (2); Nauvo (1); Parairen (1); Pohja (4); Taivassalo (1); Turku (7); Vihti (2); Västanfjärd (1). - Uusimaa. Elimäki (1); Espoo (5); Helsinki (3); Helsinki mlk. (1); Kauniainen (2); Nurmijärvi (1); Porvoo (3); Porvoo mlk. (2); Sipoo (2); Siuntio (1); Tammisaari mlk. (1); Tuusula (2). - Etelä-Karjala. Vehkalahti (1). - Satakunta. Eura (1); Karkku (1); Tyrvää (1); Yläne (1). - Etelä-Häme. Asikkala (1); Hattula (1); Hollola (1); Koskenpää (1); Kuhmoinen (1); Lammi (2); Orivesi (1); Pohjaslahti (1); Somerniemi (1); Somero (2); Tammela (4, including Karsten: «Fungi Fenniae Exsiccati«, no. 801, in $\mathrm{H}$ ); Tampere (1). - Etelä-Savo. Taipalsaari (1). - Laatokan Karjala. Parikkala (1). - Etelä-Pohjanmaa. Vaasa (2). - Pohjois-Häme. Virrat (4) - - Pohjois-Savo. Kuopio mlk. (1); Suonenjoki (1); Vieremä (1). - Pohjois-Kariala. Tuupovaara (2). - Keski-Pohjanmaa. Kokkola (1). - Pohjois-Pohjanmaa. Ii (1); Kemijärvi (2); Kiiminki (3); Muhos (1); Oulu (1). - Kuusamo. Kuusamo (1). - Inarin Lappi. Inari (1); Utsjoki (15).

U.S.S.R.: Leningrad Region. Johannes (1); Vyborg (Viipuri mlk.) (1).

Discussion. Very easy to recognize by the colour, when this shows the typical greenish shades, strong sweet odour and sporal characters. In identifying the albino form the non-hygrophanous pileus, the odour, and the sporal characters should be checked in order to avoid confusion with other white taxa, e.g. C. phyllophila v. phyllophila. 
There seems to be genetically controlled variation in the size, colour and shape of the pileus, the diameter of the stipe, and the degree of decurrence of the gills.

C. odora may somewhat favour shady and sometimes even slightly moist habitats (but not paludified ones which are deficient in oxygen). This preference has also been reported by KaLLio \& Kankainen (1964) and Tuomrooski (1959). The species does not seem to thrive in very meagre habitats with a low $\mathrm{pH}$ value.

\section{Section XI. Roseospora}

Typus: Clitocybe phyllophila (Fr.) Kumm., the holotype of the present subgenus.

Pileus small to medium-sized, always hygrophanous, pruinose or not, translucentstriate or not, whitish to buff, or pale brown, or flesh-coloured, margin at first distinctly inrolled to almost straight. Odour never strong, being fragrant, strawberry-like (except in $C$. diatreta, which is mostly odourless, being only rarely fragrant), most distinct in drying. Spores small, ca. 4.0-6.0 $\times 2.4-3.8 \mu \mathrm{m}$, plage applanated, contents \pm homogeneous, apiculus ca. $0.5-0.7 \times$.
$0.3-0.5 \mu \mathrm{m}$. Subcutis lacking or indistinct; membranal and encrusted pigments lacking in hyphae of pileus. Mostly in woods on various kinds of litter, one species, however, occurring exclusively in man-made habitats on \pm bare soil; from early August to end of November. Temperate to northern boreal, occasionally in the oroarctic (alpine) zone, being poorly represented in districts with very oceanic climate.

Subsection 1. Pruinatae Harmaja, n. subsect.

Pileus pruinosus, non striatus, carnosus. Holotypus: Clitocybe phyllophila (Fr.) Kumm.

24. Clitocybe phyllophila (Fr.) Kummer, Der Führer in die Pilzkunde, 122. 1871. v. phyllophila

Basionym: Agaricus phyllophilus Fries, Syst. Mycol. 1: 83. 1821. - Typus: No original designation. No material of FrIes existing. The following specimen is herewith proposed for neotype: $\&$ C. cerussata, Sweden, prov. Småland, par. Femsjö, Hägnen, Mörtviken, among Fagus leaves 20.9. 1948, legg. S. Lundell (5523) \& G. Haglund $\ldots$.

Figs. 20, 63, 109.

Pileus $4-10 \mathrm{~cm}$ broad, hygrophanous, white-pruinose, not translucent-striate, ground colour watery brownish in moist condition, e.g. $10 \mathrm{E} 2,11 \mathrm{D} 6$, almost white when faded, or with faint buff to brownish shades, exsiccates whitish, being much paler than $9 \mathrm{~B} 2$, or faintly coloured, $9 \mathrm{~B} 2,9 \mathrm{E} 2$, $9 \mathrm{D} \mathrm{2}, 10 \mathrm{C} 2,10 \mathrm{C} 3,10 \mathrm{D} 2,10 \mathrm{D} 3$, in badly preserved fruit bodies even darker, convex, almost hemispherical at first be-
Pileus pruinose, not translucent-striate, with rather thick flesh especially in the disc.

coming plane and slightly depressed, rarely almost infundibuliform finally, sometimes broadly gibbous; margin at first distinctly inrolled usually becoming straight and \pm horizontal finally, strikingly white-pruinose even in exsiccates; surface dry, smooth.

Stipe 4-11 $\times$ 4-15, concolorous with pileus or slightly paler, equal or slightly enlarged both upwards and downwards, extreme base usually acute and slightly radicating, often curved at base, usually soon becoming hollow, first cylindrical usually becoming somewhat compressed; surface dry, with white fibrillose coating; at the base usually copious tomentum only, rarely a few rhizoids, too.

Lamellae first adnate, becoming short decurrent, the angle of attachment being usually great, $40^{\circ}-50^{\circ}$, sometimes shallowly sinuate being decurrent with acute teeth, with pale buff tinge, colour when moist being near that of pileus, in exsiccates often creamy yellow, sometimes even then more or 
less concolorous with pileus, in 4 to 5 verticils, close to crowded, $40-60$ reach the stipe, being broadest in the middle or distally, $4-7 \mathrm{~mm}$, in the middle $1.5-4$ times broader than overlying context is thick, rarely a few forked, not intervenose (the edges of the lamellae of one S. Finnish fruiting were exceptional in being dentate).

Odour, especially in drying, faintly fragrant, resembling that of strawberries.

Taste mild, fungoid.

Spores $4.0-6.0 \times 2.6-3.7 \mu \mathrm{m}$, most to almost all of them in tetrads (and dyads) in preparations made of lamellae, all obtusebased, most elliptical to oblong, the rest being ovate and (a few) obovate, contents \pm homogeneous, apiculus ca. $0.5-0.7 \times$ 0.3-0.4 $\mu \mathrm{m}$; spore deposit pinkish buff, $9 \mathrm{~B} 2$ (the reddish tint of the spore prints has been observed to persist several years in herbarium specimens).

Anatomy of cortex of pileus. Epicutis 20 $70 \mu \mathrm{m}$ thick, hyphae interwoven to more or less parallel, $1.5-3.5 \mu \mathrm{m}$ in diameter, usually only intracellular (sometimes also intercellular) pigment present; subcutis $50-80 \mu \mathrm{m}$ thick, hyphae parallel, $1.5-6.0 \mu \mathrm{m}$ in diameter, pigmentation as in epicutis but intracellular pigment scantier.

Ecology. Mostly in arcs and whole «fairy rings«, which are rich in fruit bodies, rarely solitary, in various kinds of forest but mainly in grass-herb woodland, often on northern slopes and in otherwise shady places, in litter of coniferous (especially Picea, more rarely Pinus, or Larix sibirica) and also deciduous (Alnus glutinosa, A.incana, Betula, Fagus, Populus, Quercus, Salix caprea) trees, rarely in herbaceous litter, once in twig litter of Alnus incana, in coniferous forest often amongst moss (Hylocomium, Pleurozium, etc.). From late August to middle of November (Fig. 5).

Distribution. Temperate to northern boreal, up to ca. $250 \mathrm{~m}$ (S. and central Sweden, N. Finland). Common. (Fig. 151).

\section{Specimens examined.}

Norway: Østfold. Moss (1). - Akershus. Oslo (1). - Hordaland. Voss (1). - Sør-Trøndelag. Trondheim (1). - Nord-Trøndelag. Verdal (1). - Troms. Målselv (1); Storfjord (1).

SWEDEN: Skåne. Hyby (1); Ivetofta (2, Lundell \& Nannfeldt: «Fungi Exsiccati Suecici... no, no. 1734 , s.n. «C. cerussata, large park form《, in UPS, S); Ravlunda (1); Silvåkra (1). - Blekinge. Förkärla (1); Karlskrona (1). — Småland. Al- mesåkra (2); Femsjö (3, including LundelL \& Nannfeldt: «Fungi Exsiccati Suecici...«, no. 1731 , s.n. «C. cerussata, form of frondose woods «, in UPS); Säby (1). - Västergötland. Fässberg (1); Göteborg (16); Kållered (1). — Halland. Ö. Karup (1). - Bohuslän. Romelanda (1); Valla (1); Öckerö (1). — Värmland. Dalby (1); S. Finnskoga (1). - Södermanland. Södertälje (1). - Uppland. Adelsö (1); Alsike (1); Bondkyrka (1) ; Bro \& Låssa (1); Bälinge (2); Börje (2); Djurö (1); Gamla Uppsala (3, including Lundell \& Nannfeldt: «Fungi Exsiccati Suecici...«, no. 328, s.n. C. phyllophila f. pithyophila, in UPS, S); Stockholm (2); Sånga (1) ; Uppsala (2) ; Älvkarleby (1); Ärentuna (2). - Angermanland. Sollefteå (2). - Västerbotten. Umeå (1). - Norrbotten. Övertorneå (1).

Finland: Ahvenanmaa. Eckerö (1). - Varsinais-Suomi. Halikko (1); Korppoo (1); Koski Tl. (1) ; Lieto (1); Lohja mlk. (13) ; Lokalahti (1); Masku (3); Nauvo (1); Parainen (1); Turku (9); Uskela (1)._-Uusimaa. Helsinki (6); Helsinki mlk. (2); Kauniainen (1); Porvoo mlk. (1); Tuusula (2). - Satakunta. Huittinen (1); Pori (1). - Etelä-Häme. Hattula (2); Hollola (1); Kuhmoinen (1) ; Lammi (1); Somero (3); Tammela (5). - Laatokan Karjala. Parikkala (1). Pohjois-Häme. Virrat (3); Ähtäri (1). - Pohjois-Karjala. Pielisjärvi (1). — Pohjois-Pohjanmaa. Ii (1); Kiiminki (3). - Kuusamo. Kuusamo (1). - Inarin Lappi. Utsjoki (6).

Discussion. For the differences between C. phyllophila v. phyllophila and the similar C. dealbata, C.odora (albino form), $C$. phyllophila v. tenuis and C. anisata, see under those taxa.

Some genetic variation has been observed in the pileus shape, the stipe diameter, some characters of the lamellae, and the length and breadth of the spores. The variation in the colour of the lamellae in exsiccates (dirty whitish to faint buff, or more or less pronounced shades of yellow) may at least partially depend on the desiccation temperature, the yellow colour probably developing when the fruit bodies are dried rapidly at high temperatures. There may be some genetic variation, too, in this respect.

There is great confusion in the literature concerning C.cerussata, C.phyllophila, and C. pithyophila. The description by Fries (1821) of Agaricus phyllophilus fits the present taxon better than that of his A.cerussatus (a nomen dubium) in the same paper, though the latter name may also have been intended for this taxon. It is unknown which of them was first considered a synonym of the other. Bigelow (1965) and LE GaL (1944) were obviously discussing the present species when they preferred the 
specific epithet phyllophila. Agaricus pithyophilus Secr. was described after 1821, and its description is somewhat ambiguous.

\section{4.a Clitocybe phyllophila (Fr.) Kumm. v. tenuis Harmaja, n. var.}

Figs. 21, 64, 110.

$A$ variatione typico differt: pileo parce minore et leniter obscuriore, stipite tenuiore, obscuriore et elasticiore, caro parce tenuiore, odore sporibusque indistincte dissimilibus, in silvis siccis coniferis. - Holotypus: Finland, prov. Varsinais-Suomi, rural district Lohja, Kirkniemi, mesic coniferous heath forest 21. IX. 1966, Harri Toppari (= Harri Harmaja) $(\mathrm{H}$; isotype in $\mathrm{MICH})$.

Pileus $3-7 \mathrm{~cm}$ broad, hygrophanous, white-pruinose, not translucent-striate, ground colour pale brown, e.g. 11 B 6 , the disc often somewhat darker, exsiccates whitish to buff to brownish, $9 \mathrm{~B} 2,10 \mathrm{D} 3$, convex at first becoming plane or slightly depressed, sometimes indistinctly gibbous, rarely bowlshaped finally; margin remaining brightly white-pruinose and slightly inrolled for a long time; surface dry, smooth.

Stipe 3-9 $\times 3-6$, usually longer than the pileus diameter, concolorous with pileus, or somewhat darker than it, especially in age, mostly equal, rarely downwards enlarged, extreme base shortly attenuated, shortly or not at all radicating, at first solid becoming hollow, terete; surface dry, with indistinct fibrillose coating, at the apex at least; at the base scanty to moderate tomentum, sometimes a few rhizoids, too.

Lamellae short decurrent, angle of attachment ca. $40^{\circ}-50^{\circ}$ (rarely decurrent with teeth), pale buff when moist, being paler than pileus, in exsiccates more or less concolorous with pileus or having become yellowish, in 3 or 4 verticils, $30-40$ reach the stipe, being broadest in the middle or proximally, $4-8 \mathrm{~mm}$, in the middle $2-3(-5)$ times broader than overlying context is thick, rarely a few forked near the stipe, not conspicuously anastomosed.

Odour when moist faintly agreeable, rather like that of strawberries, in drying likewise agreeable, rather distinct, most resembling that of anise or bruised leaves of the herb Myrrhis odorata.

Taste mild, fungoid.
Spores $4.3-6.0(-6.5) \times 2.8-3.8 \mu \mathrm{m}$, most to almost all in tetrads in preparations made of lamellae, all obtuse-based, most elliptical to oblong, the rest being ovate and obovate, contents \pm homogeneous, apiculus ca. $0.6-0.7 \times 0.3-0.5 \mu \mathrm{m}$; spore deposit pinkish buff, about $9 \mathrm{~B} 2$.

Anatomy of cortex of pileus. Epicutis 45$65 \mu \mathrm{m}$ thick, hyphae slightly interwoven to subparallel, $2.0-7.0 \mu \mathrm{m}$ in diameter, only intracellular pigment observable; subcutis not differentiated.

Ecology. Solitary, in groups, rows, or arcs in coniferous dry to mesic heath forests (VT, MT, OMT), in litter of Picea or Pinus (very rarely Juniperus, Larix cf. sibirica, Betula, or Rhododendron sp.), often amongst mosses, mostly Pleurozium, Dicranum, or Hylocomium. From end of August to first half of November (Fig. 5).

Distribution. Temperate (very rare) to middle boreal, but lacking in western parts of the area, up to ca. $250 \mathrm{~m}$ (S. and central Sweden). Occasional, on barren ground. (Fig. 152).

\section{Specimens examined.}

Sweden: Småland. Femsjö (2, Lundell \& NANNFELDT: «Fungi Exsiccati Suecici...«, no. 1733 , s.n. «C. cerussata, form of coniferous woods «, in UPS, S); N. Sandsjö (1). - Gotland. Bro (1). - Västergötland. Göteborg (1); Kållered (1). Värmland. Arvika (2); Dalby (2); S. Finnskoga (1). - Uppland. Stockholm (1); Uppsala (1); Värmdö (1). - Angermanland. Sollefteå (1). Västerbotten. Umeå (1).

FrnLand: Varsinais-Suomi. Kemiö (1); Lohja mlk. (4); Paimio (1); Suomusjärvi (1). - Uusimaa. Espoo (1); Helsinki (1); Kirkkonummi (1); Porvoo (1); Porvoo mlk. (1); Sipoo (2). Etelä-Karjala. Miehikkälä (1). - Satakunta. Metsämaa (2). - Etelä-Häme. Asikkala (1); Jämsä (1) ; Pohjaslahti (1) ; Somero (1); Tammela (2). - Etelä-Savo. Juva (1); Mäntyharju (2). - Laatokan Karjala. Parikkala (1); Simpele (1). - Pohjois-Häme. Virrat (3). - Keski-Pohjanmaa. Kälviä (1). - Pohjois-Pohjanmaa. Kiiminki (1).

Discussion. C. phyllophila v. tenuis is differentiated from v. phyllophila by the slightly smaller, more strongly hygrophanous and slightly darker, browner (ground colour) pileus, the disc of which is often darker, by the longer, more slender, more elastic and darker (especially in age) stipe, and evidently by the slightly stronger and different odour. The flesh in v. tenuis also darkens, often distinctly, in age, especially in the stipe. Constant but slight differences may also be the thinner flesh of $\mathrm{v}$. tenuis, its often slightly 
broader spores, which are often more variable in size and shape, and its preference for meagre heath forests and the litter of conifers. However, since the differences are small and often quantitative only, I prefer to treat the present taxon simply as a variety of C.phyllophila.

The elasticity of the stipe of $v$. tenuis may at least partially result from the fact that the amount of stuffed, loose inner flesh, or medulla, is small in proportion to the stipe diameter, smaller than in v. phyllophila, for example.

The taxonomy of the «white« Clitocybes is very difficult, and it has not been possible to identify the present variety definitely with any taxon described in the literature, because the descriptions are very defective, often failing to mention, for example, whether the pileus is hygrophanous or pruinose, or to describe the odour, and the colour of the spore deposit. C. regularis Peck 1901 is surely nearly related, at least. There is no material of Agaricus pithyophilus Secr. provided by Segretan, at least in Genève, $(\mathrm{G})$, and the meaning of this binomial is uncertain.

25. Clitocybe anisata Velenorský, Česke Houby 2: 256. 1920.

Typus: Type material existing (in PRC), but not examined.

Figs. 22, 65, 111.

Pileus $4 \mathrm{~cm}$ broad at most, hygrophanous, white-pruinose, not translucent-striate, ground colour when moist watery brownish, whitish with faint buff or brownish tints when faded, in exsiccates usually with yellowish tints, e.g. $9 \mathrm{G} 2$, or paler than $9 \mathrm{~B} 1$, sometimes less yellowish being almost $9 \mathrm{~B} 2$, convex at first becoming plane and finally slightly depressed; margin slightly inrolled; surface dry, smooth.

Stipe slender, in old fruit bodies shorter than the diameter of the pileus, concolorous with pileus or slightly more brownish in age, equal, extreme base obtuse, solid, cylindrical; surface dry; at the base scanty tomentum, rarely a very few thin rhizoids, too.

Lamellae short decurrent, angle of attachment ca. $45^{\circ}$, watery pale buff when moist, in exsiccates more or less concolorous with pileus, in 3 verticils, both in young and old fruit bodies conspicuously distant, 25-30 reach the stipe, being broadest near the stipe, $5-6 \mathrm{~mm}$, in the middle about 3 times broader than overlying context is thick, neither forked nor intervenose.

Odour faintly fragrant, strawberry- or anise-like, being strongest in old fruit bodies.

Taste mild, fungoid, with faint disagreeable flavour.

Spores $4.6-6.0 \times 2.8-3.6 \mu \mathrm{m}$, most to slightly above $50 \%$ of them in tetrads (and dyads) in preparations made of lamellae, all obtuse-based, perhaps most elliptical, a good number being ovate, the rest oblong, contents \pm homogeneous, apiculus ca. 0.6-0.7 $\times 0.3-0.5 \mu \mathrm{m}$; spore deposit pinkish buff.

Anatomy of cortex of pileus. Epicutis 40$75 \mu \mathrm{m}$ thick, hyphae \pm parallel, 1.5-5.0 $\mu \mathrm{m}$ in diameter, only intracellular pigment present; subcutis not differentiated.

Ecology. Solitary or in rows in sparse woods and pastures, where deciduous trees (e.g. Betula) are dominant, always on boulders (e.g. siliceous) in moss carpets, amongst moss species typical of such habitats such as Abietinella abietina, Barbilophozia barbata, Hypnum cupressiforme, Schistidium apocarpum, Tortula ruralis. From early August to end of September (Fig. 5).

Distribution. Hemiboreal zone, in eastern parts of the area, near sea level. Very rare. (Fig. 153).

\section{Specimens examined.}

Sweden: Uppland. Bondkyrka (1, Ultuna, Långhagen 24. VIII. 1890, H. von Post, s.n. C. sp.; S).

FinLAND: Varsinais-Suomi. Lohja mlk. (4: Ahtiala 19. VIII. 1965; Ahtiala 20. IX. 1965; Jalassaari 8. VIII. 1961; Jalassaari 25. VIII. 1963; all collected by the present author); Parainen (1, 30 . IX. 1962, H. Heikkilä \& P. Siltanen, s.n. C. sp.; TUR).

Discussion. C. anisata is differentiated from both varieties of $C$. phyllophila by the smaller size of the basidiocarp, the more yellowish tint of the dried caps, the conspicuously distant lamellae, whose shape is possibly also always dissimilar, and by the peculiar habitats. The fruiting time of $C$. anisata is earlier, too.

It is not at all sure whether the present very interesting species really represents Velenovský's C.anisata, since it was not possible to study the type material of that species, preserved in Prague (PRG), because it is conserved in liquid and could not be sent on loan to me. 
Pileus non pruinosus (ad marginem saepe parce pruinosus), margine striato saltem in fructificationibus veteribus, minus carnosus. Kumm.

26. Clitocybe diatreta (Fr.) Kummer, Der Führer in die Pilzkunde, 121. 1871.

Basionym: Agaricus diatretus Fries, Syst. Mycol. 1:83.1821. - Typus: No original designation. No material of FrIES existing. Neotype (proposed here): 《LunDELL \& NANNFELDT: Fungi Exsiccati Suecici..., no. 1736, Sweden, prov. Småland, par. Femsjö, 'Slättagärdsskogen', amongst mosses in young dense spruce wood 17. IX. 1948, legg. S. Lundell (5468) \& G. Haglund (UPS).

Figs. 23, 66, 112.

Pileus 2-5(-9) cm broad, hygrophanous, not pruinose, weakly translucent-striate at margin in adult and old fruit bodies, more or less flesh-coloured, or pale brown with reddish tint when moist, $11 \mathrm{D} 6,11 \mathrm{E} 6$, or darker, 13 A 9, 13 A 10, 13 B 10, disc often slightly darker, colours becoming slightly paler in age, brownish to almost white when faded, in exsiccates palely flesh-coloured, e.g. $9 \mathrm{E} 3$, young pilei darker, $9 \mathrm{~F} 4,9 \mathrm{~F} 5$, disc of ten still somewhat darker, at first convex becoming plane and shallowly but broadly depressed, rarely more or less bowl-shaped finally; margin thick, slightly inrolled even in old pilei, extreme margin usually brightly white-pruinose (visible in exsiccates, too); surface dry or weakly viscid, slightly lubricous when moist.

Stipe $4.5-8 \times 3-12$, first whitish or with faint flesh-coloured tint when moist, becoming slightly darker in age but being always paler than moist pileus, in exsiccates less distinctly paler than pileus, \pm equal, rarely slightly enlarged downwards, extreme base rounded, at first solid becoming more or less distinctly hollow, usually soon conspicuously compressed, conspicuously elastic in consistency; surface dry, mat, \pm glabrous; at the base scanty whitish tomentum and often a few thin rhizoids.

Lamellae shortly but rather narrowly decurrent, angle of attachment $30^{\circ}-50^{\circ}$,
Pileus not pruinose (with the frequent exception of the very margin), with translucent-striate margin (in old fruit bodies, at least), and moderately thin flesh in the disc.

becoming slightly smaller in age, of pale flesh-colour or buff when moist, being paler than pileus, in exsiccates often almost concolorous with the latter, in 4 verticils, almost crowded, ca. 40 reach the stipe, being broadest around the middle, $3-4(-6)$ $\mathrm{mm}$, where they are 3-4 times broader than overlying context is thick, neither forked nor intervenose.

Odour mostly fungoid, sometimes old basidiocarps (especially lamellae) faintly fragrant, having strawberry-like odour.

Taste mild, fungoid.

Spores $4.5-5.7 \times 2.8-3.4 \mu \mathrm{m}$, most to almost all in tetrads in preparations made of lamellae, all obtuse-based, perhaps most elliptical, the rest ovate and oblong, contents homogeneous (rarely irregularly granulose), apiculus ca. $0.6-0.7 \times 0.4-0.5 \mu \mathrm{m}$; spore deposit pinkish buff, $9 \mathrm{~B} 2$.

Anatomy of cortex of pileus. Epicutis 40$90 \mu \mathrm{m}$ thick, hyphae almost parallel to slightly interwoven, $3.0-6.0 \mu \mathrm{m}$ in diameter, only some intracellular pigment present; subcutis not differentiated.

Ecology. In arcs, groups, or rows, rarely solitary, in barren, dry to mesic heath forest (VT, MT), especially coniferous woods, mostly in litter of Pinus, sometimes Picea or Betula (especially in the north), rarely in herbaceous litter, often amongst mosses (Pleurozium, Dicranum, Hylocomium). From latter half of August to middle of November (Fig. 5).

Distribution. Hemiboreal to oroarctic, but lacking in districts with very oceanic climate, up to $1100 \mathrm{~m}$ (central Norway). Rather common on barren ground. (Fig. 154).

\section{Specimens examined.}

Norwax: Østfold. Kråkerøy (1). - Oppland. Gran (1). - Sør-Trøndelag. Oppdal (3). Troms. Nordreisa (6); Tromsø (1). - Finnmark. Kistrand (1).

SwEDEN: Småland. Almesåkra (2); Eksjö (1); Femsjö (11, including Lundell \& Nannfetdt: «Fungi Exsiccati Suecici...«, no. 1736, in UPS, 
S); Kärda (1); Nässjö (1). - Östergötland. Skedevi (2). - Västergötland. Östad (1). Uppland. Bondkyrka (4); Djurö (2); Solna (1); Uppsala (6); Älvkarleby (2); Ärentuna (1). Gästrikland. Gävle (1). — Angermanland. Sollefteå (1). - Västerbotten. Umeå (1). - Torne Lappmark. Jukkasjärvi (3).

Finland: Varsinais-Suomi. Lohja mlk. (3); Pohja (2); Pöytyä (1); Suomusjärvi (2); Turku (1); Vihti (2). - Uusimaa. Helsinki (2); Helsinki mlk. (1); Hyvinkää mlk. (1); Kirkkonummi (1); Liljendal (1): Pernaja (1); Porvoo (1); Porvoo mlk. (1); Tammisaari (1); Tammisaari mlk. (2); Tuusula (7). - Etelä-Karjala. Vehkalahti (1). - Satakunta. Alastaro (1); Metsämaa (1); Oripää (1); Säkylä (1). - Etelä-Häme. Somero (3); Tammela (2). - Etelä-Savo. Juva (1); Punkaharju (1); Taipalsaari (1). - EteläPohjanmaa. Mustasaari (1); Vaasa (2); Vöyri (1). - Pohjois-Häme. Toivakka (1); Äänekoski (1). - Pohjois-Savo. Lapinlahti (1); Suonenjoki (1). - Keski-Pohjanmaa. Kalajoki (1); Kokkola (1). - Pohjois-Pohjanmaa. Oulu (1). - Inarin Lappi. Inari (3); Utsjoki (11).

Discussion. C. diatreta may be confused, especially with $C$. marginella; for the differences between them, see under the latter.

There seems to be some genetic variation in C. diatreta in the size of the fruit body as well as the length and breadth of the spores.

C. pinetorum Velenovský 1920 may be synonymous, but its type material does not exist in either PR or PRC, and this specific name must be considered a nomen dubium.

\section{Clitocybe agrestis Harmaja, n. sp.}

Figs. 24, 67, 113.

Clitocybes diatretae proxima, sed coloribus valde pallidis, leniter brunnescentibus in siccantibus; pileo margine epruinoso, striato; lamellis saepe subtriangularibus; sporis valde similibus sporarum C. diatretae; habitat in locis ruderalibus. - Holotypus: Sweden, prov. Uppland, par. Läby, moderately young basidiocarps on roadside 11.X.1968, Harri Harmaja ( $\mathrm{H}$; isotype in $\mathrm{MICH})$.

Pileus ca. 2-5 cm broad, hygrophanous, not pruinose, translucent-striate (except for the youngest pilei) up to halfway from the margin, when moist more or less beige, $11 \mathrm{E} \mathrm{5}$, margin somewhat paler, $10 \mathrm{G} \mathrm{4}$, disc sometimes darker than the rest of the pileus, whitish when faded, in exsiccates dirty brownish, at first slightly convex becoming plane and finally indistinctly depressed; margin thick, bent down when young, not pruinose; surface dry, indistinctly lubricous, smooth.

Stipe 2-4 $\times 2-5$, in all conditions concolorous with pileus or slightly paler, in exsiccates more or less brownish like pileus, slightly tapered downwards or equal, extreme base obtuse, not radicating, solid for a long time then evidently becoming hollow, cylindrical or slightly compressed; surface dry, more or less mat, glabrous; at the base rather scanty tomentum and often a few rhizoids, too.

Lamellae obliquely adnate to short decurrent, sometimes with teeth, angle of attachment ca. $35^{\circ}-60^{\circ}$, whitish to faintly brownish when moist, being sometimes paler than stipe in that condition, in exsiccates with faint dirty brownish tints being more or less concolorous with pileus and stipe, in 3 verticils, about 30 reach the stipe, often being almost triangular and usually broadest proximally, near the stipe, $4-5 \mathrm{~mm}$, in the middle 3-4 times broader than overlying context is thick, sometimes a few forked near stipe, not intervenose.

Odour faintly fragrant, like that of strawberries, most distinct in drying.

Taste mild, fungoid.

Spores 4.5-5.8 $\times 2.9-3.3 \mu \mathrm{m}$, most in tetrads in preparations made of lamellae, all obtuse-based, elliptical, ovate, and oblong, contents \pm homogeneous, apiculus ca. 0.6$0.7 \times 0.3-0.4 \mu \mathrm{m}$; spore deposit pinkish buff, $9 \mathrm{~B} 2$.

Anatomy of cortex of pileus. Epicutis 60$100 \mu \mathrm{m}$ thick, hyphae subparallel to rather interwoven, $1.5-4.5 \mu \mathrm{m}$ in diameter, faint intracellular pigment present, at most; subcutis not differentiated.

Ecology. Gregarious to subcespitose in man-made, more or less open habitats only, i.e., in stubble-fields (oats, rye), pastures, on roadsides, etc., on more or less bare soil of various kinds but in every case apparently rich in nutrients, sometimes among grasses and herbs, or mosses typical of such habitats (e.g. Ceratodon purpureus, Brachythecium cf. albicans). From middle of August to beginning of November (Fig. 5).

Distribution. Hemiboreal to middle boreal, in eastern parts of the area, up to ca. $250 \mathrm{~m}$ (S. Sweden). In inhabited districts, rare. (Fig. 153). 
Specimens examined.

Sweden: Småland. Almesåkra (1); Femsjö (1); Nässjö (1); Säby (3, including Lundell \& NANNFELDT: «Fungi Exsiccati Suecici...., no. 1735, s.n. C. dealbata, in UPS, S). - Uppland. Läby (1, holotype); Stockholm (3); Vaksala (1). - Angermanland. Sollefteå (1).

Finland: Varsinais-Suomi. Rymättylä (1). Etelä-Häme. Lammi (1). — Pohjois-Häme. Toivakka (2).

Discussion. Morphologically C.agrestis somewhat resembles $C$. diatreta, but it is distinguished from that species by the paler colours, the pileus margin, which is not at all pruinose but more distinctly striate, the differently shaped lamellae and the slightly brownish colour assumed by the fruit body in drying. The ecological characters of these two species are very different, too.

\section{Clitocybe marginella Harmaja, n. sp.}

Figs. 25, 68, 114.

Clitocybes diatretae valde similis; pileus pallidus, hygrophanus, centro distincte obscuriore, margine striato, exili, plerumque albomarginato; stipes \pm fragilis, saepe sursum attenuatus; odor fragrans; sporae 4.6$6.0 \times 2.4-3.3(-3.6) \mu m$, maxima pars earum in tetradibus, basi semper obtusa, ellipsoideae, ovatae vel oblongae, apiculo parvo, sporarum massa rosea. - Holotypus: Finland, prov. Etelä-Häme, par. Somero, Kultela, Suulinki, coniferous woods 17. IX. 1967, Holger Såltin (TUR; isotype in $\mathrm{MICH})$.

Pileus 2-6.5 $\mathrm{cm}$ broad, hygrophanous, though otherwise not pruinose, possessing in the moist condition (with the frequent exception of old basidiocarps and those of late autumn) a more or less conspicuous, whitishpruinose marginal zone of a breadth of $1-2$ $\mathrm{mm}$ (only rarely remaining distinct in exsiccates), already when young translucentstriate up to halfway from the margin, dirty pale brown when moist, e.g. $11 \mathrm{C} 4$, sometimes slightly darker or more reddish-tinted, the disc in all stages darker, pileus whitish with a brownish tint when faded, in exsiccat-

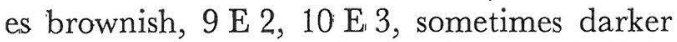

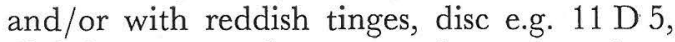
slightly convex when young becoming plane and finally shallowly depressed, rarely almost bowl-shaped; margin thin, at first bent down becoming straight, the distal ends of the lamellae do not reach the very margin; surface dry but somewhat slippery, slightly shining, smooth.

Stipe 3-10 $\times 2.5-5(-8)$, in all stages whitish when young, in age becoming approximately concolorous with pileus, usually more or less distinctly enlarged downwards, rarely equal, extreme base inside the tomentum attenuated and shortly radicating, at first solid becoming hollow, usually terete, rarely compressed; surface dry, mat, more or less glabrous; scanty whitish tomentum at the base.

Lamellae short decurrent, angle of attachment $40^{\circ}-60^{\circ}$, first whitish then of about the pileus colour to pale buff in the moist condition, in exsiccates usually with buff tints, often slightly darker than pileus, in ca. 4 verticils, close to almost crowded, about 30 reach the stipe, being almost always broadest proximally, near the stipe, 4-5 $\mathrm{mm}$, in the middle ca. 5 times broader than overlying context is thick, not forked, in age slightly anastomosed.

Odour more or less faintly fragrant, like that of strawberries, strongest in drying, in young fruit bodies sometimes indistinct.

Taste mild, fungoid.

Spores 4.6-6.0 × 2.4-3.3(-3.6) $\mu \mathrm{m}$, most in tetrads (and dyads) in preparations made of lamellae, all obtuse-based, perhaps most narrowly elliptical, the rest ovate and oblong, a few even obovate, contents homogeneous (sometimes irregularly granulose), apiculus ca. $0.6-0.7 \times 0.4-0.5 \mu \mathrm{m}$; spore deposit pinkish buff, 9 B 2.

Anatomy of cortex of pileus. Epicutis 30$50 \mu \mathrm{m}$ thick, hyphae \pm parallel, $2.0-6.0 \mu \mathrm{m}$ in diameter, only very scanty intracellular pigment discernible; subcutis 40-70 $\mu \mathrm{m}$ thick, hyphae almost interwoven, 4.0-8.0 $\mu \mathrm{m}$ in diameter, no pigment of any kind clearly discernible.

Ecology. Solitary, in groups, rows, or arcs, mostly in litter of Pinus, or Picea, rarely Juniperus, Alnus glutinosa, A. incana, Betula, Salix caprea, or herbaceous plants, often amongst mosses, such as Pleurozium, Dicranum, Hylocomium. From end of August to late November (Fig. 5).

Distribution. Temperate to northern boreal, in eastern parts of the area, up to ca. $250 \mathrm{~m}$ (S. Sweden). Apparently rather fre- 
quent in Finland, otherwise more or less uncommon. (Fig. 155).

\section{Specimens examined.}

SWEDEN: Skåne. Dalby (1). - Småland. Femsiö (3); N. Sandsjö (2). - Öland. Hulterstad (1). - Östergötland. Gryt (1).

FinLAND: Varsinais-Suomi. Bromarv (1); Lohja mlk. (5); Paimio (1); Pohja (2); Suomusjärvi (1). - Uusimaa. Kirkkonummi (1); Liljendal (1); Tammisaari (1); Tammisaari mlk. (1). Etelä-Karjala. Hamina (1); Miehikkälä (2); Vehkalahti (2); Virolahti (1). - Satakunta. Huittinen (1); Metsämaa (2); Oripää (1); Säkylä (1); Vampula (1). - Etelä-Häme. Asikkala (1); Hattula (3) ; Jämsänkoski (1); Koskenpää (1); Kuhmoinen (1); Somero (1); Tammela (3). - EteläSavo. Juva (1); Mäntyharju (1); Rantasalmi (1); Rautjärvi (1). - Laatokan Karjata. Parikkala (1). - Pohjois-Savo. Kuopio mlk. (1). - Pohjois-Pohjanmaa. Rovaniemi mlk. (1). - Inarin Lappi. Utsjoki (5).

Discussion. A very ordinary-looking species, distinguished from the sometimes very simi- lar C. diatreta by the following characters: the pileus (and other parts) is less reddishtinted when moist, the disc is \pm distinctly darker than the rest of the pileus, the margin is more distinctly translucent-striate and usually has a pruinose zone up to $2 \mathrm{~mm}$ broad, the stipe is dissimilar in some respects, the lamellae have a different shape, the flesh is thinner (especially at the pileus margin) and more fragile, the odour is almost always fragrant, the spores are on the average slightly longer and usually relatively thinner.

There seems to be some genetic variation in the size of the fruit body, the distinctness of the pruinose marginal zone of the pileus, and the length and breadth of the spores.

Velenovský (1920) may already have described the present species, but type material of C. marginata Vel. does not exist in Prague (PR, PRG), and this name is in any case a later homonym of C. marginata Peck 1902.

Section XII. Fragrantes Harmaja, ad int.

Pileus not large, $2.0-5.0 \mathrm{~cm}$ broad, hygrophanous, not pruinose, very distinctly translucent-striate, \pm pale watery brown shades predominating when moist; margin soon straight. Odour strongly reminiscent of coumarine. Spores large, ca. $6.2-8.6 \times 3.4$ $-4.6 \mu \mathrm{m}$, plage distinctly depressed to just applanated, contents one large guttule and some smaller ones, apiculus ca. 0.5-0.8 $\times$ $0.5-0.7 \mu \mathrm{m}$. Subcutis present; membranal pigment often (always?) present in hyphae of pileus, encrusted pigment absent. In woods

29. Clitocybe fragrans ([Sow.] Fr.) Kummer, Der Führer in die Pilzkunde, 121. 1871.

Basionym: Agaricus fragrans [Sow.] Fries, Syst. Mycol. 1: 171. 1821. - Typus: No original designation. No material of FrIEs existing, and none of SOWERBy in K. I have examined material from England belonging to the present species. A neotype has not been designated.

Figs. 26, 69, 115.

Pileus 2-4(-5) cm broad, hygrophanous, not pruinose, very distinctly translucentstriate (in old pilei even up to $2 / 3$ from pileus margin), watery pale brown when moist, 12 C 5, 12 D 4, 12 D 5, 12 D 7, 12 E 4, in litter, often in grass-herb forests and on calcareous ground, and often in habitats somewhat affected by man, from middle of August to latter half of December. Temperate to middle boreal.

Discussion. The present study indicates that $C$. fragrans definitely deserves a section of its own, but before the final decision is made and the formal description of the new section is given, data should be obtained on any nearly related species existing elsewhere.

becoming slightly paler in age, disc always and in all stages more or less darker, even being $8 \mathrm{~A} 12$ in moist pilei, faded pileus very pale with brownish tint, in exsiccates brown-

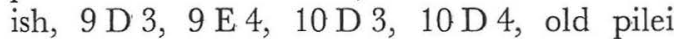
sometimes darker brown, e.g. $11 \mathrm{C} 5,11 \mathrm{C} 6$, $11 \mathrm{D} 6,12 \mathrm{D} \mathrm{7,} 13 \mathrm{D} 7$, at first slightly convex, becoming plane, finally slightly depressed, rarely even subinfundibuliform; margin bent down at first becoming straight; surface dry, with slight greasy lustre, smooth.

Stipe 4-8 $\times 3-5(-9)$, in all stages more or less concolorous with pileus, usually downwards enlarged, rarely equal, extreme base inside the tomentum tapered, solid or hollow, terete or slightly com- 
pressed; surface dry, shining (often even in exsiccates), with thin, whitish fibrillose coating; at the base tomentum, rarely a few thin rhizoids, too (slender, hyaline mycelial hairs have once been observed as an extremely rare exception).

Lamellae obliquely adnate or short decurrent, the angle of attachment being $45^{\circ}$ $70^{\circ}$, rarely longer and more narrowly decurrent, edges almost straight, brownish to dirty buff when moist, being paler than moist pileus and stipe, in exsiccates concolorous with pileus or somewhat paler, in 3 or 4 verticils, $30-35$ reach the stipe, being broadest around the middle, $3-5 \mathrm{~mm}$, where they are 3-4 times broader than overlying context is thick, not conspicuously forked or intervenose.

Odour strong, fragrant, reminiscent of that of coumarine, or flowers of Linnaea borealis, strongest in old fruit bodies (very rarely only faintly fragrant), sometimes persisting in exsiccates for months.

Taste mild, fungoid, sometimes slightly disagreeable flavour present.

Spores 6.2-8.6 $(-10.0) \times 3.4-4.6 \mu \mathrm{m}$, the great majority to slightly above $50 \%$ in tetrads in preparations made of lamellae, all obtuse-based, most elliptic-oblong to oblong, a few distinctly elliptical, ovate, or obovate (a few sometimes subfusiform), plage distinctly depressed to just applanated, contents one large and some smaller guttules, apiculus ca. $0.5-0.8 \times 0.5-0.7 \mu \mathrm{m}$; spore deposit pinkish buff, $9 \mathrm{~B} 2$.

Anatomy of cortex of pileus. Epicutis 20$45 \mu \mathrm{m}$ thick, hyphae more or less parallel, $1.5-5.5 \mu \mathrm{m}$ in diameter, only intracellular pigment present, often intercellular crystals, too; subcutis $30-60 \mu \mathrm{m}$ thick, hyphae more or less parallel, ca. 2.0-7.0 $\mu \mathrm{m}$ in diameter, pigmentation as in epicutis but intracellular pigment scantier, and membranal pigment often (always?) present.

Ecology. Solitary or in groups, rarely in arcs, in grass-herb forest, rarely in woods of lower productivity, sometimes in slightly moist (but not paludified) places, often also in half-open to almost open grassy habitats affected by human activities, such as pathsides, pastures, and parks, in litter of Alnus incana, Betula, Fagus, Picea, Pinus, Quercus (once Pinus cembra cf. ssp. cembra, likewise $P$. contorta), or in litter of herbaceous plants, noticeably often among the moss Rhytidia- delphus squarrosus. From middle of August to latter half of December (Fig. 5).

Distribution. Temperate to middle boreal, up to ca. $250 \mathrm{~m}$ (S. Sweden). More or less common. (Fig. 156).

\section{Specimens examined.}

Norway: Akershus. Baerum (1); Frogn (1); Moss (1); Nannestad (1); Nes (1); Nittedal (2) Oslo (2); Ski (2). - Buskerud. Hurum (1); Ádal (1). - Telemark. Skien (1). - Rogaland. Rennesøy (1). - Hordaland. Bergen (1); Etne (1); Fjelberg (1); Granvin (1); Laksevåg (1); Ulvik (2); Voss (3). - Sør-Trøndelag. Buvik (2). - Finnmark. Talvik (1).

Sweden: Skåne. Hyby (1); Tolånga (1). Småland. Almesåkra (1); Femsjö (3); Nässjö (4); N. Sandsjö (2); N. Solberga (1); Tånnö (1); Värnamo (1); Växjö (1). - Öland. Långlöt (1). - Gotland. Visby (2); Västkinde (1). - Västergötland. Göteborg (3). - Halland. Fjärås (1). Bohuslän. Hålta (1). - Värmland. Dalby (3). - Södermanland. Mörkö (1); Ytterenhörna (1). - Uppland. Bondkyrka (17); Djurö (15); Estuna (1) ; Färentuna (1); Hammarby (1); Sigtuna (1); Sollentuna (1); Solna (1); Stockholm (5); Uppsala (17, including Lundell \& Nannfeldt: «Fungi Exsiccati Suecici...«, no. 1740, s.n. C. obsoleta, in UPS); Älvkarleby (1). - Angermanland. Sollefteå (1).

Finland: Ahvenanmaa. Saltvik (1). - Varsinais-Suomi. Halikko (1); Karjalohja (1); Kemiö (1); Lohja mlk. (14); Naantali (1); Turku (2). - Uusimaa. Espoo (1); Helsinki (1); Helsinki mlk. (4); Kauniainen (6); Porvoo (3); Porvoo mlk. (1); Tammisaari (1); Tuusula (1). - Satakunta. Tyrvää (1). - Etelä-Häme. Hattula (2); Jokioinen (1); Kuhmoinen (1); Lammi (1); Tammela (4, including Karsten: «Fungi Fenniae Exsiccatik, no. 210, in $\mathrm{H}$ ); Tampere (1). Etelä-Savo. Imatra (1). - Pohjois-Häme. Virrat (1). - Pohjois-Savo. Iisalmi mlk. (1); Lapinlahti (1). - Keski-Pohjanmaa. Pietarsaari (1). - Pohjois-Pohjanmaa. Kiiminki (3); Oulu (1).

U.S.S.R.: Leningrad Region. Vyborg (Viipuri mlk.) (1).

Discussion. C. fragrans is easily recognized by the pileus, which is distinctly striate when moist, the long and more or less slender stipe, the strong coumarine-like odour, and the spore characters. The hyphae of the pileus and gill trama may be more inflated and shorter-celled than those of other species of Clitocybe.

There appears to be genetic variation in the degree of decurrence of the lamellae, and in the length of the spores.

Le Gal (1944), and Bigrlow \& Smith (1962) claim that the much confused C. suaveolens ([Schum.] Fr.) and C. fragrans differ from each other in that the former has a darker pileus and pinkish spore deposit, while the latter has a paler pileus and white 
spore deposit. These considerations are rather conjectural, for no type material is known for either species. These names would rather seem to be synonymous, but the epithet fragrans is chosen because the first description (and the revalidation) of Fries (1821: 171) of Agaricus fragrans fits the present species better than that of $A$. suaveolens in the same paper; this epithet is also more commonly used. FrIES (op.cit.) also states that there is some discrepancy between his interpretation of $A$. suaveolens and that of Schumacher. It is unknown which of these two names was earlier regarded as a synonym of the other. A. suaveolens is best regarded as a nomen dubium.

DoNk (1962: 57) considers WITHERING to be the correct devalidated author of $A$. fragrans. I have not yet studied this point.

Subgenus 3. Pseudolyophyllum Singer, Ann. Mycol. 41: 41. 1943.

Typus: Holotype Clitocybe metachroa (Fr.) Kumm.

Pileus small to medium-sized, always hygrophanous, mostly not pruinose, sometimes pruinose, translucent-striate or not, being as a rule striate when non-pruinose, colours more or less dull, being \pm brown, fuscous, or grey, depressed, umbilicate, or \pm infundibuliform when adult; surface dry to somewhat viscid, always smooth, often very conspicuously concentrically (tangentially) wrinkled in exsiccates (rather indistinctly in the type section). Stipe with basal tomentum, in exsiccates always \pm violet under ultra-violet light, sometimes in addition strigose, hyaline, slender mycelial hairs present (tomentum then more or less scanty), the last-named elements in exsiccates \pm chloric-greenish under ultra-violet light, only exceptionally a few inconspicuous rhizoids present, too. Lamellae more or less dull-coloured, pale to rather dark grey or brown, or greyish or brownish, usually not changing colour in drying, being violet, dirty pale brown, or \pm chloric-greenish in exsiccates under ultra-violet light. Flesh very often free of larvae. Odour fungoid (in this case in old fruit bodies sometimes like that of Cystoderma carcharias), or farinaceous (at least when bruised), one species having a faint fragrant odour in drying, which suppresses the farinaceous one during this stage, exsiccates odourless except in the lastmentioned species in which they have fishy smell. Taste usually mild being fungoid or farinaceous, rarely \pm bitter. Spores large to very small, practically all (rarely only slightly above $50 \%$ ) of them occur singly, except in the section Pseudolyophyllum, where most of them occur in tetrads (and dyads) in prepa- rations made of lamellae, mostly with obtuse, sometimes acute, never confluent base, of widely differing shapes, with small to rather large (up to ca. 1.0 $\mu \mathrm{m}$ long, and ca. $0.9 \mu \mathrm{m}$ broad) apiculus; spore deposit pure white, very pale yellow, or very pale yellow with a greyish tinge. Distinct, pale to dark brown membranal pigment always present in hyphae of pileus trama (and of gill trama and many other tissues, too); lactiferous hyphae usually absent; clamp connections always present, and evidently at each septum. Mostly in coniferous forest, very rarely above the forest limit, mostly in litter of conifers, only very rarely and occasionally on bare soil, rarely in habitats distinctly influenced by man, only exceptionally in totally man-created habitats; occurrence late, on the average, altogether ranging from beginning of August to end of December, most abundant in October. Less abundant in the temperate zone, and in districts with very oceanic climate.

Discussion. The present subgenus is characterized by the invariably hygrophanous fruit body, the more or less dull colours (also of lamellae), the constant presence of membranal pigment, the usual absence of lactifers, and the preference for coniferous woods. On the whole, it may be considered less primitive than the two other subgenera distinguished in the present study. The invariable presence of membranal pigment is an important diagnostic character which has not been reported before.

The section Bulluliferae as represented by C. hydrogramma does not belong to the present subgenus as considered by Singer (1962) (see p. 82). 


\section{Section XIII. Pseudolyophyllum}

Typus: Clitocybe metachroa (Fr.) Kumm., the holotype of the present subgenus.

Pileus small to medium-sized, ca. 1.5-7.0 $\mathrm{cm}$ broad, hygrophanous, not pruinose, translucent-striate near margin (only occasionally even), usually with predominantly grey shades, sometimes browner tinges present, usually shallowly depressed, rarely umbilicate or almost infundibuliform when adult; margin somewhat inrolled and sometimes slightly pruinose in young fruit bodies; surface \pm even to indistinctly concentrically wrinkled in exsiccates. Stipe with basal tomentum only, very rarely a few thin rhizoids, too. Lamellae pale (sometimes fairly dark) grey to brownish both when moist and in exsiccates, dirty pale brown under ultraviolet light in exsiccates. Flesh not very thin. Odour fungoid, in old fruit bodies sometimes

30. Clitocybe metachroa (Fr.) Kummer, Der Führer in die Pilzkunde, 120. 1871.

Basionym: Agaricus metachrous Fries, Syst. Mycol. 1: 172. 1821. - Typus: No original designation. No material of FrIES existing. A neotype has not been designated.

Synonym: Clitocybe raphaniolens Karsten, Hedwigia 29: 176 (Fragm. mycol. 30). 1890. - Typus: Lectotype (selected here) is specimen no. 192a in the herbarium of P. A. Karsten ( $\mathrm{H})$, collected in Finland, prov. Etelä-Häme, par. Tammela, Syrjä 25. IX. 1890 (most of the basidiocarps, i.e., those which correspond well to the original description; the remainder represent $C$. metachroides and have been separated).

Figs. 27, 70, 116.

Pileus 3-7 $\mathrm{cm}$ broad, hygrophanous, not pruinose, translucent-striate except for the central part, sometimes at the margin only (occasionally totally non-striate), in the moist condition pale to rather dark fuscous, grey-brown, $12 \mathrm{C} \mathrm{3,} 13 \mathrm{D} 6,13 \mathrm{E} \mathrm{5,} 13 \mathrm{E} \mathrm{6}$,

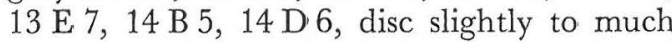
darker, e.g. 7 A 9, 14 B 4, 16 C 8, when faded

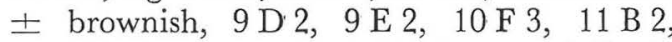
11 C 3, rarely almost whitish, especially in this stage the disc is usually conspicuously darker, e.g. $15 \mathrm{~A} 10$, in exsiccates the pileus is dirty or grey-tinted pale brown, $11 \mathrm{C} 2$, 12 B 3, sometimes darker and greyer (rarely very pale, grey-tinted), at first convex, be- like that of Cystoderma carcharias (this odour sometimes persisting in exsiccates). Taste mild and fungoid, or bitterish in adult pilei. Spores rather large, varying from 5.5 to ca. $9.5 \mu \mathrm{m}$ in length, most (at least somewhat above $50 \%$ ) of them occurring in tetrads (and dyads) in preparations made of lamellae, all obtuse-based, most elliptical to oblong, the remaining few ovate, obovate, or subfusiform, plage applanated to distinctly depressed, contents guttulate, apiculus ca. 0.6-0.9 $\times$ 0.4-0.6 $\mu \mathrm{m}$; spore deposit \pm pure white, or very pale yellow, about $9 \mathrm{~B} 1$. Subcutis present or absent; encrusted pigment sometimes present on hyphae of epicutis and subcutis. From beginning of September to end of December. Temperate to northern boreal.

coming plane, finally narrowly (but shallowly) depressed, rarely broadly and deeply depressed and bowl-shaped, or umbilicate; margin rather thick, at first (rarely later, too) somewhat inrolled, sometimes with very narrow whitish-pruinose zone; surface dry or slippery, mat or lustrous, smooth.

Stipe 4-7 $\times 4-9$, conspicuously whitish down to $0.5-1.0 \mathrm{~cm}$ from the apex, becoming darker and greyer further down, the basal part being fuscous and \pm distinctly darker and greyer than pileus, usually more or less distinctly enlarged downwards (rarely equal), extreme base attenuated, solid at first becoming hollow, terete or slightly compressed; surface dry, with thin pale fibrillose hyphal coating; at the base tomentum.

Lamellae obliquely adnate to short decurrent, angle of attachment $45^{\circ}-80^{\circ}$, very rarely shallowly sinuate, brownish with greyish tint when moist, e.g. $11 \mathrm{~B} \mathrm{1,} \mathrm{being} \mathrm{slightly}$ paler and less grey than moist pileus, in 4 verticils, ca. 40 reach the stipe, being broadest proximally, in the middle, or distally, 4-5 -8$) \mathrm{mm}$, in the middle ca. 3 times broader than overlying context is thick, usually not forked, not anastomosed.

Odour fungoid, especially in old fruit bodies in late autumn sometimes, however, like that of Cystoderma carcharias (this odour may persist in exsiccates for years).

Taste in all parts of the fruit body completely mild, fungoid. 
Spores $\quad 6.4-9.5(-11.0) \times 3.5-4.2$ (-4.6) $\mu \mathrm{m}$, somewhat more than $50 \%$ to the great majority in tetrads (and dyads) in preparations made of lamellae, all obtusebased, most elliptic-oblong to oblong, the rest elliptical (sometimes even ca. 50\%), and ovate, sometimes a few subfusiform, plage applanated to distinctly depressed, contents one large and some smaller guttules, apiculus ca. $0.6-0.9 \times 0.5-0.6 \mu \mathrm{m}$; spore deposit \pm pure white.

Anatomy of cortex of pileus. Epicutis ca. $30-50 \mu \mathrm{m}$ thick, hyphae almost interwoven to subparallel, $2.0-6.0 \mu \mathrm{m}$ in diameter, scanty intracellular and probably also membranal pigments present; subcutis indistinct, ca. 50-60 $\mu \mathrm{m}$ thick, hyphae subparallel, $4.0-9.0 \mu \mathrm{m}$ in diameter, evidently only membranal pigment present.

Ecology. Solitary, in rows, arcs, or groups in various kinds of forest (from grass-herb woodland to the most meagre dry heath forests of the Calluna site type [CT]), mostly, however, in those with high productivity, very often (especially in the most barren habitats) in places where human influence is evident, such as pathsides, pastures, etc., in litter of Picea (very often), Larix sibirica, Pinus, Alnus glutinosa, A. incana, Betula, Corylus, Fagus, Populus, Quercus, Sorbus aucuparia, Tilia, or herbaceous plants, sometimes among mosses such as Hylocomium and Pleurozium. From beginning of September to end of December (Fig. 5).

Distribution. Temperate to middle boreal, up to ca. $250 \mathrm{~m}$ (S. and central Sweden). Common. (Fig 157).

\section{Specimens examined.}

Norway: Akershus. Oppegård (2); Oslo (2); Ski (3). - Buskerud. Hole (1). - Hordaland. Fana (1); Voss (1). - Troms. Tromsø (1).

SWEDEN: Skäne. Andrarum (1); Ivetofta (2); Österslöv (1). - Blekinge. Karlskrona (1). Småland. Almesåkra (10); Femsjö (8, including Lundell \& Nannfeldt: «Fungi Exsiccati Suecici... no, no. 1737 , s.n. $C$. dicolor, in S, and no. 1738 , s.n. C. dicolor, in S); Kärda (1); Nässjö (8); N. Sandsjö (2); N. Solberga (2); Säby (1); Värnamo (2). - Gotland. Viklau (1); Visby (1). - Östergötland. Kvillinge (1). - Västergötland. Göteborg ( 7 , including LUNDELL \& NANNFELDT: «Fungi Exsiccati Suecici ...«, no. 2521, s.n. C. dicolor, in S);N. Ving (2); Österplana (1). Bohuslän. Myckleby (1). - Värmland. Dalby (1); S. Finnskoga (1); Karlstad (1). - Södermanland. Hölö (1); Nacka (1); Salem (2). Uppland. Alsike (1); Björklinge (1); Bondkyrka (11); Djurö (5); Ekerö (1); Frösunda (2); Ö.
Ryd (1); Stockholm (4); Uppsala (6, including Lundell \& NANNFELDT: «Fungi Exsiccati Suecici ... no, no. 112, s.n. C. dicolor, in S); Vada (1); Vallentuna (1). - Västmanland. Badelunda (1, Lundell \& NANNFeldT: «Fungi Exsiccati Suecici ... , no. 2520, s.n. C. dicolor, in S); Sala (1). - Dalarna. Falun (1). - Gästrikland. Gävle (2).

Frncand: Ahvenanmaa. Eckerö (2). - VarsinaisSuomi. Aura (1); Bromarv (2); Kemiö (2); Lemu (1); Lohja mlk. (17); Nousiainen (1); Nummi (1); Pohja (1); Suomusjärvi (1); Turku (5); Vihti (1). - Uusimaa. Helsinki (9); Helsinki mlk. (4); Kauniainen (1); Kirkkonummi (1); Mäntsälä (1); Orimattila (1); Porvoo (1); Sipoo (1); Siuntio (1); Tammisaari (6); Tammisaari mlk. (2); Tuusula (10). - Etelä-Karjala. Hamina (2); Miehikkälä (2); Vehkalahti (1); Virolahti (1). - Satakunta. Lappi (1); Oripää (1); Vampula (1). - Etelä-Häme. Asikkala (3); Hämeenlinna (1); Kuhmoinen (1); Pertunmaa (1); Tammela (12). - Etelä-Savo. Imatra (2); Juva (1); Mäntyharju (1). - Laatokan Karjala. Parikkala (3). - Etelä-Pohjanmaa. Vöyri (1). Pohjois-Häme. Virrat (3). — Keski-Pohjanmaa. Kälviä (1). - Pohjois-Pohjanmaa. Kiiminki (3); Oulu (3).

Discussion. For the differences between C. metachro.a and the two other, very similar species of the present section, see under those species.

There seems to be some tendency to genetic variation in the sizes of the different parts of the fruit body as well as their colours (e.g., the fruit bodies of one fruiting appeared to lack grey tinges), the shape of the stipe, and the size and perhaps also the shape of the spores.

The present species has often been called C. dicolor (Pers.), and figure 38: B with that name in LANGe (1935-1940, Vol. 1) very well depicts the macroscopic features of C. metachroa (the spores, however, are not typical in that figure).

The nomenclature of $C$. metachroa is by no means unambiguous, and FrIEs may later have confused $C$. metachroa and $C$. vibecina with each other sometimes using the epithet metachrous for C.vibecina and vice versa. I prefer to employ the very frequently used name metachroa for the present species, for it is the commonest species of the subgenus Pseudolyophyllum (A. metachrous is «vulgatissimus « also according to FrIES 1821), and because there are no contradictions between the original description and my concept.

On the other hand, Agaricus dicolor was not revalidated until after 1821, and no type material exists in Leyden (L). 
31. Clitocybe amarescens Harmaja, n. sp.

Figs. 28, 71, 117.

Clitocybes metachroae valde similis; pileus 3 - $6 \mathrm{~cm}$ latus, griseus vel brunneus, hygrophanus, non pruinosus, striatus, demum distincte depressus; stipes \pm unicolor, basi non strigosa; odor fungoideus; sapor leniter amarus in pileo adulto; sporae 6.4-8.4 $(-9.4) \times(3.1-) 3.6-4.8 \mu \mathrm{m}$, maxima pars earum in tetradibus, basi obtusa, maxima pars earum ellipsoideae, sporarum massa pure flavida; autumno seriore. - Holotypus: Finland, prov. Varsinais-Suomi, rural district of Lohja, Jalassaari, in a heap composed of needles of Picea and straw 16. X. 1965, Harri Toppari (= Harri Harmaja) ( $\mathrm{H}$; isotype in MICH).

Pileus 3-6 $\mathrm{cm}$ broad, hygrophanous, not pruinose, margin translucent-striate (sometimes even up to $3 / 4$ of way towards centre), when moist dirty brown, $12 \mathrm{~F} \mathrm{7,} \mathrm{grey-brown,}$ 12 C 6, or grey with brown tint, 14D 6, darker (even $8 \mathrm{~A} \mathrm{10}$ ) in young fruit bodies, disc in all stages darker than rest of pileus, faded pileus brownish, $9 \mathrm{Ci} 2$, $10 \mathrm{~B} 2$, disc in this stage shades such as $14 \mathrm{E} 9$, pileus in exsiccates pale brown, $9 \mathrm{D} 3,10 \mathrm{D} 3,11 \mathrm{~B} 2$, $11 \mathrm{C} 2,11 \mathrm{C} 3,11 \mathrm{C} 4,11 \mathrm{D} \mathrm{3}$, or greyish brown, $12 \mathrm{~B} 4$, in young fruit bodies shades such as $13 \mathrm{E} 7,14 \mathrm{E} 6$, at first convex soon becoming plane and distinctly depressed; margin more or less inrolled at first, often whitish-pruinose in young basidiocarps; surface dry, almost mat, smooth.

Stipe 3.5-9 9 3-9, throughout more or less concolorous with pileus when moist, in exsiccates often somewhat darker, e.g. 10 D 3, 12 B 4, 13 B 3, apex sometimes slightly paler, equal or indistinctly upwards or downwards enlarged, extreme base somewhat attenuated, solid at first, finally usually hollow, terete or compressed; surface dry, with whitish hyphal coating (especially in young fruit bodies); at the base tomentum, rarely a few thin and inconspicuous rhizoids, too.

Lamellae moderately decurrent, some of them with a decurrent tooth, angle of attachment rather small, ca. $15^{\circ}-45^{\circ}$, when moist pale brown, $11 \mathrm{~B} 2$, or more greyishtinted, $12 \mathrm{C} 6$, in exsiccates more or less concolorous with pileus, 9 D 3, 10 D 3, $11 \mathrm{C} 2,11 \mathrm{C} 3,12 \mathrm{Ci} 5$, in 4 or 5 verticils, $30-50$ reach the stipe, being broadest in the middle or proximally, $3-6 \mathrm{~mm}$, in the middle 3-4 times broader than overlyingcontext is thick, a few forked near stipe, at most weakly intervenose in old fruit bodies.

Odour fungoid, in old fruit bodies sometimes, however, like that of Cystoderma carcharias.

Taste slightly bitter in pilei of adult and old fruit bodies, in stipes and young pilei mild, fungoid.

Spores 6.4-8.4(-9.4) × (3.1-) $3.6-$ $4.8 \mu \mathrm{m}$, from somewhat above $50 \%$ to the great majority in tetrads (and dyads) in preparations made of lamellae, all obtusebased, most elliptical, the rest oblong, ovate, and obovate, plage applanated to slightly depressed, containing one large and some smaller guttules, or being irregularly multiguttulate, apiculus ca. $0.6-0.9 \times 0.5-0.6$ $\mu \mathrm{m}$; spore deposit very pale yellow, about $9 \mathrm{~B} 1$.

Anatomy of cortex of pileus. Epicutis $40-$ $80 \mu \mathrm{m}$ thick, hyphae more or less parallel, $1.5-6.0 \mu \mathrm{m}$ in diameter, most of them (the innermost excluded) containing intracellular pigment, in addition membranal and often some intercellular pigment present; subcutis not distinctly differentiated.

Ecology. In groups or rows, often subcespitose, in coniferous mesic heath forests (MT, OMT), sometimes in dry ones (VT), usually in litter of Picea, sometimes in heaps of straw (and needles), often among Pleurozium or Hylocomium. Throughout October (Fig. 5).

Distribution. Hemiboreal, in eastern parts of the area, near the sea level. Very rare. (Fig. 158).

\section{Specimens examined.}

Finland: Lohja mlk. (6: Jalassaari 8.X. 1965; Jalassaari 15. X. 1965; holotype; Jalassaari 29. X. 1965; Kunnarla 17. X. 1965; Maksjoki 17.X. 1965; all collected by the present author).

Discussion. For the characters which differentiate C.amarescens from the very similar C.metachroa and C.metachroides, see the key (p. 49), and under the lastnamed species.

When compared with C.metachroa, the present species has usually also a slightly more deeply depressed pileus, and evidently different habitats, fruiting time and distribution.

There may be slight genetic variation in the colours of the fruit body, the diameter of the stipe, and the breadth of the spores. 
32. Clitocybe metachroides Harmaja, n. sp.

Figs. 72, 118.

Clitocybes metachroae similis; pileus 1.5 $4.5 \mathrm{~cm}$ latus, hygrophanus, non pruinosus, \pm fuscus, striatus, in adultis leniter depressus; stipes \pm unicolor, \pm gracilis, basi non strigosa; lamellae breviter decurrentes, colore \pm fusco; odor fungoideus; sapor semper mitis; sporae $5.5-7.5 \times 3.2-4.2 \mu \mathrm{m}$, maxima pars earum in tetradibus, basi obtusa, maxima pars earum ellipsoideae-oblongae; autumno seriore. - Holotypus: Finland, prov. Varsinais-Suomi, par. Taivassalo, Ketarsalmi 16. X. 1960, Paavo Kallio (TUR; isotype in MICH).

Pileus $1.5-4.5 \mathrm{~cm}$ broad, hygrophanous, not pruinose, margin translucent-striate, even up to halfway towards centre, when moist dark fuscous, e.g. 14 D 6 , disc in all stages darker, in moist pileus $16 \mathrm{G} 8$, faded pileus pale brown, $12 \mathrm{C} 3$, in exsiccates dirty grey to fuscous and grey-brown, slightly depressed when adult; margin indistinctly inrolled at first soon becoming straight; surface dry, smooth.

Stipe 3-5 $\times 2-6$, slender, when moist more or less concolorous with moist pileus (rarely the very apex is somewhat paler), in exsiccates more or less darker than pileus having distinct grey tinges, \pm equal, solid at first becoming hollow, cylindrical; surface dry, with indistinct hyphal fibrillose coating, at times whitish granules at the apex; at the base some tomentum.

Lamellae obliquely adnate to short decurrent, when moist pale to rather dark fuscous, being paler than moist pileus, near $13 \mathrm{C} 5$, or $14 \mathrm{C} 5$, in 3 or 4 verticils, those which reach the stipe broadest in the middle or proximally, not forked or intervenose.

Odour fungoid, in old fruit bodies sometimes, however, faintly like that of Cystoderma carcharias.

Taste in all parts of the fruit body completely mild, fungoid.

Spores 5.5-7.5 × 3.2-4.2 um, most of them in tetrads in preparations made of lamellae, all obtuse-based, most elliptical to 土 oblong, the remaining few ovate, and obovate, mostly containing one or two large guttules, apiculus ca. $0.6-0.8 \times 0.4-0.6$ $\mu \mathrm{m}$; spore deposit white or very pale yellow (the exact colour unknown).

Anatomy of cortex of pileus. Epicutis ca. 25-50 $\mu \mathrm{m}$ thick, hyphae parallel to slightly interwoven, $2.0-4.0 \mu \mathrm{m}$ in diameter, membranal and intracellular pigments present, and often finely encrusted pigment, too; subcutis usually seen under microscope (not very distinctly) as darkest layer in pileus section, ca. 20-40 $\mu \mathrm{m}$ thick, hyphae more or less parallel, $3.0-5.0 \mu \mathrm{m}$ in diameter, pigments as in the epicutis but intracellular one scarcer and the two others often more abundant than in epicutis.

Ecology. Solitary or in groups in mostly coniferous, dry, sometimes mesic heath forests (VT, MT, OMT), in litter of Picea or Pinus, rarely Betula or Alnus incana, or partly herbaceous litter, often among mosses such as Pleurozium. From latter half of September (in very north even in late $\mathrm{Au}$ gust) to latter half of November (Fig. 5).

Distribution. Hemiboreal to northern boreal, but lacking in western parts of the area, up to ca. $250 \mathrm{~m} \mathrm{(S.} \mathrm{and} \mathrm{central} \mathrm{Swe-}$ den). Rather infrequent. (Fig. 158).

\section{Specimens examined.}

Norway: Troms. Kvaenangen (1); Nordreisa (1) ; Tromsø (1). - Finnmark. Talvik (1).

Sweden: Småland. Almesåkra (1); Nässjö (1); N. Sandsjö (3). - Värmland. Dalby (1); N. Finnskoga (1). - Uppland. Djurö (1); Sånga (1); Uppsala (1).

Finland: Varsinais-Suomi. Lohja mlk. (1); $\mathrm{Pa}$ rainen (1); Taivassalo (1). - Etelä-Karjala. Miehikkälä (1); Virolahti (1). - Satakunta. Alastaro (1). _ Etelä-Häme. Asikkala (1); Tammela (3). - Pohjois-Häme. Virrat (3). - PohjoisSavo. Joroinen (1). - Keski-Pohjanmaa. Pietarsaari (2). - Inarin Lappi. Utsjoki (1).

Discussion. This species is distinguished from C.metachroa and C.amarescens by the smaller size, darker colours (especially of the lamellae), the shorter and relatively broader spores, and the more or less different ecology and distribution. The taste is always absolutely mild in all parts of the fruit body, and the slender stipe is more or less uniformly coloured, and equal.

LANGE's description and figure of $« C$. metachroa« (1935-1940, Vol. 1: 84 and Fig. 37: D) fit the present species very well, and may actually refer to $C$. metachroides. 
Section XIV. Latisporae Harmaja, n. sect.

Pileus hygrophanus, non pruinosus, indistincte striatus, sordide brunneus vel pallidior, non griseus; basis stipitis non strigosa; lamellae elasticae; odor et sapor fungoideus; sporae parvae, solitarii, basi obtusa vel acuta, maxima pars earum globosae vel \pm subglobosae, nonnullae \pm lacrymoideae, late ellipsoideae, obovatae vel ovatae, intus heterogeneae, apiculo \pm tenui, sporarum massa pure alba. - Holotypus: Clitocybe subcordispora Harmaja.

Pileus small to medium-sized, hygrophanous, not pruinose, indistinctly translucent-striate near margin, with sordid brown colours, grey tinges absent, only depressed when adult; margin rather thick, somewhat incurved; surface dry, smooth, densely concentrically wrinkled in exsiccates. Stipe usually with basal tomentum only, rarely some thin rhizoids in addition. Lamellae brown, often with darker spots, in exsiccates either pale or rusty brown, unusually waxy and elastic in consistency, dirty brownish with more or less distinct chloricgreenish tinge under ultra-violet light. Odour fungoid. Taste mild, fungoid. Spores small,

33. Clitocybe subcordispora Harmaja, n. sp.

Figs. 29, 73, 119.

Pileus 3-6.5 cm latus, hygrophanus, non pruinosus, striatus ad marginem, brunneus, non infundibuliformis; basis stipitis non strigosa; odor fungoideus; sapor mitis, fungoideus; sporae $4.2-6.2 \times 3.0-4.0 \mu \mathrm{m}$, solitarii, basi obtusa vel acuta, maxima pars earum subglobosae vel subcordiformes, nonnullae lacrymoideae etc., intus guttulatae, sporarum massa pure alba; in silvis siccis coniferis, autumno. - Holotypus: Finland, prov. Etelä-Karjala, par. Vehkalahti, Paijärvi, dryish heath forest with Picea and Pinus 21. IX. 1967, Harri Harmaja (H; isotype in $\mathrm{MICH}$ ).

Pileus 3-6.5 cm broad, hygrophanous, not pruinose, rather weakly translucent-striate at margin, when moist brown with reddish or

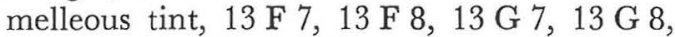
(young pilei often darker), disc darker in all stages, when moist $8 \mathrm{~A} 10,8 \mathrm{~A} 11$, pileus in the faded condition pale brown, $10 \mathrm{E} 3$,
3.2-6.2 $\mu \mathrm{m}$ long/in diameter, relatively broad, single in preparations, obtuse- or acute-based, globose, subglobose, \pm lacrymoid, broadly elliptical, obovate, or ovate, plage applanated to somewhat depressed, contents guttulate, apiculus ca. 0.6-0.9 $\times$ $0.4-0.6 \mu \mathrm{m}$; spore deposit pure white. Epicutis almost colourless under microscope, subcutis distinct, apparent under microscope as darkest layer of section of pileus; finely encrusted pigment absent from hyphae of pileus, but brown fairly large crystals present between the basidia in exsiccates of C. globispora. From middle of August to early November. In hemiboreal and southern boreal zones, in eastern parts of Fennoscandia.

Discussion. The characters given for this very distinct section, which can only be observed in moist (and faded) fruit bodies, are those of $C$. subcordispora, since I myself have not collected the other species of the section, C. globispora. The latter is, however, very nearly related to the former even on the basis of the features observable in the exsiccates.

$10 \mathrm{~F} 3,11 \mathrm{D} 4,11 \mathrm{E} 4,11 \mathrm{~F} 5$, in exsiccates somewhat paler than when moist, $13 \mathrm{E} 6$, $13 \mathrm{E} \mathrm{7}$, rarely $12 \mathrm{~F} \mathrm{7}$, convex at first soon becoming plane and narrowly depressed (but not infundibuliform); margin rather thick, always slightly bent down; surface dry or slightly slippery, smooth, with conspicuous dense concentrical wrinkles in exsiccates.

Stipe 3-8 $\times 4-8(-14)$, roughly concolorous with pileus or slightly paler when moist, in exsiccates rather dark brown with reddish tint, equal (rarely indistinctly downwards enlarged), extreme base somewhat attenuated, obtuse, solid at first becoming hollow, \pm terete; surface dry, with very thin fibrillose coating; at the base scanty tomentum (rarely some thin inconspicuous rhizoids, too).

Lamellae obliquely adnate to short decurrent, angle of attachment $40^{\circ}-60^{\circ}$, strikingly pale brownish when moist, $10 \mathrm{E} 2$, $11 \mathrm{C} 2$, $11 \mathrm{C} 3$, often with red-brown spots, in exsiccates pale brown, $12 \mathrm{~B} 6,12 \mathrm{C} \mathrm{7}$, in 4 verticils, $30-50$ reach the stipe, being broadest around the middle, $3-5 \mathrm{~mm}$, 
where they are 3-5 times broader than overlying context is thick, a few sometimes forked, not intervenose, strikingly waxy and elastic in consistency resembling those of Russula cyanoxantha in this respect.

Odour fungoid.

Taste mild, fungoid.

Spores $4.2-6.2 \times 3.0-4.0 \mu \mathrm{m}$, almost all single in all preparations, variable in shape, the great majority to ca. $50 \%$ obtuse-based, most of these being subglobose to subcordiform, the others \pm broadly elliptical, obovate, or ovate, the remainder acute-based and \pm lacrymoid, plage applanated to somewhat depressed, almost all containing one large irregular drop or several small ones, apiculus ca. $0.6-0.8 \times 0.4-0.5 \mu \mathrm{m}$; spore deposit pure white.

Anatomy of cortex of pileus. Epicutis almost colourless under microscope, 30-60 $\mu \mathrm{m}$ thick, hyphae more or less parallel to slightly interwoven, 2.0-5.0 $\mu \mathrm{m}$ in diameter, scanty intracellular as well as intercellular pigments present; subcutis distinct as darkest layer of pileus section under microscope, 50-80 $\mu \mathrm{m}$ thick, hyphae \pm parallel to slightly interwoven, ca. $3.0-6.0 \mu \mathrm{m}$ in diameter, gradually becoming broader downwards, only rich membranal pigment present.

Ecology. In rows or arcs in meagre, coniferous, dry (rarely mesic) heath forests (CT, VT, MT), in litter of Pinus or Picea (once Larix cf. sibirica), sometimes among mosses, such as Pleurozium, Hylocomium, Dicranum. From early September to beginning of November (Fig. 5).

Distribution. Hemiboreal and southern boreal, in eastern parts of the area, up to ca. $100 \mathrm{~m}$ (S. Finland). Very rare. (Fig. 159).

\section{Specimens examined.}

Finland: Varsinais-Suomi. Lohja mlk. (3: Kirkniemi 10. IX. 1965; Nummenkylä 17. X. 1967; Nummenkylä 25.X. 1967 ; all collected by the present author); Suomusjärvi (1, Kettula 7. X. 1967, H. Harmaja). - Etelä-Karjala. Vehkalahti (1, holotype). - Pohjois-Häme. Virrat (1, Killinkoski 7. XI. 1965, P. \& I. Kytövuori 1735, s.n. C. sp.; $\mathrm{H})$.

Discussion. This eastern species has spores which vary in shape within the same preparation. The specific epithet refers to the moderate percentage of principally subglobose, obovate, and lacrymoid spores whose apical (distal) end is \pm obliquely truncate (in a few even very slightly concave). These spores are thus indistinctly triangular, «subcordiform $\ll$.

34. Clitocybe globispora Harmaja, n. sp.

Figs. 74, 120.

Valde similis Clitocybes subcordisporae, sed sporis irregulariter globosis, 3.2-5.0 $\mu \mathrm{m}$ in diam., basi semper obtusa; lamellis ferrugineis in exsiccatis; in silvis coniferis, mense Augusto. - Holotypus: Finland, prov. EteläHäme, par. Tammela, Syrjä 21. VIII. 1889, P.A. Karsten, s.n. C. expallens v. trivialis (H, Herb. P. A. Karsten no. 200).

Spores 3.2-5.0 $\mu \mathrm{m}$ in diameter, single in preparations, all obtuse-based, \pm irregularly (because of the applanated plage) globose, contents several minute guttules, or, in a few, one larger one, apiculus ca. $0.6-0.9 \times 0.4$ $0.6 \mu \mathrm{m}$; exact colour of spore deposit unknown.

Anatomy of cortex of pileus. Epicutis almost colourless under microscope, 25-40 $\mu \mathrm{m}$ thick, hyphae parallel to somewhat interwoven, 1.5-3.5 $\mu \mathrm{m}$ in diameter, only scanty intracellular pigment present; subcutis distinct as darkest layer of pileus section under microscope, 25-50 $\mu \mathrm{m}$ thick, hyphae \pm parallel, $2.0-6.0 \mu \mathrm{m}$ in diameter, only rich membranal pigment present.

Ecology. Evidently in more or less mesic heath forests, always found in litter of Picea. Latter half of August (Fig. 5).

Distribution. Hemiboreal and southern boreal, in eastern parts of the area, up to ca. $100 \mathrm{~m}$ (S. Finland). Very rare. (Fig. 159).

\section{Specimens examined.}

Finland: Varsinais-Suomi. Parainen (1, Attu 25. VIII. 1953, O. v. Schulmann, s.n. Clitopilopsis hirneola; H). - Etelä-Häme. Lammi (1, Porraskoski 18. VIII. 1952, O. v. Schulmann, s.n. Clitocybe ditopa; $\mathrm{H}$ ); Tammela (1, holotype).

Discussion. I myself have not collected this species so cannot describe the odour and taste, but, judging from its dried fruit bodies, C. globispora is very nearly related to the preceding species in respect of both the macroscopical and microscopical features. It differs from C. subcordispora in the darker, rusty brown gills of the exsiccates (this colour may, partly at least, result from large brown crystals between the basidia), the globose obtuse-based spores, and very probably the fruiting time and habitat, too. 
Section XV. Ditopae (Sing.) Singer, Lilloa 22: 190. 1951.

Basionym: Clitocybe section Ditopae Singer, Sydowia Ann. Mycol. 2: 26. 1948. - Typus: Holotype Clitocybe ditopa (Fr.) Gill.

Pileus small to medium-sized, hygrophanous, pruinose or not, translucent-striate or not, colours dull, grey, fuscous, or brown, becoming browner in exsiccates with age, usually only \pm depressed (rarely \pm infundibuliform) when adult; margin thick to thin, often inrolled at first, rarely persisting so, sometimes whitish-pruinose; surface conspicuously concentrically wrinkled in exsiccates (indistinctly in C. ditopa v. ditopa). Stipe base usually with tomentum only, rarely some thin inconspicuous rhizoids, too. Lamellae rather dark and dull-coloured in both moist and dried condition, being pale to dark grey, or almost fuscous, rarely more brownish-tinted, always violet under ultra-violet light in exsiccates. Flesh usually thin, rarely moderately thick, «normally« elastic in consistency, rarely fragile. Odour, at least when bruised, always distinctly farinaceous (in C. menthiodora masked by faint, fragrant menthol-like odour during drying, but still observable when bruised). Exsiccates odourless (except for those of C. menthiodora, which have persistent fishy smell). Taste always distinctly farinaceous. Spores large to very small, practically all to the great majority of them occurring singly in all preparations except in C.vibecina, in which almost all to somewhat above 50\% in preparations made of lamellae, all obtusebased, except in two species in which a minority are acute-based, of different shapes being generally elliptical to oblong, or ovate, sometimes subglobose, obovate, \pm lacrymoid, or subfusiform, sometimes having an asymmetrical median constriction (see p. 23), plage applanated to distinctly depressed, contents \pm homogeneous to guttulate, apiculus of different sizes, ranging from 0.4 to $1.0 \mu \mathrm{m}$ in length, and 0.3 to $0.8 \mu \mathrm{m}$ in breadth; spore deposit \pm pure white (exact colour unknown, however, in C.orientalis). Subcutis present or absent; encrusted pigment absent from hyphae of pileus (however, occasionally present on hyphae of the trama of pileus, or lamellae). Occurring especially in barren forests on infertile ground and late in the year, altogether from beginning of September to latter half of December. Temperate to northern boreal.
Discussion. Singer $(1948,1951,1962)$ treated the present section as monotypic, including $C$. ditopa only, the small size and the shape of the spores being the only characters distinguishing Ditopae from, for instance, the type section of the subgenus Pseudolyophyllum. His classification is unnatural, since the size and shape of the spores vary widely in the subgenus Pseudolyophyllum (also in species nearly related to C. ditopa), and because C. ditopa is surely close to, for instance, C. vibecina and C.langei (both of which are placed in the type section by SINGER, 1962), all three species sharing the dull colours, the variation in the nature of the pileus surface (pruinose or non-pruinose), and, above all the farinaceous odour and taste. These characters, in particular the odour and taste (and the lack of mycelial hairs), make the section Ditopae in the present meaning uniform and distinct from the other sections of the subgenus Pseudolyophyllum.

There are several obviously undescribed species belonging to the present section (e.g., some with conspicuously broadly elliptical spores), but the data on most of them are so far insufficient, and accordingly they must unfortunately be excluded from the present study.

Like the section Infundibuliformes, the section Ditopae is also very natural, containing several species which are very nearly related to each other, often only differing in a few characters. Similarly, the section also contains specimens which suggest hybridization between species, namely between $C$. langei and $C$. vibecina. Such specimens, of course, have been excluded, and it will be the task of future studies to examine this assumption. As concerns the Agaricales (and generally other funci, too), there is extremely little information in the literature on possible interspecific hybrids, and so far probably no clear case of such hybridization is known.

It is not yet quite sure whether the name Ditopae is the valid one for the present section. The taxon Hygrophanae Quélet 1888 was recognized as a section (of Clitocybe, subgenus Pseudolyophyllum) by SingER (1951), who also named «C. vibecina 
sensu Ricken « as the (lecto)type. If QuéLET's taxon was, however, already recognized as a section before the establishment of Dito-

\section{Clitocybe orientalis Harmaja, n. sp.}

Figs. 75, 121.

Valde similis Clitocybes vibecinae (statura, coloribus, farinaceo odore et sapore), sporae tamen distincte dissimiles, 6.0-8.0 (-9.0) $\times 3.0-4.2(-5.0) \mu \mathrm{m}$, solitarii, basi obtusa vel acuta, maxima pars earum \pm ovatae, apiculo magno. - Holotypus: Finland, prov. Etelä-Savo, par. Valkeala, Utti, dry Pinus heath forest 12. X. 1967, Harri Harmaja (H; isotype in MICH).

Spores $6.0-8.0(-9.0) \times 3.0-4.2(-5.0)$, the great majority single in all preparations, rather variable in size and shape, the great majority obtuse-based, the rest acute-based, most (usually) of each type \pm ovate, the rest elliptical, oblong, and subfusiform, a few indistinctly concave ventrally, plage applanated to distinctly depressed, contents \pm homogeneous, apiculus ca. $0.8-1.0 \times 0.6-0.8$ $\mu \mathrm{m}$; exact colour of spore deposit unknown.

Anatomy of cortex of pileus. Epicutis ca. 40-60 $\mu \mathrm{m}$ thick, hyphae subparallel, 1.5$6.0 \mu \mathrm{m}$ in diameter, the outermost often somewhat wrinkled, membranal pigment present, evidently very scanty intracellular pigment, too; subcutis not differentiated.

Ecology. In indistinct arcs, at least, in dry heath forests (VT) and obviously in mesic heath forests, too, in litter of Pinus, or Betula (once together with chips of wood), sometimes among Pleurozium. From latter half of September (in very nort already in late August) to latter half of November (Fig. 5).

Distribution. In hemiboreal, southern boreal, and northern boreal zones, in eastern parts of the area, up to ca. $100 \mathrm{~m}$ (N. Norway, Finland). Very rare. (Fig. 160).

\section{Specimens examined.}

Norway: Finnmark. Nesseby (1, Varangerbotn 19. VIII. 1965, collected by the symposium expedition, s.n. C. vibecina; TUR).

Sweden: Uppland. Uppsala (1, Norrby 13. X. 1898, H. v. Post, s.n. C. sp.; S).

FinLAND: Varsinais-Suomi. Lohja mlk. (1, Laakspohja 20. XI. 1967, H. Harmaja). - Uusimaa. Porvoo mlk. (1, Gäddrag 18. IX. 1960, N. Malmström, s.n. C. metachroa; H). - Etelä-Savo. Valkeala (1, holotype). - Pohjois-Savo. Lapinlahti (1, Rasila 26. IX. 1956, O. v. Schulmann, s.n. C. langei; $\mathrm{H})$. pae, i.e., before 1948, Hygrophanae (Quél.) Sing. would be the correct name for the present section.

Discussion. I have not yet been able to detect any macroscopical differences between C. orientalis and C.vibecina (even young pilei may be pruinose in both), but their spores are clearly dissimilar in several respects. Also, the distribution of $C$. orientalis is pronouncedly eastern.

36. Clitocybe vibecina (Fr.) Quélet, Les champignons du Jura et des Vosges, 318. 1872.

Basionym: Agaricus vibecinus Fries, Epicrisis systematis mycologici..., 75. 1836 -1838. - Typus: No original designation. No material of FrIES existing. A neotype has not been designated.

Figs. 30, 76, 122.

Pileus ca. 2-5 $\mathrm{cm}$ broad, hygrophanous, not pruinose (sometimes pruinose in young buttons), distinctly translucent-striate at margin, even up to $2 / 3$ of way towards centre, when moist \pm fuscous (brown-grey,

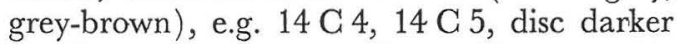
in all stages, pileus pale brownish to greyish when faded, in exsiccates grey-brown at first, grey tints disappearing with age, shallowly convex at first soon becoming plane, and shallowly and broadly depressed, rarely almost infundibuliform; margin not thin, more or less inrolled at first (sometimes whitishpruinose); surface dry, slightly lustrous when moist, smooth, conspicuously concentrically wrinkled in exsiccates.

Stipe ca. 2-7 7 2-5, more or less concolorous with pileus when moist, in exsiccates usually rather distinctly brown, often in contrast to the colours of the pileus and lamellae, being also slightly darker than the latter, \pm equal, solid at first becoming hollow, \pm terete; surface dry, glabrous or slightly «mealy« at apex (especially in young basidiocarps); at the base tomentum.

Lamellae obliquely adnate to shortly (rarely moderately) decurrent, angle of attachment usually great, $\left(30^{\circ}-\right) 45^{\circ}-60^{\circ}$, pale fuscous when moist, e.g. 12 B.1, 12 B 2, being paler than moist pileus and stipe, in exsiccates more or less grey, in 3-4 verticils, those which reach the stipe broadest 
around middle (sometimes nearer the stipe), $3-5 \mathrm{~mm}$, where they are $4-5$ times broader than overlying context is thick, neither forked nor intervenose.

Odour farinaceous, often \pm weak unless the basidiocarp is bruised.

Taste mild, farinaceous.

Spores $5.0-7.0(-7.5) \times 2.9-3.6 \mu \mathrm{m}$, almost all to somewhat above $50 \%$ single in preparations made of lamellae, all obtusebased, usually most to almost all narrowly elliptical to oblong, the rest (sometimes most) ovate, in addition a very few obovate, a few indistinctly concave ventrally, contents homogeneous to irregularly guttulate, apiculus ca. $0.6-0.8 \times 0.4-0.6 \mu \mathrm{m}$; spore deposit pure white.

Anatomy of cortex of pileus. Epicutis ca. 20-40 $\mu \mathrm{m}$ thick, hyphae indistinctly to distinctly parallel, $2.0-6.0 \mu \mathrm{m}$ in diameter, only faint membranal pigment definitely discernible; subcutis indistinct, ca. 30-40 $\mu \mathrm{m}$ thick, hyphae \pm parallel, $4.0-8.0 \mu \mathrm{m}$ in diameter, pigment as in epicutis.

Ecology. Solitary, in rows, arcs, or groups, in meagre coniferous (sometimes deciduous) dry to mesic heath forests (GT, VT, MT, OMT), mostly in litter of Pinus (besides needles, once found on a heap of loose bark, and once on cones), or Picea, rarely in litter of deciduous trees (Betula, Fagus, Quercus), once found even in needles of Pinus mugho and in those of $P$.peuce, often among the mosses Pleurozium, Dicranum, and Hylocomium. From latter half of September to latter half of December (Fig. 5).

Distribution. Temperate to northern boreal, up to ca. $250 \mathrm{~m}$ (S. Sweden). Rather common. (Fig. 161).

\section{Specimens examined.}

Norway: Akershus. Oslo (2); Ski (1); Ullensaker (2). - Telemark. Notodden (1). - Hordaland. Granvin (2). - Sogn og Fjordane. Solund (1). - Troms. Nordreisa (1); Tromsø (1).

Sweden: Skaine. Perstorp (1). - Småland. Almesåkra (6); Bringetofta (3); Femsjö (4); Kärda (3) ; Nässjö (3); N. Solberga (3); Värnamo (1). - Östergötland. Skedevi (1). - Västergötland. Björketorp (1); Fässberg (2); Göteborg (10). Södermanland. Ornö (1). - Uppland. Alsike (1); Bondkyrka (2) ; Djurö (3) ; Stockholm (2) ; Uppsala (2) ; Älvkarleby (1). - Västmanland. Köping (1). - Dalarna. Kopparberg (1).

Finland: Ahvenanmaa. Eckerö (1). - Varsinais-Suomi. Lohja mlk. (5); Perniö (1); Pohja (2); Turku (1); Uusikaupunki mlk. (1); Vihti (1). - Uusimaa. Espoo (1); Helsinki (1); Helsingin mlk. (2); Kauniainen (2); Orimattila (1);
Tuusula (5). — Etelä-Karjala. Miehikkälä (2); Virolahti (1). Satakunta. Alastaro (1); Lappi (5). - Etelä-Häme. Kuhmoinen (2); Tammela (2). - Etelä-Savo. Mäntyharju (1); Rautjärvi (1). Laatokan Karjala. Parikkala (1). — Pohjois-Häme. Virrat (1); Ähtäri (1). - Pohjois-Savo. Iisalmi (1); Lapinlahti (1). - Pohjois-Pohjanmaa. Kiiminki (1); Oulu (2). - Inarin Lappi. Utsjoki (10)

Discussion. This species is very close to C. orientalis and C.langei; the differences are described under those two species.

The consistency of the context varies and is probably genetically controlled, the flesh being either «normally« elastic or strikingly fragile.

The description and rather striking figure of C. vibecina in LANGE (1935-1940, Vol. 1: 84, fig. 37: A) do indeed seem to refer to the present species (see also the discussion of the following species).

The original description of Agaricus vibecinus by FrIES is very indefinite and flexible, especially since the odour is not indicated to be farinaceous. I have, however, followed common usage in recognizing $C$. vibecina as a not infrequent, \pm grey-coloured species with a striate pileus and a farinaceous odour and taste. This is the commonest of such species in Fennoscandia, including S. Sweden. (See also under C. metachroa.)

37. Clitocybe langei Singer ex Hora, Trans. Brit. Mycol. Soc. 43: 441. 1960.

Typus: Holotype in the herbarium of F. B. Hora (England), not examined.

Figs. 31, 77, 123.

Pileus ca. 3-4 cm broad, hygrophanous, not pruinose (sometimes pruinose in young buttons), distinctly translucent-striate at margin when adult and old, even up to halfway towards centre, grey-brown when moist, $13 \mathrm{C} 6,14 \mathrm{~B} 6,14 \mathrm{D} 6$, disc in all stages darker, pileus dirty brownish when faded, $10 \mathrm{D} 2$, in exsiccates pale brown, e.g. $10 \mathrm{D} 3$, shallowly convex at first soon becoming plane and slightly depressed; margin at first inrolled (sometimes whitish-pruinose); surface dry, slightly lutrous when moist, smooth, conspicuously concentrically wrinkled in exsiccates.

Stipe 3-9 9 3-7, more or less concolorous with pileus when moist and in exsic- 
cates, \pm equal, extreme base attenuated and rather acute, at first solid becoming hollow, at first terete, finally often compressed; surface dry, glabrous or slightly «mealy« at apex (especially in young basidiocarps); at the base tomentum.

Lamellae obliquely adnate to short decurrent, angle of attachment about $45^{\circ}-60^{\circ}$, pale fuscous when moist, e.g. $13 \mathrm{~B} 5$, being paler than moist pileus and stipe, in exsiccates more or less grey, in 3-4 verticils, $30-40$ reach the stipe, being broadest in the middle or nearer stipe, $4-6 \mathrm{~mm}$, in the middle 4-5 times broader than overlying context is thick, neither forked nor intervenose.

Odour farinaceous, often \pm weak unless the basidiocarp is bruised.

Taste mild, farinaceous.

Spores $5.0-6.5(-7.0) \times 2.9-3.6 \mu \mathrm{m}$, the distinct majority single in all preparations, rather variable in shape, perhaps most of them obtuse-based being broadly to moderately elliptical or obovate (a few even ovate), the rest acute-based being \pm lacrymoid to almost elliptical, contents \pm homogeneous, apiculus ca. $0.8-1.0 \times 0.5-0.8$ $\mu \mathrm{m}$; spore deposit \pm pure white.

Anatomy of cortex of pileus. Epicutis ca. $30-60 \mu \mathrm{m}$ thick, hyphae slightly interwoven to subparallel, $1.0-6.0 \mu \mathrm{m}$ in diameter, often somewhat wrinkled, faint intracellular pigment present, at least; subcutis ca. 25$70 \mu \mathrm{m}$ thick, hyphae \pm parallel, 3.0-7.0 $\mu \mathrm{m}$ in diameter, only faint membranal pigment present.

Ecology. In arcs or groups in meagre, coniferous, dry to mesic heath forests (VT, MT, OMT), in litter of Pinus, or Picea, often among mosses (Pleurozium, Dicranum, Hylocomium). From early September to first half of October (Fig. 5).

Distribution. Hemiboreal, southern boreal and northern boreal, lacking in western parts of the area, up to ca. $150 \mathrm{~m}$ (S. Sweden). Rare. (Fig. 162).

\section{Specimens examined.}

Sweden: Småland. Kärda (2: Hörda 29. IX. 1968; Hörda 1.X. 1968; both collected by the present author). - Bohuslän. Valla (1, Hakenäset 13. X. 1968, F. Karlvall 13280, s.n. C. metachroa; GB).

Finland: Uusimaa. Helsinki (1); Kirkkonummi (1); Sipoo (2). - Satakunta. Alastaro (1). Etelä-Häme. Tammela (3). - Inarin Lappi. Utsjoki (1).
Discussion. This species is very similar to C. vibecina, but is slightly stouter with browner colours, its spores are slightly shorter, of different shape, and with a larger apiculus, its fruiting time is somewhat earlier, and it has a different distribution. As stated under the description of the present section (p. 102), specimens exist which are morphologically intermediate between C. vibecina and C. Langei (especially in respect of the spores), thus suggesting hybridization between these species.

Unfortunately, I could not obtain the holotype of C. langei from Dr. Hora for checking the characters, so it is not completely certain whether the present species actually represents $C$. lange $i$.

Singer (1943, without Latin description) and Hora (1960), and according to them some other mycologists as well, claim that LANGE's (1935-1940) concept of C.vibecina is different from that of FrIes, and the name C. langei Sing. ex Hora was created for the species described by Lange. $C$. vibecina sensu LANGE and C.langei (sensu Hora, whose concept is to be followed, and not that of Singer) do appear to be two different species, because LANGE's (op. cit.) description and figure show the spores to be roughly elliptical to oblong, while Hora (op. cit.) describes and depicts them as more or less lacrymoid. Unfortunately LANGe did dot preserve herbarium specimens from which the spore characters of his $C$. vibecina could be checked more accurately. As explained under C.vibecina in the present paper (p. 104), it is, however, by no means sure that the present interpretation of that species, which seems to be identical with that of LANGE (op. cit.), refers to the same species as that meant by FrIes with his Agaricus vibecinus.

38. Clitocybe ditopa (Fr.) Gillet, Les hyménomycètes..., 166. 1874. v. ditopa

Basionym: Agaricus ditopus Fries, Syst. Mycol. 1: 171. 1821. - Typus: No original designation. No material of FrIES existing. A neotype has not been designated.

Figs. 1 a, 32, 78, 124 .

Pileus 4-9 cm broad, hygrophanous, greyish-pruinose (less conspicuously so in old 
pilei; with age the pruina also tends to «crack « concentrically), not striate, ground colour (the pruina excluded) when moist uniform, rather dark, ash-grey, $14 \mathrm{~B} \mathrm{5}$, 14 D 7, 15 C 5, 15 C 6, or even darker, when faded pale grey-brown, between $13 \mathrm{E} 6$ and $13 \mathrm{E} 7$, in exsiccates slightly paler than when

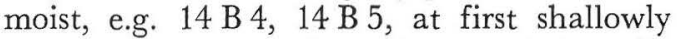
convex soon becoming plane and broadly depressed, finally bowl-shaped or \pm infundibuliform; margin thick, always more or less inrolled, usually more or less conspicuously white-pruinose; surface dry or slightly viscid, mat to slightly lustrous, smooth, indistinctly concentrically wrinkled in exsiccates.

Stipe 3-10 × 4-10, almost concolorous with pileus in all stages, being somewhat paler, e.g. $13 \mathrm{E} 6$ when moist, usually equal (occasionally enlarging indistinctly downwards or upwards), extreme base attenuated, solid at first becoming hollow, terete or \pm compressed; surface dry, \pm mat, glabrous but indistinctly whitish-pruinose in the same manner as pileus; at the base scanty to abundant tomentum (at times a few thin rhizoids, too).

Lamellae short decurrent, angle of attachment ca. $30^{\circ}-50^{\circ}$, distinctly grey when moist being concolorous with moist pileus or somewhat paler, in 3-4 verticils, 40-50 reach the stipe, being broadest around the middle, $3-5 \mathrm{~mm}$, where they are $3-4$ times broader than overlying context is thick, a few sometimes forked, only very slightly intervenose.

Odour strongly farinaceous.

Taste mild, farinaceous.

Spores $3.0-4.2(-5.0) \times 2.3-3.1 \mu \mathrm{m}$, single in all preparations, all obtuse-based, most broadly elliptical to subglobose, the rest broadly obovate, or moderately elliptical, most containing one large guttule (often difficult to discern), apiculus ca. 0.4-0.6 $\times$ $0.3-0.4 \mu \mathrm{m}$; spore deposit pure white.

Anatomy of cortex of pileus. Epicutis 50$110 \mu \mathrm{m}$ thick, hyphae more or less parallel to slightly interwoven, $2.5-5.0 \mu \mathrm{m}$ in diameter, the outermost often slightly wrinkled, intracellular and membranal pigments present; subcutis not differentiated.

Ecology. Solitary or in groups, sometimes subcespitose, in grass-herb forests (OMaT), and mesic heath forests (OMT, MT), almost always in litter of Picea, rarely in that of Pinus, Alnus incana, Betula, or herba- ceous plants, sometimes amongst mosses (Hylocomium, Rhodobryum roseum, Pleurozium, Brachythecium spp.). From beginning of September to late November (Fig. 5).

Distribution. Temperate to middle boreal, but lacking in districts with very oceanic climate, up to ca. $250 \mathrm{~m}$ (S. Sweden). Occasional. (Fig. 163).

\section{Specimens examined.}

Norway: Akershus. Oslo (4); Skedsmo (1); Ski (4). - Buskerud. Nes (2).

SWEDEN: Småland. Almesåkra (1); Bringetofta (1) ; Femsjö (1); Nässjö (1); Värnamo (2). Östergötland. Skedevi (1). - Västergötland. Fuxerna (1); Fässberg (1); Göteborg (5, including LunDell \& NANNFELDT: "Fungi Exsiccati Suecici...《, no. 1739 , s.n. C. ditopoda, in S, UPS); N. Ving (2). - Bohuslän. Rödbo (1). Uppland. Bondkyrka (1); Danmark (1); Gamla Uppsala (2, Lundele \& Nannfeldt: «Fungi Exsiccati Suecici...«, no. 111, s.n. C. ditopoda, in S, UPS); Stockholm (1); Uppsala (1). Gästrikland. Gävle (1). - Västerbotten. Umeå (1).

Finland: Ahvenanmaa. Eckerö (1). - Varsinais-Suomi. Lohja mlk. (1); Parainen (1); Suomusjärvi (1). - Uusimaa. Helsinki (1) ; Hyvinkää (1); Kauniainen (2); Porvoo (1); Tammisaari (1); Tuusula (3). - Satakunta. Lappi (1). Etelä-Häme. Hattula (1); Somero (1); Tammela (8). - Laatokan Karjala. Parikkala (1). - Etelä-Pohjanmaa. Ilmajoki (1). — Pohjois-Savo. Kuopio (1); Lapinlahti (1); Siilinjärvi (1). Pohjois-Karjala. Tuupovaara (1). - Pohjois-Pohjanmaa. Kiiminki (1).

Discussion. C. ditopa v. ditopa is easily recognized by the following combination of characters: an ashy-grey, weakly pruinose and non-striate pileus with rather thick flesh and a strikingly (especially when young) white-pruinose inrolled margin, a strongly farinaceous odour and taste, and very small, subglobose or \pm elliptical spores.

38.a Clitocybe ditopa (Fr.) Gill. v. odorula (Karst.) Harmaja, n. comb.
Basionym: Clitocybe odorula Karsten, Med- del. Soc. Fauna Flora Fennica 5: 17 (Symb. mycol. fennicam 6). 1879; Bidrag Känned. Finlands Nat. Folk 32: 81 (Rysslands, Finlands och den skandinaviska halföns hattsvampar. I). 1879. - Typus: Holotype (Finland, prov. Etelä-Häme, par. Tammela, Syrjä 31. X. 1878, P. A. Karsten; H, Herb. P. A. Karsten no. 188) examined.

Figs. 33, 79, 125.

Pileus 4-8 $\mathrm{cm}$ broad, hygrophanous, not pruinose (or rarely slightly so over disc), 
translucent-striate at margin, even up to halfway towards centre, when moist rather dark brown, near $16 \mathrm{E} 8$, sometimes $14 \mathrm{C} 6$, or pale brown, $12 \mathrm{C} 4$, rarely with grey tones, disc always slightly darker, pileus in the faded condition brownish, $10 \mathrm{E} \mathrm{2,} 11 \mathrm{D} 2$, $11 \mathrm{E} \mathrm{3,} 12 \mathrm{D} 5$, rarely more greyish, in exsiccates dirty pale brown, $11 \mathrm{C} 4,12 \mathrm{~B} 4$, or darker, or greyer, soon rather broadly depressed, finally more or less infundibuliform, or bowl-shaped, or umbilicate; margin thin, straight or somewhat incurved, almost always non-pruinose; surface dry, slightly lustrous, smooth, concentrically wrinkled in exsiccates.

Stipe 3.5-6 6 3-10, in all stages concolorous with pileus or somewhat paler, e.g. 15 C 8 when moist, equal, extreme base attenuated to rounded, long remaining solid then becoming hollow, terete to somewhat compressed; surface dry, slightly lustrous, glabrous; at the base some tomentum, which is whitish or with faint brownish tint when faded (and dry).

Lamellae rather shortly but always narrowly decurrent, angle of attachment about $20^{\circ}-30^{\circ}$, when moist pale brown to browngrey, $11 \mathrm{C} 2$, $12 \mathrm{~B} 2,13 \mathrm{E} 6$, being usually slightly paler than moist pileus, in 3-4 verticils, ca. 40 reach the stipe, being broadest in the middle or nearer the stipe, 3-4 $\mathrm{mm}$, in the middle $2-3$ times broader than overlying context is thick, neither forked nor intervenose.

Odour strongly farinaceous.

Taste mild, farinaceous.

Spores 3.2-4.2(-5.5) × 2.3-3.1 $\mu \mathrm{m}$, single in all preparations, all obtuse-based, most to somewhat below $50 \%$ broadly elliptical to subglobose, the rest moderately elliptical, and obovate, contents indistinctly uniguttulate, apiculus ca. $0.4-0.6 \times 0.3-$ $0.4 \mu \mathrm{m}$; spore deposit \pm pure white.

Anatomy of cortex of pileus. Epicutis ca. 50-70 $\mu \mathrm{m}$ thick, hyphae \pm parallel, 2.0$5.0 \mu \mathrm{m}$ in diameter, intracellular and membranal pigments present; subcutis not differentiated.

Ecology. In rows, arcs, or groups in meagre, coniferous, dry to mesic heath forests (VT, MT, OMT), in litter of Picea or Pinus, rarely among the moss Pleurozium. From beginning of October to first half of November (Fig. 5).

Distribution. Southern boreal, in eastern parts of the area, up to ca. $100 \mathrm{~m}$ (S. Finland). Very rare. (Fig. 164).

\section{Specimens examined.}

Finland: Varsinais-Suomi. Lohja mlk. (1, Lylyinen 21. X. 1967, H. Harmaja). - Etelä-Karjala. Miehikkälä (1, Salomiehikkälä 6. XI. 1967, H. Harmaja). - Etelä-Häme. Asikkala (2, both Keltaniemi 31.X. 1967, H. Harmaja); Tammela (1, holotype). - Etelä-Savo. Juva (1, Männynmäki 5. X. 1967, H. Harmaja). - Pohjois-Häme. Virrat (1, Killinkoski 7. XI. 1965, P. \& I. Kytövuori 1716 , s.n. C. sp.; H).

Discussion. C. ditopa v. odorula differs from the type variety in the more browntinged colours, the striate, completely or almost completely non-pruinose pileus with a thin margin, which is usually neither inrolled nor pruinose, the usually more narrowly decurrent lamellae, and the occurrence in barren heath forests in the east of Fennoscandia. Since the morphological differences between the typical $C$. ditopa and the present taxon seem to be only macroscopic, and sometimes even display some intergradation, I prefer to treat the latter as a variety of C. ditopa rather than an independent species, unlike its original describer.

39. Clitocybe menthiodora Harmaja, n. sp.

Figs. 34, 80, 126.

Pileus 3-6 cm latus, hygrophanus, non pruinosus, striatus, sordide brunneus, non infundibuliformis; stipes fuscus, basi non strigosa; lamellae non vere decurrentes, sordide brunneolae; odor primo farinaceus, in siccantibus fragrans (Menthae similis), in exsiccatis odoris piscis similis; sapor farinaceus; sporae $5.0-7.0(-8.0) \times 2.8-3.7 \mu \mathrm{m}$, solitarii, basi obtusa, maxima pars earum ovatae, ceterum ellipsoideae-oblongae, sporarum massa pure alba. - Holotypus: Finland, prov. Etelä-Häme, par. Tammela, Mustiala, previous pasture-land 19. IX. 1967, Harri Harmaja ( $\mathrm{H}$; isotype in $\mathrm{MICH})$.

Pileus 3-6 $\mathrm{cm}$ broad, hygrophanous, not pruinose, rather weakly translucent-striate at margin, when moist dirty brown, $14 \mathrm{D} \mathrm{7}$, $14 \mathrm{E} 6,15 \mathrm{E} 10$, disc in all stages slightly darker, faded pileus pale brown, e.g. $10 \mathrm{E} 2$, in exsiccates pale brown, $11 \mathrm{E} 4,11 \mathrm{E} 5$, at first convex becoming plane and broadly depressed, finally almost bowl-shaped or almost plane with depressed disc; margin at 
first incurved, finally straight to slightly incurved; surface dry, slightly lustrous, smooth, conspicuously concentrically wrinkled in exsiccates.

Stipe 4-5 $\times 4-10$, in all stages mostly somewhat darker and greyer than pileus, especially lower down, the apex (approximately uppermost $5 \mathrm{~mm}$ ) usually being paler and less grey and \pm concolorous with pileus, downwards tapering or equal, extreme base attenuated, solid at first becoming hollow, terete to compressed, becoming more or less conspicuously twisted in drying; surface dry, with very thin pale fibrillose coating, apex in young basidiocarps sometimes with fine pale granules; at the base rather scanty tomentum.

Lamellae extremely short decurrent to narrowly adnate, angle of attachment $60^{\circ}$ $90^{\circ}$, in old fruit bodies some of them often shallowly sinuate, when moist dirty pale brown, being paler than moist pileus, in exsiccates relatively dark, pale brown to almost fuscous, in 3-4 verticils, ca. 40 reach the stipe, being broadest in the middle, ca. $3 \mathrm{~mm}$, where they are about 4 times broader than overlying context is thick, neither forked nor intervenose.

Odour in moist fruit bodies farinaceous, in drying faint and very agreeable, reminiscent of that of peppermint, or menthol, or bruised leaves of Mentha spp. (bruising the basidiocarp still reveals the farinaceous smell), in exsiccates fishy (persisting as long as 8 years in herbarium).

Taste mild, farinaceous.

Spores $5.0-7.0(-8.0) \times 2.8-3.7 \mu \mathrm{m}$, single in preparations, all obtuse-based, most ovate, the rest elliptic-oblong, some spores of each type with a slight asymmetrical median constriction (see p. 23), irregularly guttulate to \pm eguttulate, apiculus ca. 0.5-
$0.9 \times 0.5-0.7 \mu \mathrm{m}$; spore deposit pure white.

Anatomy of cortex of pileus. Epicutis 30$40 \mu \mathrm{m}$ thick, hyphae \pm parallel, 2.0-6.0 $\mu \mathrm{m}$ in diameter, evidently only indistinct membranal pigment present; subcutis indistinct, ca. $50 \mu \mathrm{m}$ thick, hyphae \pm parallel, 4.0$8.0 \mu \mathrm{m}$ in diameter, distinct membranal pigment present causing this layer to appear under microscope as the darkest one in pileus section.

Ecology. In groups (at least), in mesic heath forests and grass-herb forests, once in previous pasture-land, in litter of Picea, Pinus, Alnus incana, Fagus, or herbaceous plants. From middle of September (in the north even in August) to early November (Fig. 5).

Distribution. Temperate to middle boreal, in eastern parts of the area, up to ca. $200 \mathrm{~m}$ (E. Finland). Very rare. (Fig. 165).

\section{Specimens examined.}

Sweden: Skåne. Allerum (1, Nällåkra 7.X. 1951, O. Andersson 264 p.p., s.n. C. hydrogram$m a$; LD).

Finland: Varsinais-Suomi. Lohja mlk. (1, Seppälä 10. XI. 1967, H. Harmaja). - Etelä-Häme. Somero (1, Kultela 21. IX. 1967, H. Såltin, s.n. C. sp.; TUR); Tammela (1, holotype). - Pohjois-Karjala. Juuka (1, Petrovaara VIII. 1965, A. J. Huuskonen, s.n. C. sp.; OULU). - Pohjois-Pohjanmaa. Oulu (3: Korkeasaari 8. X. 1965; Maaherransaari 3.X. 1965; Oritkari 24. IX. 1965; all collected by T. Ulvinen, s.n. C. sp., OULU).

Discussion. This very clearly distinguished species differs from other species of the section Ditopae in the colours, the peculiar features of its odour, the mode of gillattachment, and some characters of the stipe. The spores are also different from those of the other species, though $C$. vibecina has rather similar spores.

Section XVI. Strigipedes Harmaja, n. sect.

Pileus hygrophanus, non pruinosus, striatus; basis stipitis semper strigosa; lamellae \pm pallidae, raro brunneolae-cinereae; odor fungoideus, raro leniter farinaceus; sapor in basidiocarpis adultis mitis et non farinaceus, raro amarus; sporae parvae vel magnae, solitarii, plerumque basi obtusa, raro acuta, ovatae, ellipsoideae, oblongae, obovatae vel lacrymoideae, apiculo tenui vel crasso. Holotypus: Clitocybe lohjaënsis Harmaja.

Pileus small to medium-sized, hygrophanous, not pruinose, translucent-striate, at least at margin, colours with more or less brown tones, depressed, or umbilicate, rarely \pm infundibuliform when adult; margin thick to thin, often somewhat inrolled at first, never 
pruinose; surface with conspicuous dense concentrical wrinkles in exsiccates. Stipe equal or enlarging downwards, often with chloricgreenish reflection under ultra-violet light in exsiccates, its base always with strigose, slender, hyaline mycelial hairs, which are \pm chloric-greenish under ultra-violet light in exsiccates, usually (always?) scanty tomentum present, too (occasionally in addition a few thin inconspicuous rhizoids). Lamellae \pm pale, brownish, rarely pale brown to almost grey, chloric-greenish (at least with, reflection of that colour) under ultra-violet light in exsiccates, except in C. strigosa in which violet. Flesh very thin. Odour mostly fungoid (even when bruised), in C.lohja$\ddot{e} n s i s$ weakly farinaceous in young fruit bodies, in old fruit bodies of C. strigosa sometimes like that of Cystoderma carcharias, exsiccates always odourless. Taste mild and fungoid in adult basidiocarps (in C.lohjaënsis weakly farinaceous in young ones), except in $C$. schulmannii, which has a bitter taste. Spores small to large, all to the overwhelming majority single in preparations, all of them obtuse-based, except in C. strigosa, which has a number of acute-based spores, too, ovate, elliptical, oblong, obovate, or \pm lacrymoid, sometimes having an asymmetrical median constriction (see p. 23), plage applanated, contents homogeneous to indistinctly guttulate, apiculus of different sizes, its length ranging from 0.5 to $1.0 \mu \mathrm{m}$

\section{Clitocybe strigosa Harmaja, n. sp.}

Figs. $1 \mathrm{~b}, 35,81,82,127$.

Pileus 2.5-6.5 cm latus, hygrophanus, non pruinosus, striatus ad marginem, badius, umbilicatus; stipes deorsum incrassatus, basi valde strigosa; lamellae brunneolae-cinereae; odor non farinaceus; sapor mitis; sporae ca. $5.8-8.4 \times 3.4-4.8 \mu \mathrm{m}$, solitarii, basi obtusa vel acuta, typice maxima pars earum obovatae, ceterum praecipue ellipsoideae et lacrymoideae, apiculo crasso, sporarum massa sordide flavida. - Holotypus: Finland, prov. Varsinais-Suomi, rural district of Lohja, Jalassaari, rather young basidiocarps in coniferous woods among Hylocomium splendens 25. VIII. 1965, Harri Toppari (= Harri Harmaja) ( $\mathrm{H}$; isotype in MICH).

Pileus 2.5-6.5 cm broad, hygrophanous, and breadth from 0.3 to $0.9 \mu \mathrm{m}$; spore deposit pure white, or very pale yellow with a greyish tint, its colour unknown in two species. Subcutis always present, distinct as darkest layer of pileus section under microscope; encrusted pigment present on hyphae of epicutis and/or subcutis, or totally lacking on hyphae of pileus; hyphae of pileus trama \pm parallel. From early August to late November. Temperate to oroarctic, mainly in eastern parts of Fennoscandia, lacking in districts with very oceanic climate.

Discussion. C. strigosa has some characters (large size, rather dark lamellae with a violet ultra-violet reaction, large, mostly obovate and lacrymoid, partly acute-based spores with a broad apiculus, a greyishyellowish spore deposit, and perhaps also some ecological and distributional features) which suggest that it might be justifiable to place it in a separate subsection or even section of its own. However, a larger number of species of the subgenus Pseudolyophyllum with mycelial hairs should be thoroughly studied before any decision is made on this point.

There are some obviously undescribed species belonging to the present section, especially in the east of Fennoscandia, but the data on them are so far insufficient, and accordingly they must unfortunately be excluded from the present investigation.

not pruinose, rather weakly translucentstriate at margin (sometimes even up to $3 / 4$ of way towards centre), when moist chestnut

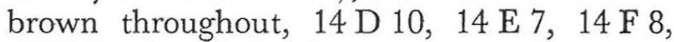
$15 \mathrm{E} \mathrm{7}$, when faded brownish to pale yellowbrown, $9 \mathrm{E} \mathrm{2,} 9 \mathrm{~F} \mathrm{3,} 10 \mathrm{E} 2,11 \mathrm{E} \mathrm{5,} 12 \mathrm{~B} \mathrm{3,}$ $12 \mathrm{C} 3,12 \mathrm{~F} 6$, sometimes slightly darker brown, or greyish, in exsiccates pale yellowbrown to pale brown, $11 \mathrm{D} 6,11 \mathrm{E} 6$, or greyer, $12 \mathrm{~B} 6,12 \mathrm{E} \mathrm{7}$, or darker, $13 \mathrm{C} \mathrm{7}$, in young basidiocarps sometimes very dark brown, 14 B 7, 14 C 7, 14 D 6, even 16 A 12, convex when very young soon becoming umbilicate (very rarely more broadly depressed being \pm bowl-shaped); margin at first slightly incurved becoming straight or remaining bent down, usually extending ca. $0.5 \mathrm{~mm}$ beyond distal ends of lamellae; surface dry, very shining, smooth, in exsiccates with pronounced concentrical wrinkles 
(the distinctly depressed disc usually remaining even).

Stipe 3-11 $\times$ 3-15, concolorous with pileus or slightly paler when moist, in exsiccates slightly darker and greyer, $12 \mathrm{~B} 6$, 13 A 2, 14 B 3, 14 B 5, 14 B 6, 15 C. 9, extreme apex usually strikingly white in both stages because of hyphal coating, \pm distinctly enlarging downwards (very infrequently \pm equal), extreme base usually attenuated, solid at first later becoming hollow, terete or slightly compressed; surface dry, with white fibrillose hyphal coating (especially at apex) which is distinct, especially on faded and dry stipes; at the base some tomentum, often extending rather high on the stipe, in addition always abundant to rather scanty mycelial hairs (most copious in deep moss), these are conspicuous, strigose, slender, being hyaline when moist and usually brownish in exsiccates (true rhizoids lacking, but sometimes rhizoid-like hyaline elements present lowest down).

Lamellae always short decurrent, but angle of attachment variable, $10^{\circ}-60^{\circ}$, when

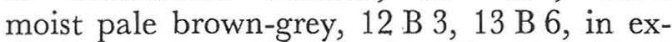
siccates greyer, $13 \mathrm{~A} 3,14 \mathrm{~A} 3,14 \mathrm{~A} \mathrm{4}, 14$ A 5, $15 \mathrm{~A} 7$, in the dried stage very often «hoary" with discharged spores, in 4-5 verticils, 25-35 reach the stipe, being broadest in the middle or on either side of it, $4-6$ $(-8) \mathrm{mm}$, in the middle ca. 3 times broader than overlying context is thick, a few rarely forked, hardly intervenose.

Odour fungoid (in old fruit bodies rarely faintly like that of Cystoderma carcharias). Taste mild, fungoid.

Spores (5.4-) $5.8-8.4(-10.2) \times 3.4-$ $4.8(-5.2) \mu \mathrm{m}$, the great majority single in all preparations, very variable in size and shape, most to below $50 \%$ obtuse-based, most of these usually obovate, the rest (sometimes the majority) elliptical, a few oblong and ovate, the remaining spores (minority to somewhat above $50 \%$ of all spores) acutebased being \pm lacrymoid, contents \pm homogeneous, apiculus ca. 0.8-1.0 $\times 0.7-$ $0.9 \mu \mathrm{m}$; spore deposit abundant, very pale yellow with a greyish tint, roughly between $19 \mathrm{~A} 1$ and $19 \mathrm{~B} 1$.

Anatomy of cortex of pileus. Epicutis 25$30(-80) \mu \mathrm{m}$ thick, hyphae \pm parallel, 2.5 $-7.0 \mu \mathrm{m}$ in diameter, many of them wrinkled, intracellular, membranal, and encrusted pigments present; subcutis distinct as darkest layer of pileus section under microscope, $100-120 \mu \mathrm{m}$ thick, hyphae parallel to slightly interwoven, about as broad as in epicutis but gradually broadening downwards, rich membranal pigment present, sometimes some intercellular crystals, too.

Ecology. Solitary, in groups, rows, or arcs, in both coniferous and deciduous grass-herb to mesic heath forest, often (especially in Picea forests) in shady places in deep moss carpet, e.g. on northern slopes, rarely above forest limit in Dryas octopetala heaths on calcareous ground, in litter of Picea, or Fagus, rarely Pinus, Betula, Tilia, or herbaceous plants, almost always among the moss Hylocomium (sometimes no litter other than decaying bases of that moss was observable). From early August to first half of October (Fig. 5).

Distribution. Temperate to southern boreal, also oroarctic (alpine), mostly in the southeast, lacking in districts with very oceanic climate, up to above 1000 (S. Norway). More or less infrequent. (Fig. 166).

\section{Specimens examined.}

Norway: Buskerud. Hol (1). - Sør-Trøndelag. Oppdal (2). - Nordland. Hamarøy (1).

SWEDEN: Skåne. Allerum (1); Andrarum (1); Baldringe (1); Bara (1); Genarp (1); Svedala (1); Tolånga (3). - Småland. Femsjö (2); Växjö (1). - Öland. Böda (1). - Östergötland. Skedevi (2). - Södermanland. Julita (1). Uppland. Bondkyrka (2); Börje (1); Djurö (3); Läby (1); Ärentuna (1). - Härjedalen. Tännäs (1). - Torne Lappmark. Jukkasjärvi (3).

Fintand: Varsinais-Suomi. Karjalohja (1); Karkkila (1); Lohja mlk. (14); Parainen (3). Uusimaa Espoo (1). - Etelä-Häme. Hattula (1); Lammi (1); Tammela (1).

U.S.S.R.: Leningrad Region. Vyborg (Viipuri mlk.) (1).

Discussion. C. strigosa is very clearly distinguished by the following characters: the umbilicate pileus, which is dark chestnut brown and shining when moist, and conspicuously and regularly concentrically wrinkled in exsiccates, the \pm clavate stipe with copiose strigose mycelial hairs at its base, the abundant yellowish spore deposit with a greyish tint, and the spores, most of which are usually obovate and lacrymoid in varying proportions, many of them resembling those of C.squamulosa. Also, the encrusted pigment on the hyphae of the epicutis may be a constant character of $C$. strigosa. Though striking in appearance, the present species does not seem to have been described earlier. 
There is some genetic variation in the colour of the faded and dry pileus, the pileus shape, and the angle of gill-attachment.

In the light of the present material, $C$. strigosa seems to have two more or less separate distribution areas in Fennoscandia: one alpine (bisentric), on distinctly calcareous ground, the other southeastern, temperate to southern boreal lowland area where the species is less dependent on high concentration of lime in the ground (Fig. 166). It would perhaps have been better to distinguish for C. strigosa a distribution type of its own (see p. 40). Concerning the vascular plants, similar types of distribution (e.g. Hultén 1950: 86, groups $F$ and $G$ ) suggest that the more or less alpine populations of many species have arisen from populations overwintered over the latest glaciation in certain places, on some Norwegian mountains in particular, and that the lowland population only immigrated after the glaciation, especially from the east and southeast. Further studies are needed to prove whether the Fennoscandian area of C. strigosa is really discontinuous, in which case this species would well have overwintered during the Ice Age.

\section{Clitocybe fennica Harmaja, n. sp.}

Figs. 36, 83, 128.

Pileus usque $4 \mathrm{~cm}$ latus, hygrophanus, non pruinosus, striatus, brunneus; basis stipitis strigosa; lamellae pallidae; odor fungoideus; sapor mitis; sporae $5.5-7.0(-8.0) \times 2.8$ -3.3 $\mu \mathrm{m}$, solitarii, basi obtusa, maxima pars earum ovatae. - Holotypus: Finland, prov. Varsinais-Suomi, rural district of Lohja, Virkkala, grass-herb forest in Picea needles 27. X. 1968, Harri Harmaja ( $\mathrm{H}$; isotype in $\mathrm{MICH})$.

Pileus ca. $2.5-4.0 \mathrm{~cm}$ broad, hygrophanous, not pruinose, weakly translucent-striate at margin, even up to $1 / 3$ of way towards centre, when moist chocolate brown with slightly darker disc, colour darker in young than in older basidiocarps, being sepia brown (e.g. 8 A 10), dirty pale brown when faded, dirty brown grey in exsiccates, \pm plane at first soon becoming \pm umbilicate, finally \pm infundibuliform; margin rather thick, some- what incurved; surface slightly viscid, shining, smooth, concentrically wrinkled in exsiccates.

Stipe 3-5 $52-5$, concolorous with pileus or slightly paler in all stages, equal, extreme base almost obtuse, solid at first becoming hollow, terete or slightly compressed in age; surface dry, somewhat shining, glabrous; base with scanty tomentum (especially upper portion) and mycelial hairs, rarely also some inconspicuous thin rhizoids.

Lamellae short decurrent, angle of attachment ca. $30^{\circ}-40^{\circ}$, dirty brownish when moist, very pale brownish in exsiccates (in young fruit bodies almost whitish), distinctly paler than pileus and stipe in all stages, in 4 verticils, 30-50 reach the stipe, being broadest in the middle, $3-4 \mathrm{~mm}$, where they are ca. 3 times broader than overlying context is thick, not forked, some of them weakly anastomosed.

Odour fungoid (in very old basidiocarps sometimes slightly musty).

Taste mild, fungoid.

Spores $5.5-7.0(-8.0) \times 2.8-3.3 \mu \mathrm{m}$, single in preparations, all obtuse-based, almost all ovate, the rest \pm oblong, some spores of each type with a slight asymmetrical median constriction (see p. 23), contents homogeneous to irregularly guttulate, apiculus ca. $0.6-1.0 \times 0.5-0.7 \mu \mathrm{m}$; exact colour of spore deposit unknown.

Anatomy of cortex of pileus. Epicutis almost colourless under microscope, ca. 25$70 \mu \mathrm{m}$ thick, hyphae \pm parallel, $1.5-4.0$ $\mu \mathrm{m}$ in diameter, some of them slightly wrinkled, scanty intracellular and moderately abundant encrusted pigments present; subcutis distinct as darkest layer of pileus section under microscope, ca. 15-30 $\mu \mathrm{m}$ thick, hyphae \pm parallel, 3.0-7.0 $\mu \mathrm{m}$ in diameter, membranal and abundant encrusted pigments present.

Ecology. Solitary or in indistinct arcs in mesic heath forest (MT) and grass-herb forest, in litter of Picea, and mixed litter of Picea and Populus. October (Fig. 5).

Distribution. Hemiboreal and southern boreal, in eastern parts of the area, near sea level. Very rare. (Fig. 167).

Specimens examined.

Finland: Varsinais-Suomi. Lohja mlk. (1, holotype). - Uusimaa. Liljendal (1, church village 12. X. 1967, H. Harmaja). 
Discussion. This rare, obviously eastern species differs from the nearly related $C$. lohjaënsis in having darker colours, less conspicuous mycelial hairs, a more striking colour contrast between the lamellae and the stipe, and larger spores. C. schulmannii has somewhat different colours, a bitter taste, and larger spores of slightly different shape. Also, the spore apiculus in C.fennica is larger than that of the other two species.

\section{Clitocybe schulmannii Harmaja, n. sp.}

Figs. 84, 129.

Clitocybes fennicae similis, sed sapore amaro; sporis majoribus, 6.2-8.0 × 3.0$4.0 \mu \mathrm{m}$, maxima pars earum ellipsoideaeoblongae, ceterum ovatae, apiculo minore. Holotypus: Finland, prov. Uusimaa, town Tammisaari 11. X. 1957, Otto v. Schulmann, s.n. C.fuligineipes $(\mathrm{H}$; isotype in $\mathrm{MICH})$.

Spores $6.2-8.0 \times 3.0-4.0 \mu \mathrm{m}$, the great majority single in preparations, all obtusebased, perhaps most \pm narrowly ellipticoblong, a considerable remainder \pm narrowly ovate, contents homogeneous to indistinctly guttulate, apiculus ca. $0.5-0.7 \times 0.3$ $-0.5 \mu \mathrm{m}$; exact colour of spore deposit unknown.

Anatomy of cortex of pileus. Epicutis ca. 15-25 $\mu \mathrm{m}$ thick, hyphae almost parallel to moderately interwoven, $1.5-3.5 \mu \mathrm{m}$ in diameter, at least intracellular pigment present; subcutis appearing indistinctly as darkest layer of pileus section under microscope, ca. $15-35 \mu \mathrm{m}$ thick, hyphae more or less parallel, 3.0-6.0 $\mu \mathrm{m}$ in diameter, faint intracellular, membranal, and encrusted pigments present.

Ecology. In litter of some deciduous trees. First half of October (Fig. 5).

Distribution. Hemiboreal, in eastern part of the area, near sea level. Very rare. (Fig. 167).

\section{Specimens examined.}

Finland: Uusimaa. Tammisaari (1, holotype).

Discussion. I myself have not collected this species. Judging from the dried specimen, it is clearly distinguished from the nearly related C.fennica and C.lohjaënsis by the slightly darker colours of the stipe and lamellae, its bitter taste, and its larger spores, most of which are elliptic-oblong. The apiculus is rather small.

v. Sahulmann (1961: 14: «C.fuligineipes Métr., E $11.10 .57 \ll)$ thought that his bittertasting specimen represented some form of C.fuligineipes Métr., but I have seen material of that species collected by MÉTrod in France, and it is clearly different from the species found by v. Schulmann (being obviously related to $C$. metachroa and C.amarescens).

\section{Clitocybe lohjaënsis Harmaja, n. sp.}

Figs. 37, 85, 130.

Pileus 1.5- $6 \mathrm{~cm}$ latus, hygrophanus, non pruinosus, striatus, sordide alutaceus vel plus fuscus; stipes basi strigosa; lamellae pallidae; odor leviter farinaceus in fructicationibus juvenilibus, dein fere fungoideus; sapor mitis; sporae 4.2-6.0 $\times 3.0-3.6 \mu \mathrm{m}$, solitarii, basi obtusa, maxima pars earum ovatae, in massa pure albae. - Holotypus: Finland, prov. Varsinais-Suomi, rural district of Lohja, Jalassaari, grass-herb forest in litter of Picea 15. X. 1965, Harri Toppari (= Harri Harmaja) ( $\mathrm{H}$; isotype in MICH).

Pileus 1.5-6 cm broad, hygrophanous, not pruinose, distinctly translucent-striate, even up to $2 / 3$ of way towards centre, colour often varying slightly even within the same fruiting, when moist pale brown, $12 \mathrm{G} 6,12 \mathrm{E} 5,12 \mathrm{~F} \mathrm{7,}$ or slightly darker, $13 \mathrm{E} \mathrm{8,} \mathrm{or} \mathrm{more} \mathrm{greyish-tinted,} 13 \mathrm{H} \mathrm{7}$, $14 \mathrm{Ci}$, when faded usually very pale, brownish, in exsiccates pale brown, $10 \mathrm{~F} 5,11 \mathrm{C} 3$, $11 \mathrm{C} 4,11 \mathrm{D} 4,12 \mathrm{~B} \mathrm{4}, 12 \mathrm{C} 5,12 \mathrm{E} 6$, or yellow-brown, $12 \mathrm{G} \mathrm{8}$, or greyish brown, $13 \mathrm{C} 6$, rarely with olive tinge, $14 \mathrm{~F} 6$, disc usually slightly darker in all stages, convex at first, becoming plane, and finally slightly depressed, rarely umbilicate or bowl-shaped; margin incurved at first usually becoming \pm straight, not pruinose; surface dry but slightly slippery, indistinctly lustrous, smooth, conspicuously concentrically wrinkled in exsiccates.

Stipe $2-9 \times 3-10$, in all stages \pm concolorous with pileus, in exsiccates distinctly darker than lamellae, equal, extreme base often slightly attenuated, solid at first becoming hollow, at first \pm terete usually becoming slightly compressed; surface dry, 
slightly lustrous, with very thin fibrillose hyphal coating (most evident in dried or young fruit bodies, especially at the apex); base with very scanty tomentum (sometimes even lacking?) and abundant to scanty strigose, slender, hyaline (mostly becoming \pm brownish in drying) mycelial hairs, very rarely a few thin inconspicuous rhizoids, too.

Lamellae short decurrent, often with small teeth (very rarely even sinuate), angle of attachment ca. $20^{\circ}-50^{\circ}$, in all stages strikingly pale, brownish or with faint greyish tint (always a paler shade of the pileus colour), when moist shades such as $9 \mathrm{G} 2$, $10 \mathrm{~F} 5$, in 3-4 verticils, 30-40 reach the stipe, being broadest in the middle or proximally, $2-5 \mathrm{~mm}$, in the middle $3-4$ times broader than overlying context is thick, usually not forked, sometimes slightly intervenose, rarely with darker spots in age.

Odour weakly to distinctly farinaceous in newly collected young fruit bodies, in age the mealy smell usually disappears, old basidiocarps having fungoid smell only (when bruised, odour \pm fungoid in all stages).

Taste mild, in young fruit bodies usually weakly farinaceous, in old ones usually fungoid only.

Spores $4.2-6.0 \times 3.0-3.6 \mu \mathrm{m}$, practically all single in all preparations, all obtusebased, most to ca. $50 \%$ ovate (most evident in face view), the rest elliptical to oblong, rarely a few obovate spores present, too, sometimes a few spores of each type with a slight asymmetrical median constriction (see p. 23), contents indistinctly guttulate to homogeneous, apiculus ca. 0.5-0.7 $\times 0.3-$ $0.5 \mu \mathrm{m}$; spore deposit pure white.

Anatomy of cortex of pileus. Epicutis almost colourless under microscope, 40-90 $\mu \mathrm{m}$ thick, hyphae parallel to almost interwoven, 2.0-6.0 $\mu \mathrm{m}$ in diameter, some of them sometimes slightly wrinkled, the outermost very often slightly gelatinized, only scanty intracellular pigment discernible; subcutis distinct as darkest layer of pileus section under microscope, 30-70 $\mu \mathrm{m}$ thick, hyphae \pm parallel, $3.5-8.5 \mu \mathrm{m}$ in diameter, only rich membranal pigment present.

Ecology. Mostly in groups, rarely solitary or in arcs, especially in coniferous or mixed coniferous and deciduous grass-herb forests, sometimes in mesic, rarely even in dry heath forests, usually in litter of Picea, sometimes Larix cf. sibirica, Pinus sylvestris, $P$. contorta, P. strobus, Alnus incana, Betula, Corylus, Populus, Ribes alpinum, Tilia, occasionally in litter of herbaceous plants, or on \pm bare ( \pm calcareous) soil, sometimes among mosses. From latter half of August to late November (Fig. 5).

Distribution. Temperate to southern parts of the northern boreal zone, in eastern parts of the area, up to ca. $250 \mathrm{~m}$ (N. Finland). Uncommon. (Fig. 168).

\section{Specimens examined.}

Sweden: Öland. Gräsgård (1). - Östergötland. Klockrike (1). - Uppland. Bondkyrka (2); Djurö (6); Frösunda (1); Össeby-Garn (1).

Frnland: Varsinais-Suomi. Lohja mlk. (23); Nummi (1). - Uusimaa. Helsinki (4); Kauniainen (1). - Satakunta. Säkylä (1); Tyrvää (2). - Etelä-Häme. Asikkala (1); Kuhmoinen (1); Pertunmaa (1); Somero (1); Tammela (3). Laatokan Karjala. Parikkala (1). - Pohjois-Pohjanmaa. Kiiminki (2). - Kuusamo. Posio (1).

Discussion. The present species is differentiated from the two preceding, nearly related species by the paler colours, the faint farinaceous smell present in young fruit bodies, and the smaller spores, most of which are ovate. The taste is absolutely mild, and the spore apiculus is rather small.

The following characters show a tendency to genetic variation: the size, colour and shape of the pileus, the diameter of the stipe, the mode of gill-attachment, and the breadth of the gills. The pileus colour often varies within the same fruiting, too.

The species seems to be rather common in some eastern parts of Fennoscandia, at least where the soils are calcareous, e.g., in S. W. Finland in the rural district of Lohja ( $\ll$ lohjaënsis«), and the parish of Djurö in E. Sweden. It can also be expected to be common in certain parts of the Leningrad Region and the Karelian A.S.S.R. 


\section{Excluded taxa}

This chapter comprises species, varieties and forms which have been described as new within the genus Clitocybe (or Agaricus subgenus Clitocybe, in one case subgenus Tricholoma) on the basis of Fennoscandian material, and for which a type specimen or type material exists. Species belonging to other genera, and nomina dubia of Clitocybe s. str. are involved. The genus contains so many very similar taxa that little would be gained by discussing all the dozens of epithets of Clitocybe for which no original material is available for checking the microscopic and many similarly neglected macroscopic characters. Among the many taxa which must be considered more or less dubious, in the absence of preserved material, are all the Friesian species (apart from those recognized as valid in the present study), which are accordingly excluded from the following list.

Agaricus (Clitocybe) adsentiens Karsten, Bidrag Känned. Finl. Nat. Folk 25: 53. (Mycol. fennica 3). 1876. - The holotype seems to be specimen no. 26 in the herbarium of P. A. Karsten (H), which was collected in prov. Etelä-Häme, par. Tammela, Mustiala, in a garden, in September 1866. The specimen corresponds well to the original description and belongs to Melanoteuca verrucipes (Fr.) Sing., as do two additional specimens collected in the same year in the same district.

Clitocybe ambigua Karsten, Meddel. Soc. Fauna Flora Fennica 9: 57 (Symb. mycol. fennicam 10). 1882. - The lectotype (selected here) is the sole specimen existing, no. 30 in the herbarium of P. A. KarsteN $(\mathrm{H})$, which was collected in prov. EteläHäme, par. Tammela, Mustiala, Syrjä, on 21. IX. 1882. The macroscopic and microscopic characters correspond well to the original description. Though the colour of the spore deposit is unknown, C. ambigua obviously belongs to the section Roseospora, subsection Epruinatae, but it is difficult to decide whether it is conspecific with $C$. diatreta or represents an independent species. Accordingly, it is so far a nomen dubium.

Agaricus (Tricholoma) interveniens Karsten, Bidrag Känned. Finl. Nat. Folk 25: 365 (Mycol. fennica 3). 1876. Later (Bidrag Känned. Finl. Nat. Folk 32: 63. 1879.) KARSTEN transferred this species to the genus
Clitocybe. - There is only one specimen of Karsten (H) which was collected before 1876, viz. on 17. IX. 1865, and it is labelled by him as «Lepista interveniens Karst. Clitocybe gigantea?«. This specimen represents C. harperi Murr. It cannot, however, be selected as the lectotype of $A$.interveniens, because there is some discrepancy between the original description and the characters of the specimen, and thus Murrill's name can be retained. Karsten describes the spores as tapering towards both ends, and 6-7 $\times$ $2-2.5 \mu \mathrm{m}$ in size. In some later papers he gives spore characters which are more typical of $C$. inornata. Three specimens with the epithet interveniens, collected after 1876, do indeed represent $C$. inornata (in addition, two later specimens represent C. alexandri, one C.harperi, one C.phyllophila v.phyllophila, and one Lepista cf. caespitosa). The fruit bodies on which the original description of A.interveniens was based, seem to have got lost, and it is probable that they represented $C$. inornata. The present name is best regarded as a nomen dubium.

Clitocybe inversa f. pallidispora O. v. Schulmann, Karstenia 3: 63. 1955. - The specimen in question $(\mathrm{H})$ is probably Rhodocybe caelata. The name is a nomen invalidum, because a Latin diagnosis is lacking.

Clitocybe lauta Karsten, Rev. Mycol. 33: 9. 1887. - The lectotype (selected here) is specimen no. 151 in the herbarium of P.A. Karsten (H), which was collected in prov. Etelä-Häme, par. Tammela, Saloinen, in early August 1886. The specimen corresponds well to the original description and represents Melanoleuca verrucipes (Fr.) Sing., as does the other specimen of KarSTEN, who later considered C. lauta a synonym of C. puellula.

Clitocybe macrophylla Karsten, Hedwigia 20: 177. 1881; Acta Soc. Fauna Flora Fennica 2: 7. 1881. - The only existing specimen seems to be the holotype. It is no. 124 in the herbarium of P. A. Karsten $(\mathrm{H})$, and was collected in prov. Etelä-Häme, par. Tammela, Mustiala, in ox dung, on 10. VIII. 1881. The basidia are large, as was stated in the original description, and no spores were clearly discernible. The specimen surely represents a dark-spored agaric, possibly Stropharia semiglobata, the fruit 
body of which is sterile for some reason. The substrate (dung) is also foreign to a Clitocybe, but appropriate to the Stropharia species.

Clitocybe nauseosodulcis Karsten, Hedwigia 22: 177. 1883; Icones selectae Hymenomycetum Fenniae nondum delineatorum 1: 11, Fig. 23. 1883. - The holotype seems to be specimen no. 123 in the herbarium of P. A. Karsten $(\mathrm{H})$, which was collected in prov. Etelä-Häme, par Tammela, Saloinen, on an ant-hill, in September 1883. The microscopic characters of this and the other specimen in $\mathrm{H}$ are clearly characteristic of the genus Leucopaxillus. Singer \& SMith (1943: 115) studied a specimen of C. nauseosodulcis, collected by Karsten and deposited in NY, and, treating the species as valid, transferred it to Leucopaxillus. They did not, however, discuss the typification.

Clitocybe nybergii O. v. Schulmann, Seltene Pilze, 6. 1950. - I have seen one specimen of the material listed in the protologue, and it is C.pruinosa. v. SchulmanN himself later (1955: 25) admitted that C. nybergii is a synonym of C.rhizophora (with which name he means C.pruinosa). The present name is, however, a nomen invalidum, because there is no Latin diagnosis.

Clitocybe pallens Karsten, Hedwigia 29: 176 (Fragm. mycol. 30). 1890. - The lectotype (selected here) is the sole specimen existing, no. 134 in the herbarium of P. A. Karsten $(\mathrm{H})$, which was collected in prov. Etelä-Häme, par. Tammela, Mustiala, in a garden, on 5. IX. 1890. It is probably a Clitocybe from the section Roseospora, subsection Epruinatae. It is (so far, at least) impossible to tell whether C.pallens is an independent species or conspecific with some recognized species. It remains accordingly a nomen dubium.

Clitocybe pantoleucoides Karsten, Meddel. Soc. Fauna Flora Fennica 16: 14 (Symb. mycol. fennicam 24). 1888. - The lectotype (selected here) is the sole specimen existing, no. 135 in the herbarium of P. A. Karsten $(\mathrm{H})$, which was collected in prov. EteläHäme, par. Tammela, Mustiala, on wood of Alnus incana, in October 1887. It represents a species of the genus Pleurotus (P. dryinus?).

Clitocybe pometi v. ( $\beta$ ) saliceti Karsten, Meddel. Soc. Fauna Flora Fennica 5: 18
(Symb. mycol. fennicam 6). 1879; Bidrag Känned. Finl. Nat. Folk 32: 85 (Rysslands, Finlands och den skandinaviska halföns hattsvampar. I.). 1879. - The holotype is specimen no. 144 in the herbarium of P. A. Karsten (H) : «Ag. (Pleur.) Pom. Fr. var. Saliceti Karst. Must. in trunco Salic. pent. Aug. 1878«, which was collected in prov. Etelä-Häme, par. Tammela, Mustiala, in August 1878. It is very probably a Pleurotus species, the wood substrate also being foreign to Clitocybe. Two additional specimens collected by W. NyLANDER from Helsinki, which were determined by KARSTEN as «Clitocybe saliceti«, clearly belong to Pleurotus.

Agaricus (Clitocybe) puellula Karsten, Bidrag Känned. Finl. Nat. Folk 25: 52 (Mycol. fennica 3). 1876. - The lectotype (selected here) is specimen no. 176 in the herbarium of P. A. Karsten $(\mathrm{H})$, which was collected in prov. Etelä-Häme, par Tammela, Sipilä, in a paludified place, on 2. IX. 1865. This specimen is Melanoleuca verrucipes (Fr.) Sing., as are five additional specimens of the type material. BRESADOLA (1892: 5-6) thought similarly that KARSTEN's species is Melanoleuca [«Tricholoma《] verrucipes.

Clitocybe rigidata Karsten, Hedwigia 22: 177 (Fragm. mycol. 4). 1883; Icones selectae Hymenomycetum Fenniae nondum delineatorum 1: 11, Fig. 23. 1883. - The holotype is the sole specimen existing, no. 202 in the herbarium of P. A. Karsten $(H)$, which was collected in prov. Varsinais-Suomi, town of Turku (Åbo), on 2. IX. 1883. The spores are severely deformed, perhaps by some parasite, and the only conclusion that can be drawn from the specimen is that it perhaps belongs to the section Roseospora, subsection Epruinatae. C. rigidata is accordingly a nomen dubium.

Agaricus (Clitocybe) subviscifer Karsten, Meddel. Soc. Fauna Flora Fennica 2: 171 (Symb. mycol. fennicam 4). 1878. - The type material consists of at least four conspecific specimens, collected on the same day (25. IX. 1877) and evidently from the same site in Mustiala (prov. Etelä-Häme, par. Tammela). Of them, specimen no. 225 in the herbarium of P. A. KARsten $(H)$ is the lectotype (selected here), while the other specimens ( 2 in $\mathrm{H}$, one in UPS), also examined by the present author, are isolecto- 
types. The specimens correspond well to the original description and represent some species of Hygrophorus s. str. I am not sure about the species, but Singer (1943: 47) states that KARsTEN's species is a synonym of Hygrophorus eburneus (it is not known whether he has seen the type material).

\section{Summary}

1. The present study is a taxonomic revision of the Fennoscandian taxa of the agaric genus Clitocybe (Fr.) Staude. Every specimen of the Fennoscandian material of Clitocybe was examined under the microscope. Of that material 3220 specimens could be included (the rest were either in too poor condition to be determined, or represented unknown taxa), ca. 500 of which were collected by the present author.

2. The history of the epithet Clitocybe is discussed, and the most important studies on the genus, from the taxonomical or nomenclatural viewpoint, are briefly reviewed. The delimitation of the genus mainly follows the concepts of modern authors (e.g., Singer 1962), but species with uneven spores are excluded, i.e., the «section « Eulepistae (Konr. \& Maubl.). The distinctions between Clitocybe and the related genera are discussed, and some new ideas on intergeneric differences, e.g. ecological ones, are proposed for further studies. The type species problem is briefly discussed, and Agaricus nebularis [Batsch] Fries is acknowledged as the lectotype of Agaricus tribus Clitocybe Fries, the basionym of the generic name.

3. The infrageneric diagnostic characters of Clitocybe are treated fairly comprehensively. Many characters which have often been ignored or undervalued previously were found to show genetic variation, and have considerable diagnostic importance in the infrageneric taxonomy down to the specific level. Such characters are especially the following: certain features of the pileus surface (especially the presence contra absence of a «pruina «), the organization of the basal mycelium of the stipe (tomentum; mycelial hairs; rhizoids), the colour of the lamellae, the water-absorbing capacity of different parts of the fruit body (nonhygrophany contra hygrophany), the odour (especially fragrant, or farinaceous contra fungoid), the responses of the dried lamellae and the basal mycelium of the stipe under ultra-violet light, the exact colour of the spore deposit (especially pinkish buff, or \pm yellow contra pure white), the occurrence of spores in preparations (single contra in tetrads), some other spore features, on the basis of some of which a new system for spore shape classification is presented (founded on the distinction of three kinds of spore base: the obtuse, the acute, and the confluent base), the pigmentation of the hyphae of the pileus (especially the presence contra absence of membranal pigment, and some features of encrusted pigments). Some characters are supposed to be original, and others derived. Of the macrochemical reagents tested, $\mathrm{KOH}$ proved to be of some use. Information on the cytology (e.g. the chromosome number) of C.phyllophila $\mathrm{v}$. phyllophila is given.

4. The following characters were found to be more or less uniform throughout the genus, and they (or at least some of them) may thus be diagnostic of the genus: the development of the fruit bodies (i.e., the absence of a veil), the gill-attachment (lamellae \pm decurrent, only occasionally somewhat sinuate), many features of the context, the response of the dried pileus and context under ultraviolet light ( \pm violet $)$, the spore wall (very thin, completely smooth, neither amyloid nor dextrinoid), the size and shape of the basidia (rather small, \pm clavate), the constituents of the hymenium (cystidia and pseudocystidia lacking), the construction of the cortex of the pileus (always composed of filamentous hyphae thinner than those of the pileus trama), the construction of the pileus trama in many respects, some features of the pigmentation of the hyphae (fine encrusted pigment only rarely present), the anatomy of all the mycelial elements of the stipe base, the anatomy of the gill trama to a high degree (e.g. usually regular), and the clamping (clamp connections evidently almost always present at each septum). 
5. The ecology of the species of Clitocybe is paid more attention than by previous authors. The species occur in mesic or dry habitats, but never in wet plant communities (swamps, bogs, wet meadows, etc.; only a very few species are occasionally found in moist places). The great majority grow more or less exclusively in forests in needle and leaf litter, being obviously effective decomposers of this kind of plant remains. Particularly the species of the subgenus Pseudolyophyllum prefer the litter of conifers (needles) and thus occur mostly in coniferous woods. Different species often have different requirements as to the degree of productivity (site type) of the forest. A few species occur outside forest, more or less exclusively on different kinds of bare, or fairly bare, soil (though never on peat), others are found above the forest limit (especially in alpine Dryas heaths); none grow on decaying wood, nor do any appear to have an obligate association with a living green plant. The relation between the occurrences of the species and the lime content of the ground varies widely within the genus, the strongly calciphilous species being the fewest. The relation to human influence varies greatly with the species, the euhemerobic species (those occurring in man-made habitats only) being the fewest. More or less distinct differences exist between the different taxa in respect of the time of fruiting (the production of fruit bodies). On the whole the fruiting of the genus extends throughout the year, culminating in September and October with 33 and 37 species and varieties, respectively. On the average, the subgenus Clitocybe is the earliest, and Pseudolyophyllum the latest one. There are also some specific differences in the extent of the fruiting time, and the age of single basidiocarps.

6. The relatively large material has made it possible to devote a considerable amount of attention to phytogeographical questions. The genus is present in all the vegetation zones of Fennoscandia, from the temperate to the oroarctic (alpine) zone. The distribution areas of many species coincide well with the limits of the Fennoscandian vegetation zones and/or their oceanity sections, which seems to indicate that the distributions of these (= most?) species are primarily determined by the regional (macro-) climatic factors. The hemiboreal and southern boreal zones are richest in species, their number decreasing both towards the south and the north. Some alpine and subalpine species exist, but extremely southern or southwestern ones are so far unknown. Many species avoid a very oceanic climate. Many species, especially in the subgenus Pseudolyophyllum, have a pronouncedly eastern distribution, a large number of them occurring in Finland only. The last-named type of distribution, in particular, suggests that geohistorical factors, especially those associated with the latest glaciation, have greatly affected the distribution of species of Clitocybe (and surely of the other larger fungi, too), as is the case with very many vascular plants, mosses, and lichens. Only extremely rarely (e.g. perhaps in C.geotropa) the distribution may be determined primarily by edaphic factors. The microclimatic factors likewise seem to have only slight, if any, influence on the distributions. These facts explain why Finland has a larger number of Clitocybe species than the other Fennoscandian countries, having 41 species and varieties, while Sweden has 37, and Norway 26. Three species are recorded for the first time outside N. America, and two outside Asia.

7. The evaluation of the information obtained from the present material resulted in the recognition of 3 subgenera, 16 sections, 2 subsections, 43 species, and 2 varieties. The following are described as new: the subgenus Roseospora Harmaja; the sections Alexandriformes Harmaja, Clavipedes Harmaja, Sinopicae Harmaja, Gilvaoideae Harmaja, (Odorae Harmaja, ad interim), (Fragrantes Harmaja, ad interim), Latisporae Harmaja, and Strigipedes Harmaja; the subsections Pruinatae Harmaja, and Epruinatae Harmaja; the species C.lapponica Harmaja, C. ruderatis Harmaja, C. agrestis Harmaja, C. marginella Harmaja, C. amarescens Harmaja, C.metachroides Harmaja, C.subcordispora Harmaja, C. globispora Harmaja, C. orientalis Harmaja, C. menthiodora Harmaja, C. strigosa Harmaja, C. fennica Harmaja, C. schulmannii Harmaja, and C. lohjaënsis Harmaja; the variety C. phyllophila v. tenuis Harmaja. In addition, there are several species, most of which are evidently undescribed, belonging especially to the sections Infundibuliformes, Candicantes, Roseospora, Ditopae, and Strigipedes, but so 
far their material is so defective in one way or another that they have had to be excluded from the present study. The following new combinations are introduced: section Vernae (Sing.) Harmaja, section Bulluliferae (Sing.) Harmaja, C. gracilis (Big. \&
Smith) Harmaja, and C. ditopa v. odorula (Karst.) Harmaja. Lectotypes or neotypes are proposed for several species. The author citations of some sectional and specific names are corrected.

\section{References}

Aaltonen, V. T. 1950: Die Blattanalyse als Bonitierungsgrundlage des Waldbodens. Commun. Inst. Forestaliae Fennici 37 (8): $1-41$.

Ahti, T., Ḧ̈мет-Ahti, L. \& Jalas, J. 1968: Vegetation zones and their sections in northwestern Europe. - Ann. Bot. Fennici 5: $169-211$.

Bigelow, H. E. 1962: The genus Clitocybe (Fries) Kummer in Michigan. - 286 pp. Unpublished $\mathrm{Ph}$. D. Thesis, Univ. of Michigan, Ann Arbor.

- 1965: The genus Clitocybe in North America: Section Clitocybe. - Lloydia 28: $139-180$.

- 1968: The genus Clitocybe in North America. II. Section Infundibuliformes. Lloydia 31: 43-62.

- and Rowley, J. R. 1968: Surface replicas of the spores of fleshy fungi. - Mycologia 60: 869-887.

- and Sмrith, A. H. 1962: Clitocybe species from the western United States. - Mycologia 54: 498-515.

- 1969: The status of Lepista - a new section of Clitocybe. - Brittonia 21: 144177.

Bresadola, J. 1892: Fungi tridentini novi, vel nondum delineati, descripti, et iconibus illustrati, 2: fasc. 8-10. - 46 pp., pls. 106-150. Tridenti.

- 1928: Iconographia mycologica. Vol. 4. pls. 151-200. Mediolani.

Dennis, R. W. G., Orton, P. D. and Hora, F. B. 1960: New check list of British agarics and boleti. - $225 \mathrm{pp}$. London. (supplement to Transactions of the British Mycological Society).

Donk, M. A. 1949: Nomenclatural notes on generic names of agarics (Fungi: Agaricales). - Bull. bot. Gdns. Buitenzorg III 18: $271-402$.

- 1962: The generic names proposed for Agaricaceae. - Beih. Nova Hedwigia 5: $1-320$

Douwes. G. A. C. und von Arx, J. A. 1965: Das hymenophorale Trama bei den Agaricales. - Acta Bot. Neerl. 14: 197-217.

EkLund, O. 1943: Zur Pilzflora des Schärenarchipels SW-Finnlands. - Memoranda Soc. Fauna Flora Fennica 18: 2-21.

Eriksson, J. and Strid, A. 1969: Studies in the Aphyllophorales (Basidiomycetes) of northern Finland. - Ann. Univ. Turku. (A II) 40 (Rep. Kevo subarctic res. stat. 4): 112 -158 .
FAVre, J. 1948: Les associations fongiques des hauts-marais jurassiens et de quelques régions voisines. - Matériaux pour la Flore Cryptogamique Suisse 10 (3): $1-228$.

- 1960: Catalogue descriptif des champignons superieurs de la zone subalpine du Parc National Suisse. - Ergebn. wiss. Unters. schweiz. Nationalparks, N. F. 6: 1-610.

FrIES, E. 1821: Systema mycologicum, sistens fungorum ordines, genera et species, huc usque cognitas, quas ad normam methodi naturalis determinavit, disposuit atque. Vol. 1. - 520 pp. Lundae.

- 1836-1838: Epicrisis systematis mycologici, seu synopsis hymenomycetum. - 610 pp. Upsaliae.

Gillet, C. C. 1874: Les hyménomycètes ou description de tous les champignons qui croissent en France. - 828 pp. Alençon.

Harmaja, H. 1969a: A neglected species, Gyromitra ambigua (Karst.) Harmaja, n. comb., and G. infula s. str. in Fennoscandia. Karstenia 9: 13-19.

- 1969b: On hygrophany of basidiocarp in the genus Clitocybe Kummer. - Karstenia 9: $51-53$.

- 1970: Notes on Fennoscandian fungi. 1. Karstenia 11 (under preparation).

Herkrilë, H. and Kallio, P. 1967: On the problem of subarctic basidiolichens I. - Ann. Univ. Turku. (A II) 36 (Rep. Kevo subarctic res. stat. 3 ): $48-74$.

Herm, P. 1954: Observations sur le noyau des basidiomycètes. - Rev. Mycol. 19: 201249, pls. II-IV.

Hora, F. B. 1960: New check list of British agarics and boleti. IV. - Trans. Brit. Mycol. Soc. 43: 440-459.

Horak, E. 1968: Synopsis generum Agaricalium (Die Gattungstypen der Agaricales). Beitr. Kryptogamenflora Schweiz 13: 1741.

Hultén, E. 1950: Atlas över växternas utbredning i Norden. Fanerogamer och ormbunksväxter. (Atlas of the distribution of vascular plants in N. W. Europe). - 512 pp. Stockholm.

Ingold, C. T. 1969: The ballistospore. - Friesia 9: $66-76$.

JaLAS, J. 1955: Hemerobe und hemerochore Pflanzenarten. Ein terminologischer Reformversuch. - Acta Soc. Fauna Flora Fennica 72 (11): $1-15$.

Kallio. P. and Kankainen. E. 1964: Notes on the macromycetes of Finnish Lapland and adjacent Finnmark. - Ann. Univ. Turku. 
(A II) 32 (Rep. Kevo subarctic res. stat. 1) : $178-235$.

Kankainen, E. 1969: On the structure, ecology and distribution of the species of Mitrula s.lat. (Ascomycetes, Geoglossaceae). Karstenia 9: 23-34.

Kits van Waveren, E. 1968: The 'stercorarius group' of the genus Coprinus. - Persoonia $5(2): 131-176$

Konrad, P. et Maublanc, A. 1924-1937: Icones selectae fungorum. Vol. 1-6. - Paris.

Kummer, P. 1871: Der Führer in die Pilzkunde. - 146 pp., 4 pls. Zerbst.

Kühner, R. 1934: Clitocybe gallinacea (Scop.) Fr. - Bull. Soc. Mycol. France 50: Atlas, pl. 64 .

- 1945a: Nouvelles recherches sur les divir sions nucléaires dans la baside et les spores des Agaricales. - C. R. Acad. Sci. 220: $618-620$.

- 1945b: Le problème de la filiation des Agaricales à la lumière de nouvelles observations d'ordre cytologique sur les Agaricales leucosporées. - Bull. Soc. Linn. Lyon 14: $160-169$.

LANGE, J. E. 1935-1940: Flora agaricina danica. Vol. 1-5. - Copenhagen.

LANGE, M. 1948: The agarics of Maglemose. Dansk Bot. Arkiv 13: 1-141.

Lanjouw, J. and Stafleu, F. A. 1964: Index herbariorum. I. The herbaria of the world. 5 th ed. - $251 \mathrm{pp}$. Utrecht.

Le Gal, M. 1944: Trois espèces du genre Clitocybe. - Rev. Mycol. 9 (suppl.) : 32-35.

Lundell, S. 1937: Three undescribed vernal agarics, Mycena vernalis H. v. Post in sched., Clitocybe verna Egeland in sched., and Entoloma vernum. - Svensk Bot. Tidsskr. 31: 186-195.

Maerz, A. and Paul, M. R. 1950: A dictionary of color. - 208 pp., 50 pls. New York.

Malmström, N. 1933: Senhöstens hattsvampar i frost och blida. - Memoranda Soc. Fauna Flora Fennica 9: 69-91.

- 1938: Beobachtungen über die Grosspilze des Hochwassergebietes von Tvärminneträsk und Sandträsk. - Memoranda Soc. Fauna Flora Fennica 13: 103-109.

Métrod, G. 1949: Les Clitocybes. - Rev. Mycol. 14 (suppl.) : 4-37.

Moser, M. 1960: Die Gattung Phlegmacium. Die Pilze Mitteleuropas 4: 1-440.

NAnNFeldt, J. A. 1966: On Otidea caligata, $O$. indivisa and $O$. platyspora (Discomycetes Operculatae). - Ann. Bot. Fennici 3: $309-318$

Nǘsch, E. 1926: Die Trichterlinge. Mono- graphie der Agariceen-Gattung Clitocybe mit Bestimmungsschlüssel. - 279 pp. St. Gallen.

Pinto-Lopes, J. 1948: Contribution to the study of the nuclear structure in fungi. 1. Portugaliae Acta Biol. (sér. A) 2: 191210.

QuéLET, L. 1872: Les champignons du Jura et des Vosges. - pp. 43-332, 24 pls. Montbéliard.

- 1886: Enchiridion fungorum in Europa media et praesertim in Gallia vigentium. - 352 pp. Lutetiae.

- 1888: Flore mycologique de la France et des pays limitrophes. - 492 pp. Paris.

Rarthelhuber, J. 1969: Über die Variationsbreite von Clitocybe hydrogramma. - Zeitschr. Pilzk. 34 (3/4): 175-181.

von Schulmann, O. 1955: Pilzstudien in Finnland. - Karstenia 3: 17-68.

- 1961: Zur Kenntnis der Basidiomyceten Finnlands. - Karstenia 5: 5-99.

Singer, R. 1937: Notes sur quelques Basidiomycètes. 3. - Rev. Mycol. (N. S.) 2: $226-242$.

- 1943: Das System der Agaricales. III. Ann. Mycol. 41: 1-189.

- 1948: Diagnoses fungorum novorum Agaricalium. - Sydowia Ann. Mycol. 2: 26 $-42$.

- 1951: The «Agaricales« (mushrooms) in modern taxonomy. - Lilloa 22: 1-832.

- 1961: Type studies on Basidiomycetes. X. - Persoonia 2 (1): 1-62.

- 1962: The Agaricales in modern taxonomy. 2nd ed. - 915 pp., 73 pls. Weinheim.

- and Morello, J. H. 1960: Ectotrophic forest tree mycorrhizae and forest communities. - Ecology 41: 549-551.

- and Sмith, A. H. 1943: A monograph on the genus Leucopaxillus Boursier. - Pap. Mich. Acad. Sci. Arts Lett. 28: 85-132, 8 pls.

Smith, A.H. and Singer, R. 1964: A monograph on the genus Galerina Earle. 384 pp. New York and London.

Staude, F. 1857: Die Schwämme Mitteldeutschlands, insbesondere des Herzogthums Coburg. - 150 pp., 10 pls. Coburg.

Tuomrkoski, R. 1959: Sienet värikuvina. - 245 pp., 343 pls. Porvoo-Helsinki.

Velenovský, J. 1920: Česke houby. 2. - pp. 201 -424. Praha.

Weinmann, C. A. 1836: Hymeno- et GasteroMycetes hucusque in imperio Rossico observatos. - 676 pp. Petropoli. 


\section{Index to the taxa}

page

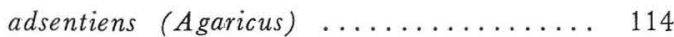

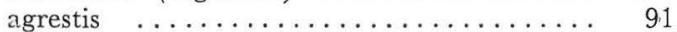

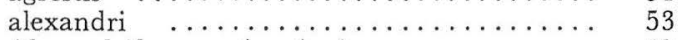

Alexandriformes (section) .......... 52

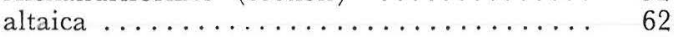

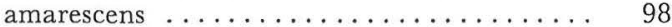

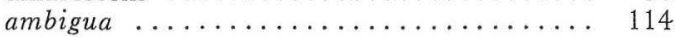

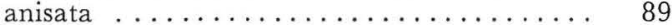

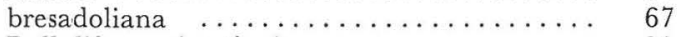

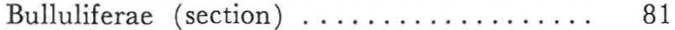

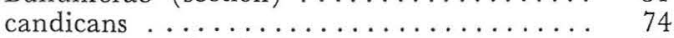

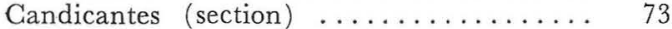

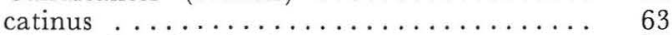

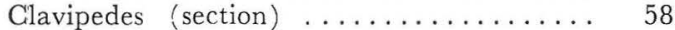

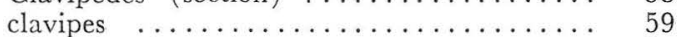

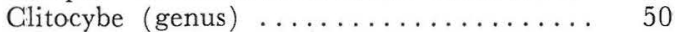

Clitocybe (subgenus) ............. 52

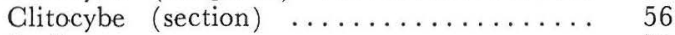

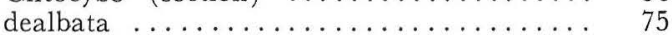

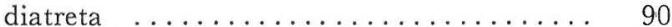

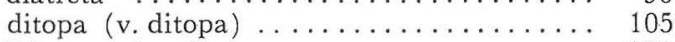

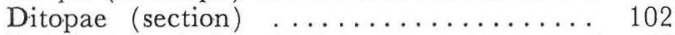

Epruinatae (subsection) ............ 90

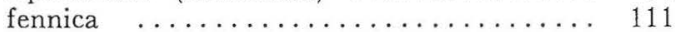

fragrans .................... 93

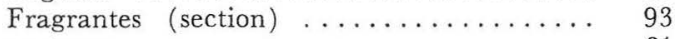

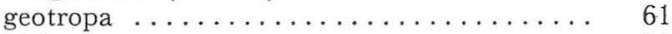

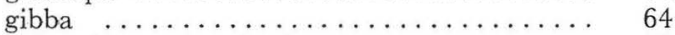

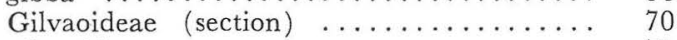

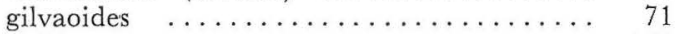

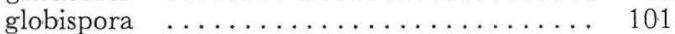

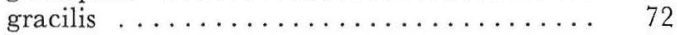

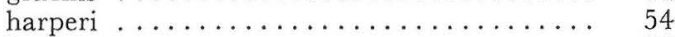

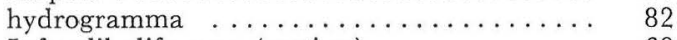

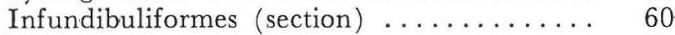

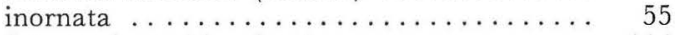

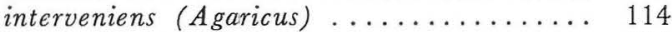

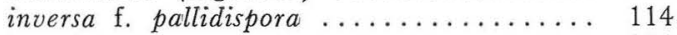

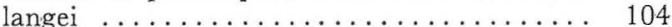

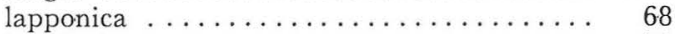

laricicola ................. 76

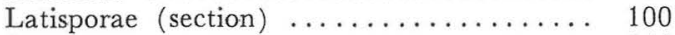

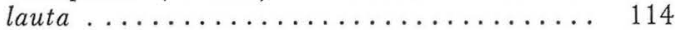

page

lohjaënsis . . . . . . . . . . . . . . . . . . 112

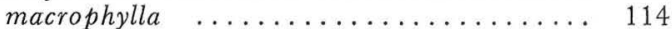

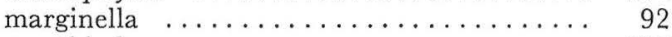

menthiodora .................. 107

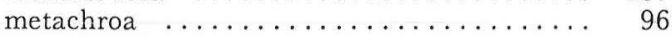

metachroides ................... 99

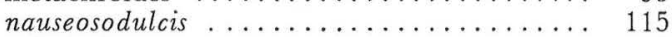

nebularis ..................... 57

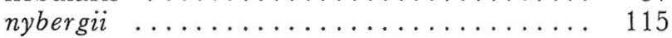

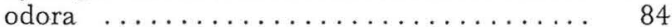

Odorae (section) $\ldots \ldots \ldots \ldots \ldots \ldots . \ldots \ldots$

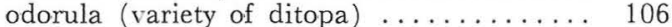

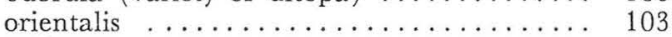

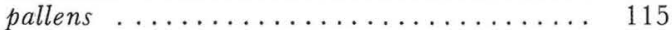

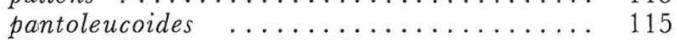

phyllophila (v. phyllophila) ......... 86

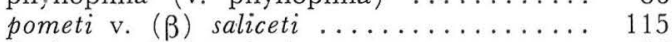

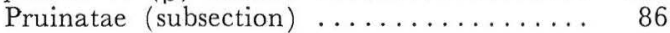

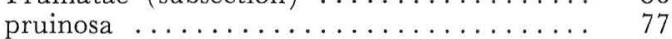

Pseudolyophyllum (subgenus) .......... 95

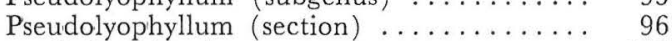

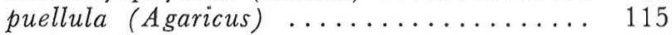

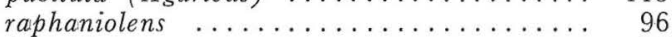

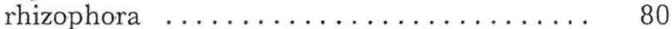

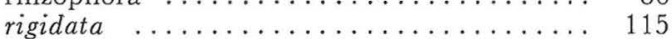

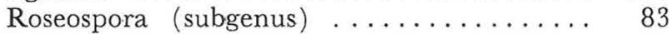

Roseospora (section) .............. 86

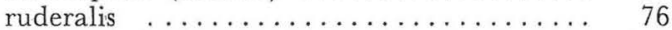

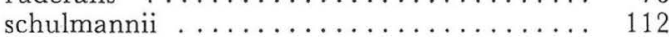

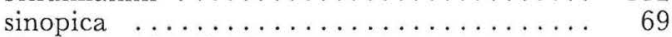

Sinopicae (section) .............. 69

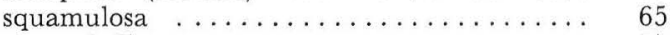

stenophylla .................. 57

stenophylla (* $[=$ subspecies $]$ of nebularis) 57

stenophylla (variety of nebularis) ...... 57

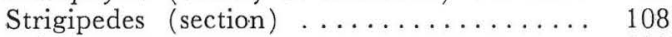

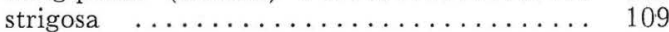

subcordispora $\ldots \ldots \ldots \ldots \ldots \ldots \ldots \ldots$

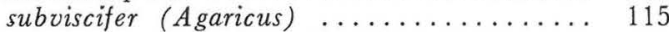

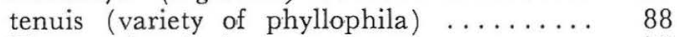

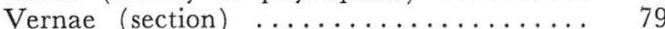

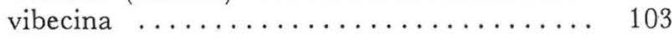




\section{Figures}

The drawings of the fruit bodies are in the natural sizes. All of them were drawn from fruit bodies collected by the present author, and the specimens are accordingly deposited in $\mathrm{H}$. These were collected in the rural district of Lohja in Finland, prov. VarsinaisSuomi, unless otherwise stated. The photographs show dried fruit bodies except for nos. 60 and 82. All of them were taken by Mr.
Mauri Korhonen except for no. 82 which was taken by Mr. Pertti Uotila, Ph. Cand. The spores were drawn in Melzer's reagent and are magnified 2000 times. The spores of each species and variety were always obtained from the same dried specimens that were photographed. The spores on the left are depicted in the face view, and those on the right in the side view. 


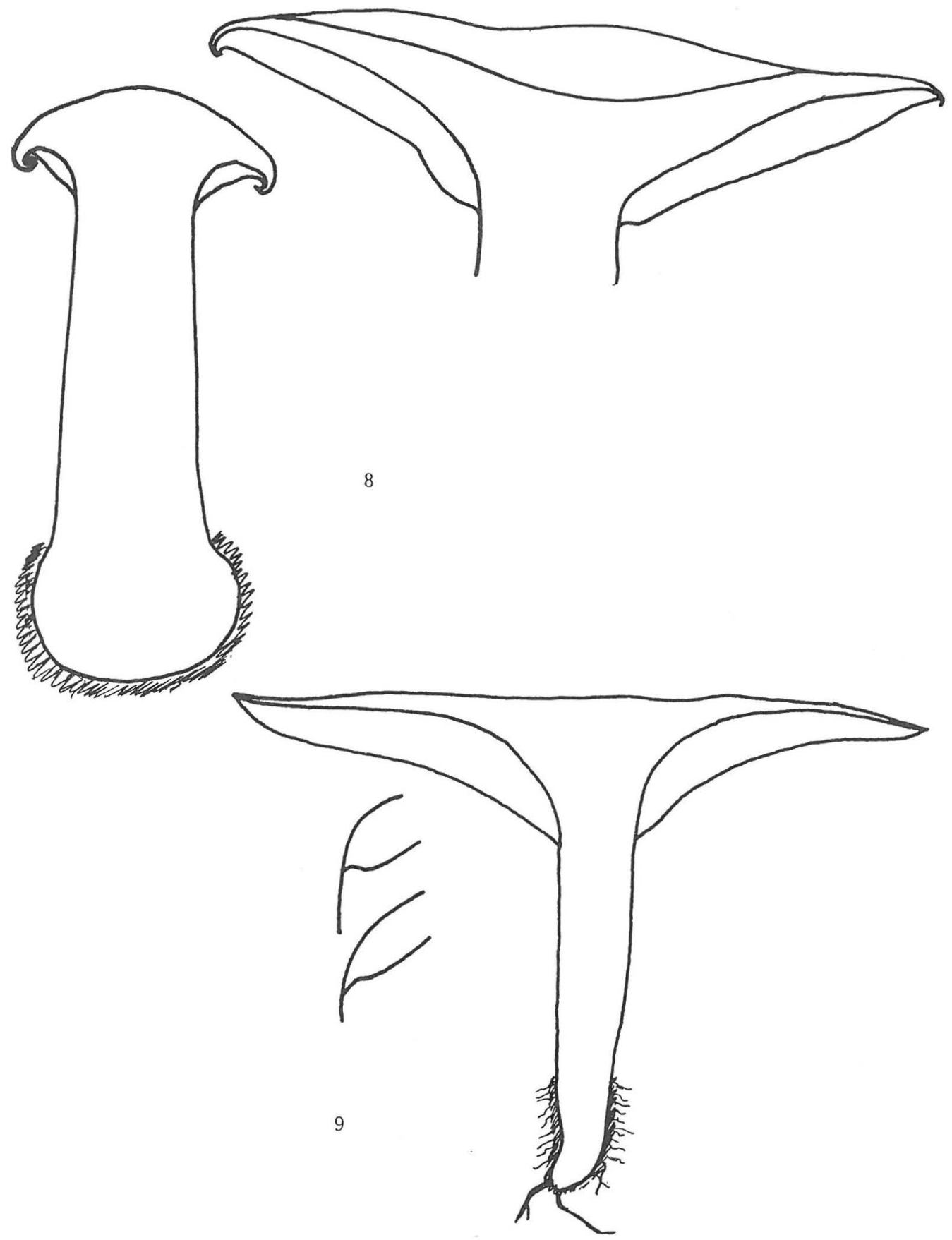

Fig. 8. C.alexandri (left 24. IX. 1966; right 15. X. 1965). - Fig. 9. C. inornata (left 2. X. 1965, details of gill-attachment; right 21. X. 1967). 


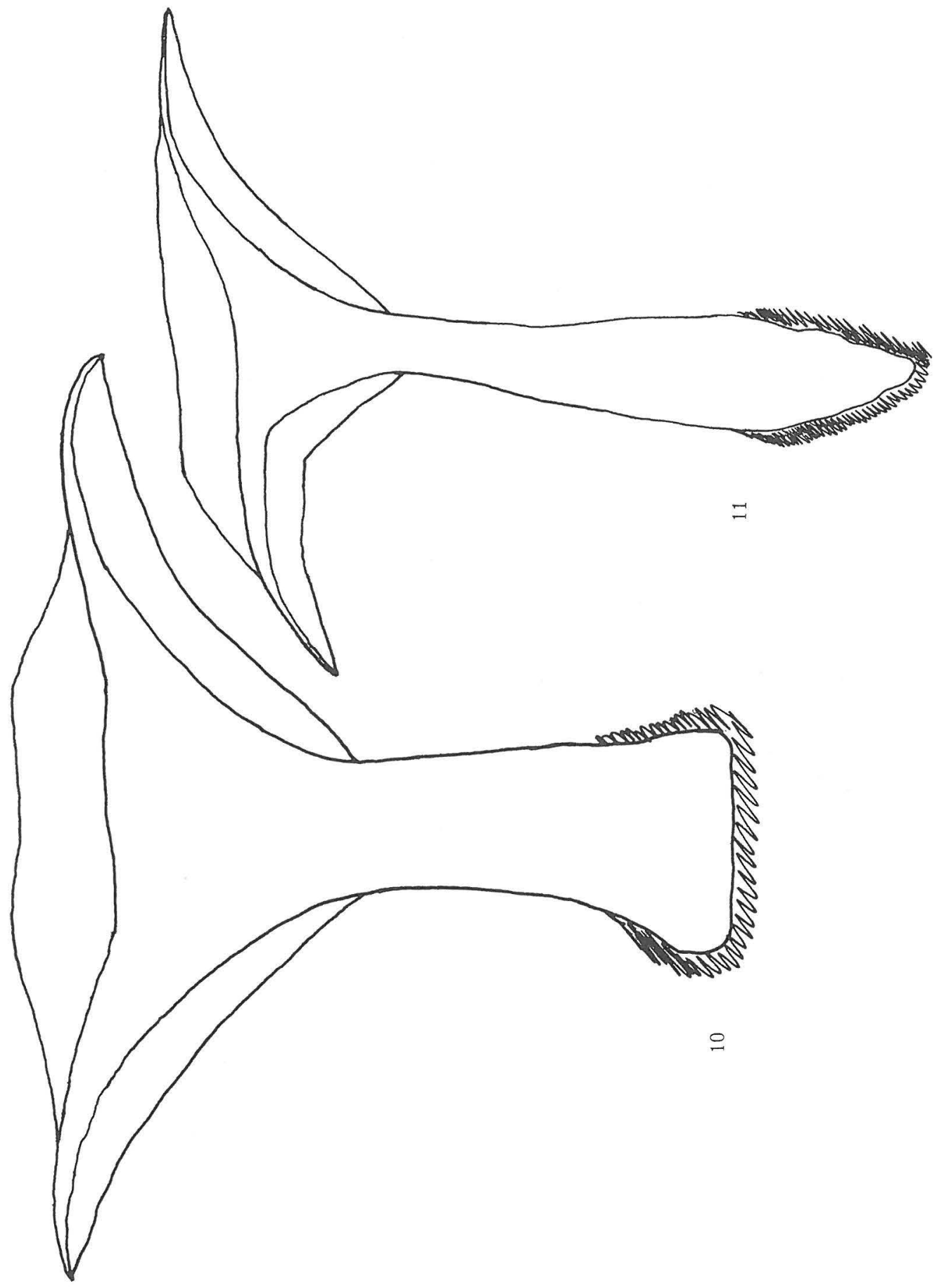

Fig. 10. C. nebularis (8. X. 1965). -- Fig. 11. C.clavipes (Sweden, prov. Småland, par. Kärda 2.X. 1968). 


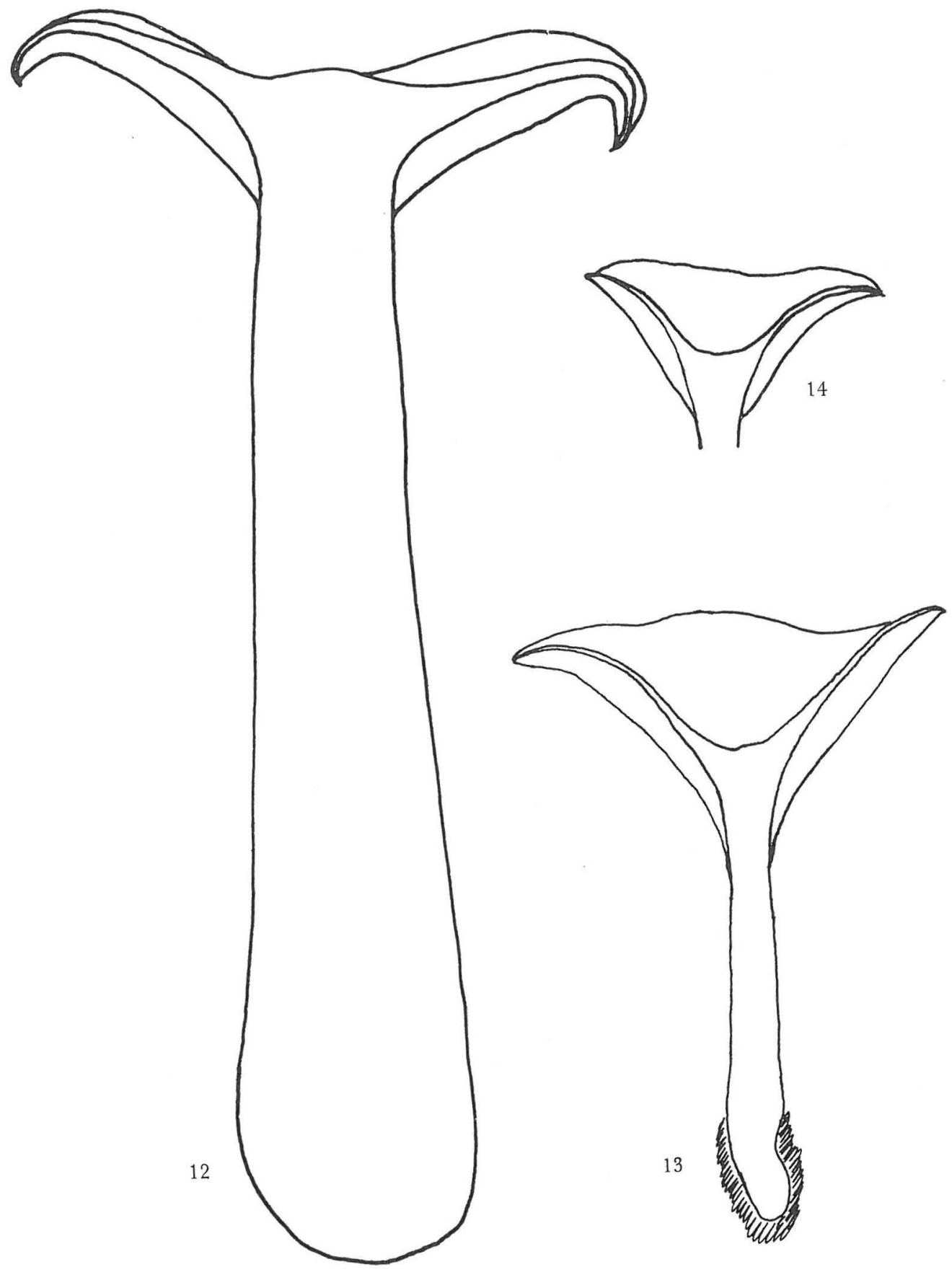

Fig. 12. C. gectropa (17.X. 1967). - Fig. 13. C. gibba (Finland, prov. Varsina
19.X. 1968). - Fig. 14. C. squamulosa (10. IX. 1965). 

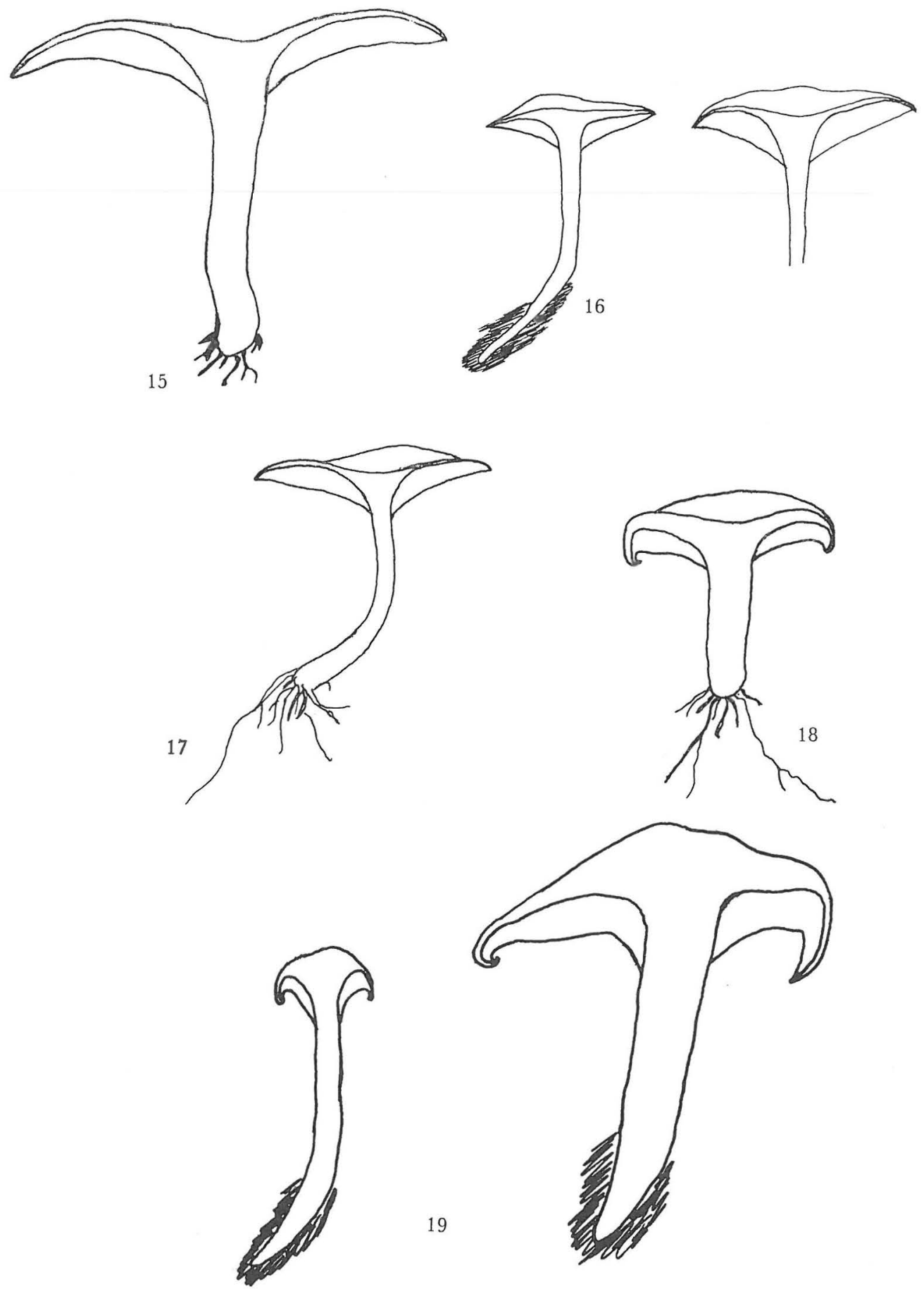

Fig. 15. C. sinopica (7. IX. 1966). - Fig. 16. C.candicans (left 21. IX. 1966; right 7. IX. 1965). -

Fig. 17. C. pruinosa (Finland, prov. Etelä-Häme, par. Längelmäki 21. V. 1967). - Fig. 18. C. rhizophora (19. V. 1968). - Fig. 19. C. odora (21. VIII. 1966). 

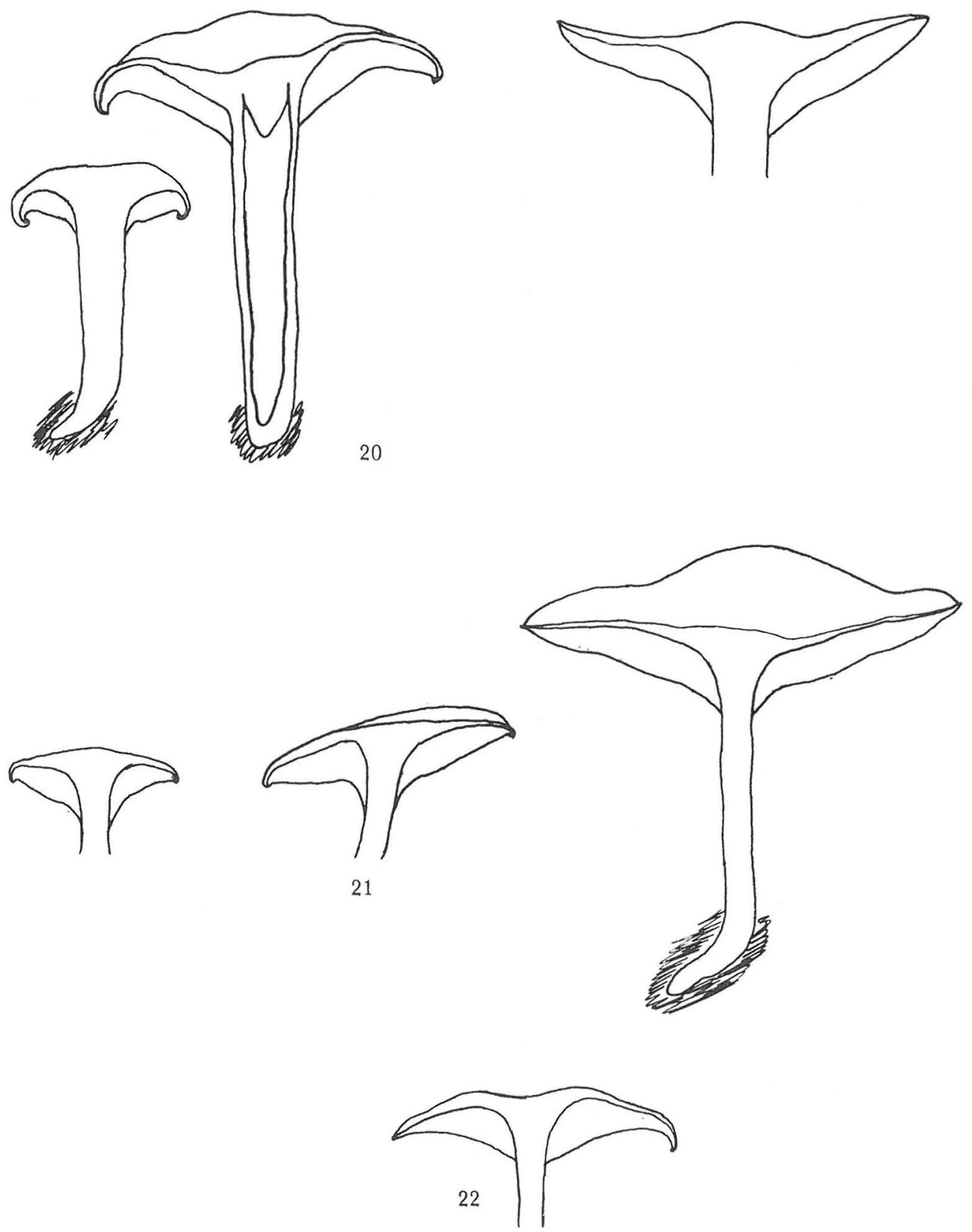

Fig. 20. C. phyllophila v. phyllophila (left 8. IX. 1966; right 30. VIII. 1965). - Fig. 21. C. phyllophila v. tenuis (left 10. X. 1965; right Finland, prov. Etelä-Savo, par. Mäntyharju 5. X. 1967). - Fig. 22. C. anisata (20. IX. 1965). 

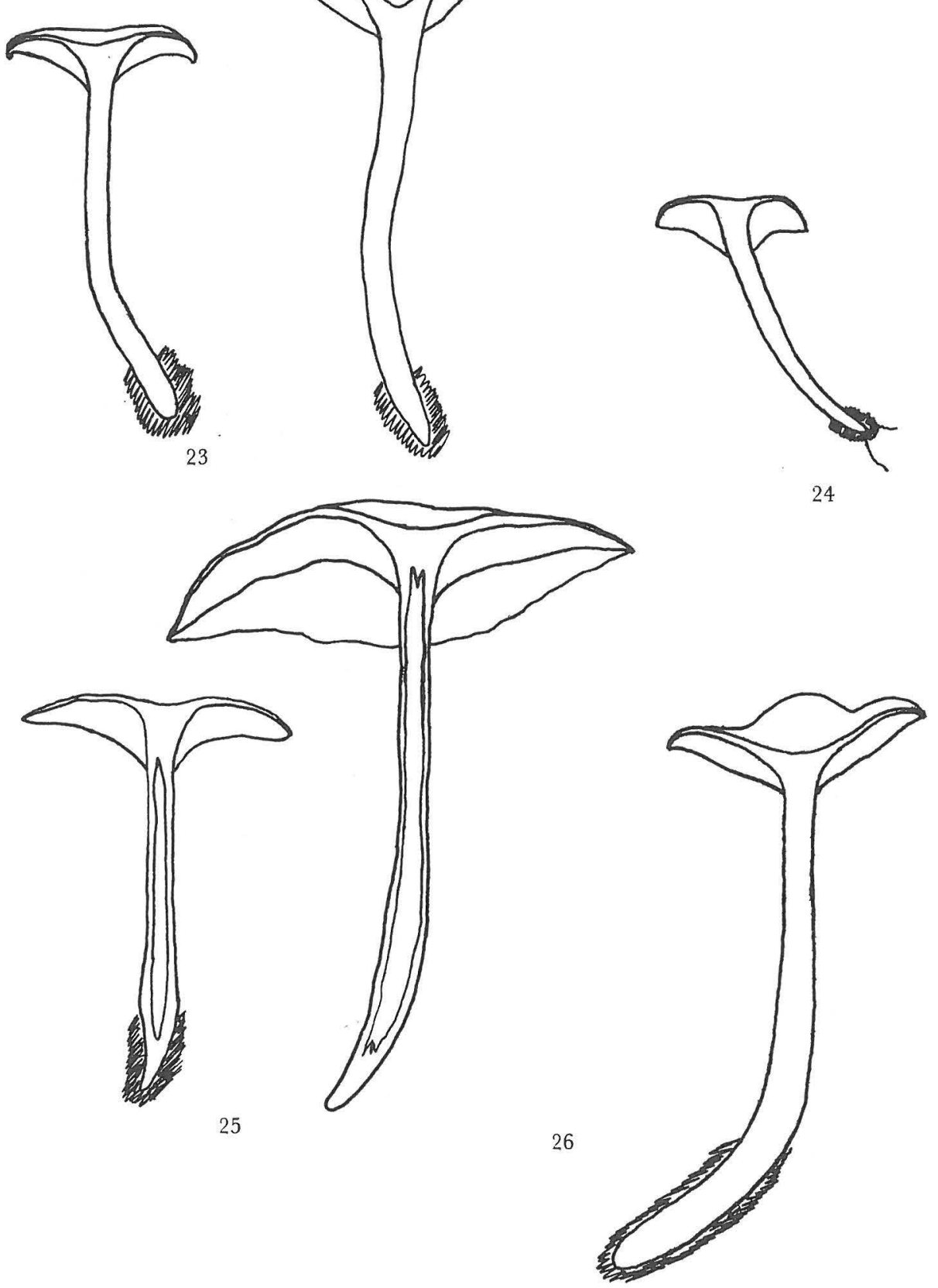

Fig. 23. C. diatreta (left Finland, prov. Uusimaa, par. Kirkkonummi 8. IX. 1967; right Finland, prov. Uusimaa, par. Pohja 14. IX. 1967). - Fig. 24. C. agrestis (holotype). - Fig. 25. C. marginella (left Finland, prov. Uusimaa, par. Kirkkonummi 8. IX. 1967; right Finland, prov. Satakunta, par. Metsämaa 28. IX. 1967). - Fig. 26. C. fragrans (Sweden, prov. Småland, par. Tånnö 5. X. 1968). 


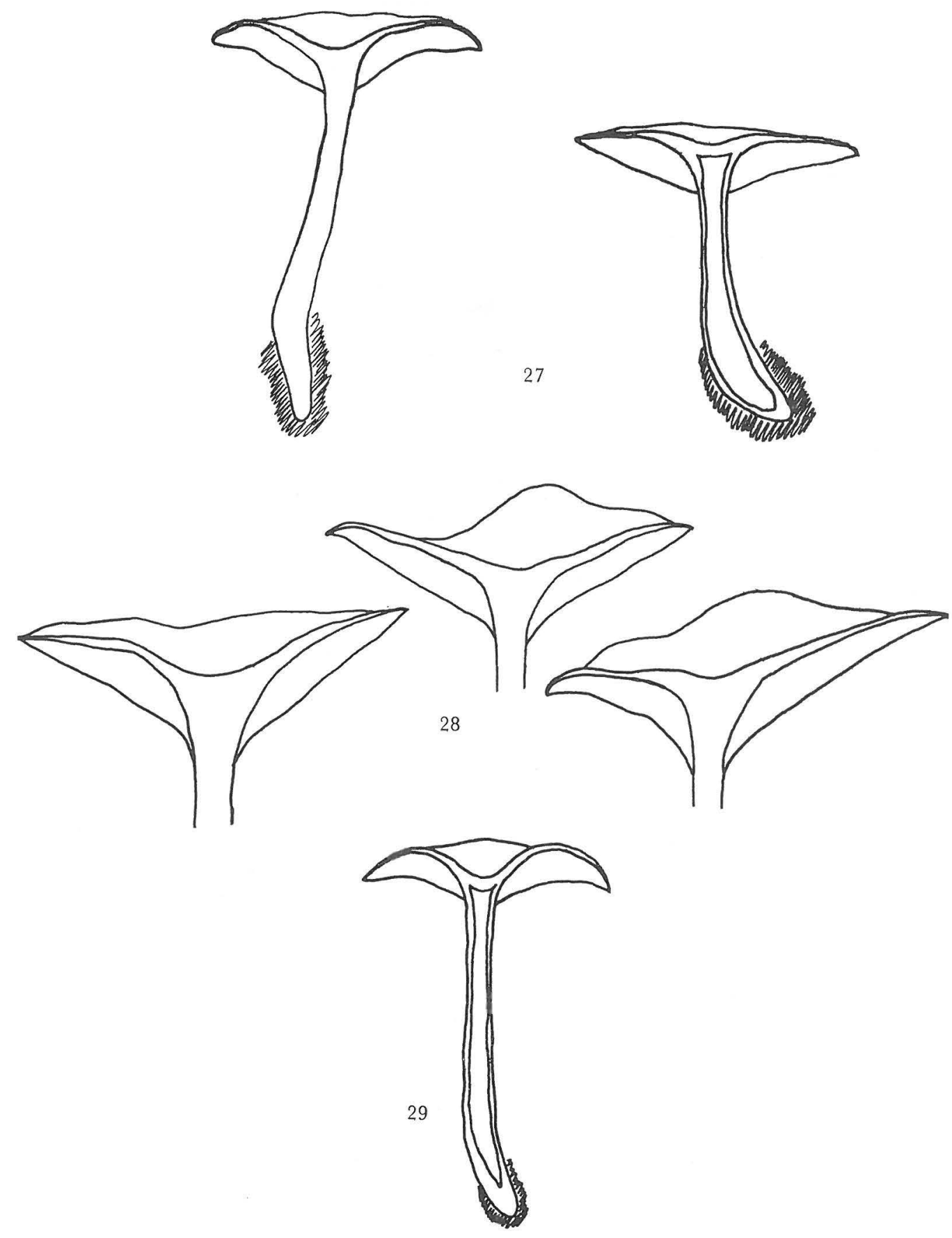

Fig. 27. C. metachroa (left Finland, prov. Etelä-Häme, par. Tammela 19. IX. 1967; right d:o 15. X. 1967). - Fig. 28. C. amarescens (left 8. X. 1965; middle holotype; right 17. X. 1965). - Fig. 29. C. subcordispora (holotype). 


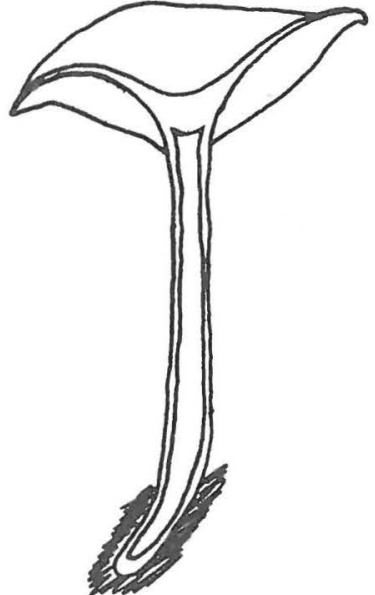

30

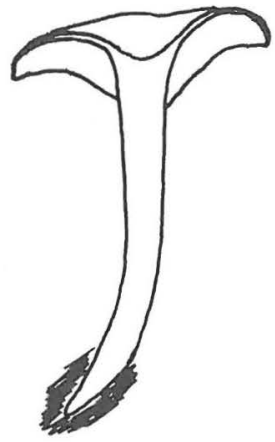

31

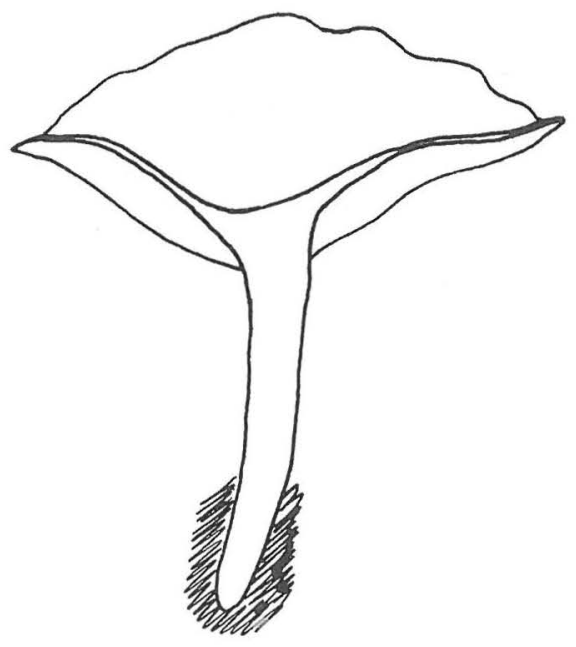

32
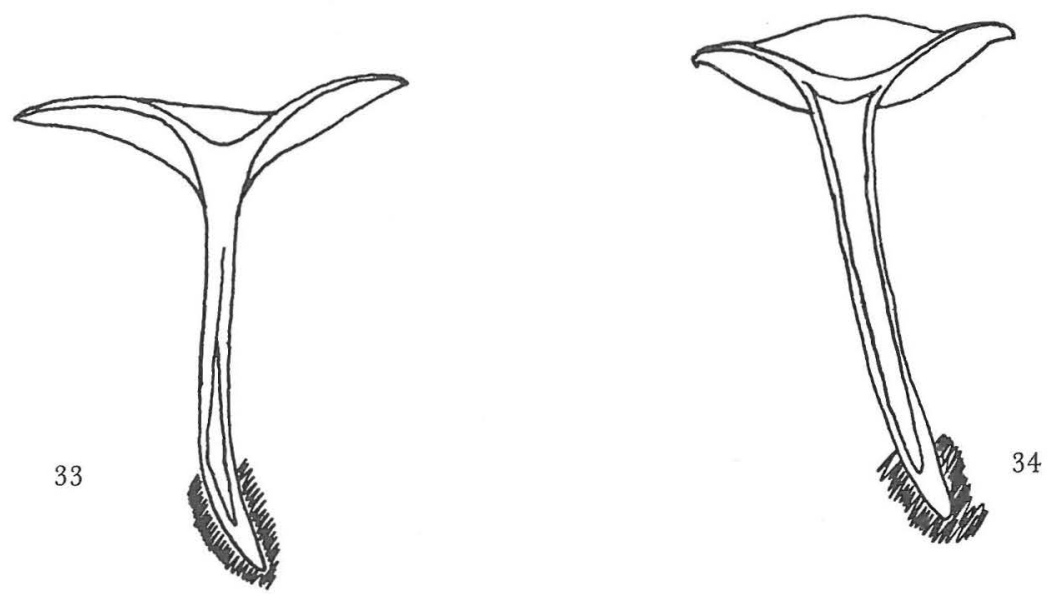

Fig. 30. G. vibecina (Finland, prov. Laatokan Karjala, par. Parikkala 12. X. 1967). - Fig. 31. C. langei (Finland, prov. Uusimaa, par. Kirkkonummi 8. IX. 1967). - Fig. 32. C. ditopa v. ditopa (Finland, prov. Laatokan Karjala, par. Parikkala 12. X. 1967). - Fig. 33. C. ditopa v. odorula (Finland, prov. Etelä-Savo, par. Juva 5. X. 1967). - Fig. 34. C. menthiodora (holotype). 


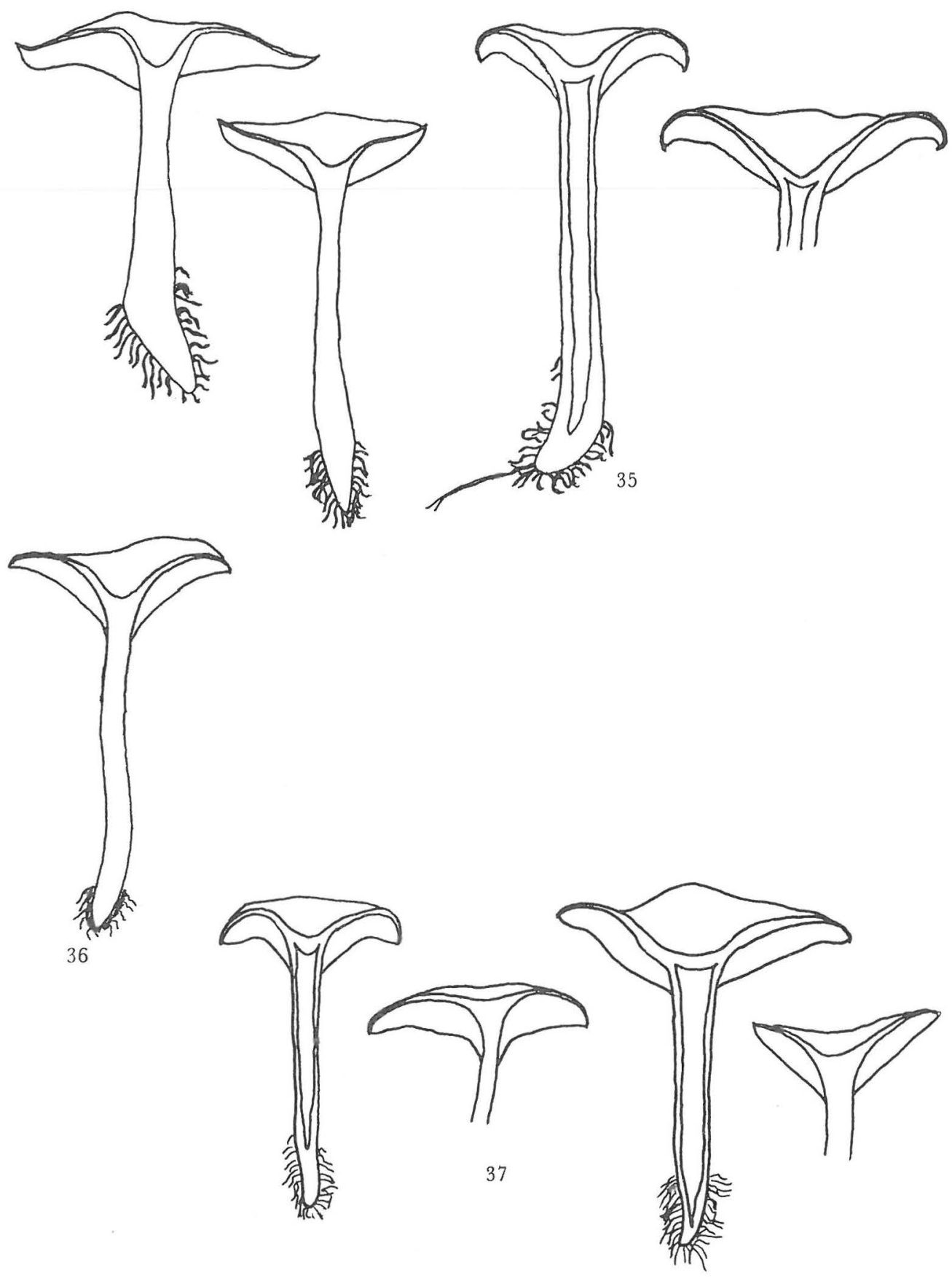

Fig. 35. C. strigosa (two fruit bodies on the left 7. IX. 1966; those on the right 21. VIII. 1966). -

Fig. 36. C. fennica (holotype). - Fig. 37. C. lohjaënsis (the first fruit body from the left 7. IX. 1966; the second 2.X. 1965; the third 3.X.1967; the fourth 8. IX. 1965). 

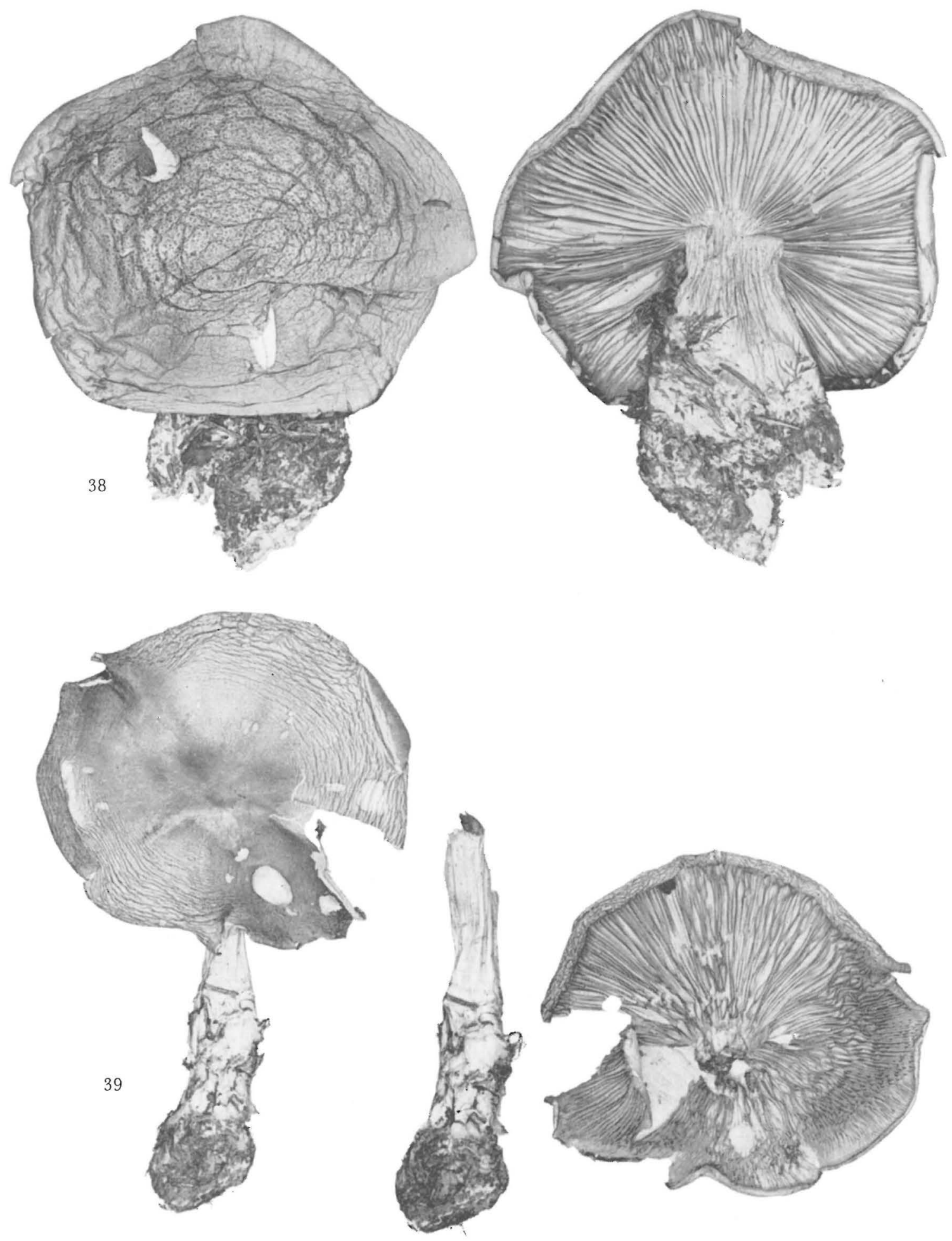

Fig. 38. C. alexandri ( $\times$ 0.75; Sweden, prov. Uppland, par. Bälinge, 24. VIII. 1956, H. Smith; UPS).

- Fig. 39. C. harperi ( $\times$ 0.75; Finland, prov. Pohjois-Pohjanmaa, par. Kiiminki, 8. IX. 1966, T. U1vinen; OULU). 

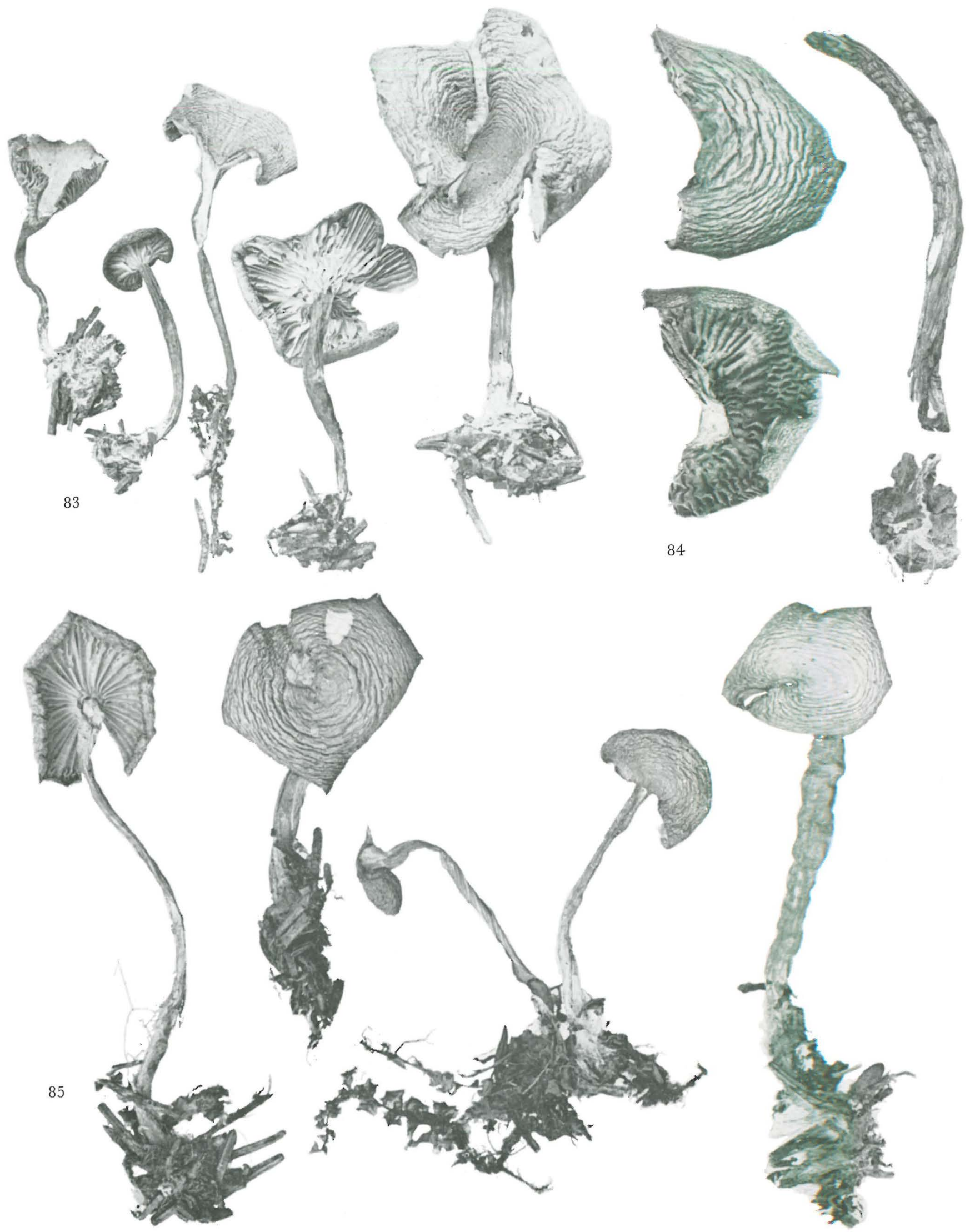

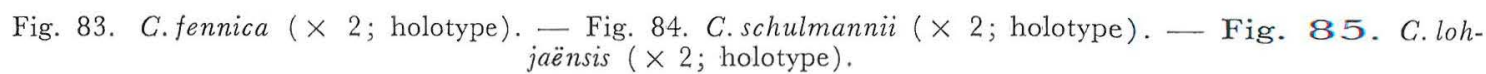


OD

86
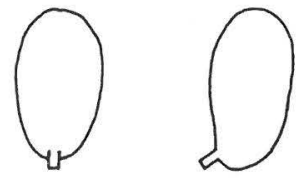

89
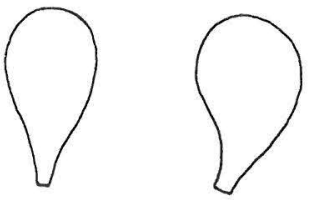

92
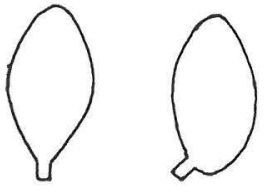

90
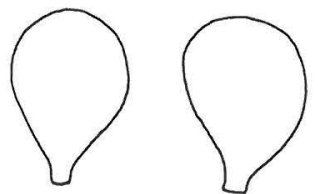

93

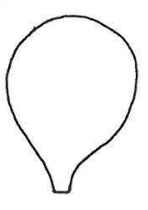

91
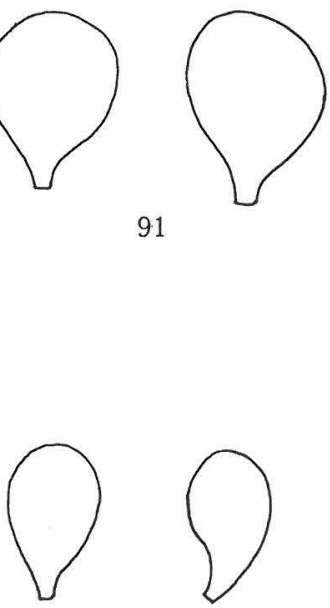

94
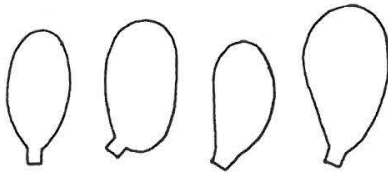

96

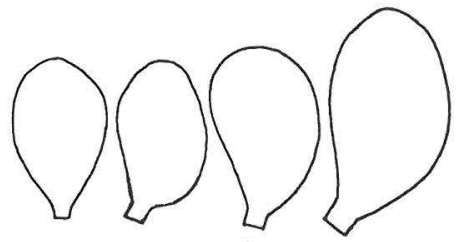

97
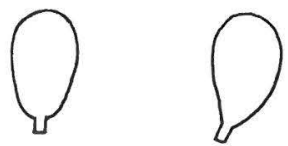

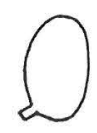

98
99

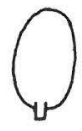

100

Fig. 86. C. alexandri. - Fig. 87. C. harperi. - Fig. 88. C. inornata. - Fig. 89. C. nebularis. - Fig. 90. C. clavipes. - Fig. 91. C. geotropa. - Fig. 92. C. altaica. - Fig. 93. C. catinus. - Fig. 94. C. gibba. - Fig. 95. C. squamulosa. - Fig. 96. C. bresadoliana. - Fig. 97. C.lapponica. - Fig. 98. C. sinopica. - Fig. 99. C. gilvaoides. - Fig. 100. C. gracilis. 
Q D

101<smiles>C1CCCCC1</smiles><smiles>C1CCCCC1</smiles>

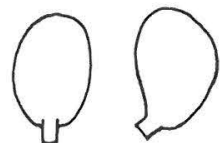

107
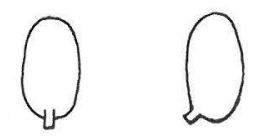

102<smiles>C1CCCCC1</smiles>

103

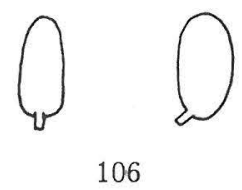

(<smiles>C1CCCCC1</smiles>

109

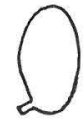

112

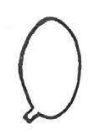

$(1$
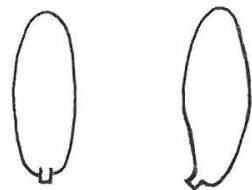

115

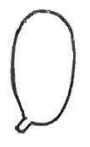

Fig. 101. C. candicans. - Fig. 102. C. dealbata. -Fig. 103. C.ruderalis. - Fig. 104. C. laricicola. Fig. 105. C. pruinosa (from specimen depicted in Fig. 57). - Fig. 106. C. rhizophora. - Fig. 107. C. hydrogramma. - Fig. 108. C.odora. - Fig. 109. C.phyllophila v. phyllophila. - Fig. 110. C. phyllophila v. tenuis. - Fig. 111. C. anisata. - Fig. 112. C. diatreta. - Fig. 113. G. agrestis. Fig. 114. G. marginella. - Fig. 115. C. fragrans. 


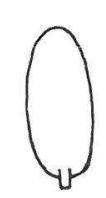

116

(<smiles>C1CCCCCC1</smiles><smiles>C1CCOCC1</smiles>

119
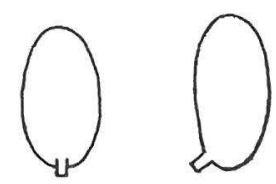

117

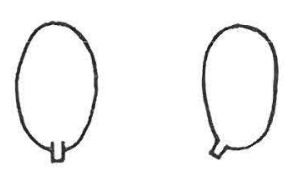

118

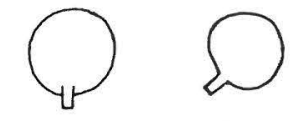

120

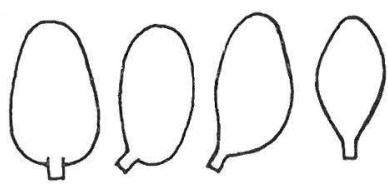

121
9

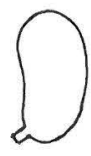

122

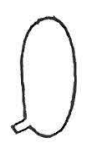

iv

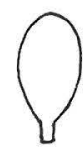

123

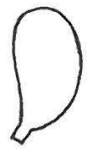

$Q_{4}$

124
$(2$<smiles>C1CCCCC1</smiles>

125

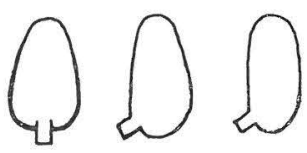

128
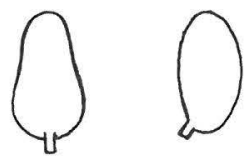

126

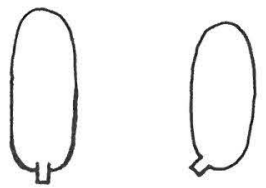

129

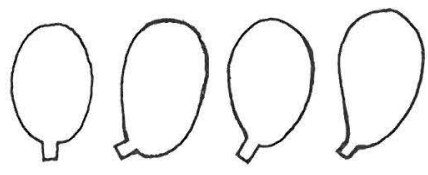

127

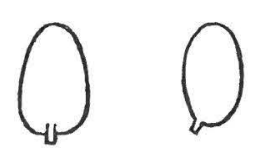

130

Fig. 116. C. metachroa. - Fig. 117. C. amarescens. - Fig. 118. C. metachroides. - Fig. 119. C. subcordispora. - Fig. 120. G. globispora. - Fig. 121. G. orientalis. - Fig. 122. G. vibecina. - Fig. 123. C. langei. - Fig. 124. C. ditopa v. ditopa. - Fig. 125. C. ditopa v. odorula. - Fig. 126. C. menthiodora. - Fig. 127. C. strigosa. - Fig. 128. G. fennica. - Fig. 129. C. schulmannii. - Fig. 130. C. lohjä̈nsis. 


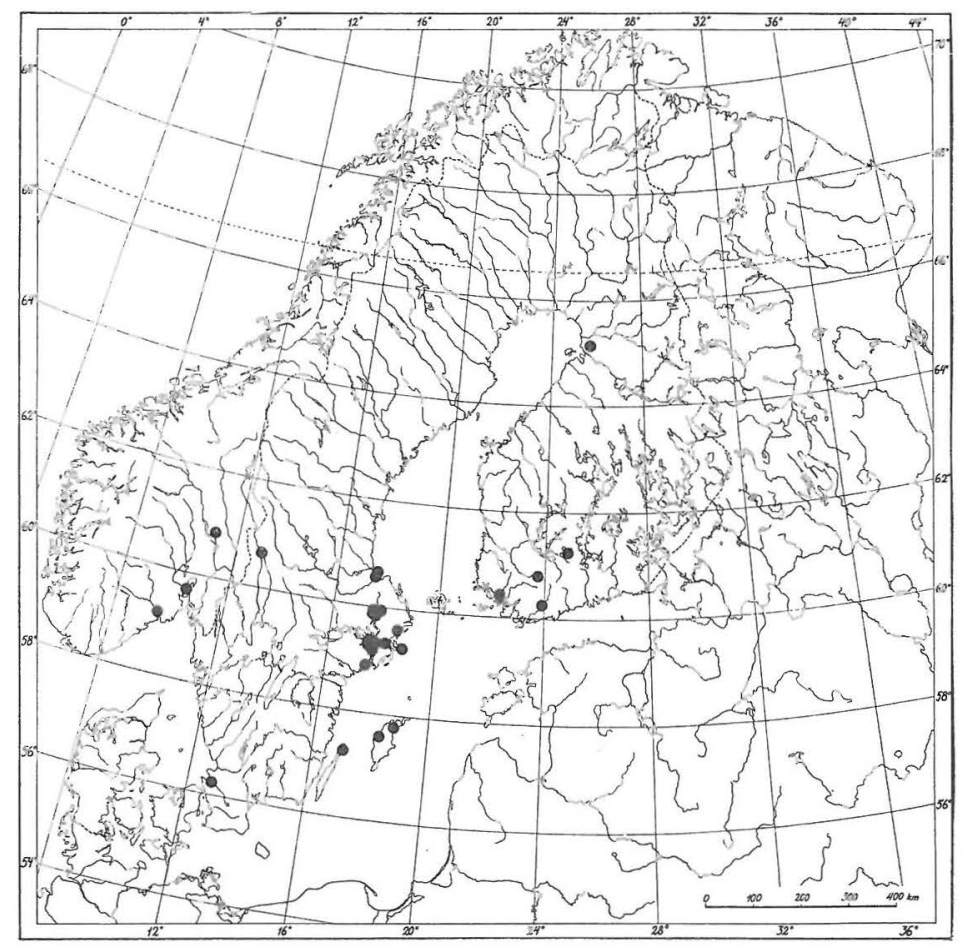

Fig. 131. G. alexandri.

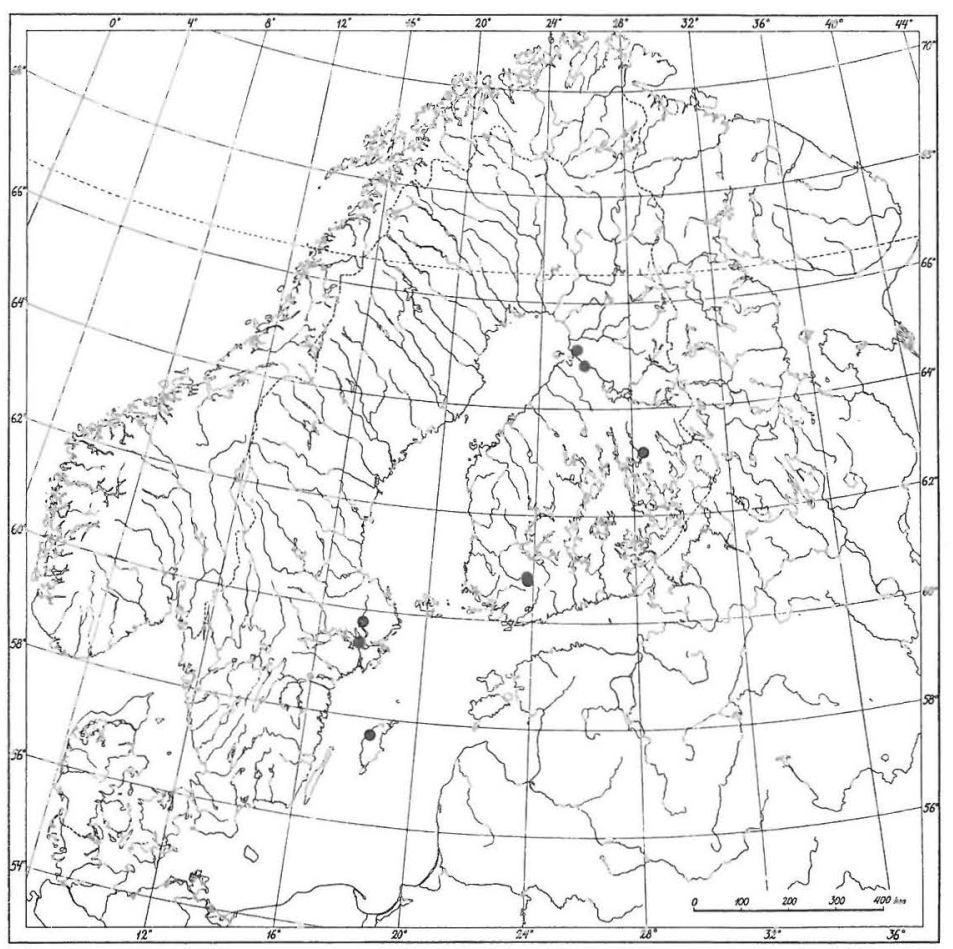

Fig. 132. G. harperi. 


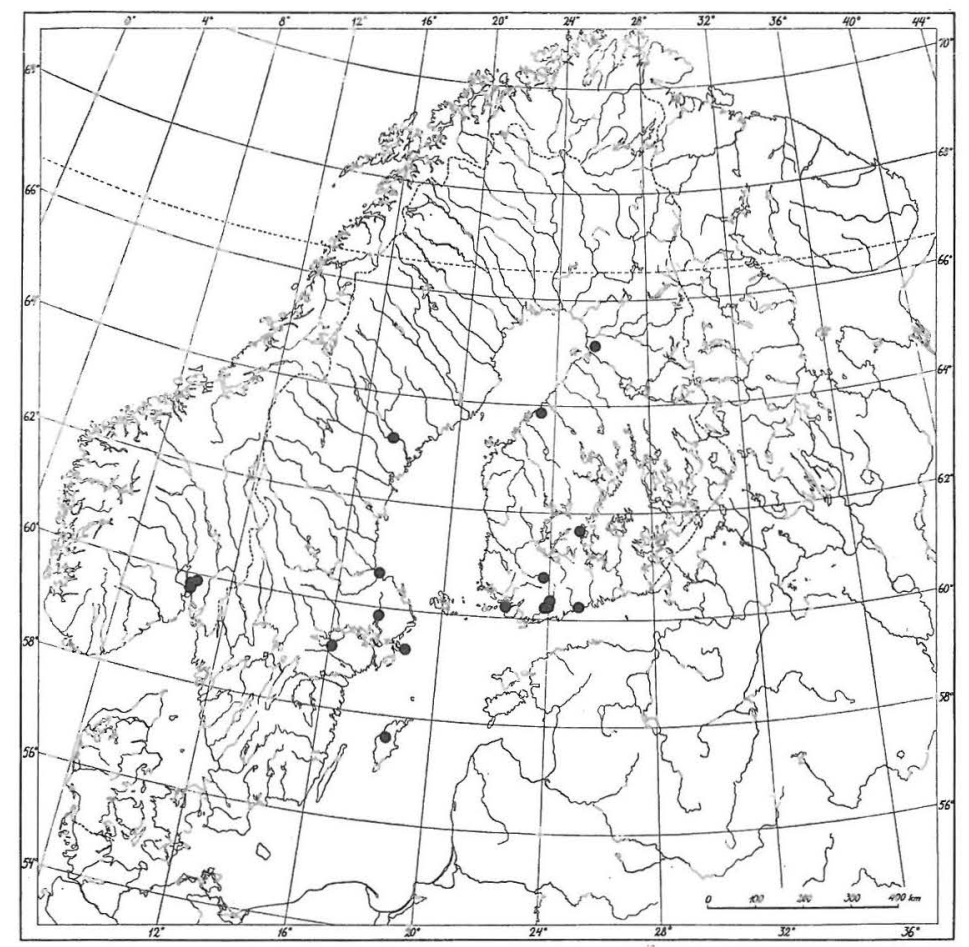

Fig. 133. C. inornata.

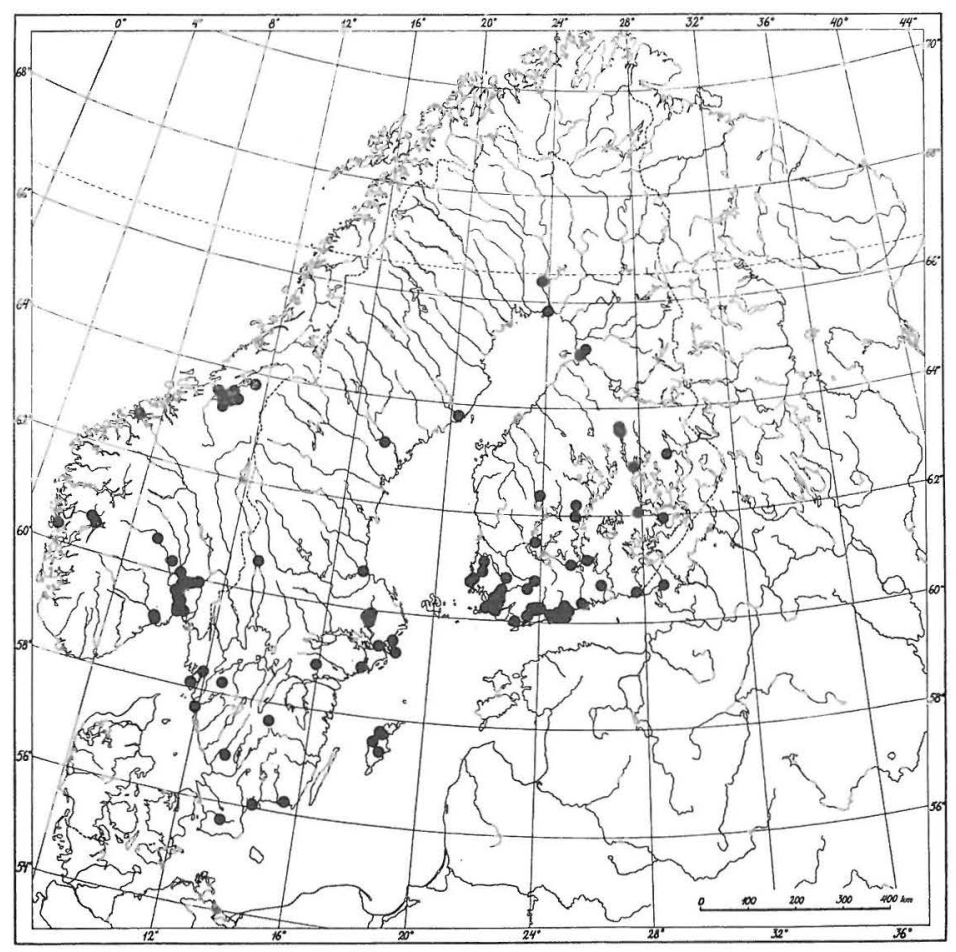

Fig. 134. C. nebularis. 


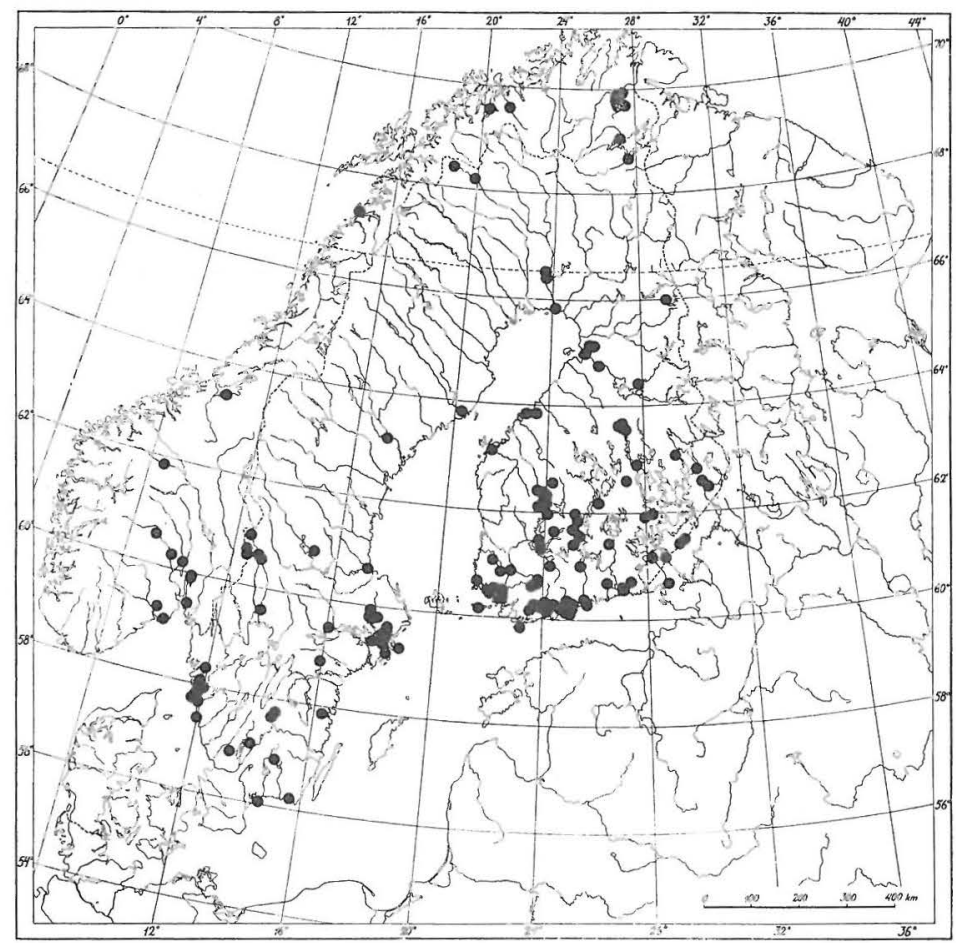

Fig. 135. C. clavipes.

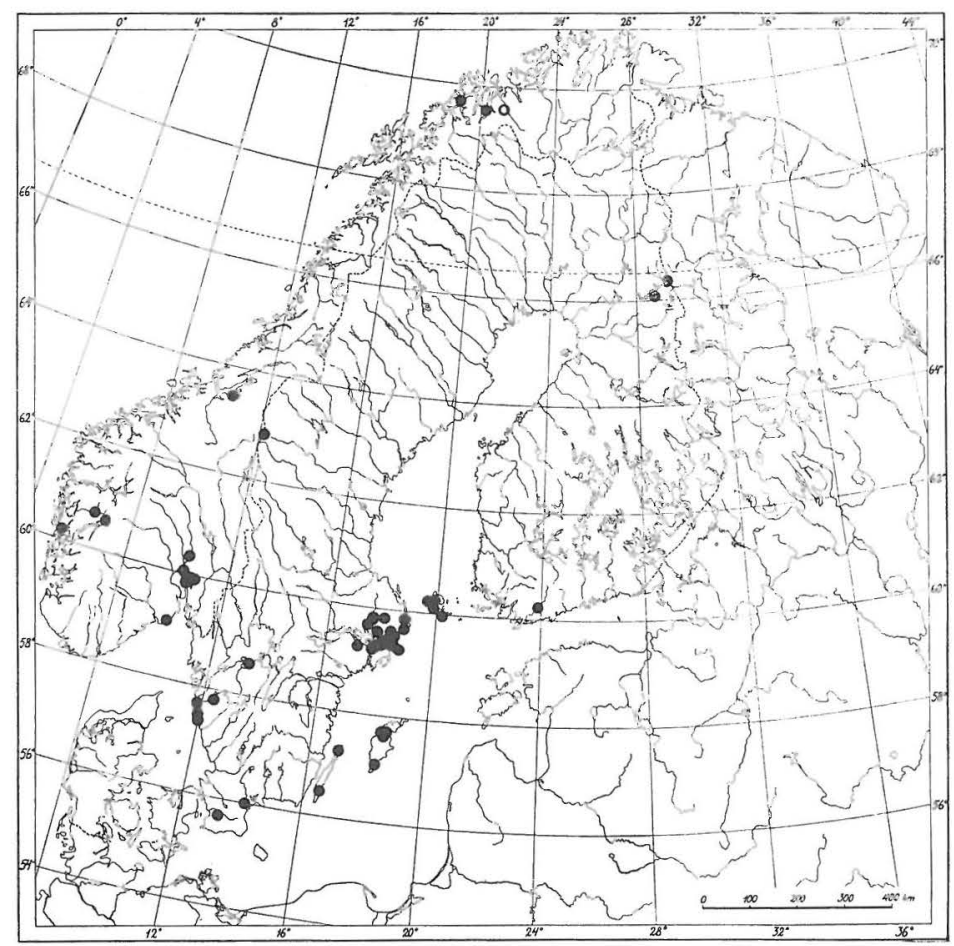

Fig. 136. C. geotropa (dots) and C. altaica (circle). 


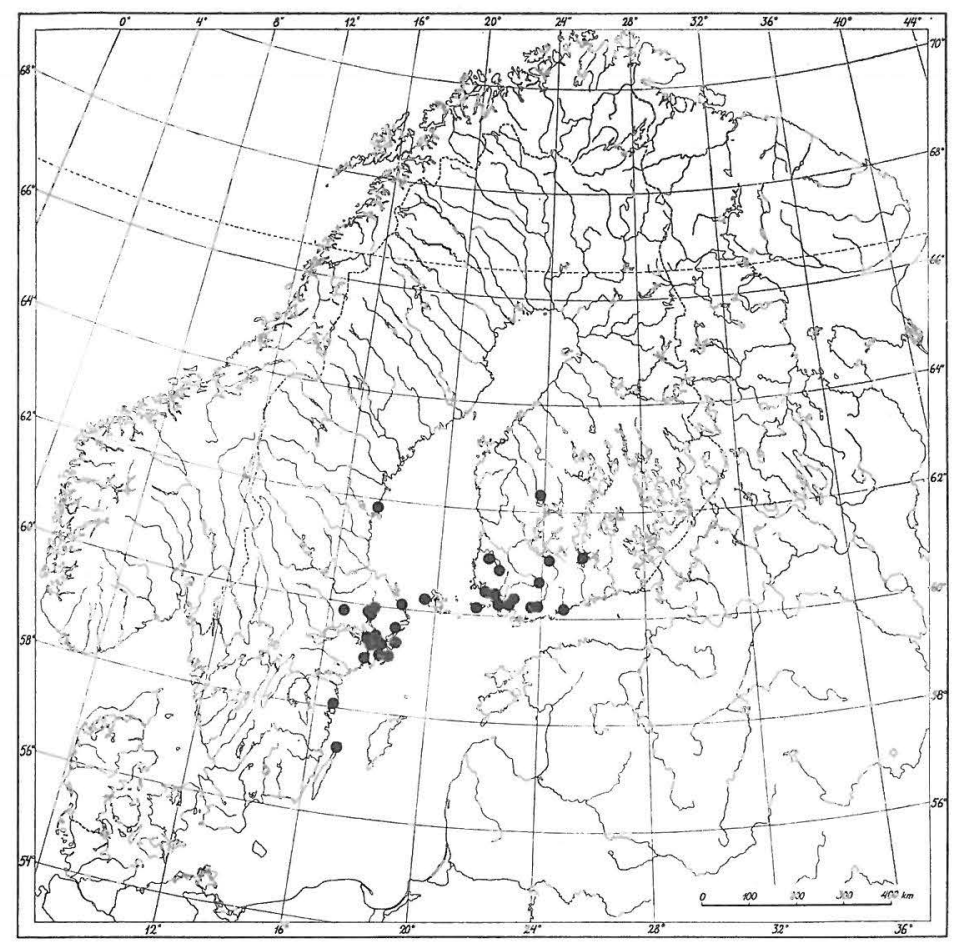

Fig. 137. C. catinus.

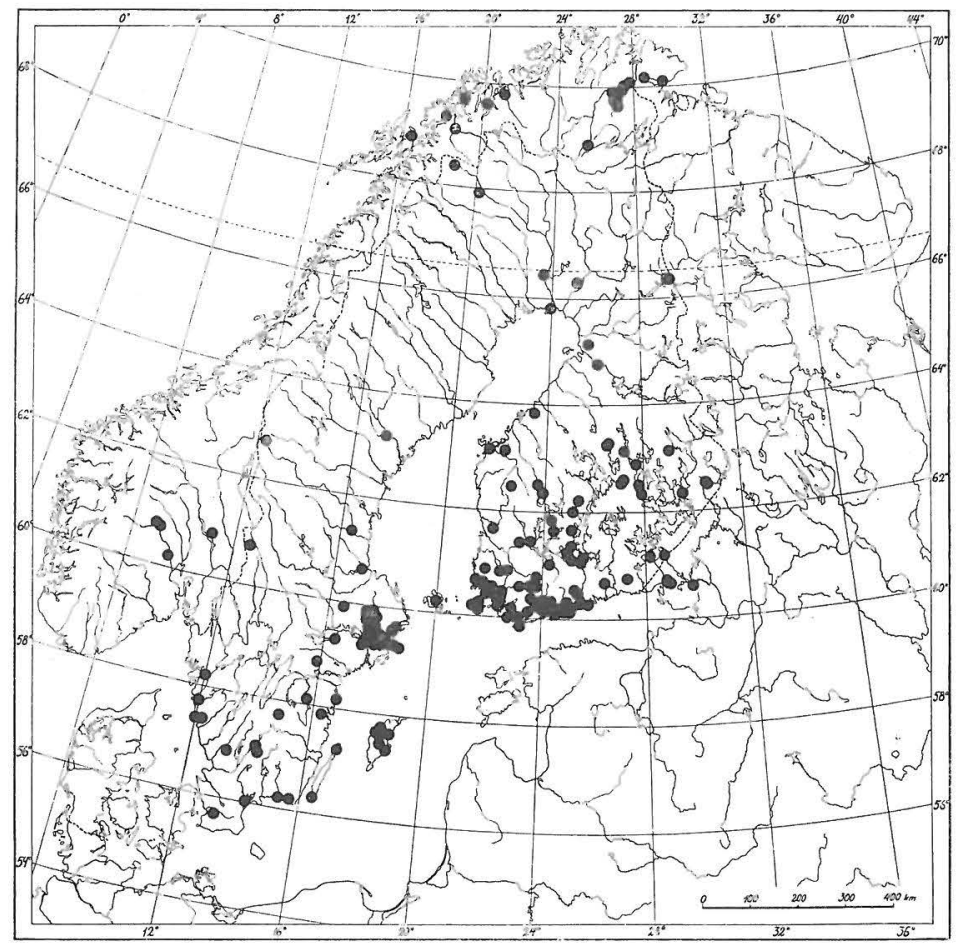

Fig. 138. C. gibba. 


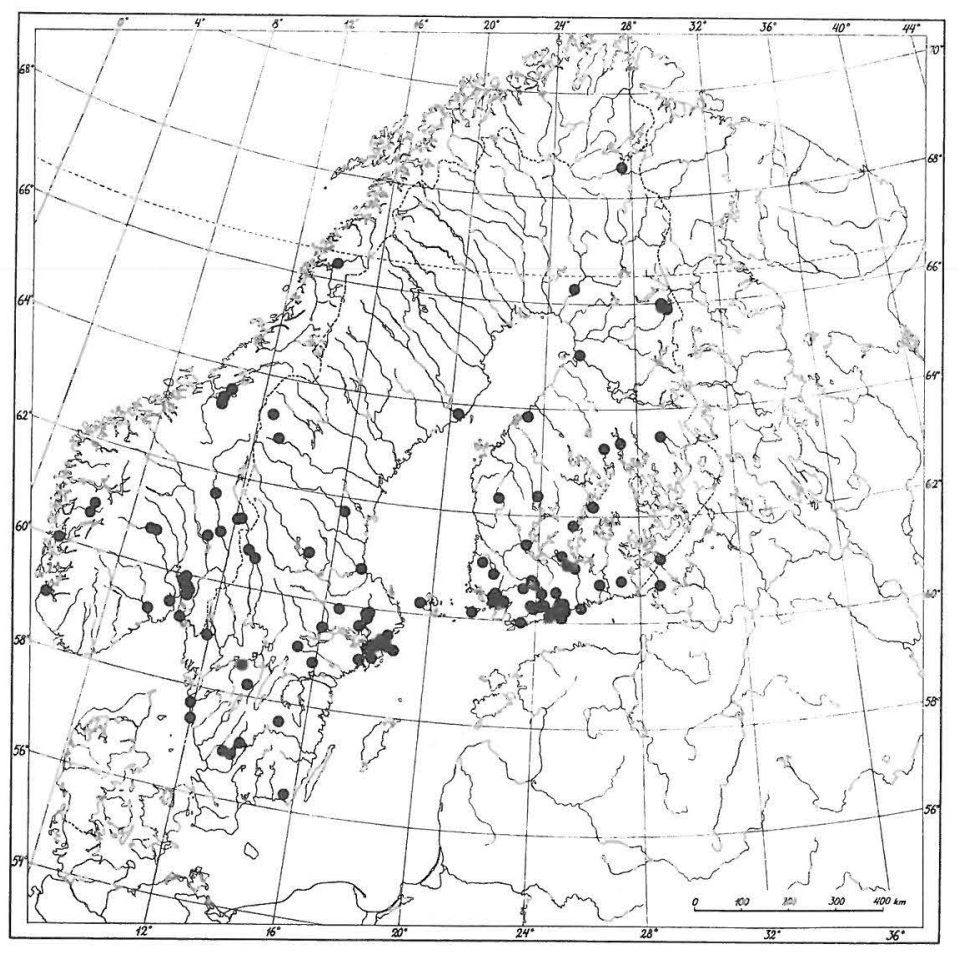

Fig. 139. C. squamulosa.

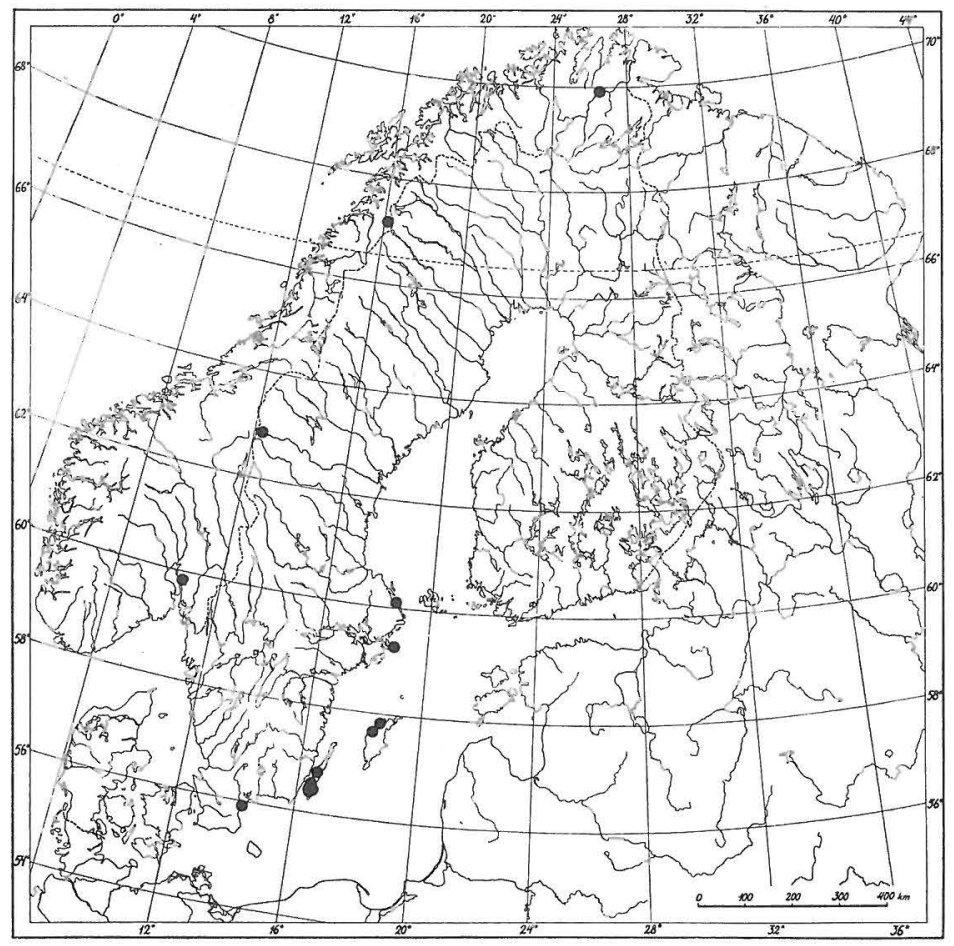

Fig. 140. C. bresadoliana. 


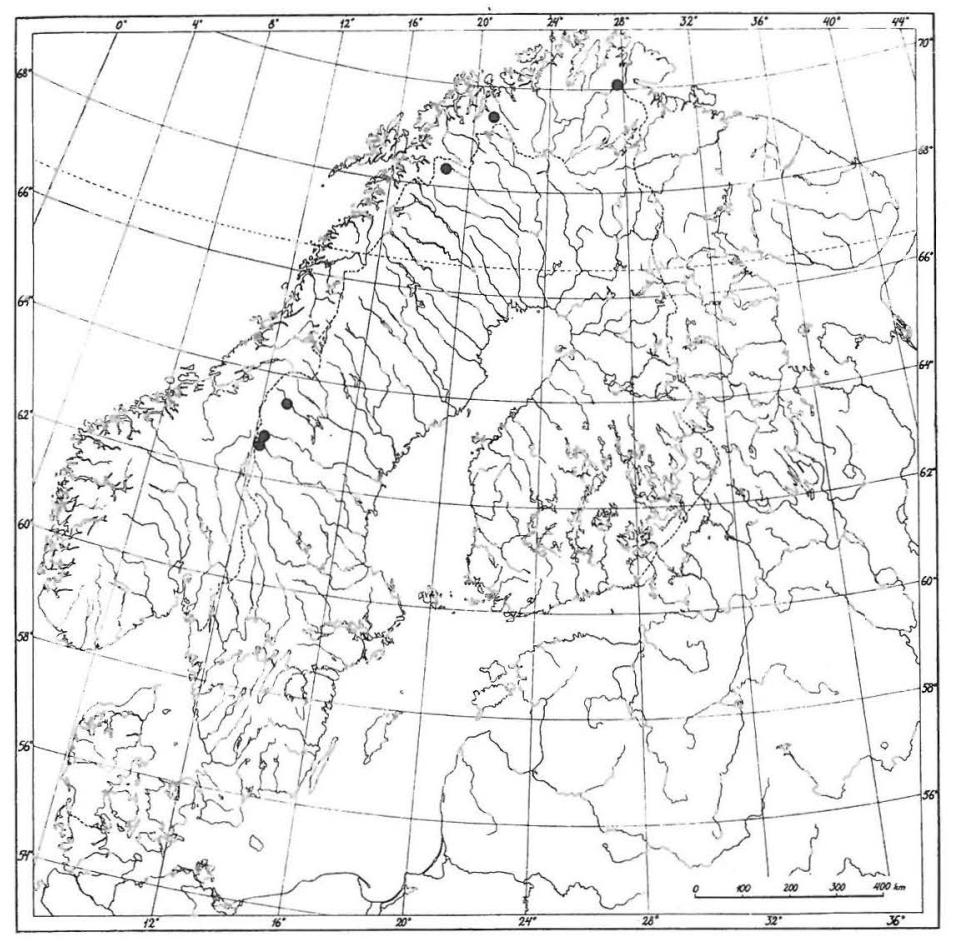

Fig. 141. C. lapponica.

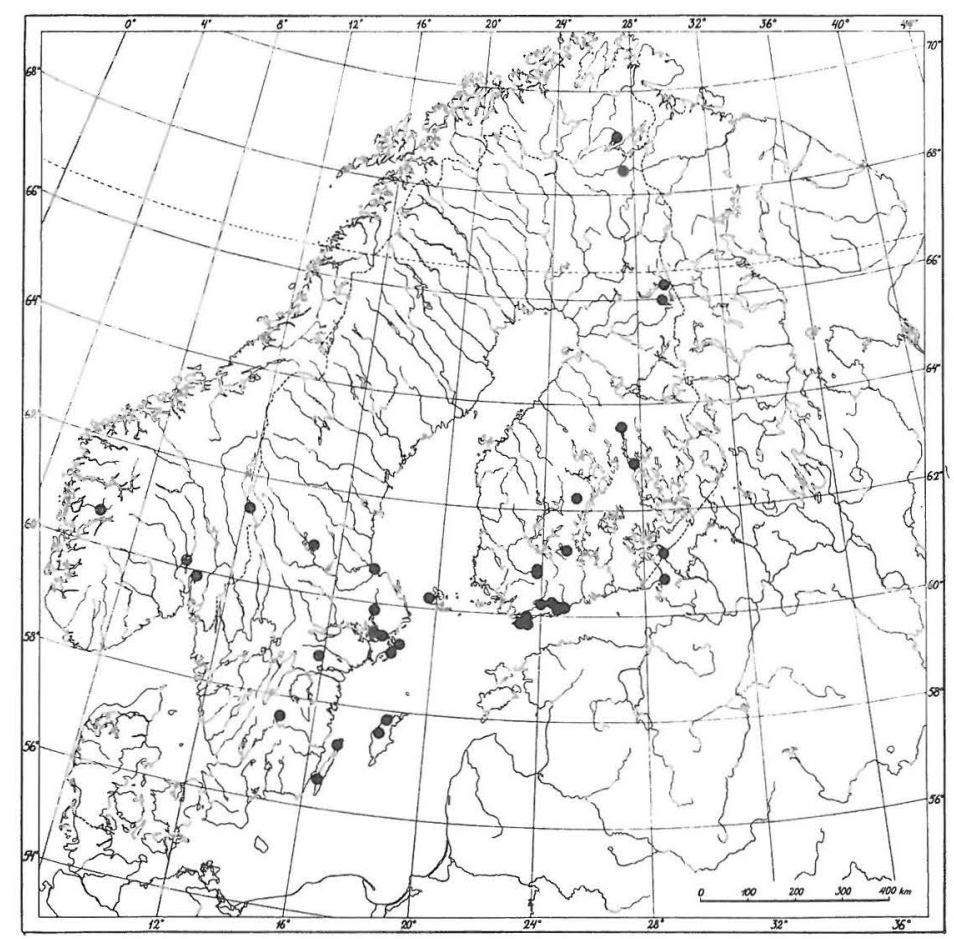

Fig. 142. C. sinopica. 


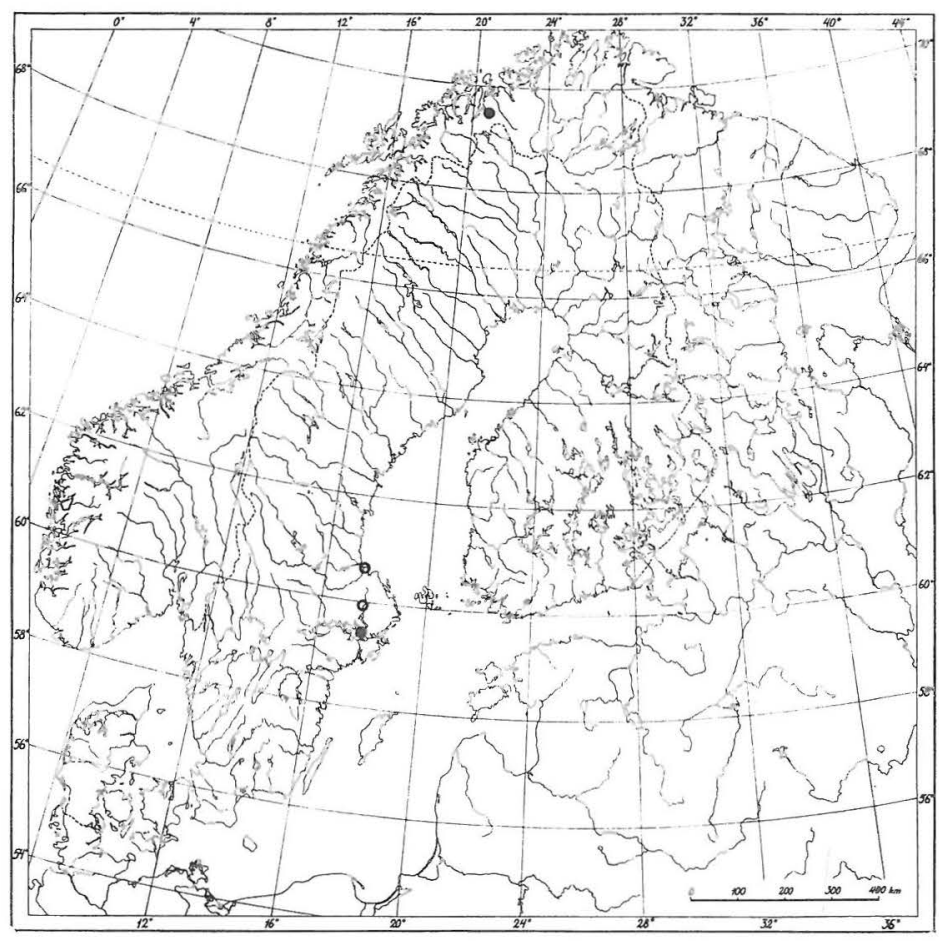

Fig. 143. C. gilvaoides (dots) and C. gracilis (circles).

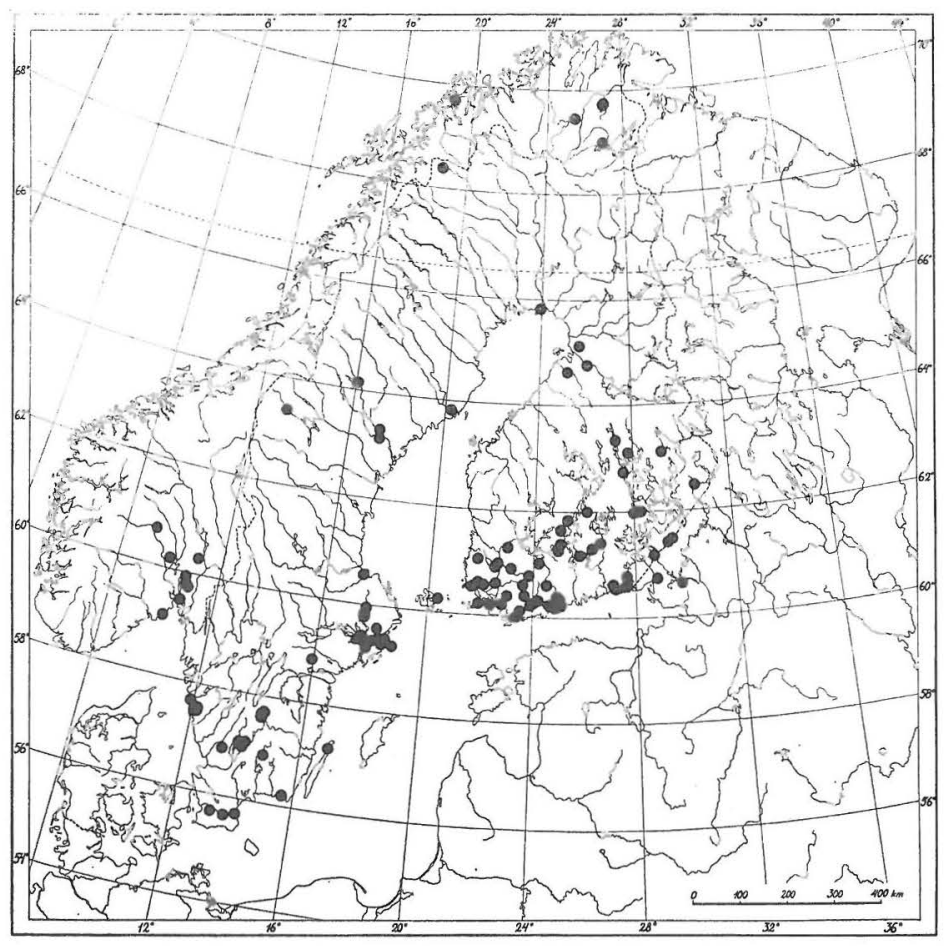

Fig. 144. C. candicans. 


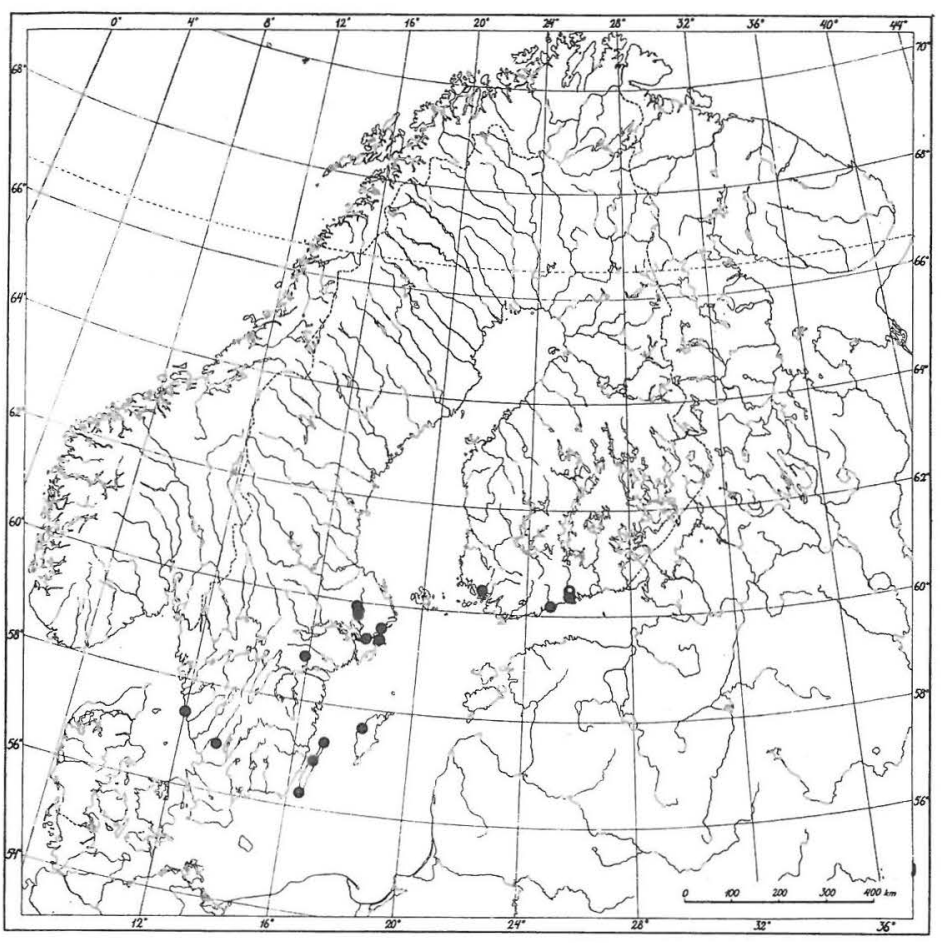

Fig. 145. C. dealbata (dots) and C.ruderalis (circle).

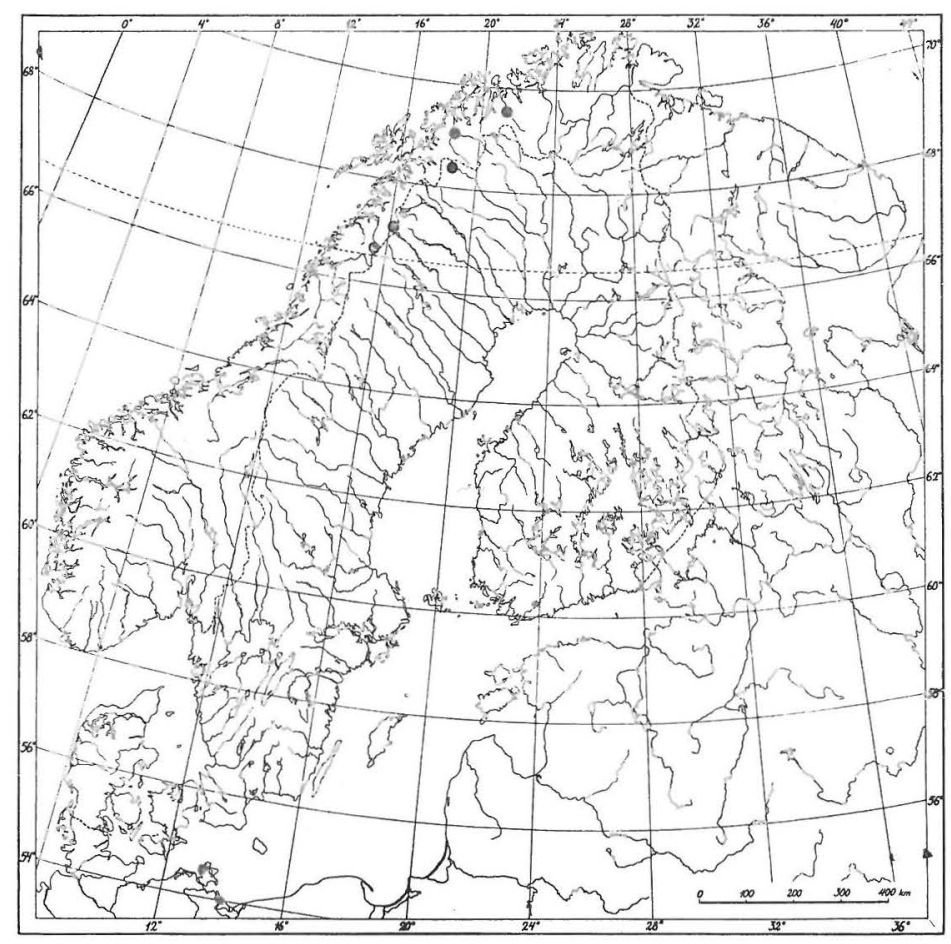

Fig. 146. C. laricicola. 


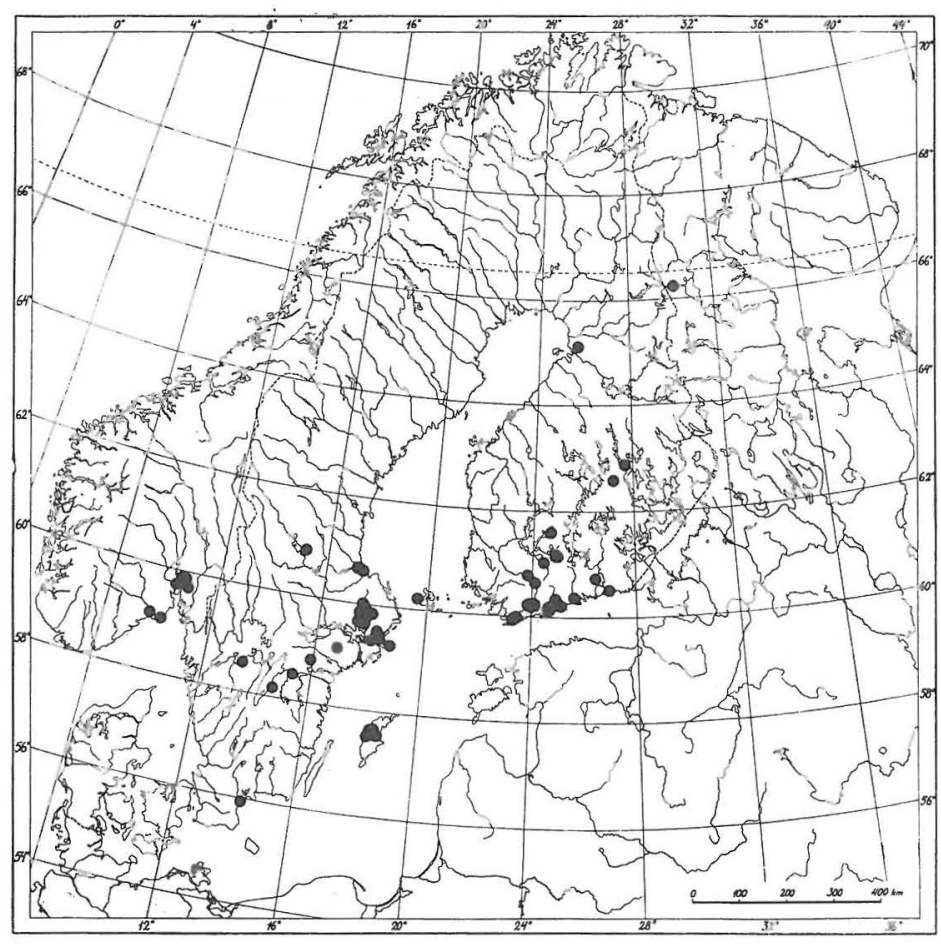

Fig. 147. C. pruinosa.

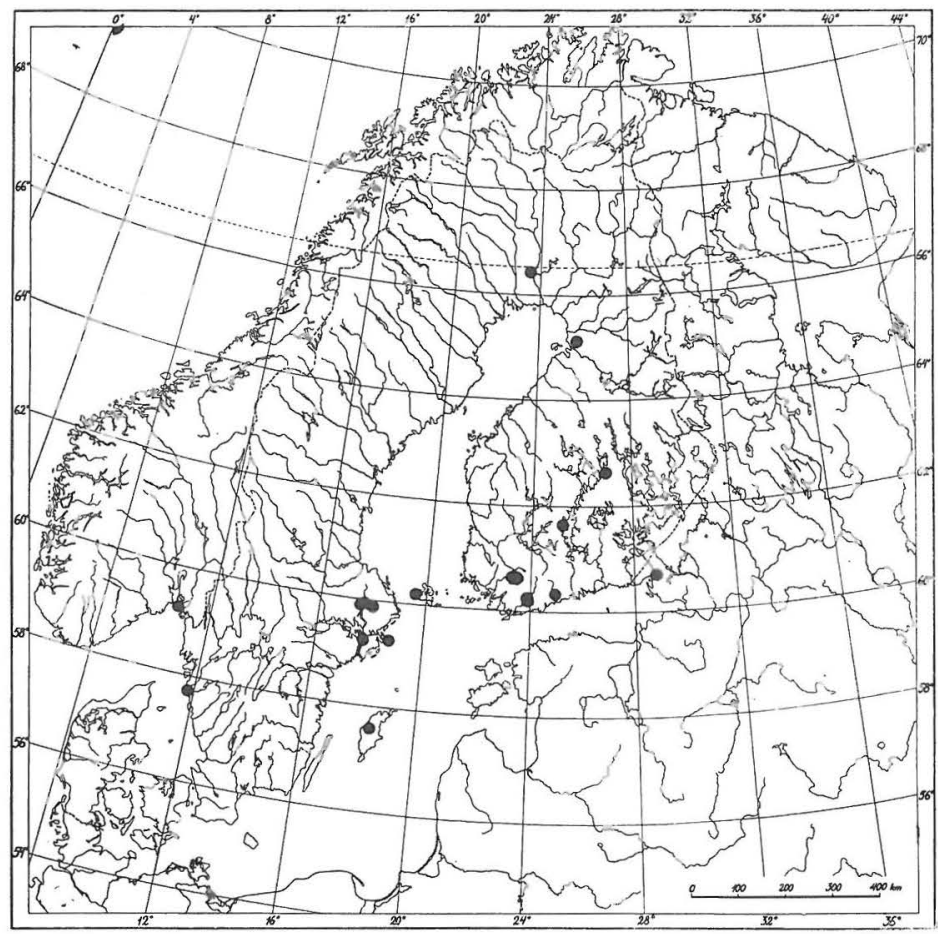

Fig. 148. C. rhizophora. 


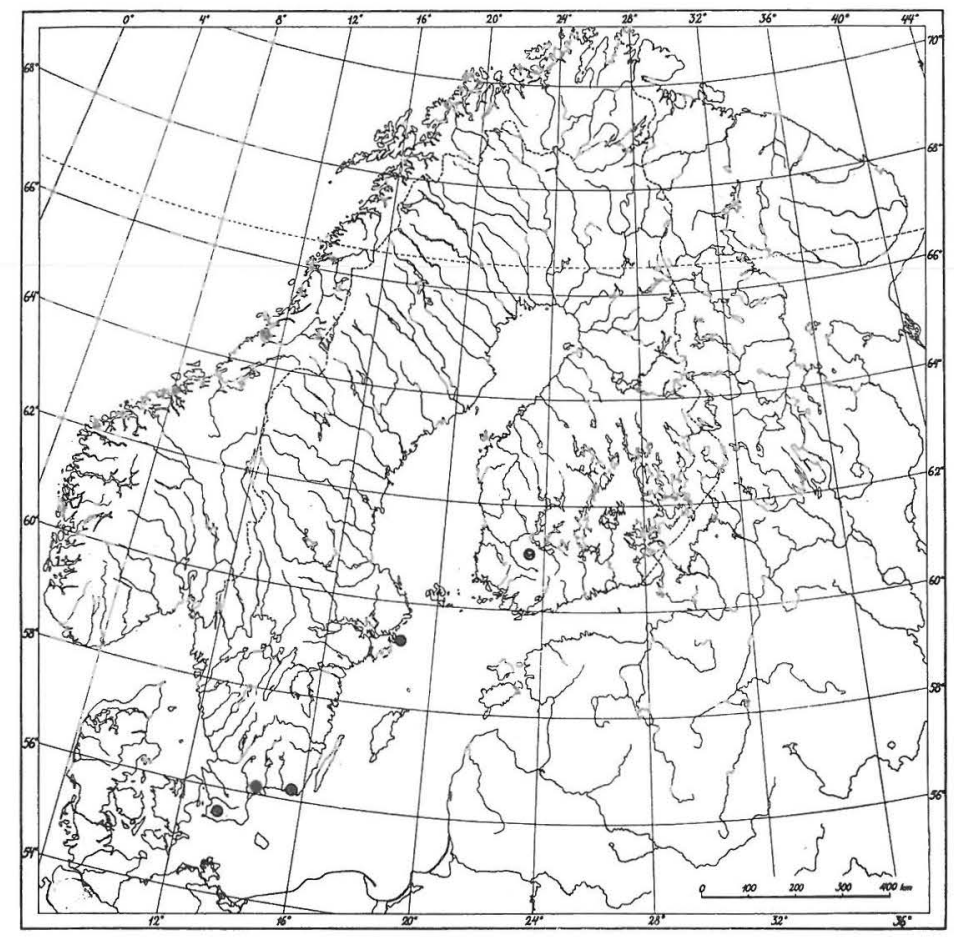

Fig. 149. C. hydrogramma.

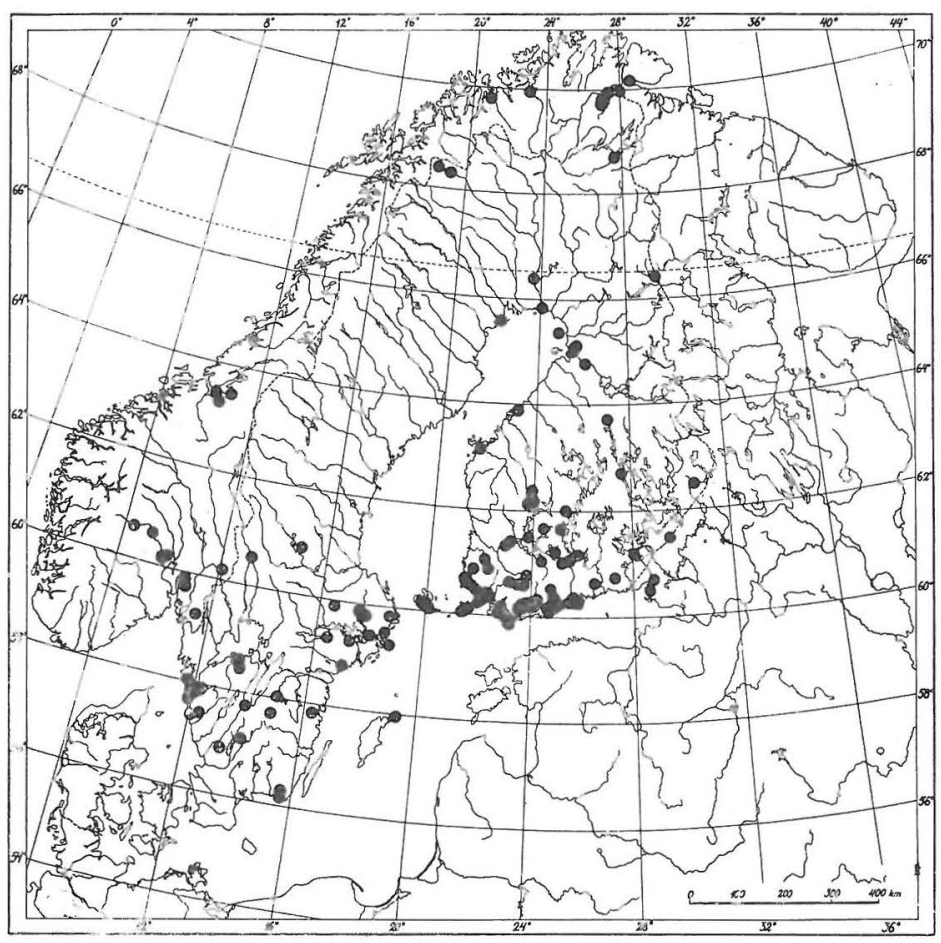

Fig. 150. G. odora. 


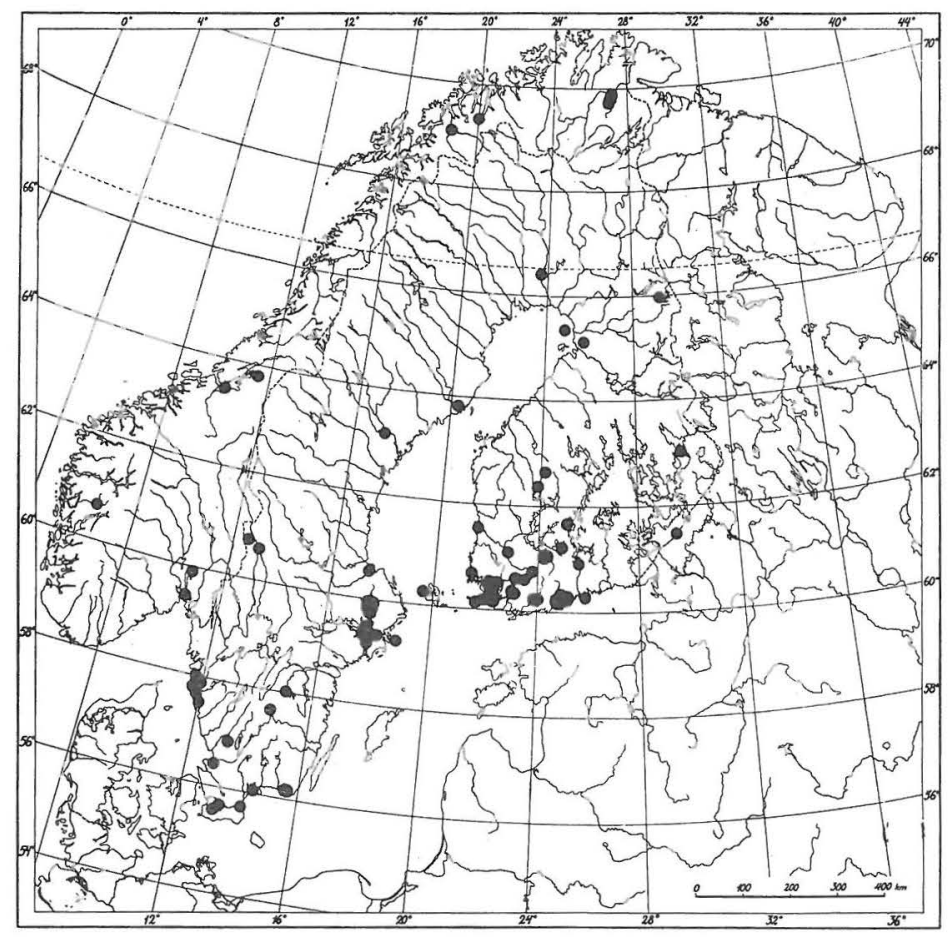

Fig. 151. C. phyllophila v. phyllophila.

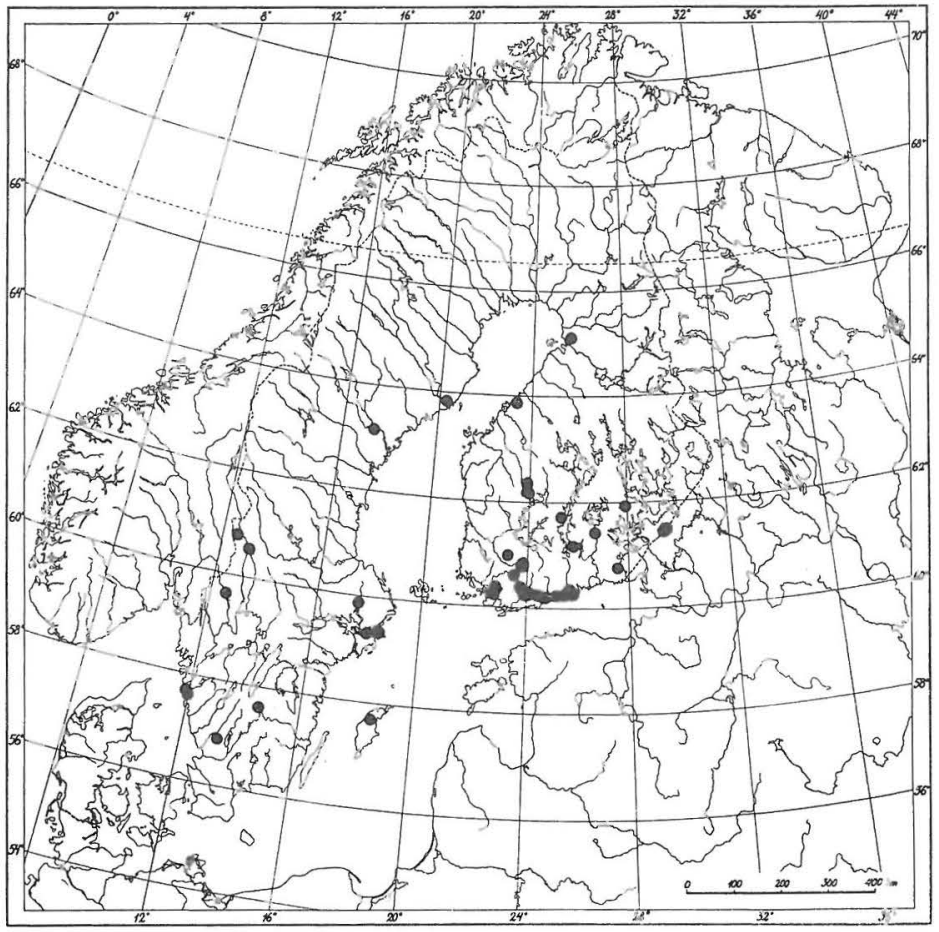

Fig. 152. C. phyllophila v. tenuis. 


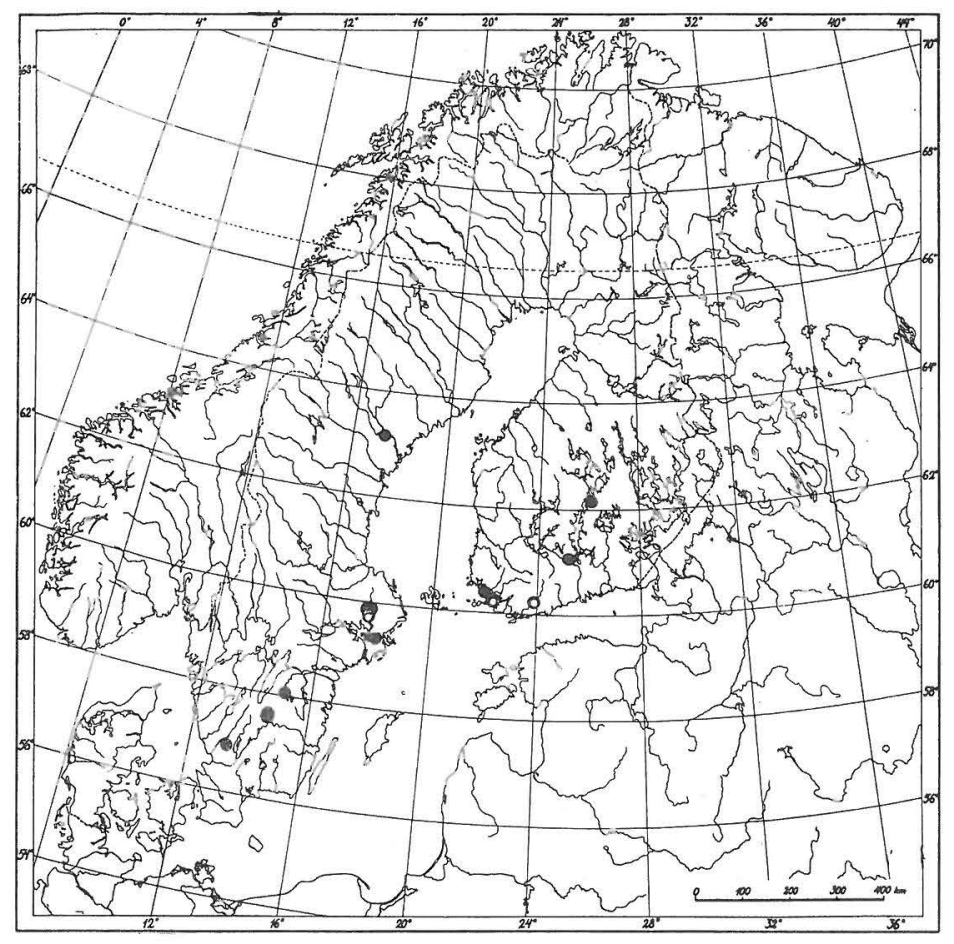

Fig. 153. C. anisata (circles) and C.agrestis (dots).

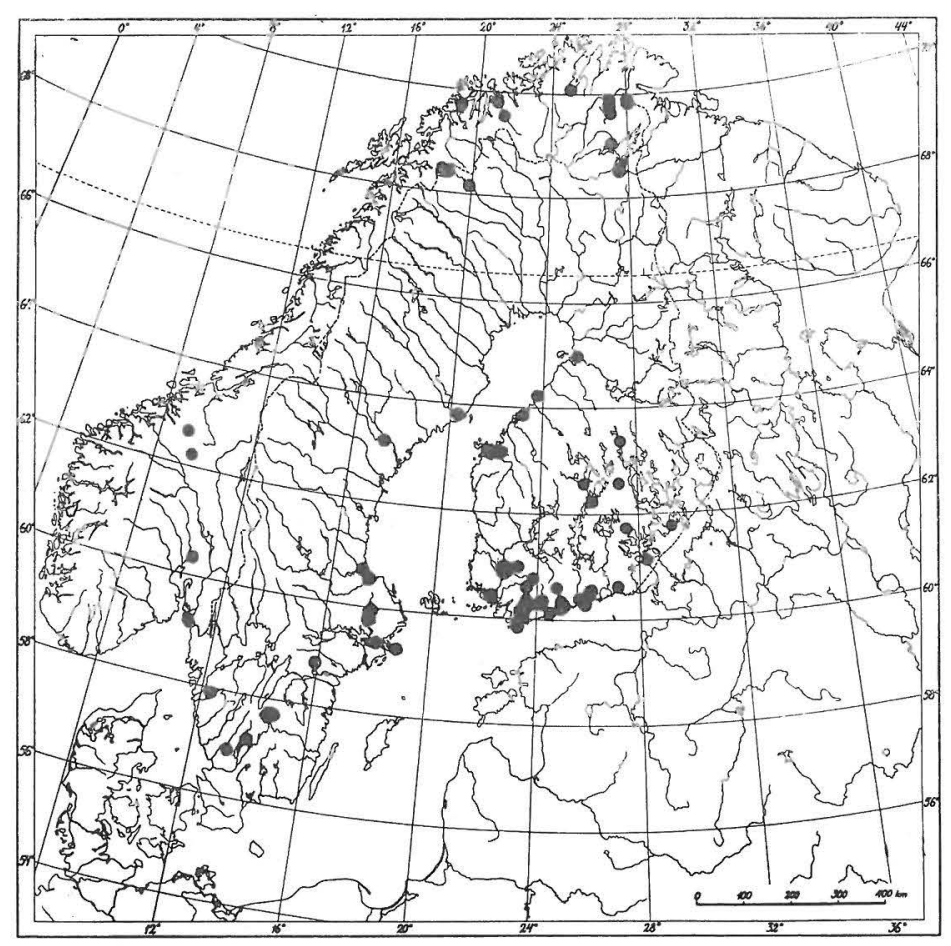

Fig. 154. C. diatreta. 


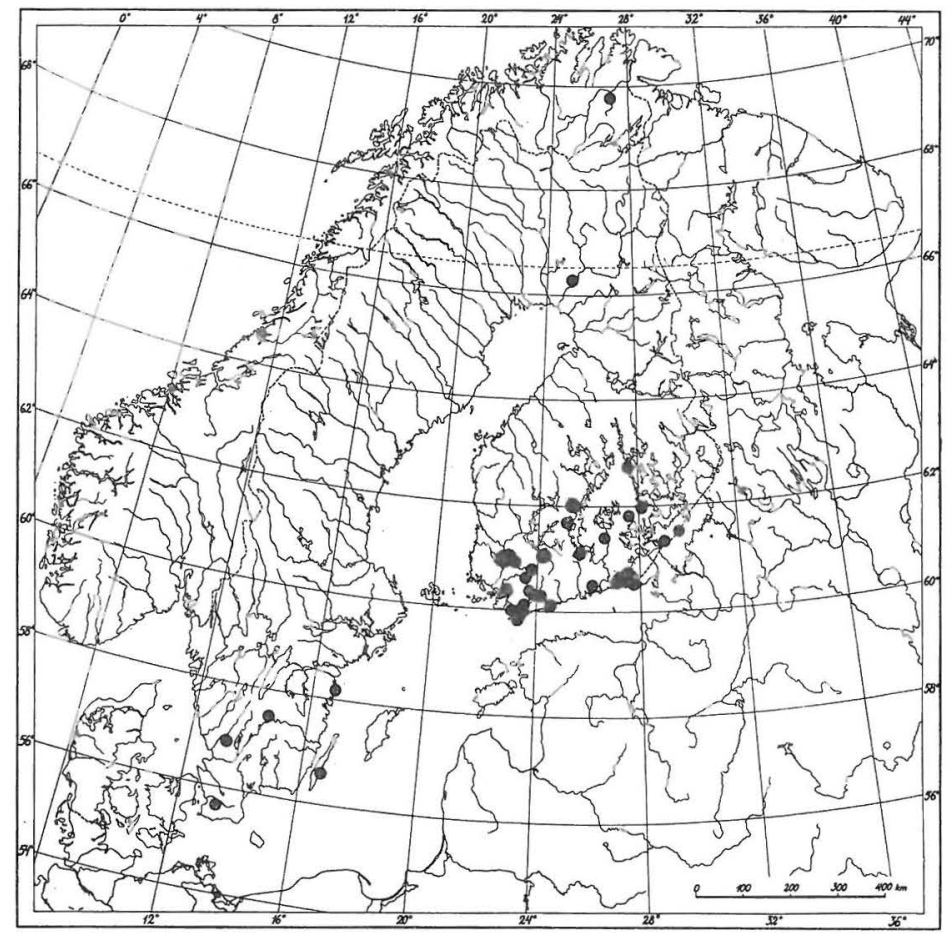

Fig. 155. C. marginella.

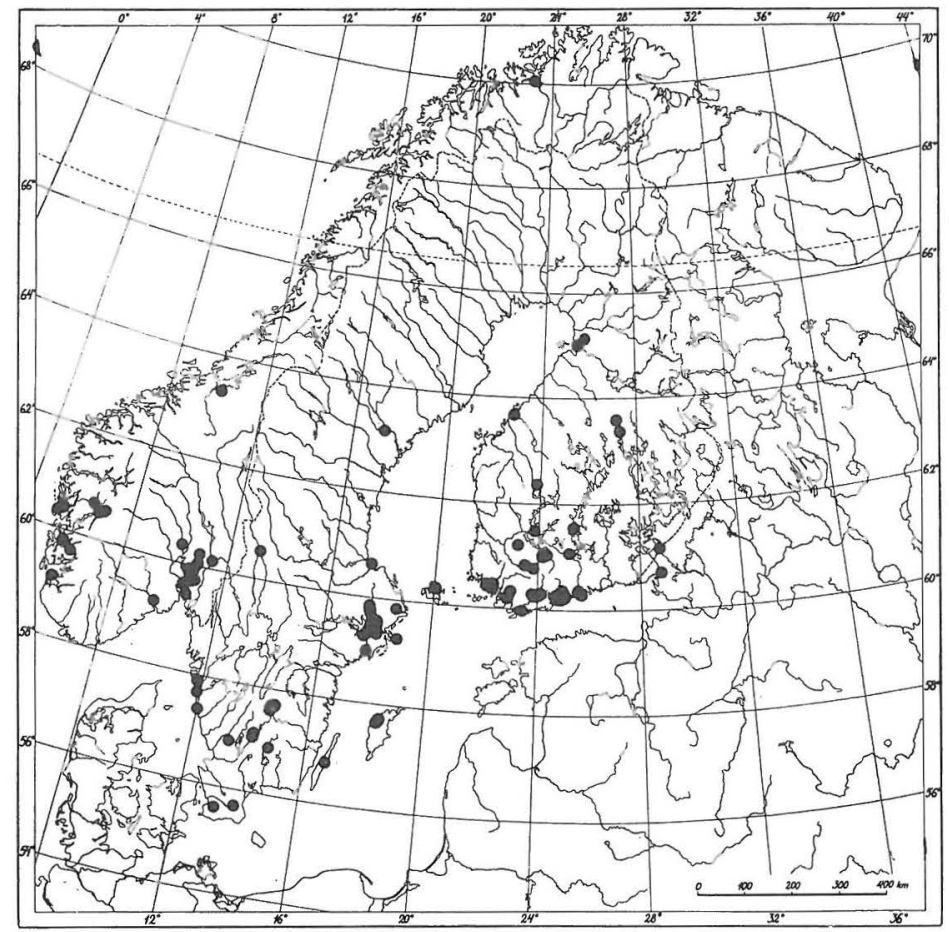

Fig. 156. C. fragrans. 


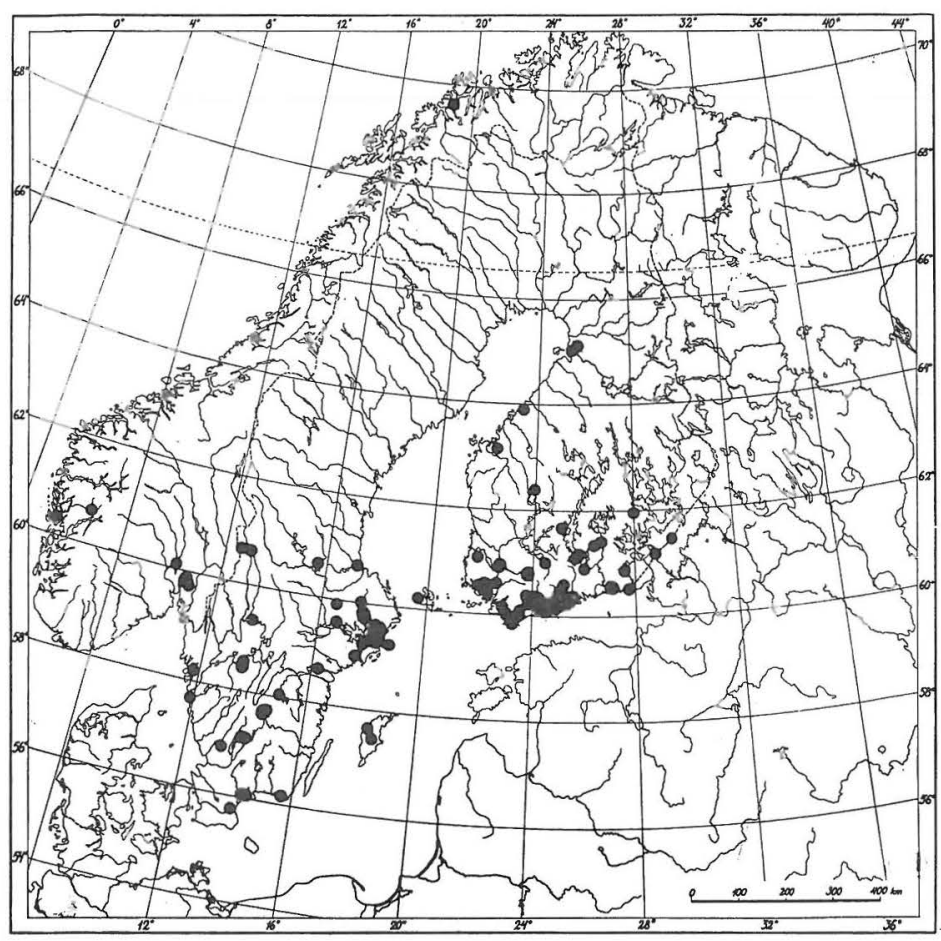

Fig. 157. C. metachroa.

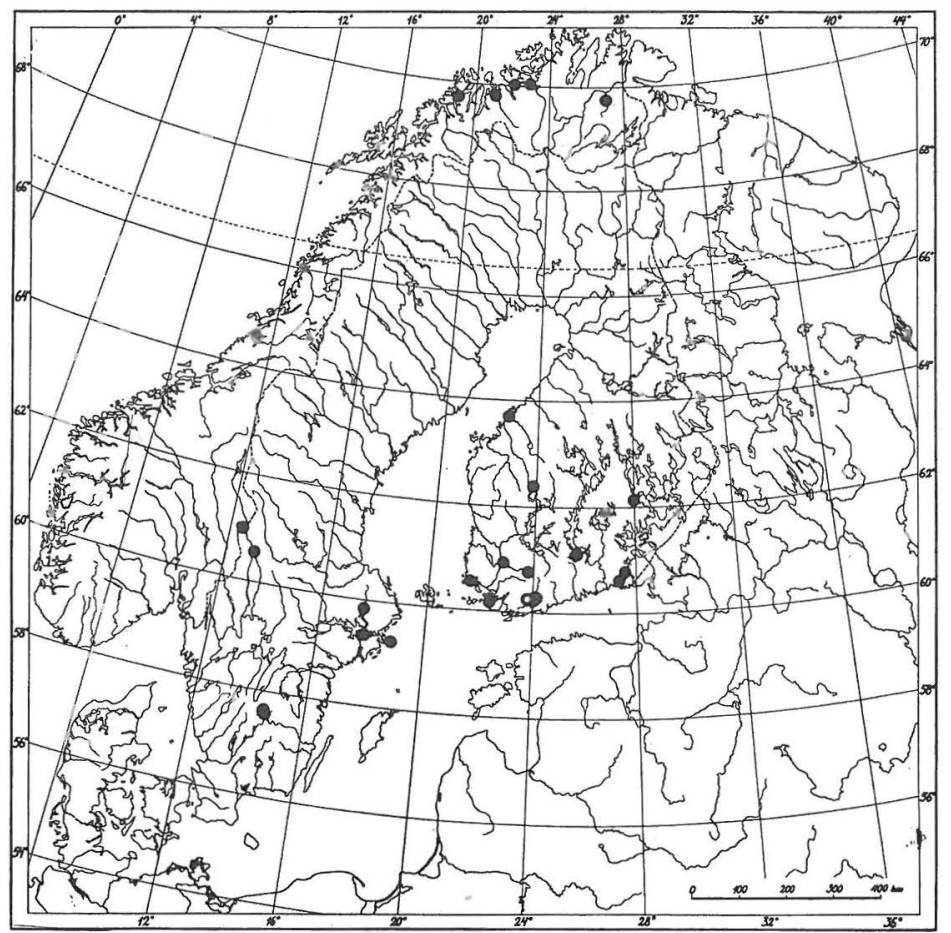

Fig. 158. C. amarescens (circle) and C. metachroides (dots). 


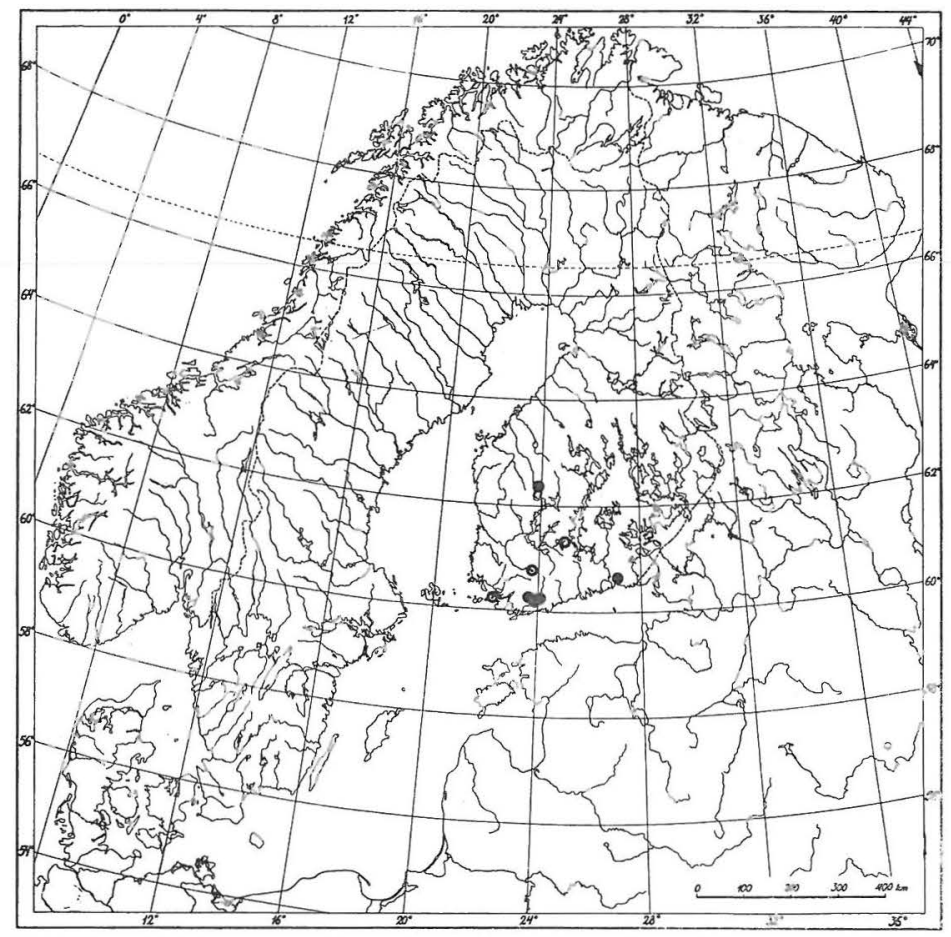

Fig. 159. C. subcordispora (dots) and C. globispora (circles).

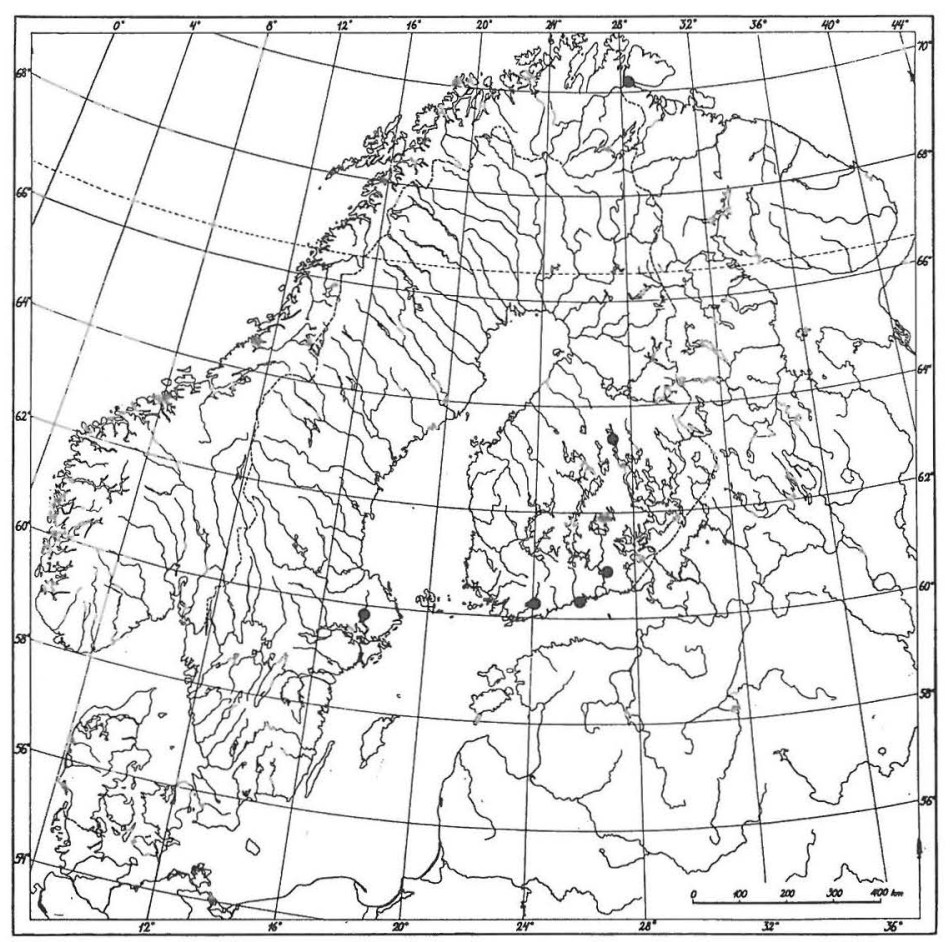

Fig. 160. C. orientalis. 


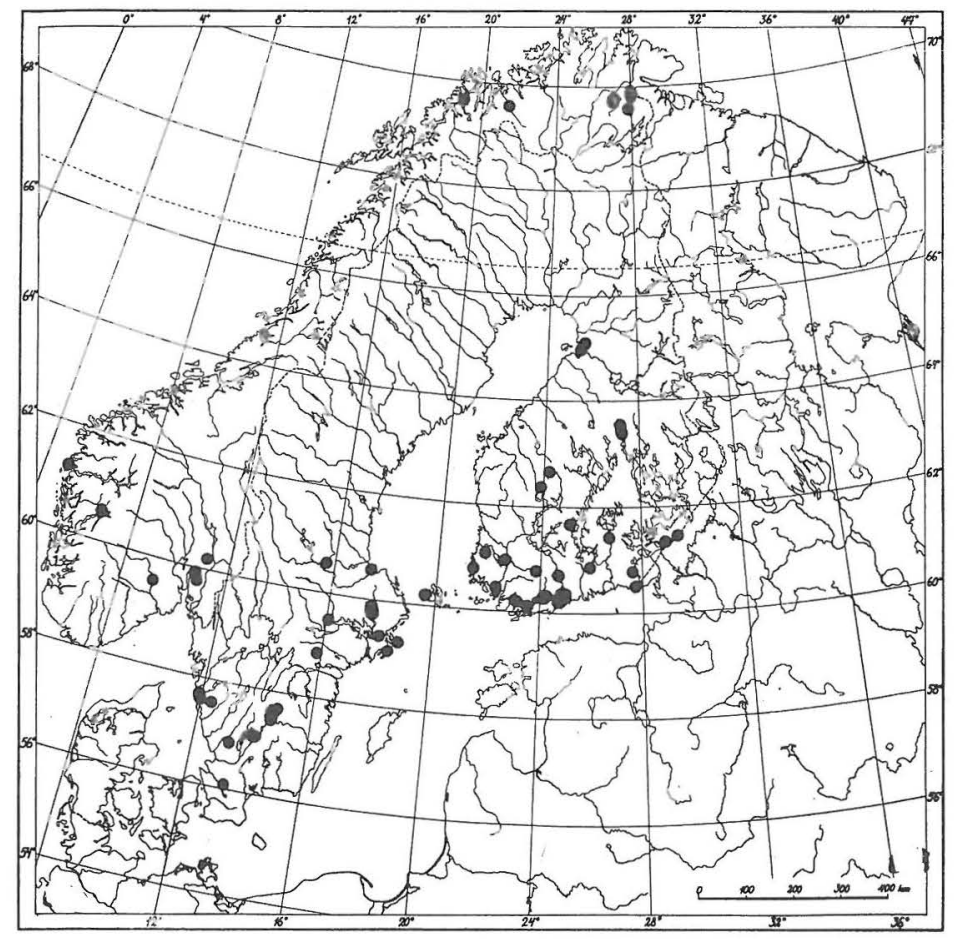

Fig. 161. C. vibecina.

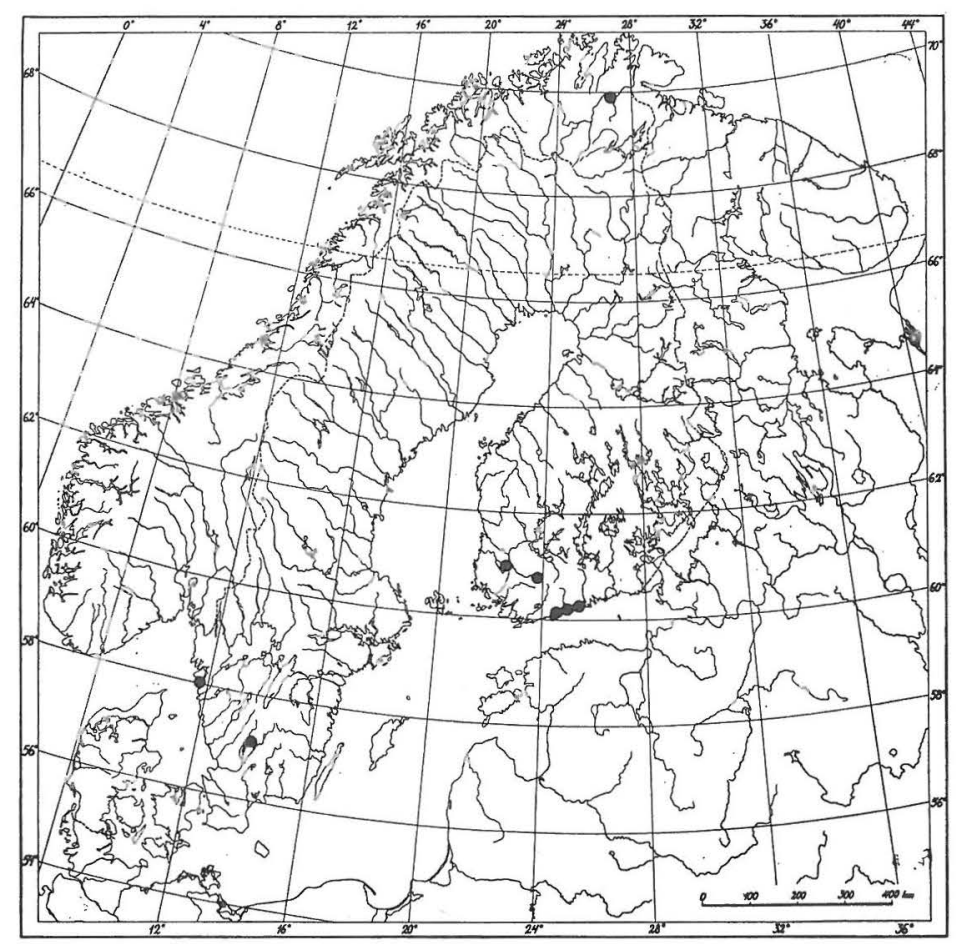

Fig. 162. C. langei. 


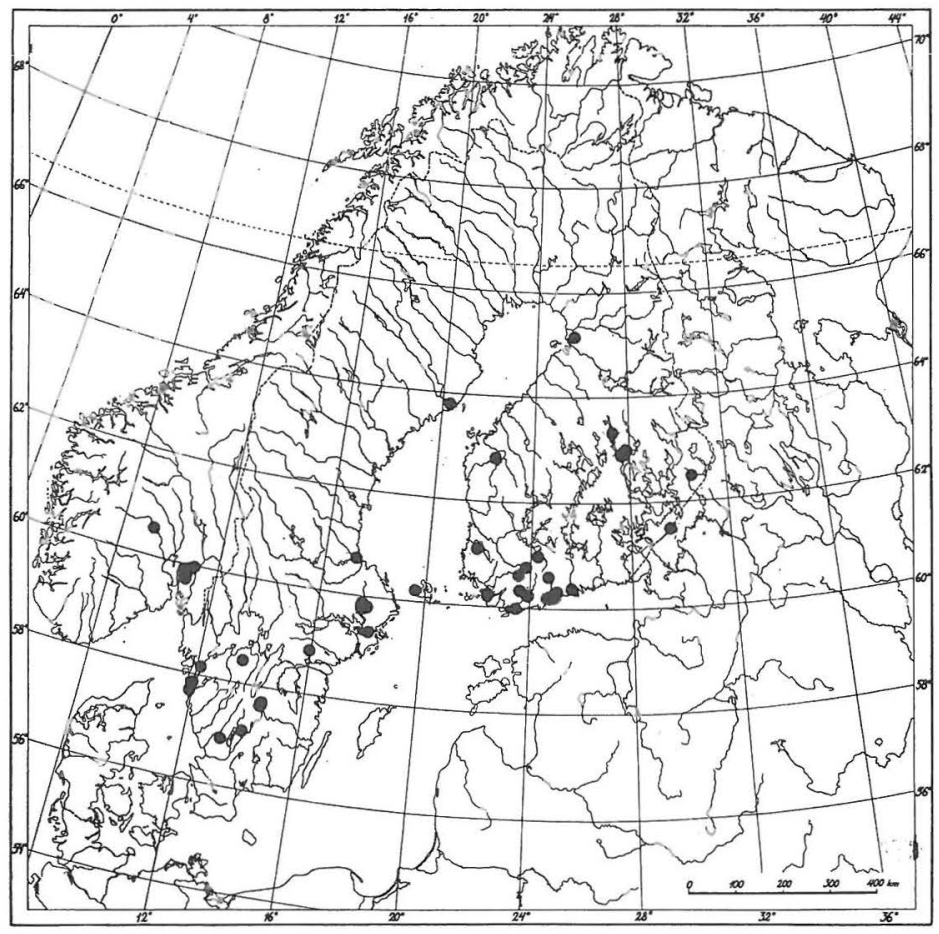

Fig. 163. C. ditopa v. ditopa.

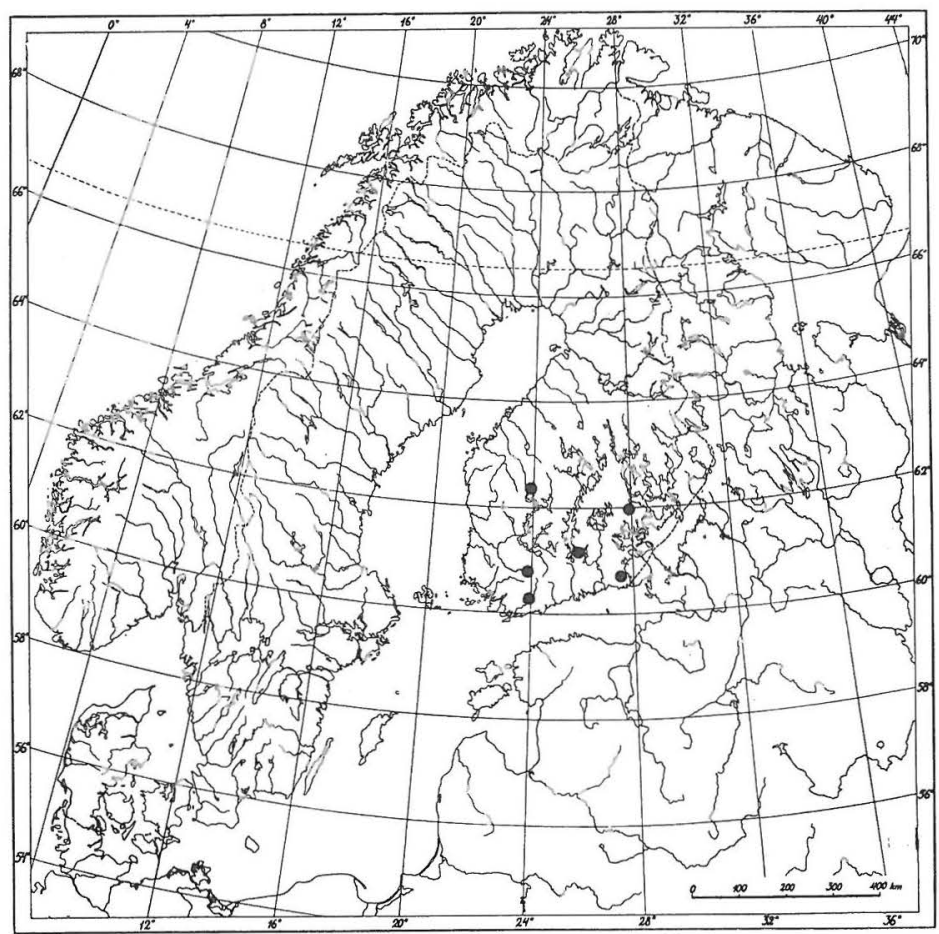

Fig. 164. C. ditopa v. odorula. 


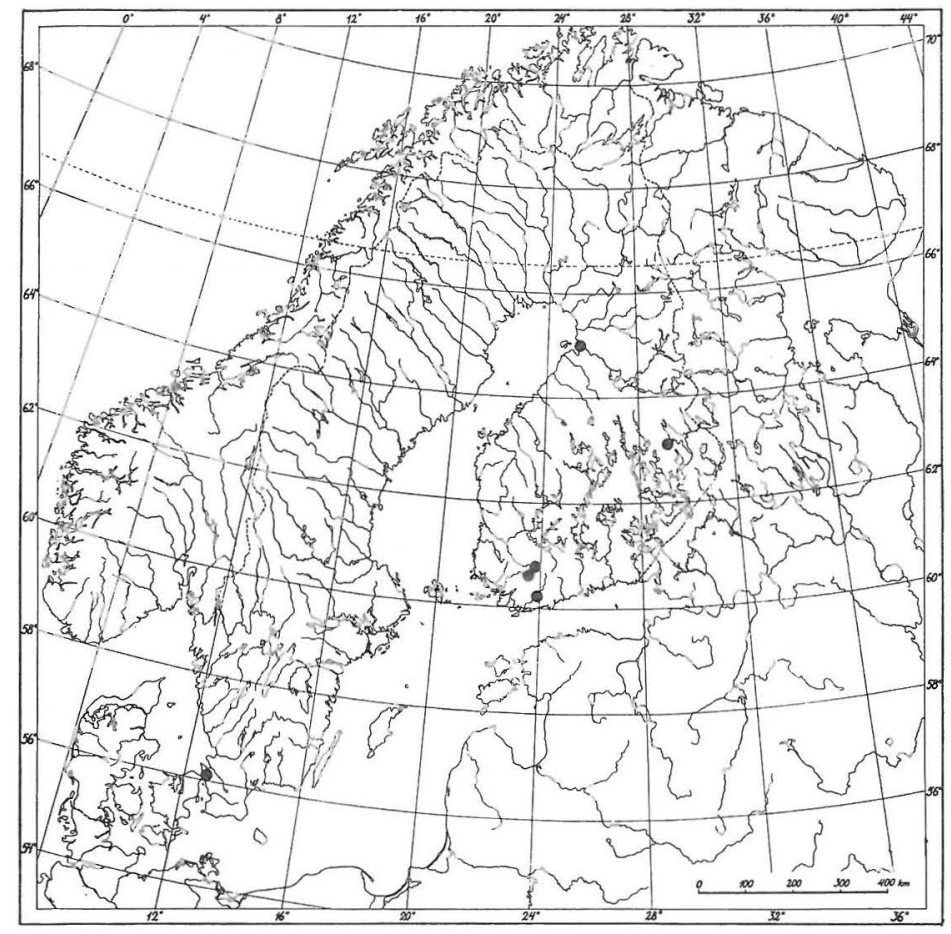

Fig. 165. C. menthiodora.

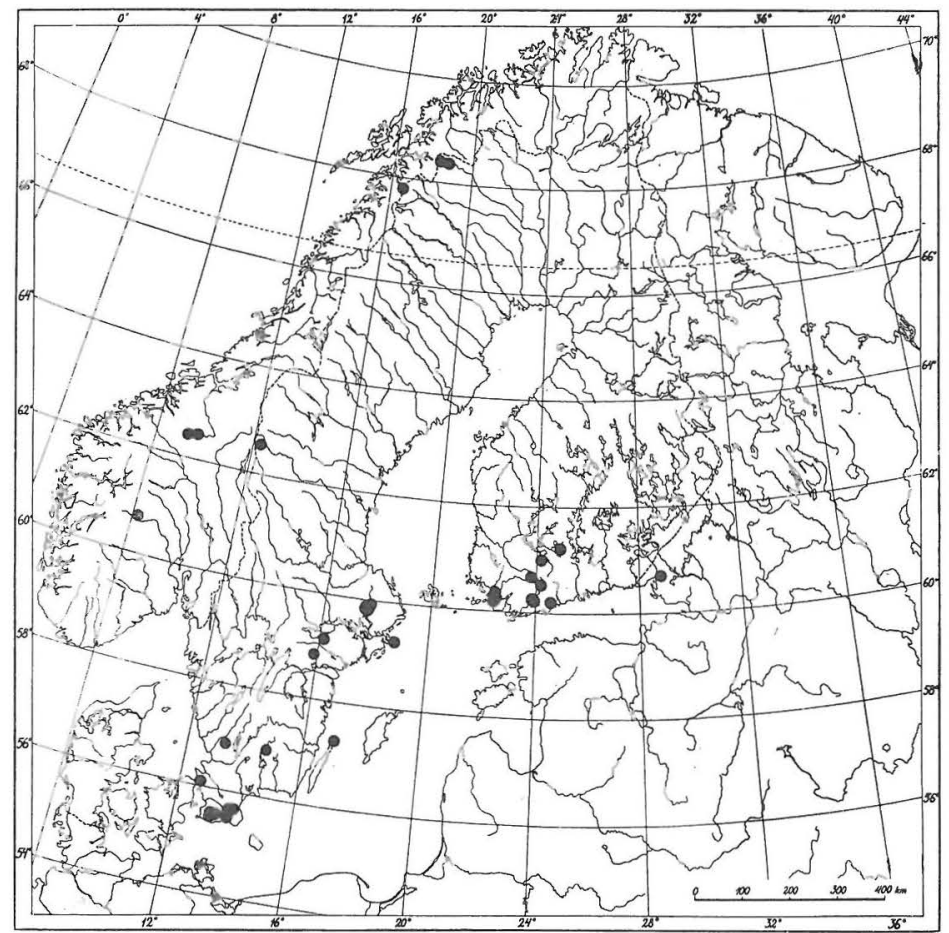

Fig. 166. G. strigosa. 


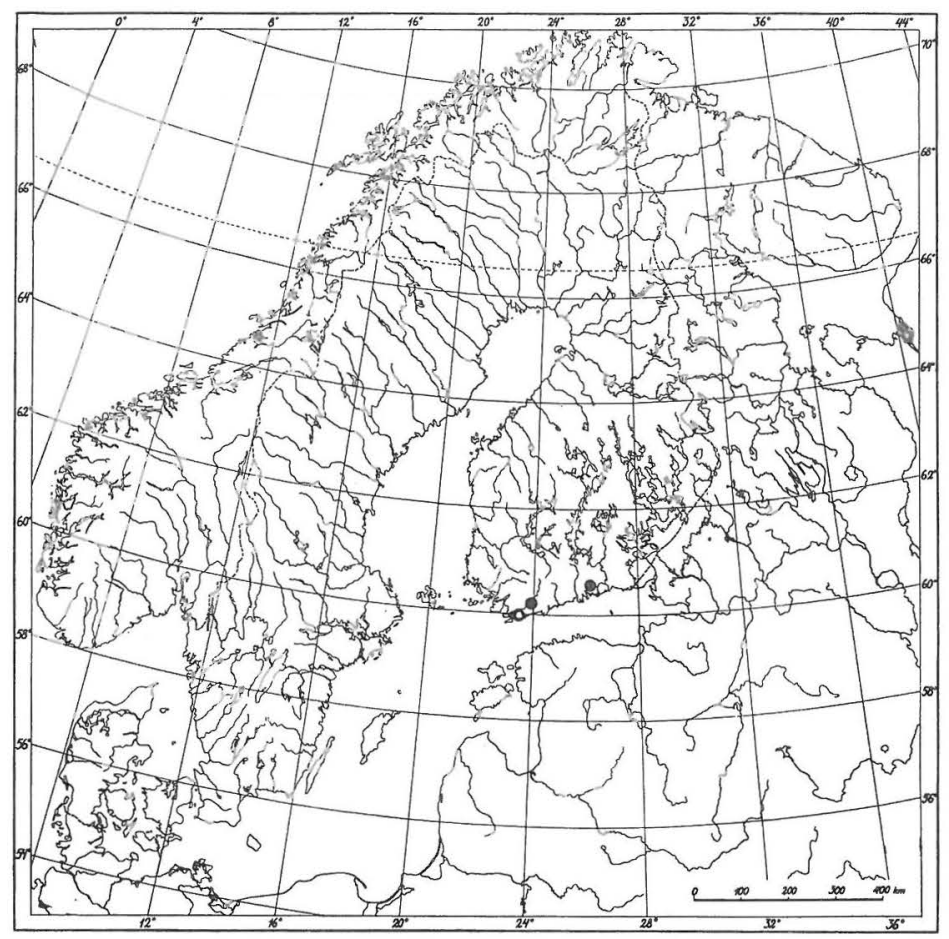

Fig. 167. C.fennica (dots) and C.schulmannii (circle).

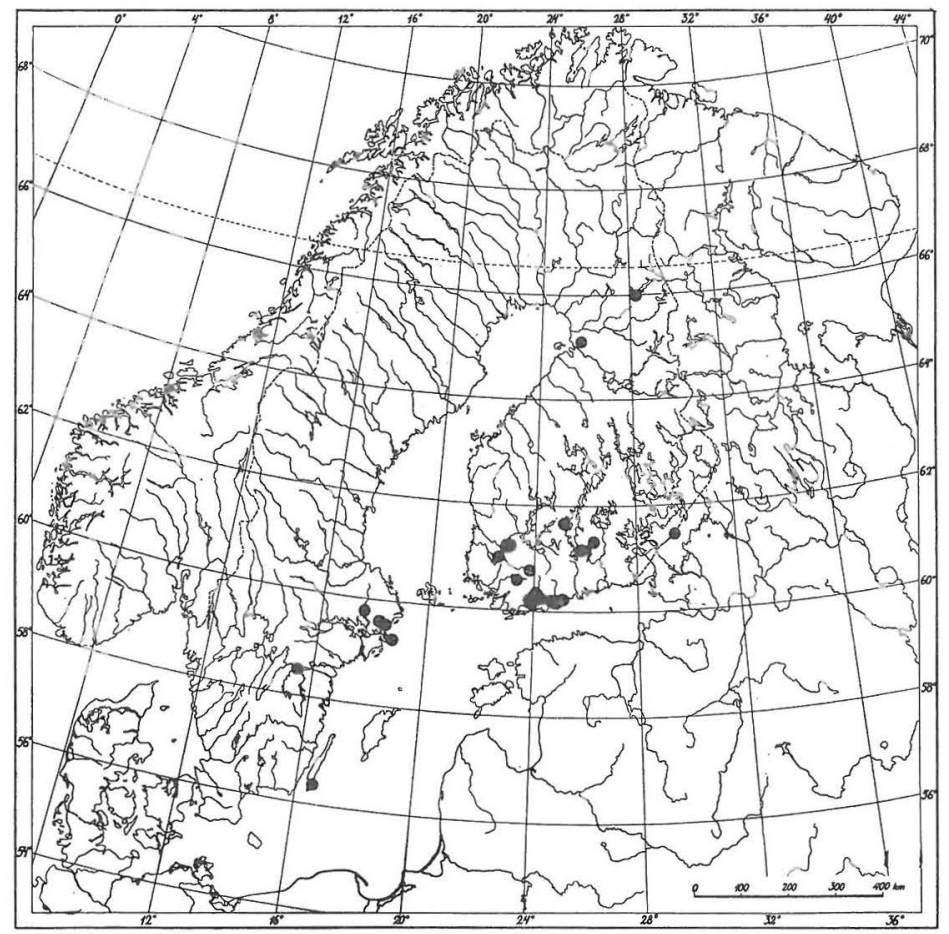

Fig. 168. C. lohjaënsis. 